\author{
Kimberly A. Carlson
}

Dissertation submitted to the faculty of the Virginia Polytechnic Institute and State University in partial fulfillment of the requirements for the degree of

Doctor of Philosophy

In

Public Administration and Public Affairs

\author{
Karen M. Hult, Chair \\ Larkin S. Dudley \\ Minnis E. Ridenour \\ James F. Wolf
}

August 30, 2011

Blacksburg, Virginia

Keywords: succession planning, talent management, public higher education, university, research institute, research center 


\title{
The People behind the Curtain: A Proposed Succession Planning Model for University-Wide Research Institutes
}

\begin{abstract}
Kimberly A. Carlson
ABSTRACT

Public universities and their university-wide research institutes constantly search for ways to evolve to stay relevant and "marketable" in an ever-changing environment. The scholarly literature shows that the majority of higher educational institutes do not participate in succession planning, although numbers of research projects and researchers continue to increase over time, suggesting a great need for universities and institutes to learn how to sustain their work beyond current faculty or how to strategically grow and develop their current employees. The purpose of this research was to review current succession management strategies in large complex organization and to determine whether and how succession planning applies to university-wide research institutes in public, doctoral universities with very high research activity. To understand how succession planning might apply to institutes, this research involved a three phase process: 1) qualitative synthesis of scholarly literatures, 2) electronic surveys of institute directors and university-level administrators, and 3) follow-up telephone interviews. The research synthesis focused on successful succession programs in for-profit, non-profit, and governmental organizations. Characteristics that were found across all three sectors were incorporated into a survey of executive directors and administrative overseers of research institutes to see which features applied in this university setting. Results from the survey were used in the development of a model for succession planning, which then was reviewed by institute directors for relevance to their organizations. Although several suggestions for improvement were given, many interviewees agreed that the model was relevant to their institutes. As such, I confirmed that succession planning should be a part of university-wide research institutes' management strategies to help officials make intentional decisions about their employee needs. This research is important for public administrators as they look at how best to use public funds and other resources in public universities' research activities.
\end{abstract}




\section{Dedication}

To my husband, Eric, who has stood by my side through this entire process, and loved me anyway.

To Dr. Chris Hague, who sparked a desire in me at the age of five to pursue a dream.

To the late Rev. Dr. Lisa M. Tabor, who took me under her wing as a fellow doctoral student and inspired me to finish that dream no matter what challenges come my way. 


\section{Acknowledgements}

This journey would not have been possible without the support, guidance, and encouragement of my advisor and committee chair, Dr. Karen Hult. Thank you for being a fabulous mentor and for being the kind of professor I could only dream of being. I appreciate all the time and energy you put into this work and I will never be able to thank you enough for walking this path with me, holding my hand every step of the way!

At the same time Dr. Hult held one hand, Minnis Ridenour held the other. Thank you, Minnis, for constantly challenging me to be a level five thinker. I always appreciated that you gave graduate students in the office enough rope to do things our own way but not enough to hang ourselves. Your leadership, support, and mentorship helped me tremendously during the past six years as I continued down this path!

I would also like to acknowledge my other committee members, Drs. Larkin Dudley and Jim Wolf. Dr. Dudley, thank you for recruiting me to CPAP and for being a champion for students within and outside the department. Dr. Wolf, thank you for helping me through the tough times and for always being a voice of reason when I needed it.

I would like to thank everyone who helped me in this process by writing letters of support, reading narrative drafts, participating in pre-surveys and pre-interviews, and giving me advice when I happened to be stuck. At the risk of leaving some people out, I would like to especially thank Dr. Charles Steger, Dr. Mark McNamee, Dr. Karen Roberto, Dr. Dennis Dean, Dr. Robert Walters, Dr. Skip Garner, Dr. Ted Fuller, Dr. Steve Janosik, MeKeisha Williams, Connie Masters from Georgia Tech, Laboratory for Interdisciplinary Statistical Analysis (LISA) at Virginia Tech, Courtney Grohs, Jonathan McCloud, and Jerald Walz.

I also would like to acknowledge the faculty and staff at Virginia Tech who have had a tremendous impact on my success while here. Thank you to all the CPAP and SPIA faculty who have taught me so much during classes and academic projects, especially Gary Wamsley, John Rohr, Anne Khademian, Angie Eikenberry, Russ Cargo, and Max Stephenson. Several faculty outside of CPAP also have guided my learning in an enormous way, including Karen DePauw, VP and Dean of Graduate Education, Bob Leonard from Theatre, Shelli Fowler from Learning Technology, Ellen Plummer from Higher Education, Jack Finney from the Provost's office, Dave McKee in Music, Andy and Trudy Becker from Classics, and Jack Dudley and Terry Papillon from the Honors Program. Thank you also to Paul Knox, Frances Keene, and Christine Haimann from Virginia Tech's Long Range Planning Office for helping me to think strategically about universities, in a big way.

A huge part of my graduate learning and experience has been with the Graduate Honor System. Thank you Monika, Pat, Lauren, and Nancy for all the support and help you've given me over the past few years. Thank you to the student investigators with whom I have worked closely Greg, Tracey, Jesse, Katelin, Tara, and Sheldon - your dedication and commitment (and friendship) has been a real blessing! I would like to also thank all the faculty and students who volunteer with the GHS to make sure that academic integrity is held high on our campus. The GHS just wouldn't work without you! 
There are many student colleagues within my department and at the Grad School who have been a tremendous support system, allowing me to vent and brainstorm, all while giving me encouragement to keep putting one foot in front of the other. Thank you to those who have paved the way before and with me. In CPAP, I especially want to acknowledge Gabe, Glenn, Dale, Dan, David, Boris, Lisa, Michelle, Travis, Chad, Tammy, Edie, and Patrick. While there are many fellow students in the Graduate School who have walked the walk with me through the years, I especially want to thank my tailgating crew, my fellow GPers, the awesome editors from PKJ, the amazing creative folks from [classified], my wonderful small group, my classmates from the hardest but the most amazing class I've ever taken - Grassroots Participation - those who always had a smile and kind word of encouragement, or just knew how to get down, and I can't forget the oldies but goodies who became my first friends during those first crucial weeks.

While at Virginia Tech and in Blacksburg, I have met some truly wonderful people who have blessed my life more than I could ever have asked for... Natalie and Jeremy, Angela and Jonathan, Dave and Steph, Britta and Jan, and Kendra and Elliott. I also want to thank Kimberly, who I met the first go around at VT and who has stayed by my side for almost 20 years! These friends have journeyed with me, through celebrations and triumphs, through stumbling blocks and challenges, through heartache and tears and through several glasses of wine. I am so thankful I can call you friends!

Although not officially part of Virginia Tech, there are several community folks who have made a difference in my life in amazing ways - Tommy McDearis, Andy Morikawa, Brian and Angie Hoff (and Carter!), Tim Filbert, and Charles Lattimer. Thank you for believing in me and continuing to challenge me to be a better person!

I also want to thank my family - Kevin, Krista, Kelly, Rachel, Kristie, Jason, Mom, Dad, Nancy, Paul, Grandma, Grandpa, Aunt Bonnie, MeMe, Micah, and Wendy. Although you have teased me the entire time, I know you are proud of me! Just think, Dad was the first generation to attend college and now there are three masters and one doctor!! And yes, there is a time when I'm not a forever student! I also want to say thank you to my nieces and nephews who have kept me in stitches for the past 21 years - laughter is always the best solution!

Where would I be without the love of my life? I've enjoyed every moment with you for the past 4+ years! Thank you for bringing me sushi during my prelims. Thank you for kindly redirecting my attention to what I was supposed to be doing. Thank you for listening attentively to me moan, complain, and sing silly songs. I am so happy to celebrate this time with you and I look forward to one day calling you "Dr. Carlson" too! 


\section{Table of Contents}

CHAPTER 1: INTRODUCTION......................................................................................................... 1

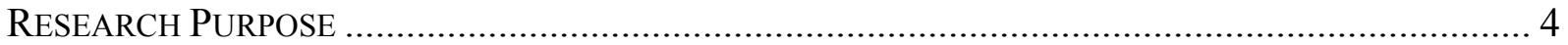

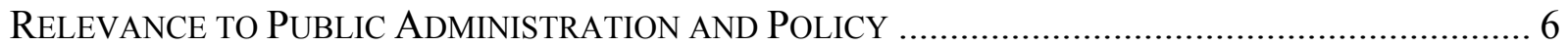

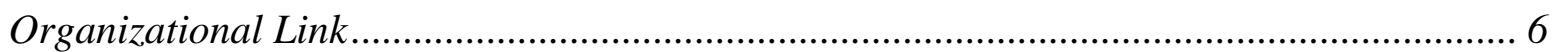

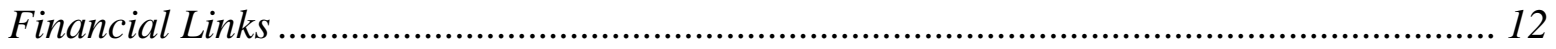

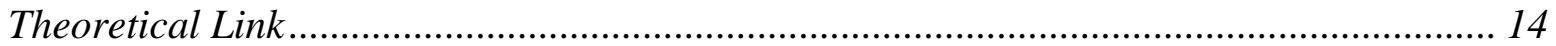

RELEVANCE OF RESEARCH TO UNIVERSITIES................................................................... 15

Increased Research Funding and Activity ................................................................. 16

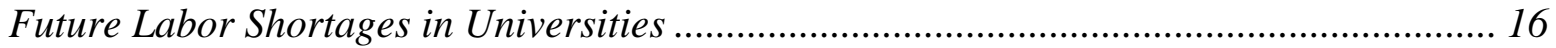

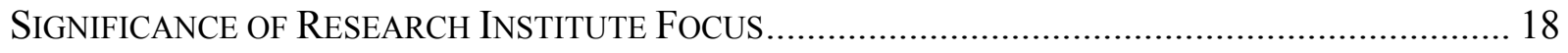

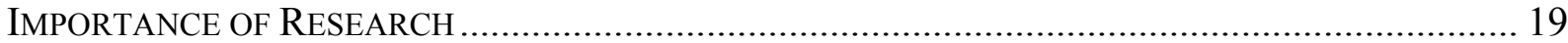

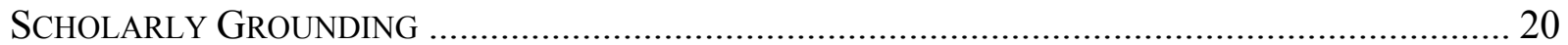

Succession Planning Definition ................................................................................. 20

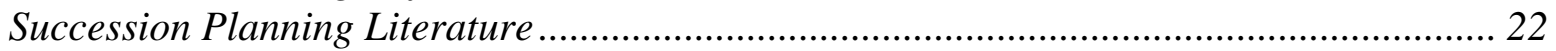

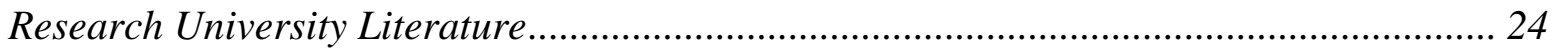

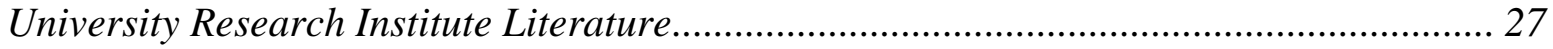

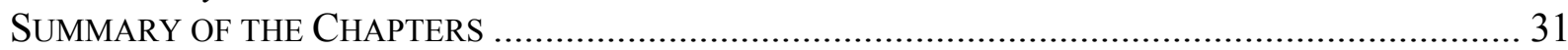

CHAPTER 2: FRAMEWORK AND METHODOLOGY ................................................... 33

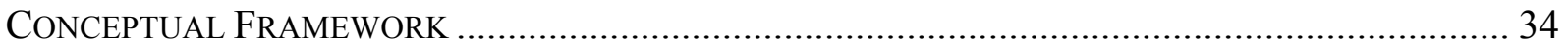

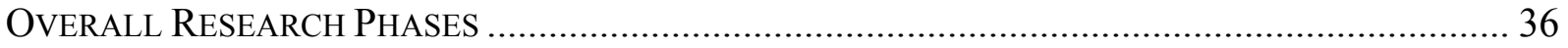

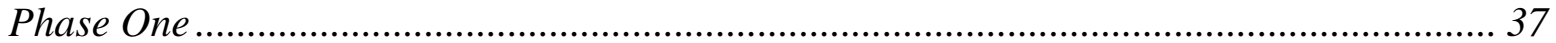

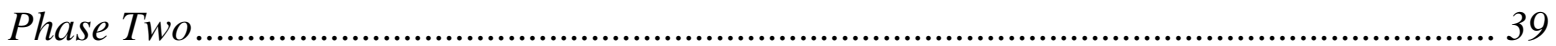

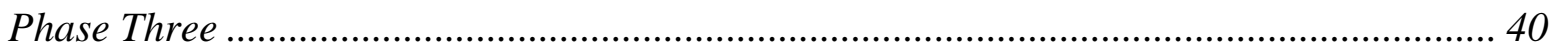

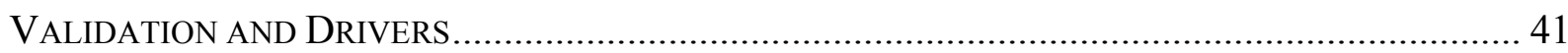

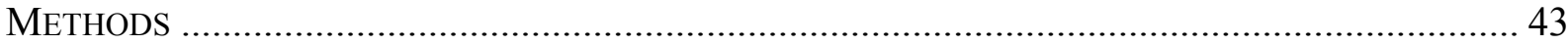

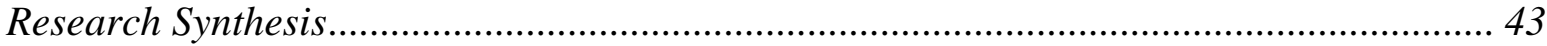

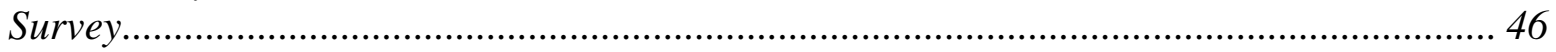

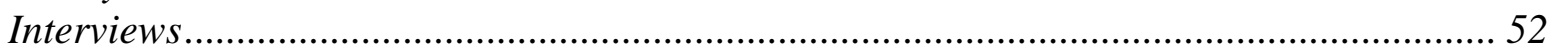

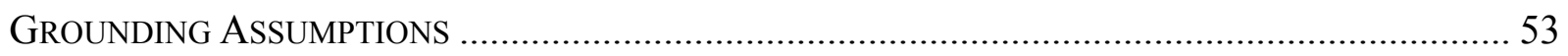

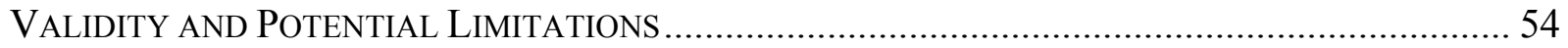

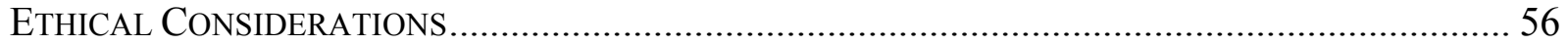

CHAPTER 3: QUALITATIVE RESEARCH SYNTHESIS OF THE LITERATURE ....... 57

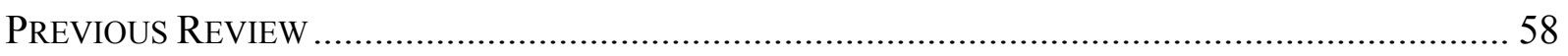

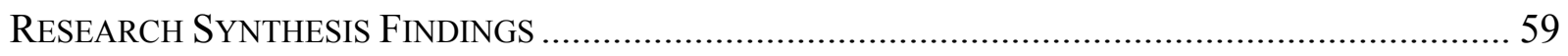

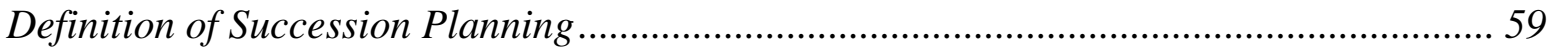

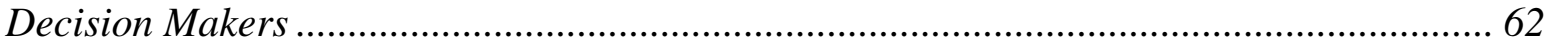

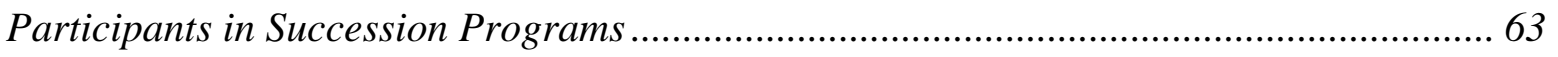

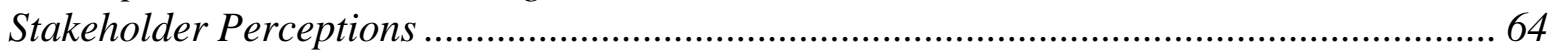

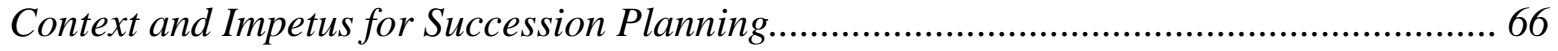

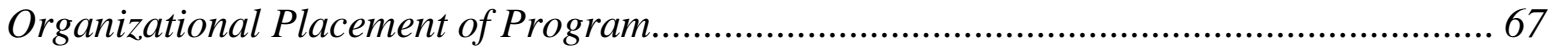

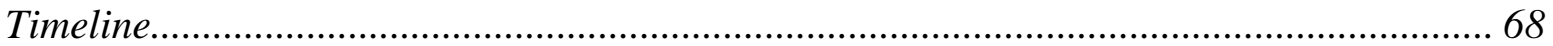

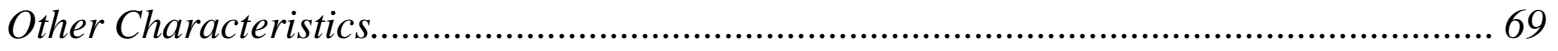

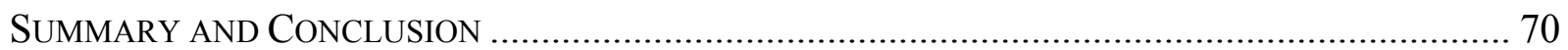




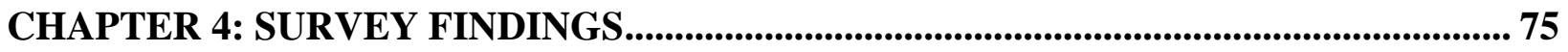

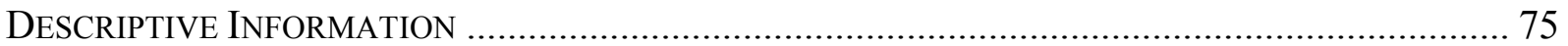

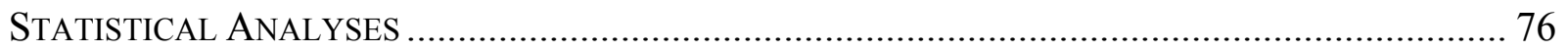

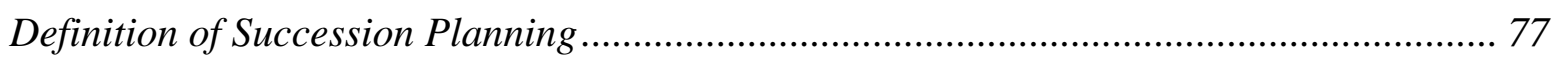

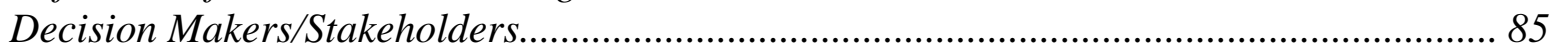

Participants in Succession Program.................................................................................. 89

Stakeholder Perceptions ................................................................................................ 92

Context and Impetus for Succession Planning.................................................................. 97

Organizational Placement of Program............................................................................ 102

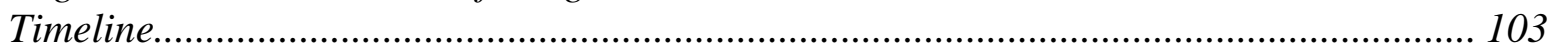

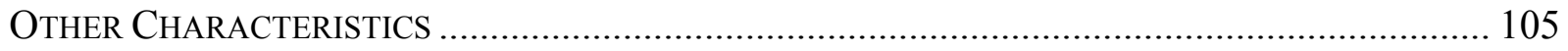

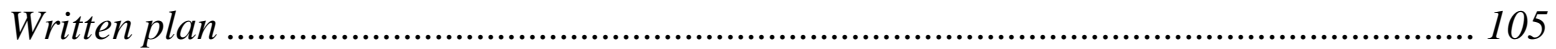

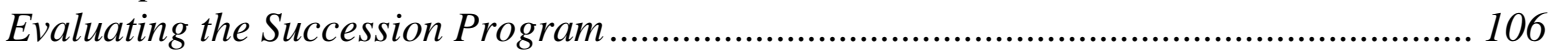

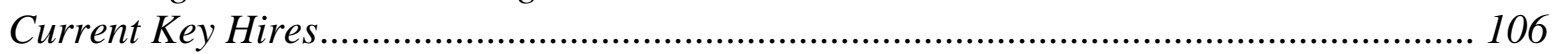

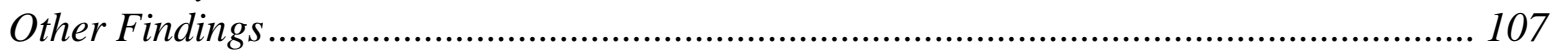

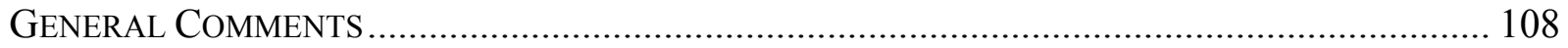

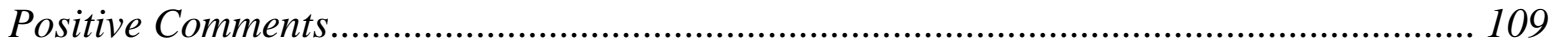

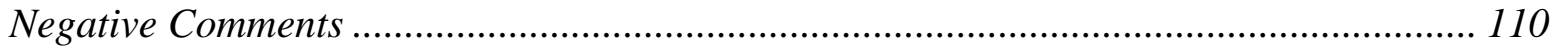

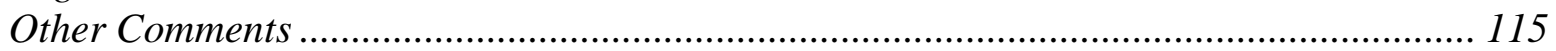

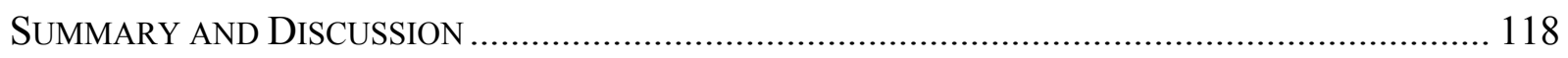

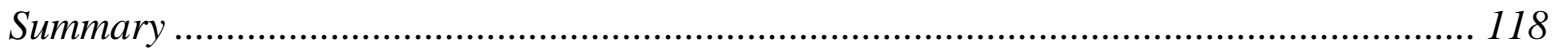

Proposed Succession Planning Process Model ................................................................ 121

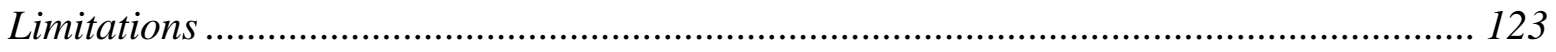

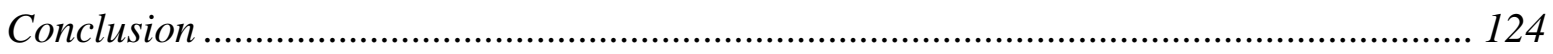

CHAPTER 5: DEVELOPMENT AND REVIEW OF THE PROPOSED SUCCESSION

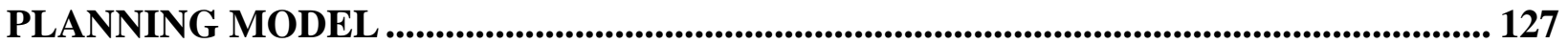

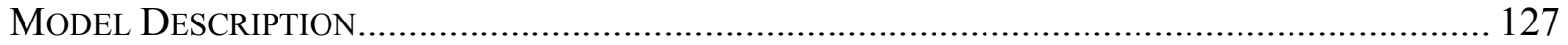

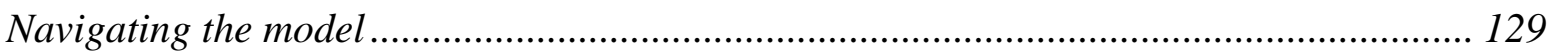

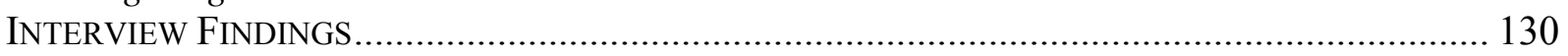

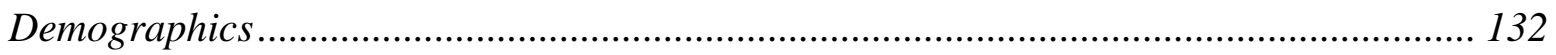

Question 1: Relevance of Succession Planning .......................................................... 132

Question 2: Reaction to the Proposed Model ............................................................... 134

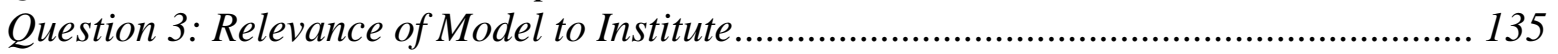

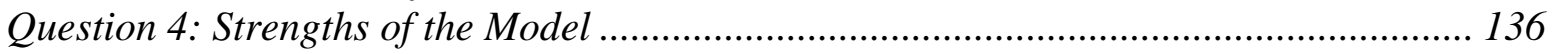

Question 5: Suggested Changes to the Model ................................................................... 137

Question 6: Knowing succession planning was successful............................................... 137

Question 7: Additional Comments .............................................................................. 138

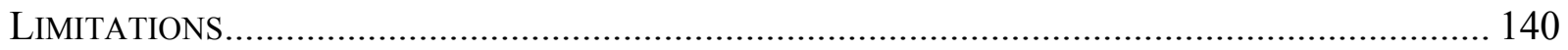

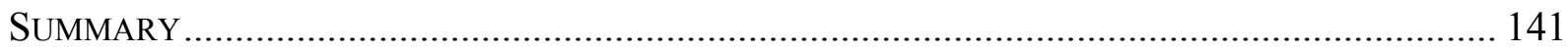

CHAPTER 6: CONCLUDING REMARKS ......................................................................... 145

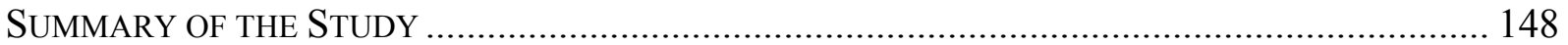

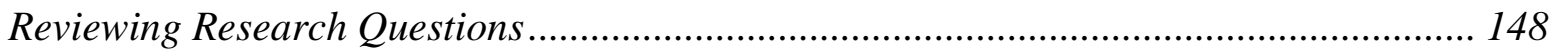

So What? IMPLICATIONS, RECOMMENDATIONS, AND FUTURE RESEARCH .............................. 152

Implications for Research Institutes and Public Universities.............................................. 152 
Implications for Public Administration .............................................................................. 155

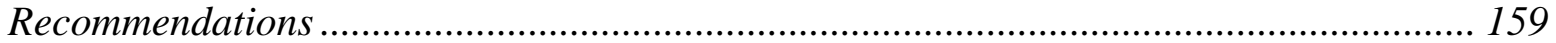

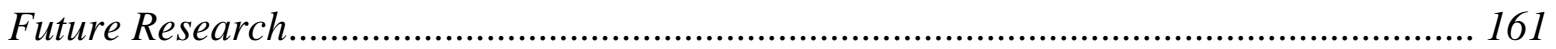

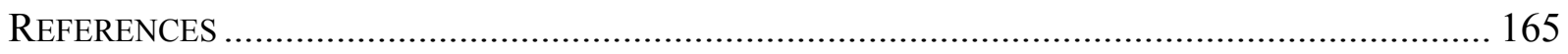

APPENDIX A: POLICY MAKING MATRIX ..................................................................... 242

APPENDIX B: OVERALL RESEARCH DESIGN OPERATIONALIZED....................... 243

APPENDIX C: EXAMPLE OF SURVEY CORRESPONDENCE........................................ 245

APPENDIX D: EXAMPLE OF SURVEY - EXECUTIVE DIRECTOR ............................ 249

APPENDIX D, CONTINUED: EXAMPLE OF SURVEY - UNIVERSITY

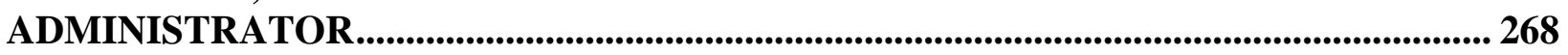

APPENDIX E: UNIVERSITIES AND RESEARCH INSTITUTES ..................................... 284

APPENDIX F: MEDIAN NUMBER OF RESEARCH INSTITUTES PER SCHOOL PER

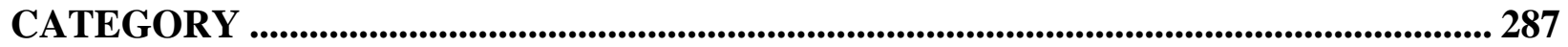

APPENDIX G: EXAMPLE OF INTERVIEW CORRESPONDENCE .............................. 288

APPENDIX H: INTERVIEW QUESTIONS ........................................................................... 290

APPENDIX I: DEMOGRAPHICS OF UNIVERSITIES THAT PARTICIPATED IN

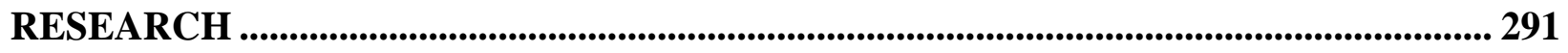

APPENDIX J: PROPOSED MODEL FOR SUCCESSION PLANNING FOR

UNIVERSITY-WIDE RESEARCH INSTITUTES. 


\section{List of Figures}

FIGURE 1: RELATIONSHIPS WITH UNIVERSITY-WIDE RESEARCH INSTITUTES ............................... 8 Figure 2. CONTEXT-INPUT-PROCESS-OUTPUT-OUTCOME MODEL OF SCHOOLING (SCHEERENS, J.,

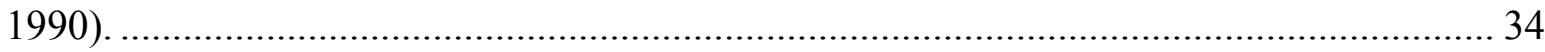

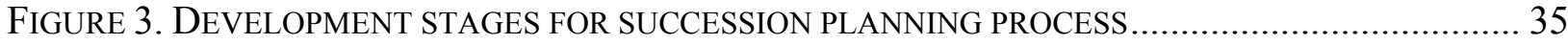

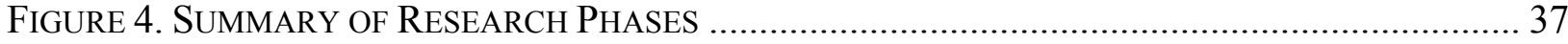

Figure 5. Where EMPLOYEES COME FrOM REPORTED BY EXECUTIVE DiRECTORS .................. 240

FIGURE 6. WHERE EMPLOYEES COME FROM REPORTED BY UNIVERSITY ADMINISTRATORS....... 241

FIGURE 7. CONCEPTUAL MODEL FOR SUCCESSION PLANNING IN UNIVERSITY-WIDE RESEARCH

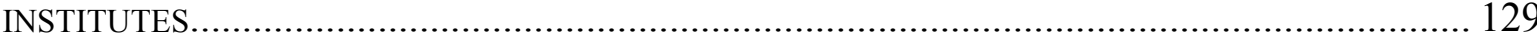




\section{List of Tables}

TABle 1: Numbers of UNIVERSITY RESEARCH CENTERS AND NATIONAL EXPENDITURES FOR

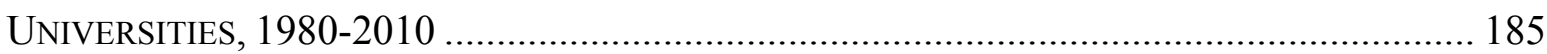

TABLE 2: CHARACTERISTICS OF DRIVERS............................................................................ 186

TABLE 3: SURVEY QUESTION BY NUMBER OF RESPONDENTS ................................................ 187

TABle 4: Definition Of SUCCESSION PlanNING ACROSS ThreE SECTORS .............................. 188

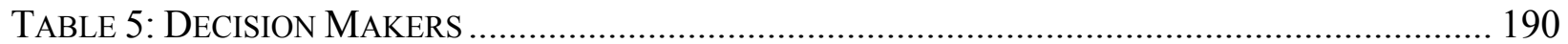

TABLE 6: PARTICIPANTS IN SUCCESSION PlanNING PROGRAMS. .............................................. 192

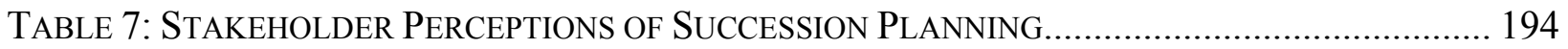

TABLE 8: CONTEXT AND IMPETUS FOR SUCCESSION PLANNING ............................................ 198

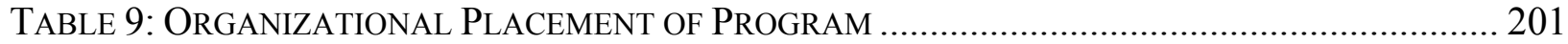

TABLE 10: TIMELINE OF SUCCESSION PROGRAM ............................................................... 202

TABLE 11: TYPES AND ELEMENTS OF SUCCESSION PLANS..................................................... 203

TABLE 12: SUMMARY OF SYNTHESIS FINDINGS ................................................................. 71

TABLE 13: CHARACTERISTICS OF SURVEY RESPONDENTS (\% RESPONDENTS [N])* .................. 210

TABLE 14: DESCRIPTIVE CHARACTERISTICS OF RESEARCH INSTITUTES (\% RESPONDENTS [N])* 211

TABle 15: CONTEXTUAL CHARACTERISTICS OF RESEARCH INSTITUTES* (\% RESPONDENTS [N])**

TABle 16: CHARACTERISTICS OF SUCCESSION PLANNING REPORTED AS IMPORTANT BY

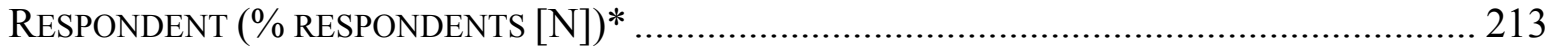

TABLE 17: "IMPORTANT" CHARACTERISTICS OF SUCCESSION PLANNING BY TYPE OF RESPONDENT, INSTITUTE, AND UNIVERSITY* ........................................................................ 214

TABle 18: IMPORTANT CHARACTERISTICS OF SUCCESSION PlaNNING BY UNIVERSITIES WiTH More RESEARCH INSTITUTES, CONTROLLING FOR UNIVERSITY SIZE *............................ 215

TABLE 19: IMPORTANT CHARACTERISTICS OF SUCCESSION PlaNNING BY UNIVERSITIES WITH MORE RESEARCH INSTITUTES, CONTROLLING FOR YEAR INSTITUTE WAS CREATED* ........ 216

TABLE 20: IMPORTANT CHARACTERISTICS OF SUCCESSION PLANNING BY UNIVERSITIES WITH More Research Institutes, CONTROLling For How Policies ARE Created AND IMPLEMENTED*...

Table 21: Desired Decision Makers in Succession Planning Processes by Respondent (\%

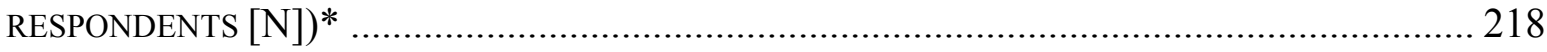

Table 22: Desired Decision Makers in Succession Planning Processes by ResPondent,

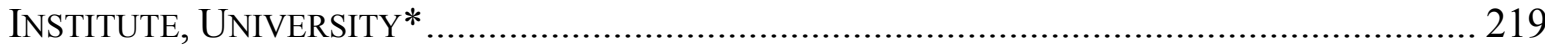

Table 23: Desired Participants in Established Succession Planning Programs by RESPONDENT (\% RESPONDENTS [N])* ................................................................. 220

TABle 24: Desired Participants in Established Succession PlanNing Programs By RESPONDENT, INSTITUTE, AND UNIVERSITY * .......................................................... 221

TABle 25: Desired Participants in SuCCESSION Planning By SOCIAL SCIENCE Institutes, CONTROlling For University Size, Institute Size, Year Institute Was Created, Institute Budget, Current Succession Planning Activities, How Polices Created AND IMPLEMENTED*

TABle 26: Items Inhibiting/Benefitting Succession Planning Processes By Respondent (\% RESPONDENTS $[\mathrm{N}])^{*}$.... 223

Table 27: Items Inhibiting/Benefitting Succession Planning Processes by Respondent, INSTITUTE, AND UNIVERSITY* . 
TABLE 28: IMPORTANT SUCCESSION PlANNING CHARACTERISTICS FOR RESEARCH InSTITUTES BY

RESPONDENT (\% RESPONDENTS [N])* 225

TABLE 29: IMPORTANT SUCCESSION PLANNING CHARACTERISTICS BY RESPONDENT AND

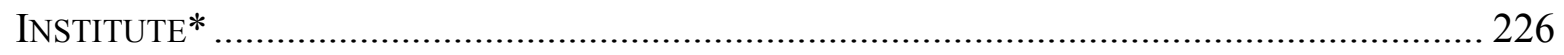

TABLE 30: IMPORTANCE OF EMPlOYEE DEVELOPMENT METHODS BY RESPONDENT (\%

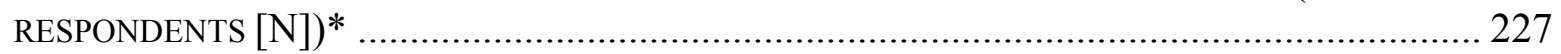

TABLE 31: EMPLOYEE GROWTH AND RETIREMENT (EXECUTIVE DiRECTOR REPORTS) (\%

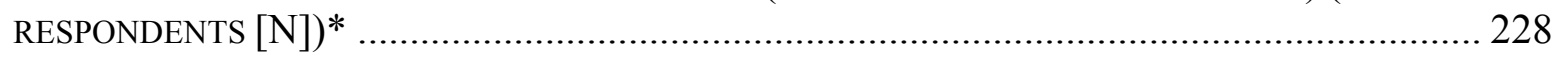

TABLE 32: IMPORTANCE OF REASONS FOR SUCCESSION PLANNING BY RESPONDENT (\%

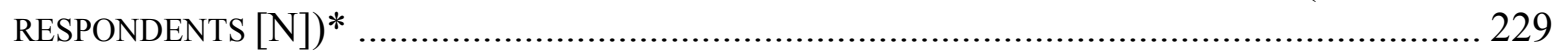

TABle 33: Why SuCCESSION Plans EStABLISHED By RESPONDENT AND InSTITUTE* ............. 230

TABle 34: Frequency of DeVelopment Programs by TyPe of EMPloyeE AND RESPONDENT

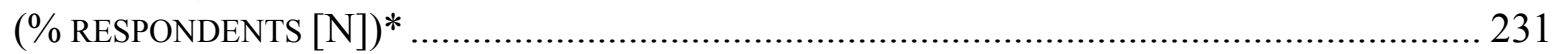

TABLE 35: FREQUENCY AND TARGET OF DEVELOPMENT OPPORTUNITIES BY RESPONDENT, INSTITUTE, AND UNIVERSITY* ............................................................................. 232

TABle 36: Contents of Written SuCCESSION Plan By RESPONDENT (\% RESPONDENTS [N])* 233

TABle 37: Characteristics SuCCESSION Plan EVAluAtion By RESPONDENT (\% RESPONDENTS

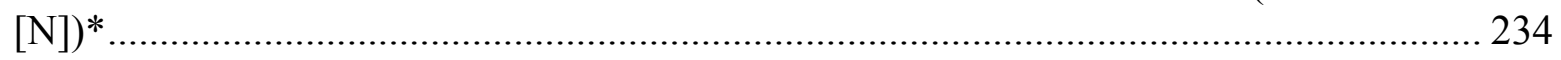

TABLE 38: SOURCES OF Key HiRES (EXECUTIVE DiRECTOR REPORTS) (\% RESPONDENTS [N])*. 235

TABLE 39: SOURCES OF KEY HiRES (UNIVERSITY ADMINISTRATOR REPORTS) (\% RESPONDENTS

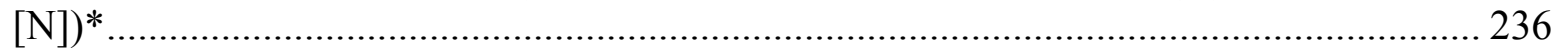

TABLE 40: SUMMARY: SURVEY SUPPORT FOR HYPOTHESES ................................................. 119

TABLE 41: RESPONSES AND THEMES By DiRECTOR AND INSTITUTE TYPE............................... 237

Table 42: Relevance of Succession Planning to Institutes' Strategic Plan by Theme

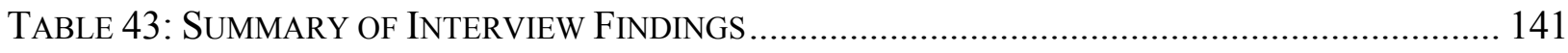




\section{Chapter 1: Introduction}

Knowledge has to be improved, challenged, and increased constantly, or it vanishes.

- Peter F. Drucker (Drucker \& Wartzman, 2010)

Today's public organizations work in an ever-changing environment, forcing them to continually update and improve to stay relevant and to continue serving their community. Several scholars have described these environmental forces as "specific worldwide crises" (Goodsell, 2001, p. 1), competitive markets, corporate images (Lynn, 1998; Considine \& Lewis, 1999), constitutional constraints, administrative law (Rosenbloom \& Piotrowski, 2005), and changing expectations (Keast, Mandell, Brown, \& Woolcock, 2004). Joan Pynes (2004a) believes that six major contextual forces are putting pressure on public organizations to change reduction in fiscal resources with increased social needs; shifts in the demographic composition of our population and its beliefs; increased reliance on technology and automation; changes in the legal environment through new initiatives, policies, and regulations; increases in privatization; and increases in competition for the best workers.

No matter what the drivers pushing for change are, scholars studying the context of public organizations and their environment in turn frequently recommend that change. Leaders of public organizations must respond to these changes in a more strategic manner in order to "survive, prosper, and do good and important work" (Bryson, 2004, p. 4). Based on data from accountability measures, many scholars call for reforms and look to "reinvent" governance in hopes to improve public organizations. Since many organizations' most valued asset is their workforce, one area of reform that organizational leaders must review is human resources.

Pynes (2004a) describes a possible strategy for coping in such a setting as strategic human resources management (SHRM), which facilitates public organizations to "improve the 
quality of their services" (p. 17). One purpose of SHRM is to analyze the future of an organization and to forecast its future labor needs. This forecast looks at the increased labor needs due to growth of the organization and changes in employee skill sets due to changes in the environment and technology, as well as labor needs stemming from attrition, such as retirements. SHRM then examines the current organization to determine who it currently employs and how it will plan for future needs. Pynes (2004a) described this activity as a gap analysis, which "is the process of comparing the workforce demand forecast with the workforce supply projection" ( $p$. $30)$.

A current gap that exists in human capital in public organizations in the United States can be found between retirement-eligible workers who tend to be the leaders in organizations and the next age range and potential leaders in those same organizations. As the majority of current leaders look toward retirement, many people are beginning to wonder who will take their places. How will the organization sustain its labor force in order to continue its activities and to respond to other changes in the environment?

Another gap exists between current employee skills sets and skills sets that public organizations will need in the future based on their strategic planning. As organizations evolve to meet the needs of a changing society, an organization may not have the right people with the right skills sets to accomplish all that it hopes and plans to accomplish.

To address these gaps, SHRM activities include succession analysis and planning. Forprofit companies have a track record of succession planning to help address impending leadership transitions and deficient skill sets, while nonprofit and governmental organizations, such as public institutions of higher education, lag behind. Pynes (2004a) offered several 
reasons why SHRM, including succession planning, is not used more often in public organizations:

- Managers "are reluctant to give HRM professionals the flexibility to initiate new programs or to suggest new organizational structures";

- "HRM professionals lack the capabilities and skills necessary to move human resource management to a more proactive role";

- Organization change, such as SHRM, "requires higher levels of coordination across functions and departments," which can be difficult;

- "Some employees may be reluctant to change"; and,

- Lack of committed financial resources and political realities may also hinder SHRM. (pp. 34-35)

McKinney and Howard (1998) argued that change can take place in public organizations if the organizational leaders have a vision for the future of the organization and its employees, communicate that vision to everyone, and empower the subordinate leaders to support the organizational change. They further described planning as the process that moves the entire agency in one desired direction (McKinney \& Howard, 1998). Succession planning is the SHRM process by which human resource managers help the organization develop the talent and employees that are needed in the future to achieve the strategic goals of the organization.

The general topic of the research reported here is succession management and planning in large complex public organizations. In particular, the research focused on university-wide research institutes located in four-year, public doctoral universities with very high research activity, as defined by The Carnegie Foundation for the Advancement of Teaching (2007). Virginia Tech (VT) is an example of such a university. 
The purpose of this research is to review current succession management in large complex organizations and to determine whether and how it applies to research institutes in public institutions of higher education. I accomplished this by developing a succession planning process model and reviewing it for relevance to university-wide research institutes.

In this chapter, I first explain the research purpose and questions, the importance of this study, and its relevance to public administration and policy. Then, I briefly review scholarship related to succession planning, research universities, and university research institutes. A more in-depth synthesis of relevant scholarly literatures can be found in chapter three. I conclude chapter one with a summary of the other chapters in this dissertation.

\section{Research Purpose}

The main question driving this research was what processes of succession planning are relevant in a model of succession planning for university-wide research institutes in four-year, public doctoral universities with very high research activity? To examine this question, this study involved the development and evaluation of the relevance of a succession planning process model to such research institutes. ${ }^{1}$ Specifically, the study included analyses of successful succession planning models both in the scholarly literature and through surveys of directors of university-wide research institutes and university administrators as the bases for developing a process model for succession planning for these institutes. This process model then was reviewed by directors of research institutes for relevance and possible future implementation.

For this research, I considered the succession planning model as a process; the implementation of that process, which is beyond this study, would become a succession planning

\footnotetext{
${ }^{1}$ This proposed succession planning process model was based on an assumption of rational decision making processes. There can be gaps between rational models and actual processes in real world situations. The model was developed in such a way as to allow as much flexibility as possible to accommodate various organizational contexts; however, it may not be relevant to all organizational situations.
} 
program for a particular institute. The qualitative literature synthesis searched for characteristics of succession planning processes across sectors (i.e., public, private, and nonprofit). The surveys' focus was on the university and research institute contexts in which the process model would be situated. These stages are described more fully in the conceptual framework section found in chapter two.

Examination of the primary research question was informed by exploration of several secondary questions:

- According to the scholarly literatures related to public, private and nonprofit organizations, what processes of succession planning are important or appropriate for university-wide research institutes in four-year, public doctoral universities with very high research activity?

- What processes of succession planning do leaders in complex public organizations generally, and university-wide research institutes specifically, engage in?

- How might a proposed process model best be implemented in universitywide research institutes?

To better understand why these questions are relevant to public administration generally, I suggest linkages that universities and research institutes have to public administration and policy. To further understand why these questions are relevant in today's universities specifically, I referred to trends related to increased university research activity and the significant role that research institutes play within universities. I then give reasons for the importance of the research generally. 


\section{Relevance to Public Administration and Policy}

Exploring succession planning in university-wide research institutes within large public universities is relevant to public administration and policy through organizational, financial, and theoretical linkages. Public universities ${ }^{2}$ have an organizational linkage because many are public organizations that must report and account to state governments. Universities are connected to the public financially because they receive public support through student financial aid, grants and contracts, and state government appropriations for budgetary items such as faculty salaries and operating expenses (Slaughter \& Leslie, 1997). Theoretically, university-wide research institutes have a connection to broader economic and social policies because a better educated society benefits the country as a whole. Additionally, research that public universities in the United States embark on helps to enhance the country's global significance and reputation as well as help address major issues throughout the world. Moreover, these institutes have management and human resource issues similar to other public institutions.

\section{Organizational Link}

Public universities and their research institutes have an organizational link to public administration because they are public institutions, or agencies. University-wide research institutes are embedded in a complicated, yet interconnected web of agencies and associations (see Figure 1). Hierarchically, these semi-independent institutes fall under the president and senior officials of a public university, the university's board of trustees, often a state governing board (e.g., the State Council for Higher Education in Virginia, SCHEV), the state government and finally the federal government. More horizontal relationships can be found with private

\footnotetext{
${ }^{2}$ Although many private universities and their institutes receive federal grants and contracts, this research specifically focuses on the distinctive characteristics of public universities as public agencies and the duties of public officials to strategically plan for succession in those organizations.
} 
corporations and foundations as well as other universities, research institutes and professional associations.

The dual arrows in Figure 1 between the research institute and outside entities indicate that each relationship is reciprocal. For instance, the overall university may oversee the research institute as well as support it financially, and in return the research institute may give the university money (e.g., a percentage of incoming sponsored research funds) or prestige and legitimacy in certain fields of inquiry. 


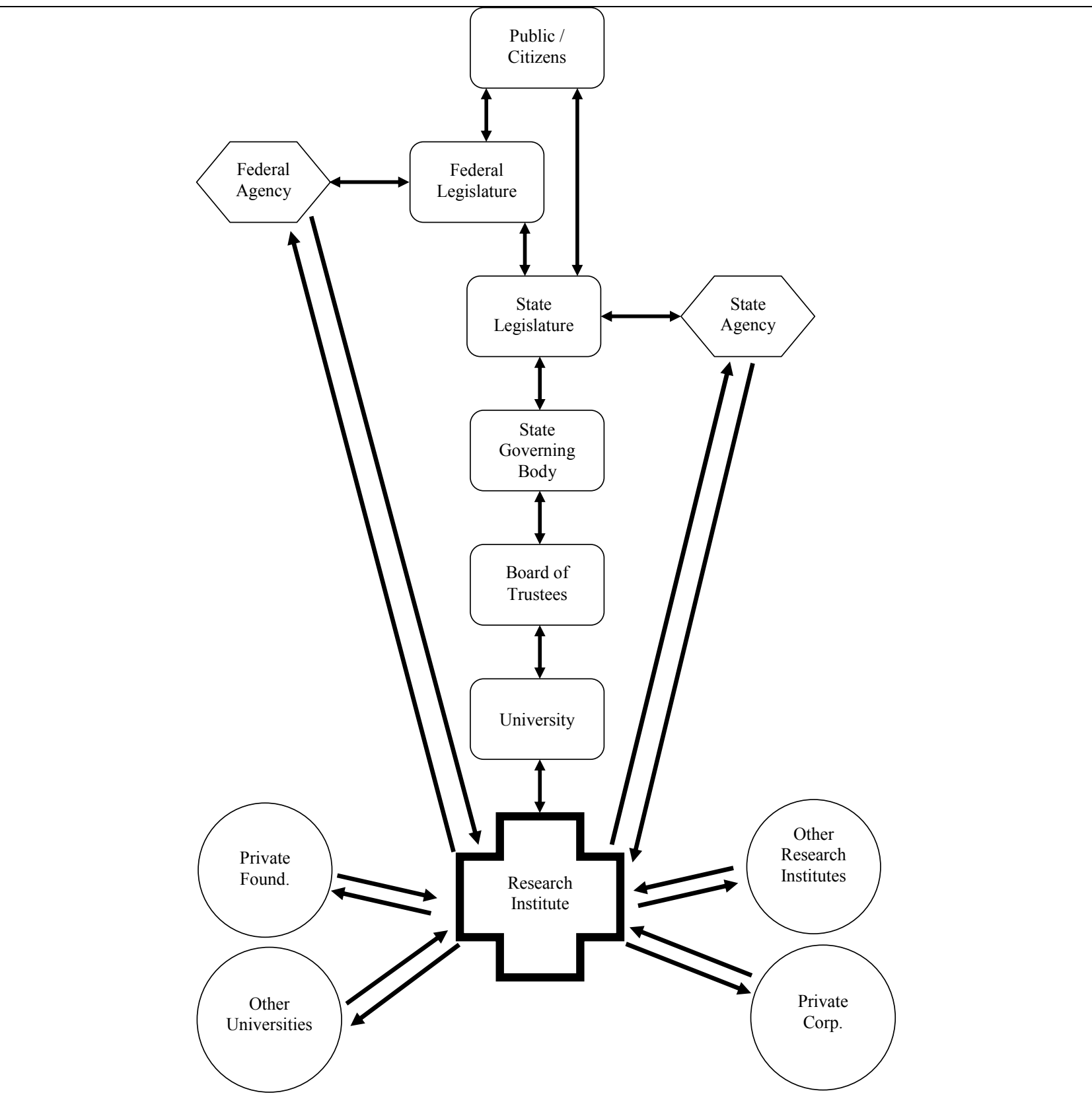

Figure 1: Relationships with University-wide Research Institutes

Each entity in this mostly hierarchical structure is placed at levels similar to Janosik's policy matrix levels - federal, state and institutional (Janosik, 2006). I added a fourth level - an institutional subunit because each research institute within the university has its own policies (see Appendix A for details of the policy matrix). The columns found in the policy matrix are 
funding, regulating, planning and coordinating. Various agencies, both public and private, affect the activities and policies of other agencies and subunits along these dimensions.

The funding dimension involves financial support to the research institute. The regulating column refers to statutes enacted by state and federal legislatures and regulations issued by administrative agencies that affect the research institute. Janosik (personal communication, February 10,2010) posits that planning activities are performed by commissions and organizations that make recommendations to universities. Finally, coordinating activities are those undertaken by government agencies that create regulations for other agencies to follow. (Janosik, personal communication, February 10, 2010)

As public agencies that receive funding and other support from federal and state sources, universities must follow both public policies, particularly state policies since public higher education is the responsibility of individual states. Several states, like Virginia, have policies related to succession planning. Virginia's Workforce Planning Policy 1.90 requires agencies to “develop plan[s] outlining issues and options for addressing [workforce] needs" (DHRS, 2003). The state provides no funding to public agencies to develop their plans; however, the Department of Human Resource Management is responsible for helping agencies to develop plans, reports, and strategies to meet their workforce needs (DHRS, 2003).

Not only do state government policies affect universities, so do those of accreditation agencies. For example, the Southern Association of Colleges and Schools (SACS) evaluates colleges and universities in Virginia and gives them accreditation. SACS' assessment focuses on vision and mission, school effectiveness as it relates to student learning, and governance and leadership that is effective in reaching defined visions. One assessment standard that may be particularly important to succession planning is standard 2.10, "Implements an evaluation system 
that provides for the professional growth of all personnel" (AdvancED, 2010, p. 2). Indicators of this standard are "succession plan[s] demonstrate leadership transitions" and policies that demonstrate opportunities for and knowledge of professional development (AdvancED, 2009, pp. 13, 15).

Definite legal and recommended policies are related to succession (or workforce) planning at the state, public agency, and accreditation levels for public, doctoral research universities; yet there is still a dearth of university policies in this area. Because no funding accompanies these policies, universities and research institutes may not make succession planning a priority. As units in public agencies, the institutes are subject to the requirements for workforce plans; yet, there seems to be a lack of oversight or policies and regulations related to workforce or succession planning at these institutes. They fall under the public agency requirement for workforce plans; however, they evidently are not creating these plans. This may be the case because the overall university in which an institute is housed has or is in the process of creating such a workforce plan. It is unclear whether the university plan will address workforce needs in particular research institutes.

This study examined 59 public universities with very high research activity located in 34 states. $^{3}$ Although they are part of the public organization network, many may not look like traditional government agencies because their structure is a professional bureaucracy rather than a machine bureaucracy. First identified by Max Weber, McKinney and Howard (1998) explained that a professional bureaucracy is one that allows:

\footnotetext{
${ }^{3}$ There are 95 universities, private and public, categorized by the Carnegie Foundation as doctoral universities with very high research activity. The number was reduced to 78 universities because some did not have characteristics similar to Virginia Tech or what Virginia Tech aspires to be (SCHEV Peer Institution, Top 30, Public Land Grant, AAU member) or did not have university-level research institutes. Private universities were included in the surveys to better understand any possible trends in comparison to public universities; however, the main focus of this research is public universities and institutes.
} 
highly trained experts to be hired to operate as an efficient group or core. Professional bureaucracy combines standardization and professionalization. Because of the knowledge explosion and the complex job requirements, undergraduate and graduate degrees are necessary to enable professionals to produce goods and services needed... The power in the professional bureaucracy resides with the operating core because of the critical skills that the organization requires. The professionals have a very high degree of autonomy through the operation of the decentralized style. This model allows professionals to exercise maximum discretion to apply their expertise. (p. 141)

Even though public universities are autonomous in many respects, they must report their activities to the governor and state legislature through the university's board of directors ${ }^{4}$. Universities are directly accountable to the state legislature and indirectly to the citizens because they receive sizeable portions of their budgets from tax revenues ${ }^{5}$.

While public institutions of higher education have different structures than other state agencies (in some states they may not be considered state agencies at all), they still are linked organizationally with state and federal governments by policies and practices to which they are bound to follow. For instance, employee policies related to tenure and disciplinary issues fall under the jurisdiction of the U.S. Equal Employment Opportunity Commission and its state counterparts. Universities must also follow policies related to students, such as the Family Educational Rights and Privacy Act (FERPA), and to research, such as the 2000 Federal Research Misconduct Policy from the Office of Science and Technology Policy in the Executive

\footnotetext{
${ }^{4}$ In many states, public university board of directors are appointed by that state's governor or state legislature, which is a direct linkage to the state governing system.

${ }^{5}$ Currently, for example, the state funds 21\% of Virginia Tech's operating budget (2010-2011 Authorized Budget Document, Consolidated Budget Summary, as cited by the Office of Budget and Financial Planning, 2010, What percent of the total university budget comes from the state? Section, para. 1).
} 
Office of the President. Institutes may conduct research for private corporations, but because they are formally linked to public governments, and not considered private companies, they are required to follow federal regulations.

Not only are state budgets interlinked with higher education budgets and policies, their missions also are entwined. Public universities play important roles both in the education of young people (and increasingly people of all ages) and in the generation of knowledge to advance society. Many public universities have a land grant mission in which the knowledge that is generated is disseminated to the people in an effort to enhance the general public welfare. Spanier (1999) described the land-grant university's vision as advancing “access, relevance and service to society" through a "tripartite mission of teaching, research and public service" ( $p$. 199). Land-grant institutions such as Virginia Tech have increased their enrollments, expanded their research programs, and broadened their public service activities to "address the increasingly complex needs of each passing era" (Spanier, 1999, p. 199). As such, the current and relevant research that institutes in these universities conduct is frequently important to society in general, and therefore it is important to understand how to continue such work.

\section{Financial Links}

Universities receive financial benefits from state and federal governments beyond the budgetary support they receive as formal government agencies, such as research grants and contracts or federal financial aid for students. Similarly, in addition to the accountability structures set up because of their organizational linkages, universities are called to account for how they spend public money through their research.

Research universities are interlinked with governments, both federal and state, because many of them receive additional public monies through research grants and contracts from such 
federal agencies as the National Science Foundation (NSF), the National Institutes of Health (NIH), and the U.S. Department of Education. Most university-wide research institutes conduct research for the "public good" through government grants and contracts. According to the NSF (2009b), "public [universities] spent a total of $\$ 35.3$ billion on R\&D in FY 2008, with 55\% funded by the federal government." Research expenditures rose 5.8\% from FY 2008 to FY 2009 , including an increase of $4.2 \%$ in federal funding (NSF, 2010). Narin, Hamilton, and Olivastro (1997) found that $73 \%$ of published research articles in the fields of biomedicine, chemistry, physics, and engineering from 1987-1994 referred to research done by public institutions funded by NSF, NIH, and other public agencies. Similarly, Cohen, Nelson and Walsh (2002) found that one third of survey respondents, who were industrial researchers in engineering and applied science fields $(n=1,478)$, relied on research findings from publicly funded research.

Policy makers and public administrators, including university administrators, are constantly looking for new and inventive ways to protect their financial investment and advance the public good. The activities that a university takes on, including sponsored research ${ }^{6}$, are reviewed through various models of accountability at the federal, state, and institution levels, such as federal accreditation standards, state reporting requirements regarding institutional performance, and goals found within the university's strategic plan (D. Hanna, personal communication, October 13, 2009). Additionally, most granting agencies require universities and research institutes to file reports explaining how the university spent the grants that it received.

\footnotetext{
${ }^{6}$ This research focuses on sponsored research, which is funded by external research grants, rather than on other types of scholarly activity that takes place on university campuses.
} 


\section{Theoretical Link}

Aside from organizational and financial links, some scholars link higher education and research theoretically to the general public welfare. They argue that higher education contributes to economic growth, which in turn helps to boost the United States' position in the global economy. Slaughter and Leslie (1997) write that better educated employees who possess knowledge and skills promote economic growth, and because universities have the greatest amount of highly educated labor, they in turn have a great impact on society:

Universities are the repositories of much of the scarce and valuable human capital that nations possess, capital that is valuable because it is essential to the development of the high technology and technoscience necessary for competing successfully in the global economy... when faculty implement their academic capital through engagement in production, they are engaging in academic capitalism. Their scarce and specialized knowledge and skills are being applied to productive work that yields a benefit to the individual academic, to the public university they serve, to the corporations with which they work, and to the larger society. (pp. 10-11)

Similarly, the Association of American Universities (2001) argued that academic research, both science and arts and humanities research: 1) promotes sustainable economic development and positions the United States as a leader in global technologies, 2) better educates and prepares citizens for the workplace of the future, 3) encourages medical breakthroughs and improves public health, and 4) helps maintain national security.

Another theoretical link is related to management and human resource issues that exist in most complex public organizations. In order to address many of these issues, scholars look to 
strategic human resource management (SHRM), as mentioned earlier. Succession planning is one type of SHRM activity that can enhance both current and future governance. It helps organizational leaders to think strategically about the future of their organization and the leadership capacity within that organization (Lynn, 2001). Succession planning helps to reduce the effects of what Milward and Provan (2000) called a hollowed out state, or lack of available and necessary skills, by assuring leadership continuity (Leibman, Bruer, \& Maki, 1996). Through succession planning, leaders learn to use public funds more effectively and efficiently by making sure the right people are in the right positions that fit their skills and expertise, which enhances productivity and reduces expended resources recruiting and training new employees (Christie, 2005; Collins, 2001). In relation to higher education, succession planning enables universities to remain relevant and ready to face challenges in society by allowing faculty to continue the work that they do (Hanna, 2003).

\section{Relevance of Research to Universities}

Succession planning is important for universities and research institutes because it helps them to prepare for the future by giving them a process to think strategically about their future labor needs as well as plan for replacement of key organizational leaders. Labor costs are typically the highest percentage of university expenditures; by thinking strategically about these precious resources, universities can sustain the services that they offer without becoming a hollowed out organization. Trends show that labor needs will increase in the future both through greater research activity as well as increased retirements of current researchers. Because of these trends, it is important to review succession planning policies of research institutes. 


\section{Increased Research Funding and Activity}

Data from 1980 through 2008 show a rise in the number of research centers at public universities as well as increased university research expenditures (see Table 1). The 2003 International Research Center Directory, edited by Alan Hedblad, showed an increase in the creation of research centers $-6,000$ by $1980 ; 10,000$ by 1990; and over 13,000 by 2003 (as cited by Mallon, 2004, p. 65). The National Science Board (2010) reported that "national R\&D spending has increased mostly uninterrupted since 1953 . Over the past 20 years, growth in R\&D spending has averaged $5.6 \%$ in current dollars and $3.1 \%$ in constant dollars-somewhat ahead of the average pace of GDP growth over the same period (in both current and constant dollars)" (chapt. 4, Trends in National R\&D Performance section, para. 3). The number of academic science and engineering researchers "grew $2.5 \%$ per year (from 82,300 to 183,700 ) between 1973 and 2006" (National Science Board, 2010, chapt. 5, Doctoral Scientists and Engineers in Academia section, para. 7). It is hard not to speculate that such large numbers of university research expenditures and centers have a sizable impact on the research community in general. If the trends continue, this may be an indication that there will be employee needs within university-wide research institutes in the future. If the trends do not continue [some analysts worry about cuts in federal research funding (Hand, 2011)], this research becomes even more important as universities and institutes will need to think strategically about possibly reducing their future employee ranks.

\section{Future Labor Shortages in Universities}

There is some concern over an expected gap in labor or potential labor shortages in the near future. In its most current report, the Bureau of Labor Statistics (BLS) predicts that by 2018 total U.S. employment will increase by $10.1 \%$, while the total number of available employees 
will increase at a slower rate (a total of $8.2 \%$ ) due to retirements of baby boomers, those who were born between 1946 and 1964 (BLS, 2009a; Toossi, 2009). Similarly, the Partnership for Public Service (2009) predicts that by 2012 over 240,000 federal employees will retire from their positions, and the federal government will need to hire 273,000 new employees in "missioncritical jobs" not only to replace these workers but also to deal with growth in demand for government services.

The BLS is hesitant to predict an overall labor shortage by 2018; however, it does agree that some organizations will have a more difficult time finding an adequate amount of employees. These organizations will grow at a faster rate than others and will have difficulty filling positions because at least 20 percent of their employee base is over the age of 55 (Horrigan, 2004). "For these occupations, hiring, if only for replacement purposes, is going to be fairly brisk - and the need to expand total employment levels will only serve to accentuate the hiring challenge" (Horrigan, 2004, p. 14). While the numbers reported here are based on the population in general, colleges and universities also are experiencing the effects of the baby boomers' retirements. The BLS places both public and private colleges and universities in its top ten industries that will have the largest growth in employment and wage needs - a $19.1 \%$ increase by 2018 (BLS, 2009c).

Although it does not specifically address employee needs within university-wide research institutes, the BLS does predict that jobs requiring a doctoral degree will increase $16.6 \%$ by 2018 (BLS, 2009d). Generally, by 2016, jobs for researchers in computer and information science will increase $24.18 \%$, and those for mathematical operations research analysts will increase $22.02 \%$ (BLS, 2009b). These projections may indicate overall increased research in the future that in turn may require increased numbers of researchers and other staff in university-wide research 
institutes. Such percentages may have some limitations because they relate more to physical and natural science subjects with no projections related to social science research.

Because of these trends, many human resource managers have come to believe that a large gap does exist in human capital in the United States (HRM Guide Network, 2008b). These HR managers are beginning to understand that they should develop programs to prepare future leaders to help address this gap (HRM Guide Network, 2008a). To do that, they are looking at the development of succession planning, or talent management, programs.

\section{Significance of Research Institute Focus}

Many scholars, such as Daniel Pink (2005), believe that human society is transforming from an informational age to a conceptual age in which successful people will need to be able to create new knowledge more generally, understand context and big picture connections, and become "meaning makers" (p. 50). Consequently, research and the creation of new knowledge will become even more important in the future. If universities in the United States hope to stay relevant in this coming conceptual age, they must understand processes of knowledge creation or transfer. Additionally, it may be important to understand how university research institutes and sponsored research play a role in this knowledge creation. Among these processes, scholars need to better understand how research institutes continue their work beyond the current researchers working for those institutes; in other words, how they do and might conduct succession planning for the future.

While focusing on the creation of knowledge is intriguing, understanding how this creation of knowledge continues beyond current generations is also important. Even more importantly, it is necessary to understand methods by which universities can strategically plan for the future of their institutes and the development of their employees, no matter what that 
future might hold. Addressing this needed method, I developed a succession planning model for possible implementation in university-wide research institutes at four-year, doctoral universities with very high research activity, examining both public and private institutions.

Using Virginia Tech as a framework, these institutes have the following characteristics: they are university-wide; independent of colleges and departments; report to a university-level official, such as the vice president of research; are fairly independent in regards to HR, budgeting, and administration; and are typically interdisciplinary in nature (VPI\&SU, 2008). The Office of the Senior Fellow for Resource Development at Virginia Tech reviewed the evaluation processes of university-wide research institutes at four-year doctoral universities with "very high research activity" (as defined by The Carnegie Foundation for the Advancement of Teaching, 2007) and established a list of recommendations, one of which included developing and implementing succession planning processes (C. Grohs, personal communication, July 10, 2009). This research was a direct result of that review and its recommendations.

\section{Importance of Research}

Data show that research institutes within public universities are increasing in number as well as research activity; if these trends continue research institutes will need a greater number of employees to meet demand. In addition, many organizations, including universities and research institutes, will lose their top executives in the next five to ten years due to the retirement and career changes of individuals in the baby boomer generation. As such, it is necessary to think about leadership transitions and the associated planning and organizational development that are essential in preparation for those transitions (Teegarden, 2004).

While succession planning is well known in the corporate world, a brief review of the literature shows a large gap in scholarly research related to succession planning in public and 
nonprofit organizations, especially those in higher education. Some articles are related to nonprofit and governmental organizations in general; however, very few discuss higher education or research institutes. Accordingly, this study will contribute to the literature to bridge the gap in knowledge.

Although this study has a potential to make a major contribution to human resource policy, one challenge is ascertaining whether the research fills a hole in the scholarship or whether it is considering a topic that few consider relevant - hence the lack of scholarly journal articles. As observed in the trends mentioned earlier, I believe that the topic is of great importance not only because university research institutes are increasing in number but also because soon they will begin to lose their senior managers and, at the moment, there seems to be no plans for younger generations to take over the reins. This topic is also important because universities and their research institutes have to continuously evolve, or replicate themselves, in order to keep up with the constant changes in the environment and with technology and therefore survive (Morgan, 1981).

\section{Scholarly Grounding}

\section{Succession Planning Definition}

For this research, I use Rothwell's $(2001 ; 2010)$ definition of succession planning and management (SP\&M): "a deliberate and systematic effort by an organization to ensure leadership continuity in key positions, retain and develop intellectual and knowledge capital for the future, and encourage individual advancement" (p. 6). He further posits that SP\&M should not be confined to executive management positions but applied to all job categories in organizations (Rothwell, 2001). The goal of SP\&M is to train and develop current talent and capacity of an organization to prepare it for future needs (Rothwell, 2010). 
While most people would agree that SP\&M is necessary, many may confuse this overarching term with more specific ones - replacement planning, leadership development, or organizational development. Rothwell (2010) described replacement planning as "a form of risk management," because it plans for who will take over key positions when an "immediate and unplanned loss of key job incumbents" happens, such as a sudden death or resignation (p. 12). Succession planning goes beyond replacement planning by looking at the entire human capacity of an organization and how that capacity should be developed for future needs. It is not simply deciding which employee will take over what position during vacancies.

Like replacement planning, leadership development is related to succession planning, but it is only part of the process. Leadership development refers to increasing the capacity of individual employees to become leaders within a particular organization (Day, 2000). Succession planning takes a further step by intentionally aligning these leaders with organizational goals and strategies.

Similarly, organizational development (OD) is only part of succession planning. It is related to long-range organizational change and betterment (Fullan, Miles, \& Taylor, 1980). OD looks for techniques to offer better programming and services and, in the case of for-profit businesses, to increase the bottom line. Nevertheless, what may be good for the entire agency may not be the type of individualized professional development needed by its employees and leaders.

Succession planning and management is a more holistic approach that focuses on longrange planning and the capacity of organizational members, individually and collectively, to implement, facilitate, and lead the betterment of the organization (Rothwell, 2001). Some scholars and human resource managers refer to this planning as "talent management." Rothwell 
(2010) distinguishes succession planning from talent management because the latter focuses only on the "upper 1 to 10 percent" while the former helps develop employees at all levels of the organization.

Many managers believe that succession planning is a positive and necessary step for organizations to undertake to help prepare their organization for future human capital needs. Most organizations, however, including higher education institutions, do not know how to begin their planning. Since universities often benchmark their ideas with other institutions to learn from their processes and the challenges they confront, this research focused on scholarly literature to lay a foundation of knowledge for universities as they develop their succession planning processes for their university-wide research institutes. Because there is minimal succession planning literature related to universities, I looked to for-profit, public, and nonprofit institutions for these benchmarks.

\section{Succession Planning Literature}

Kesner and Sebora (1994) found that research in the 1960s and 1970s had an organizational focus, referring to size, turnover frequency, how leadership styles relate to organizational context, and the relationship between the CEO and board of directors. Research in the 1980s and 1990s added factors related to the successor him- or herself, such as personal characteristics, experience, and actions (Kesner \& Sebora, 1994). Most of the studies that Kesner and Sebora reviewed examined characteristics or actions of the CEO or the relationship between succession and organizational performance. Process characteristics noted by the articles included: duration (Hashemi, 1980, as cited by Kesner \& Sebora, 1994), effects (Day \& Lord, 1988, as cited by Kesner \& Sebora, 1994), and approaches (Kelly, 1980; Gilmore \& McCann, 1983; Gabarro, 1986, as cited by Kesner \& Sebora, 1994). Successful processes emphasized 
"high CEO involvement, allocated significant resources to formal human resource functions, and established accountability in support of their succession processes" (Friedman, 1986, p. 360, as cited by Kesner \& Sebora, 1994).

More recent research by Ayse Karaevli and Douglas T. Hall (2003) found several common characteristics in successful succession planning processes from 13 businesses "known for their succession planning and talent identification and development programs" (p. 64). Common characteristics across these 13 businesses were related to identifying potential successors within the organizations:

- "High potentials" are relative to the organization's context;

- Process is different from what the organization had done in the past;

- Line managers, not HR professionals, make the identifications;

- Data to determine high potentials are related to "past and current performance appraisal results, 360-degree feedback, and competency assessment" (p. 66);

- Group discussion methods helped to promote transparency and development;

- "Development process is increasingly becoming more individualistic" (p. 68); and

- Each plan focuses on developing a pool of people, not just one or two employees as future replacements. (Karaevli \& Hall, 2003)

Focusing more on colleges and universities, Witt/Kieffer (2008), a national search firm, surveyed presidents, board chairs and trustees at 135 universities and colleges. Of those higher education institutions, 74 percent report engaging in some type of succession planning processes for their university (Witt/Kieffer, 2008). Of those doing some type of succession planning, 77\% 
of the plans focus on board members, $64 \%$ include senior administration, and 59\% also include chief academic officers and deans (Witt/Kieffer, 2008). Other findings from the survey include:

- Replacement planning - identifying and nurturing internal leaders - is common;

- Proactive identification of successors has a negative perception, leading to the belief that open, public searches are needed;

- Shared governance and balancing succession planning with diversity are challenges;

- Succession planning must be transparent, participatory and part of overall professional development;

- Succession planning must be intentional and requires new thinking and cultural change; and

- Colleges and universities need to remain open to new ideas, focus on longterm goals and hold high internal leadership standards. (Witt/Keiffer, 2008, pp. 2-5)

Another study regarding university succession planning in Ivy League schools was conducted in 2003 by Jack Heuer. Although Heuer's research served as a foundation on which I built my research, it is distinctly different as he gives no attention to university-wide research beyond Ivy League schools, and he focuses solely on impediments to succession planning rather than on developing a model for succession planning.

\section{Research University Literature}

To understand how succession planning may work in university research institutes, it is important to understand trends in research universities in general because they also may be seen 
in research institutes specifically. The values and trends found in research universities may relate to institutes because they take place under the same institutional mission, structure, and culture.

According to Frank H. T. Rhodes (2001), universities in their current form have been around since the early 11th century but their mission and financial and governance structures evolved over time. Between the 11th century and the late 1890 s, universities transitioned away from a mission "to conserve and transmit the learning and skills of the church" (p. 4) to become:

- the essential gateway to and foundation of every major profession;

- the primary agents for basic research;

- a huge economic and employment influence on local regions;

- the major agents of social mobility; and

- the significant providers of social services. (Rhodes, 2001, p. 4)

Although universities made major changes throughout the centuries, Rhodes (2001) argued that since the 19th century, universities have become stagnant in their organizational, management and governance structures with only minor changes due to "opportunism." $\mathrm{He}$ wondered "whether the university, in spite of all its success, is prepared for the major growth in responsibility that it must assume in the new millennium" (p. 5).

Rhodes (2001) argued that although U.S. society has changed drastically over time, universities have remained fairly static in their organizational, management, and governance structures (p. 5). As such, universities will need to manage six needs in the future:

- More defined missions, roles and functions (p. 5);

- New methods of learning and means of delivery of knowledge (p. 5);

- More creative uses of information technology (p. 7); 
- A balance of outreach with realistic university capacities (p. 8);

- A review of the continued relevance of the tenure process (p. 9); and

- A review, and possible overhaul, of university organization, governance, leadership and management (p. 9).

Similarly, Brian White and Peter Eckel (2008) published a series of essays on the future of higher education. In Collective Foresight: The Leadership Challenges for Higher Education's Future, they too discussed trends that university and college presidents will need to contend with:

- push for greater assessment, accountability, and transparency;

- changing relationships between universities and state governments;

- demographic changes with rise in baby boomer retirements and upcoming generations;

- advances in technology and "the presence of science in everyday life" (p. ii); and

- effects of globalization.

In addition to these trends, universities will face three major challenges that White and Eckel (2008) categorized as funding, public perception, and knowledge and information. As costs rise, funding will become focused on short-term priorities and outcomes, and universities will have to compete in unforgiving markets while also trying to advance their traditional missions (White \& Eckel, 2008). The greater reliance on outside funding and market pressures tends to steer universities to more competition for grant dollars and greater sponsored research expenditures, as evidenced by NSF's and The Top American Research Universities' rankings of universities by amount of research dollars spent (Lombardi, 2005). 


\section{University Research Institute Literature}

A limited amount of scholarship relates to governance and management structures of university research institutes specifically; most work examines the transition of knowledge creation to industry, a topic not relevant to this study. I found only five articles related to governance or structure of research institutes; several suggest that the presence of research institutes on university campuses detracts from the primary mission of universities to educate young adults. Each article ends with the author's guidance on how to improve the impact of those research institutes on universities in general.

The first article was an examination of the discordant relationship between departmental faculty and faculty in research institutes. In Center and Institutes in the Research University: Issues, Problems, and Prospects, Gerald Stahler and William Tash (1994) reviewed organized research units (ORU), sometimes called research centers or institutes, and their role in the top 150 fastest-growing research universities from 1983 to 1990 . They found that centers accounted for an average of $28 \%$ of their university's research expenditures (p. 547); conducted research in engineering, physical sciences, or medicine (p. 548); were interdisciplinary (p. 548); were closely integrated with traditional departments (p. 548); and were "perceived as an essential element in the expansion of research at these institutions" (p.549). They concluded that centers play an integral role in the university and offer six recommendations to help reduce conflicts between departmental faculty and research faculty.

The first four recommendations focus on the responsibility of the university: (1) university administration must endorse the research institute, and the institute's mission should match that of the university; (2) the university must be willing to provide the institute with adequate resources; (3) the university must develop clear goals for the institute's leadership and 
make sure the leaders have skills to accomplish those goals; and (4) universities should house ORUs in central locations within the university to encourage their interdisciplinary nature ( $\mathrm{pp}$. 550-552). The remaining recommendations are the center's responsibility. The center's leadership should affiliate with academic departments to foster a helping relationship rather than one of conflict (Stahler \& Tash, 1994). Finally, the centers "should be reviewed on a regular basis to determine whether they are achieving their goals, whether changes in direction and internal support are necessary, and what they are contributing to their universities" (Stahler \& Tash, 1994, p. 552).

In the second article, Disjointed Governance in University Centers and Institutes, Mallon (2004) maintained that core governance structures of universities have changed and eventually become disjointed by the creation of research centers. According to Mallon, (2004), disjointed governance in universities means that various governance structures have been layered upon one another, causing complexity, confusion, and tugs-of-war over power structures and authority. The author pointed to four characteristics that are evidence of disjointedness, increases in: (1) new governance structures; (2) external stakeholders in decision making processes; (3) nontraditional faculty (part-time and non-tenured) and faculty-like groups (post-docs and graduate assistants) in decision making processes; and (4) views that these non-traditional faculty are citizens of the university community (p. 63).

Mallon (2004) argued that research institutes have significant influence on university governance for three reasons: they play a role in who is hired, generate revenue, and employ significant numbers of employees who sit on university commissions and make decisions. Mallon (2004) ended his article with five implications of disjointed governance:

- the importance of traditional, formal faculty governing bodies will decline; 
- representation of the interests of non-traditional faculty will continue to rise;

- individual faculty members who bring in considerable external resources will gain more power and authority over the faculty as a group;

- faculty loyalty to the institution may shift to external markets rather than focusing on disciplines and professions as they do now; and

- power will shift from the traditional core, or academic mission, of the university to its fringes, where sponsored research occurs (p. 70-72).

Three of the articles focus on centers created in medical schools. Members of the Association of Professors of Medicine describe the purpose of centers as an attempt to "increase the marketing appeal of an institution at a local, state, and national level" (Ibrahim, O'Connell, LaRusso, Meyers, \& Crist, 2003, p. 337). They worry that people think centers are more efficient than departments, when in reality the centers seem more efficient because they have "freedom from such distractions as the need to meet regulatory entities" (p. 338). In conclusion, Ibrahim et al. (2003) believe that centers are having a detrimental effect on medical schools' ability to educate future physicians because of their ever changing department structures; they ask that the medical community continue to examine these effects.

Mallon and Bunton (2005) view research centers more positively; they argue that medical schools have developed interdisciplinary research centers to make "once-rigid boundaries between departments, schools, and institutions more permeable and fluid" (p. 1005). In their research, Mallon and Bunton (2005) found that centers have various structures; most are small with important but somewhat limited influence on departments and medical schools, while a small group of them, which the article terms "power centers," have "greater resources and broader influence than most" due to their "position within the university hierarchy" and the high- 
level university administrators with whom they interact (pp. 1008, 1010). They conclude with praise for centers and institutes:

Regardless of purpose, size, or type, research centers and institutes can make important contributions to the research mission of academic institutions. As researchers increasingly work across disciplinary boundaries for the advancement of science and health, medical schools and universities will need to facilitate the work of research centers and institutes and academic departments to ensure scientific progress and the improvement of human health. (Mallon \& Bunton, 2005, p. 1010)

One year later, Mallon (2006) conducted a study to better understand the benefits of centers and institutes. He found that centers were created to:

- aid faculty recruitment and retention,

- facilitate and incubate scientific collaboration,

- secure research resources and provide research support,

- offer a sense of community and promote continued learning,

- afford organizational flexibility, and

- focus on societal problems and raise funds. (Mallon, 2006, p. 504)

Although Mallon (2006) found several benefits to medical research centers, he also found several challenges: "competition with departments, challenges in faculty recruitment, fragmented mission, evaluation, governance and authority, tenure and promotion, and junior faculty development" (p. 507). The author concluded that these challenges can be mitigated if leaders in the university are supportive of the center, if the center's mission and purpose is clearly 
delineated, and if administrators are careful to not allow centers to replace departments and their "prerogatives, such as faculty appointment, space, and funds-flow" (Mallon, 2006, p. 512).

After reviewing available scholarship, it seems that succession planning is a much needed strategic process that universities, especially research institutes, have not sufficiently valued in their organizations. As research becomes more prominent in university settings, greatly affecting both the governance and financial characteristics of the university, it will become necessary for higher education leaders to develop succession planning processes within their university research institutes. It is this future challenge that was the impetus for this research.

\section{Summary of the Chapters}

Chapter two is a detailed review of the research's methodology, hypotheses, and conceptual framework. The research had three data collecting phases: 1) a qualitative research synthesis of scholarly literature, 2) an electronic survey, and 3) follow-up interviews. The research synthesis examined scholarly literatures to identify key process characteristics found in for-profit, governmental, and nonprofit organizations that may apply to succession planning in university research institutes. The findings from this analysis were integrated into an electronic survey $^{7}$ that was sent to executive directors of university-level research institutes and one university administrator at 78 universities classified by the Carnegie Foundation for the Advancement of Teaching as universities with very high research activity.

Chapters three, four, and five summarize the findings of the qualitative synthesis, surveys, and follow-up interviews. Chapter three focuses on succession planning characteristics found in all three sectors, such as support from executive leaders, linkage to the organization's strategic plan, and a plan tailored to individual organizational needs. Chapter four explores

\footnotetext{
${ }^{7}$ [Used with permission] Special thanks to William J. Rothwell for the use of several survey questions from his 2001 book Effective succession planning: Ensuring leadership continuity and building talent from within.
} 
whether and how the survey responses were consistent with the findings of the research synthesis. Chapter five describes the development and characteristics of my proposed succession planning model for university-wide research institutes in four-year, public doctoral universities with very high research activity. It concludes with a description of the results of the interviews and analysis of the findings.

The final chapter concludes the dissertation with a summary of the findings and a discussion of the implications of the current research and possible future research. As I expected, succession planning characteristics found in the public, private, and for profit sectors are indeed relevant to university-wide research institutes. 


\section{Chapter 2: Framework and Methodology}

Research is formalized curiosity. It is poking and prying with a purpose.

- Zora Neale Hurston (1942)

To better understand how public university research institutes might incorporate strategic human resource management and succession planning, I designed a research project with a mixed-methods approach. Guided by Creswell and Plano Clark (2007), a mixed-methods research design is one that uses quantitative and qualitative data in the overall design of the study to provide a "better understanding of research problems than either approach alone" can provide (pp. 8-9). The combination of three different types of data - qualitative data from scholarly literature, quantitative survey data, and qualitative interview responses - afforded me a comprehensive examination of a complex research question. The qualitative literature analyses guided my understanding of successful succession programs that already exist. The quantitative survey data focused those findings on a specific population (i.e., university-wide research institutes) and allowed me to develop a proposed model for succession planning for this population. The qualitative interviews then gave me an opportunity to validate that model, answering my overall research question.

This chapter details this mixed-methods approach. I first describe the conceptual framework in which the research is grounded. I then discuss the three phases of the research design, the validation and characteristics driving the findings, and the methodologies of this mixed research. The chapter concludes with information to help the reader better assess the overall project by describing my grounding assumption, research limitations, and ethical considerations. 


\section{Conceptual Framework}

Before describing the methodology for this study, it may help the reader if I explain the theoretical understanding of the succession planning process on which the research is based. The conceptual framework brings together expectations of how a process model may work. It is conveyed in a diagram that shows the elements and stages involved in my succession planning process.

Scheerens's (1990) Context-input-process-output-outcome Model of Schooling is relevant to this study's concentration on succession planning processes. He posits that inputs feed into processes that influence the outputs and eventual outcomes. He further argues that this entire system is embedded in a context, which it influences and by which it is influenced (see Figure 2).

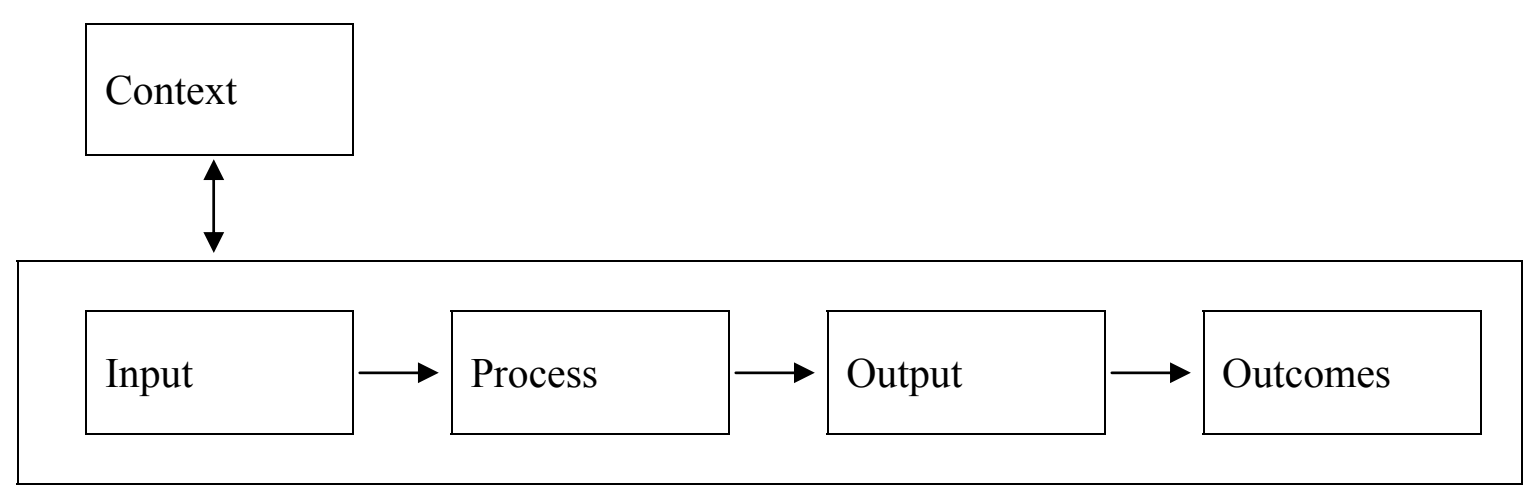

Figure 2. Context-input-process-output-outcome Model of Schooling (Scheerens, J., 1990). [fair use]

Based on Scheerens's (1990) Model of Schooling, I developed a framework for this research (see Figure 3). Although university-wide research institutes vary in purpose, research techniques and primary funding, leadership and succession planning processes may be similar across organizations, just as Karaevli \& Hall (2003) found. As such, succession planning 
processes found in other organizations may be used to help develop a model for succession planning for these research institutes.

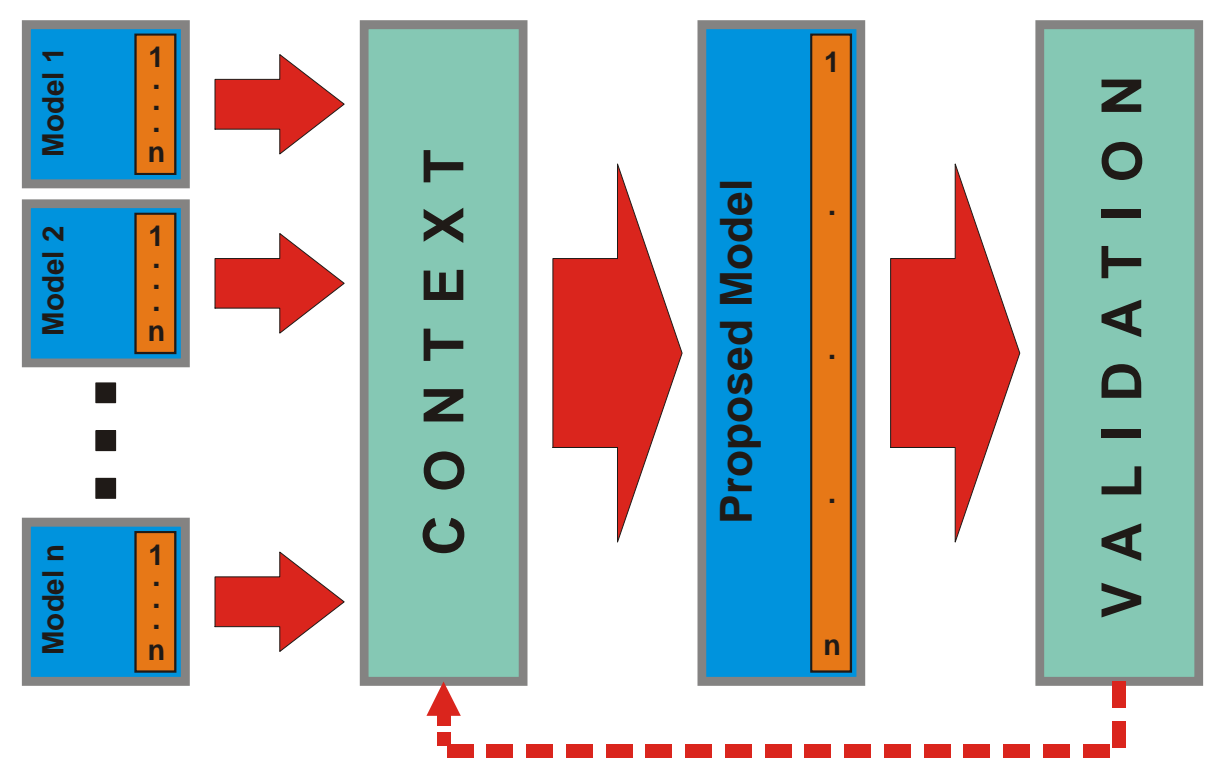

Figure 3. Development stages for succession planning process

I view the entire succession planning model as encompassing the process; together the steps in figure 3 comprise the process for succession planning. This figure stops at Scheerens's "process" step and does not incorporate the output and outcomes steps. In the context of my research, the output and outcomes steps are the implementation of the succession planning process, which then becomes a succession planning program for a specific organization.

The inputs of this study (boxes on the far left) include process characteristics of model succession plans, such as timeline, reasons for developing a succession plan, and decision makers and participants as well as their perceptions. The focal process is a strategic succession management model for organization or reorganization of university-wide research institutes (shown here as the "proposed model"). The output is an actual plan for succession planning (not shown). The desired outcome (not shown) is an effective administrative system for addressing the current and future labor needs of university-wide research institutes. All of these steps 
influence and are influenced by the university research institute context, which includes resources, skills and talents of current administrative employees, the goals and vision of the organization's strategic plan, and the future needs for effective administrative labor, including skills, talent, roles and responsibilities. This is indicated by the context filter in figure 3 .

Varying structures of higher education institutions necessitate a flexible process model without predetermined rules for succession planning. I expect, however, that certain process features of succession planning will be similar across universities and research institutes. As mentioned before, I view the entire succession planning model as the process. This research focused on characteristics of other models and how they might fit within the context of the university and research institute setting. A process analysis of succession planning best allowed me to focus on development of a succession planning model and the context in which is it situated.

\section{Overall Research Phases}

This study utilized a mixed-methods research design, more specifically an explanatory design with participant selection (Creswell and Plano Clark, 2007). The design had three phases, as shown in Figure 4:

1. collection and analysis of qualitative data from scholarly literature and quantitative data from surveys;

2. collection and analysis of qualitative data from expert interviews, which was informed by the previous findings; and

3. analysis and writing. (Creswell \& Plano Clark, 2007) 


\section{Succession Management Process Research}

\section{for Research Institutes in Four-Year Universities with Very High Research Activity}

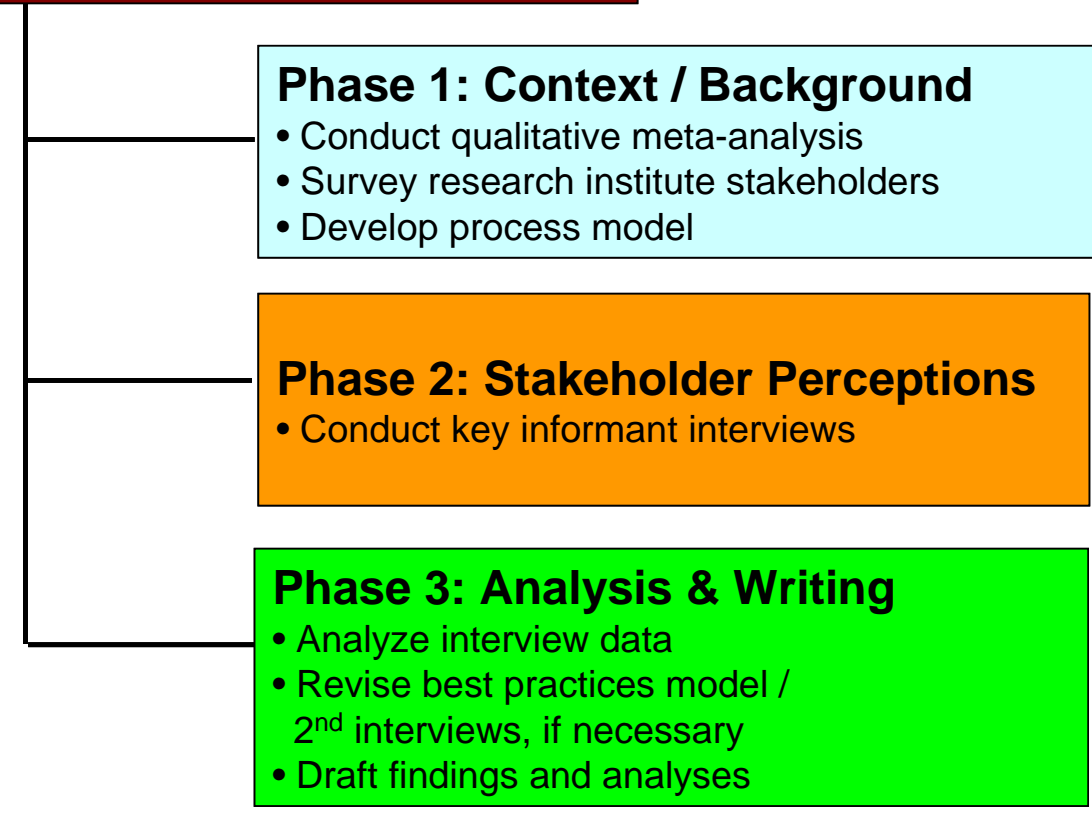

Figure 4. Summary of Research Phases

\section{Phase One}

The first phase was an exploratory study that focused on contextual and background information related to succession planning in large complex organizations. The purpose was to develop a hypothesized model for university-wide research institutes based on succession planning trends found in large, complex organizations. These trends focused on the process of succession planning rather than the content of the plans, examining, for example, who is involved, how they became involved, and how decisions are made. This phase determined the inputs, context, and proposed model in the conceptual framework in Figure 3.

Important questions in this phase included: 
- What does succession planning involve? How is it different from leadership development or replacement planning?

- Are there key process characteristics in succession management programs that are consistent across for-profit, public and nonprofit sectors?

- Based on the process characteristics and the university research institute's context and culture, is it possible to develop a process model for succession planning for university-wide research institutes in four-year, public doctoral universities with very high research activity?

During this phase, I conducted a synthesis qualitative research synthesis of scholarly literatures to identify key process characteristics found in nonprofit, governmental and for-profit organizations that may apply to succession planning in university-wide research institutes. Additionally, definitions in this area of research were formulated from the synthesis. Some words and phrases that needed further defining included leadership development, succession planning, replacement planning, and key process indicators, characteristics, or aspects.

After the research synthesis, I surveyed key stakeholders in research institutes (e.g., institute director and university-level administrator) to better understand the context and needs of those organizations. I used the synthesis of existing research and best practices of succession planning in organizations as well as the survey results as background information in the development of a process model for succession planning in university-wide research institutes. Although this research focused on public universities, administrators at research institutes in private universities were surveyed as well to better understand any variation that may appear between these two types of higher education institutions. 
Although there is a need for succession planning in all organizations, currently only a handful of universities and colleges are addressing this issue, and there is a dearth of literature related to succession planning in university-wide research institutes. The goal of the model was to provide a roadmap for current university leaders to develop processes for smooth transitions in their institutes' administration from one generation to the next. Additionally, it serves as a guide to help administrators create employee development opportunities to better prepare both the employee and the institute for the future.

\section{Phase Two}

The second phase used multiple expert interviews to explore the possible implementation of the proposed succession model in research institutes at universities with very high research activity. The goal of this phase was to examine whether executive directors of research institutes would find the model designed in the first phase to be appropriate or relevant to their institutes. This served as the validation in the conceptual framework.

Key questions included:

- What are the responses to the proposed succession management plan by key stakeholders at university-wide research institutes at universities with very high research activity?

- How might such a succession plan by implemented?

- How would key actors know that the implementation of the model was successful?

The research institute directors were chosen through opportunistic sampling; they were selected from the list of stakeholders who participated in the survey in phase one and who agreed to participate in a follow-up interview. These respondents provided the necessary feedback and 
comparison to validate the applicability of the proposed process model. The model was presented to research institute executive directors, who then had an opportunity to review it. Data were gathered by interviewing these high-level staff.

\section{Phase Three}

The third phase focused on analysis of the interview (and other) data and writing the results. This phase used both sets of data (quantitative and qualitative) but with an emphasis on the qualitative findings regarding the executive directors' belief and value systems relevant to succession planning. The purpose of this phase was to contribute to understanding succession planning in university-wide research institutes in four-year universities with very high research activity.

Relevant questions in this stage were:

- Is the process model developed in phase one credible? What are its strengths and weaknesses?

- Can one best practice model for succession planning in research institutes in U.S. higher education be developed from this study?

- How portable is this best practice model to other research institutes in institutions of higher education? Can the process model apply to other research centers, such as department or college level centers, well as to other parts of the university?

This phase included analysis of the key informant interviews, revisions of the succession planning process model and writing the dissertation document. If the proposed model had needed substantial revisions, a second round of key informant interviews would have been 
conducted to record the reactions to the model changes. No major revisions to the model were required, however, so no second interviews were necessary.

\section{Validation and Drivers}

The validation step in this study was the extent to which top-level administrators of university-wide research institutes perceived the succession model to be relevant to their institutes. In more variable-oriented, quantitative research, such perceptions of relevance would be called a dependent variable but I moved away from variable language because the research's concentration on processes with potential drivers, not causal variables.

Here, my understanding of process was based on Van de Ven (1992) and Langley (1999). Additionally, I relied on Falleti and Lynch's (2009) work to add the value of context. Van de Ven's (1992) cumulative progression model, which he labeled a teleological theory of process, "posits a standard of what an envisioned end state for an entity is" without prescribing how to get to that end state (p. 178). The characteristics of the succession planning process built upon one another to develop a complete succession program. His definition of process was "a category of concepts and variables that refers to actions of individuals or organizations" that work together to create certain outcomes (Van de Ven, 1992, p.169). Because this study focused on developing and validating a process model based on categories of process characteristics, Langley’s (1999) synthetic strategy appeared most appropriate:

With the sensemaking strategy that we have termed synthetic, the researcher takes the process as a whole as a unit of analysis and attempts to construct global measures from the detailed event data to describe it. The researcher then uses these measures to compare different processes and to identify regularities that will 
form the basis of a predictive theory relating holistic process characteristics to other variables (e.g., outcomes and contexts). (p. 704)

The succession planning process was the whole process that the research studied; each data collection phase had its own unit of observation. For the research synthesis, the units of observation were the characteristics of succession planning; for the surveys and interviews, the units of observation were the perceptions of key stakeholders. Characteristics of these processes, which Van de Ven called categories of concepts and Langley referred to as global measures, were the drivers that influenced the validation of the process. These categories could include "communication frequency, work flows, decision making techniques, as well as strategy formulation, implementation, and corporate venturing" (Van de Ven, 1992, p. 170). Accordingly, drivers in this study that may have influenced the validation were categories of process concepts related to current succession planning models.

As Langley noted, these characteristics were related to context. Falleti and Lynch (2009) not only agreed that process mechanisms were related to context; they also believed that context plays an important role linking processes to outcomes. Context can influence the types of outcome the process mechanism can produce (Falleti \& Lynch, 2009). Based on Falleti and Lynch, context-related drivers in this research included: (1) characteristics of university-wide research institutes, and (2) characteristics of policy implementation in university-wide research institutes.

Based on theories proposed by Van de Ven, Langley, and Falleti and Lynch, the drivers in this study are operationalized in Table 2 . In addition, I allowed for other trends to emerge even if they did not fall within one of the identified characteristics in Table 2. A more detailed 
table of how the validation and drivers were operationalized and how they related to the research, and survey, questions can be found in Appendix B.

\section{Methods}

As mentioned previously, the research design was a mixed-methods approach that Creswell and Plano Clark (2007) describe as an explanatory design with participant selection. Although before I briefly referenced data collection as it fit within the overall research phases, I now turn to more detailed information concerning how each method was executed.

\section{Research Synthesis}

The first step in this study's data collection was a research synthesis of scholarly literatures, as described by Harris Cooper's 2010 book Research Synthesis and Meta-Analysis:

He divides the process of research synthesis into seven steps:

- Step 1: Formulating the problem

- Step 2: Searching the literature

- Step 3: Gathering information from studies

- Step 4: Evaluating the quality of studies

- Step 5: Analyzing and integrating the outcomes of studies

- Step 6: Interpreting the evidence

- Step 7: Presenting the results. (Cooper, 2010, p. 12)

Cooper (2010) refers to "meta-analysis" as research synthesis of quantitative data. Some scholars use the term "meta-synthesis" when referring to evaluating data from qualitative literature (Clemmens, 2003; Siau \& Long, 2005). Clemmens (2003) described qualitative metasynthesis well: 
Meta-synthesis is a technique developed to produce interpretive translations, grand narratives or theories by integrating or comparing the findings from qualitative studies (Beck, 2002; Sandelowski, Docherty, \& Emden, 1997). In contrast to meta-analysis, which reduces quantitative study results into averages, meta-synthesis enlarges qualitative research by elevating the uniqueness of individual study into an interpretive whole. (p. 94)

Step 1. This synthesis used a mostly inductive approach in looking for patterns in the processes, changes in definitions or rhetoric related to succession planning, and key characteristics that scholars and other experts in the field argue are necessary for a successful process (Thomas, 2006). David Thomas (2006) describes inductive analysis as "approaches that primarily use detailed readings of raw data to derive concepts, themes, or a model through interpretations made from the raw data by an evaluator or researcher" (p. 238).

Step 2. The population of organizations examined in the review of succession planning processes was for-profit, public and nonprofit organizations, including higher education institutions, entirely headquartered within the United States. This population was broad to identify national trends found in succession planning processes. Relevant scholarly and practitioner-oriented literature was sampled through Web-based searches using Google Scholar and library databases, including the ERIC database related to the U.S. Department of Education.

Using ABI/INFORM Global, ProQuest Dissertations \& Theses, and Google Scholar, I searched for peer-reviewed scholarly literature related to succession planning in the three major sectors from 2000 through 2010. A large portion of so-called baby boomers are turning 65 years old in 2011, and many are retiring or may retire soon (Love, 2010). In order to include the effect 
of the baby boomer generation, I chose to look back only ten years because I expected that most researchers did not focus on this cohort before then.

Key words used in the search included for-profit, government, nonprofit, succession planning, succession management, strategic human capital planning, workforce planning, human resource management, and human resource development.

Step 3. I looked for raw data related to specific characteristics found within succession plans, including:

- definition;

- decision makers;

- participants;

- stakeholder perceptions;

- context or impetus for developing a succession program;

- level the program was placed in the organization;

- timeline;

- type of development activities;

- formulation, implementation, change or termination; and

- other features that may be relevant to succession planning in university-wide research institutes.

Step 4. I ruled out articles related to international organizations, changes in elected officials, board succession, and family-owned businesses because these types of organizations and transitions have special challenges or characteristics that may not be relevant to universitywide research institutes. 
My search produced a total of 89 articles: 24 articles related to succession planning in nonprofit organizations, 28 articles on public organizations, and 28 articles on the for-profit sector. I also found eight articles related to succession planning in colleges and universities; only one of the higher education articles focused on research institutes. These institutes were federal research labs that had affiliations with universities but were not controlled by university administrators.

Steps 5 \& 6. Data related to the nine characteristics mentioned previously were gathered in an Excel database to better identify patterns within and across sectors. My premise was that process characteristics found in all three sectors would apply to university-wide research institutes.

Step 7. Those characteristics that were found in all three sectors, as well ones in the higher educational literature, helped inform the development of the electronic surveys as well as the proposed succession planning model. They appear as well in Chapter Three.

\section{Survey}

After conducting the research synthesis, trends found across the three sectors were used in the design of two electronic surveys. The purpose of the surveys was to better understand the context in which these characteristics may or may not be applicable.

Following the survey design approach by Dillman, Smyth, and Christian (2009), I developed an electronic survey through SurveyMonkey and a protocol that allowed me to contact participants four times with two different methods to enhance the survey response rate: 1) prenotice email, 2) survey invitation, 3) post-card reminder, and 4) follow-up email with survey end date. Examples of the emails and postcard correspondence can be found in Appendix C. 
Pre-notice email. Before the pre-notice email was sent, I asked administrators at Virginia Tech (VT) and its research institutes to evaluate the survey through pre-survey reviews. In particular, I asked them for feedback on language, relevance, and clarification purposes. To gain access to these VT administrators, I asked VT's President, Dr. Charles Steger, to help make initial contacts via letter.

After final edits were made to the survey, a pre-notice email was sent to the entire population in my research. This email was an initial contact with the directors and university administrators to inform them that they would receive a survey invitation shortly in the future. Additionally, Minnis Ridenour, formerly the Executive Vice President for VT, signed a support letter that was sent with this pre-notice, in hopes that his endorsement of this research would encourage their participation. Mr. Ridenour worked on a comprehensive assessment of research institutes that recommended succession planning for university institutes. His knowledge in this area was helpful in gaining access to these institutes.

Survey invitation. An electronic survey invitation using SurveyMonkey was sent to executive directors of 812 university-level research institutes at 78 universities classified by the Carnegie Foundation for the Advancement of Teaching (2007) as universities with very high research activity. Twenty-five institutes were not included in the survey invitation because no contact information could be found, the same person was director of multiple institutes, or the director requested not to be sent the invitation after receiving the pre-notice email.

A shorter survey with similar questions was sent to one university administrator at each of the 78 schools. The administrator chosen was the person that the university-wide research institutes reported to within the university, either the vice president of research or the academic provost. 
Because the SurveyMonkey software allows for up to 1,000 responses, I sent the request to all schools in my population, a total of 812 research institutes in 78 universities after VT institutes were excluded. This helped reduce any sampling errors that might have occurred when setting up sample strategies (Fowler, 2002).

It took approximately 25 minutes for participants to complete the online survey. In particular, they were asked questions about their views regarding succession planning and decision making related to their particular research institute and university. The surveys can be found in Appendix D.

Response Rate. In the end, I had a response rate of $26.5 \%$ from the executive directors and $28.2 \%$ from the university-level administrators. Although the majority of the 214 executive director respondents answered most of the questions, only 86 answered every question. Twentysix additional executive directors opened the survey but answered none of the questions. Of the 22 administrator respondents, only 14 answered every question. Two additional administrators opened the survey but did not answer questions. Table 3 details the number of executive director and university administrator respondents for each question in the survey.

Of the 78 universities included in the survey request, 13 were not represented in the executive director survey results:

- Brown University,

- Case Western University,

- Colorado State University,

- Montana State University,

- University of California, Los Angeles,

- University of California, San Diego, 
- University of California, Santa Cruz,

- University of Chicago,

- University of Colorado, Denver,

- University of Georgia,

- University of Hawaii, Manoa,

- University of Rochester, and

- University of South Carolina.

The university administrator respondents represented 16 different states. Additionally, they represented five schools that had no institute directors participate, including University of California - San Diego, University of Georgia, University of Hawaii - Manoa, University of Rochester, and University of South Carolina. Because the data represent a variety of types of institutes from universities throughout the United States, there appear to be few meaningful patterns when one compares the respondents and non-respondents.

Hypotheses. Although my overall research focused on processes and drivers, several hypotheses were developed for the quantitative survey portion of the research. I expected that respondents who were more familiar with succession planning because they have been at their institution longer, who were from older institutes, who were from bigger institutes, or who had experience with succession planning programs would have more positive reactions to succession planning than others. Given their experience over time in research institutes, I expected that they either would have gone through a succession process or might be looking strategically toward the future and how their institute might need to develop or prepare for loss of key employees.

I expected that the following characteristics of respondents would have little, if any, impact on the importance of succession planning: number of institutes in a university, type of 
respondent (executive director - ED, or university administrator - UA), type of institute (i.e., hard science versus social science), and whether the university was private or public. I did not expect an impact because my assumption was that most leaders across organizations, including institutes and universities, are similar in their leadership styles for planning for the future of their organization and its staff.

Each of my hypotheses was that the following types of respondents would report that succession planning characteristics are more important and would find fewer items that inhibit succession planning:

- Respondents from older institutes;

- Respondents from larger institutes as measured by numbers of employees;

- Respondents from larger institutes as measured by budget size;

- Respondents from larger universities as tapped by numbers of enrolled students;

- Respondents from institutes that have strategic plans;

- Respondents from institutes currently participating in succession planning activities;

- Executive directors who have been in place longer; and

- Respondents with self-reported knowledge of succession planning.

These stakeholders would be focused on the future of their organizations based on their past and current experiences and, therefore, would be expected to be thinking about how to better develop their institutes, including planning for the development of their staffs. The relationships that emerged as statistically significant were used in the development of my proposed model. I 
tried to incorporate all of these characteristics (e.g., size, type, and experience with succession planning) into the questions and narrative of the model.

Population / Sampling for Survey. The population of key stakeholders for the survey phase again was broad: officials in university-wide research institutes in universities that the Carnegie Classification System categorized as four-year, doctoral universities with very high research activity (Carnegie Foundation for the Advancement of Teaching, 2007). Key stakeholders included research institute directors and university level executives to whom the institute director reports, such as the vice-president of research.

A total of 96 universities have the Carnegie classification of "four year," "doctoral," and "very high research activity," with over 4,400 research centers and institutes (Carnegie Foundation, 2007). The Carnegie Foundation (2007) further classifies doctoral into "single doctoral (education)," "single doctoral (other field)," "comprehensive doctoral with medical/veterinary," "comprehensive doctoral (no medical/veterinary)," “doctoral, humanities/social sciences dominant," "doctoral, STEM dominant," and "doctoral, professions dominant." Institutions in all of these classifications were included in my search.

Since Virginia Tech was chosen as a beginning reference point from which to explore the succession planning process, the number of research institutes was narrowed to those in 88 universities that were similar to Virginia Tech (SCHEV Peer Schools or land-grant institutions) or were similar to what Virginia Tech (VT) aspires to be (in the list of AAU and Top 30 research schools). This number was further reduced to 78 universities by asking each school's executive administrator of research (vice president, vice provost, or vice chancellor of research) to identify institutes that were similar to VT's definition of university-wide research institute. VT had six institutes in 2008 (now seven in 2011) that a) are university-wide, b) are independent of colleges 
and departments, c) report to a university-level administrator, such as the vice president of research, and d) are fairly independent in regards to human resources and budgeting (VPI\&SU, 2008). They also typically are interdisciplinary in nature (VPI\&SU, 2008).

The population for this research included 818 research institutes in 79 universities, with 45 universities responding to my initial inquiry. Virginia Tech institute directors were asked to participate in my pre-survey and pre-interview review; as a result, their answers were not included in the data analyses. A list of the schools and their research institutes can be found in Appendix E. Each of these research institutes was categorized by type of research (i.e., hard science or social science; see Appendix F).

I chose to examine university-wide research institutes rather than other types of centers at the college or department level to narrow the focus and enhance the feasibility of this study. In addition, generalizability may be increased if the characteristics of research institutes are kept similar; department and college level research centers tend to have narrower foci than universitywide research institutes. Future research on college- and department-level centers may be conducted at a later date.

\section{Interviews}

The purpose of the interviews was to review the proposed succession planning model developed in the first phase of the study. After the model of succession planning based on the synthesis data and survey responses was developed, I contacted executive directors through emails. An example of the interview correspondence can be found in Appendix G.

Telephone interviews were scheduled at the participant's convenience and took approximately thirty minutes. Participants were asked to review the succession planning model before the actual interview; it took approximately thirty minutes to review the model. 
Interview questions can be found in Appendix H. The interviews were conversational in nature, which allowed for additional questions to be asked based on the respondents' answers to the initial questions. For instance, one executive director said he needed to solve some other issues before embarking on a succession planning process. After saying this several times, I asked him, "You mention several issues that you would want to work through before embarking on a succession planning process. What are some of those issues?" This example and other follow-up questions allowed me to gain a better understanding and depth of knowledge of what the interviewees were telling me.

Sample for Expert Interviews. The subject pool for the second phase expert interviews consisted of executive directors at university-wide research institutes at four-year, public doctoral universities with very high research activity. These respondents were chosen based on an opportunistic sampling process from stakeholders who participated in the surveys in phase one. Such a participant selection model is used when "a researcher needs quantitative information to identify and purposefully select participants for a follow-up, in-depth, qualitative study" (Creswell \& Plano Clark, 2007, p. 74).

The last question of the survey asked if the executive directors would be willing to participate in a one-hour follow-up interview. Executive directors at 54 institutes from 36 different universities agreed to the follow-up. Of these institutes, I considered 39 to be traditional hard science institutes and 15 social science entities. I randomly selected six hard science institutes and four social science institutes from which to interview $(\mathrm{n}=10)$.

\section{Grounding Assumptions}

As a constructivist, I believe that although some things can be physically observed (e.g., a natural scientist can observe how microorganisms change or even die when exposed to various 
chemicals), social realities, such as relationships, values, emotions, or behaviors, frequently are subtler than physical atoms and molecules. Although these realities are more complex and may seem like they are, as some argue, subjective in nature, the constructivist researcher contends that they are realities but also that our interpretation of these realities can be shaped by a variety of factors (Mir \& Watson, 2001). As such, it is necessary to uncover all of these factors, such as meanings, power and context, interpretations, and symbols. By observing the various beliefs and values that feed people's perceptions, we can begin to deconstruct, and eventually come to better understand, such social realities.

It is possible to "measure" these realities; however, it requires a different form than observing molecules under a microscope. A researcher observes these social realities through dialogue and interaction with participants (e.g., talking with people, reviewing textual traces, and observing their beliefs, values, and behaviors) all while, making notes on the context in which those participants sit (e.g., how different situations influence their knowledge, which in turn may influence behavior) (Guba \& Lincoln, 1994; Mir \& Watson, 2001).

The mixed-methods nature of this research design takes into account my research assumptions and allowed me to observe the influences of context, beliefs, and values of the participants in this study.

\section{Validity and Potential Limitations}

Building upon and expanding the research of Jack Heuer (2003), the findings of this research may significantly contribute to scholarly knowledge by addressing an area of research that has received little attention but may become an important topic in the next several years. Although this study was designed and conducted with the intention of reducing biases and increasing its validity, it does have limitations. These limitations include low generalizability 
and response bias because results may only be related to the research institutes within the selected universities and not other research institutes or other universities; not all institute directors participated; and not all universities or research institutes may understand or may be doing succession planning. In addition, some respondents may have been reluctant to be honest about their universities for fear of retribution or loss of their jobs. I reduced this fear by making all data confidential and focusing on their values and perceptions of the future of their institute, not their perceptions of the university's current processes.

Finally, the utilization of these particular data collection methods has limitations.

Surveys tend to be inflexible, may not encompass all possible and relevant answers, and may not allow for the social context of the respondents' institute, university and research emphasis to be included. These limitations were reduced by including several open-ended questions and an “other, please explain" answer category when appropriate. The surveys were conducted through a secure survey research website, SurveyMonkey, to ensure confidentiality, which may have boosted more open and truthful answers. The results also were supplemented with other data collection methods.

These other methods - key informant interviews and synthesis of literature - may have produced more subjective interpretations. This was reduced by keeping thorough notes in real time, which included being self-reflective about my own biases. Since efforts were made to reduce the limitations through triangulation of data sources and other techniques, validity of this study should be high. 


\section{Ethical Considerations}

Because the research involved surveying and interviewing human participants, all activities were strictly evaluated to ensure high ethical conduct. An institutional review board application was submitted for approval before proceeding with the survey or interviews.

Steps to ensure that no more than minimal risk was involved included ensuring voluntary participation, providing participants with written information sheets describing the project and researchers, making the surveys confidential, offering no promises or guarantees of benefits to the participants to coerce them to participate, and separating all participants' identifying information from data collection. Additionally, all data were kept in a locked office, and no one had access to the data who did not appear on the IRB application.

Along with possible ethical concerns, there may have been stalwart political considerations at play due to some of the universities being public agencies with strict policies regarding human resources as well as any possible bias towards favoring institutes that receive very large grants and contracts. Although this topic is an important one to study and understand, the nature of this study centered on organizational development and change and not political relationships. While I respected the institutions, their value systems, and their documentation and operational procedures, and did not intend to cause harm to the universities involved, I honored the data and subsequent conclusions the research produced.

This chapter focused on how I designed my research and located and contacted potential research participants. The following chapters will look at the specific data in more detail. The next chapter focuses on the findings from the qualitative research synthesis. 


\section{Chapter 3: Qualitative Research Synthesis of the Literature}

Get the habit of analysis - analysis will in time enable synthesis to become your habit of mind.

- Frank Lloyd Wright (1953)

During the first phase of this research, I conducted a qualitative research synthesis of the literatures. The literature included were scholarly articles related to succession planning across the three sectors: 24 nonprofit, 28 government, and 28 for-profit articles. I expected that the process characteristics found in all three sectors would apply to university-wide research institutes in higher education.

As the previous chapter detailed, the research synthesis focused on several process characteristics of succession programs: definition of succession planning, decision makers, participants, stakeholder perceptions, context or impetus for establishing a succession program, organizational placement, and timeline for the program. I also allowed the articles to highlight other characteristics that the initial list did not include.

In addition, I located several articles related to higher education at the university and community college levels. Very few articles involved succession planning in research institutes; however, I did locate five articles and two dissertations on succession planning in universities and community colleges. One additional article focused on succession planning in a national research institute system that was affiliated with a university.

During this synthesis I came across a previous literature review by Kesner and Sebora (1994). This chapter includes a summary of their findings, followed by a summary of the results of the synthesis, with a focus on processes found in all three sectors. 


\section{Previous Review}

Kesner and Sebora (1994) reviewed succession planning research from the 1960s through the 1990s, setting a perfect foundation for my research synthesis beginning in 2000. Rather than taking a holistic approach to succession planning, as my research did, they concentrated on CEO succession, asserting that the CEO's position is more critical due to "the nature of the job, the infrequency of turnover, the visibility of the event, and the background of the decision-makers" (Kesner \& Sebora, 1994, p. 329).

Despite finding research that was "diffused and often chaotic," several themes did emerge (Kesner \& Sebora, 1994, p. 327). Research in the first two decades (1960s and 1970s) focused on where the successor came from, organizational size, how succession related to organizational performance, succession contingencies like individual leadership style and organizational characteristics, and the relationship between the new CEO and the board of directors (Kesner \& Sebora, 1994). Research in the 1980s and 1990s added factors related specifically to the CEO before and after arriving at the organization, as well as characteristics related to defining terms, context, and the relationship between CEO experience and postsuccession performance.

While the majority of the studies that Kesner and Sebora reviewed examined characteristics or actions of the CEO, a few articles examined succession processes, such as typical duration (Hashemi, 1980, as cited by Kesner \& Sebora, 1994), delayed rather than immediate effects (Day \& Lord, 1988, as cited by Kesner \& Sebora, 1994), and a staged approach (Kelly, 1980; Gilmore \& McCann, 1983; Gabarro, 1986, all cited by Kesner \& Sebora, 1994). Friedman (1986) reported that a successful succession process emphasized "high CEO involvement, allocated significant resources to formal human resource functions, and established 
accountability in support of their succession processes" (p. 360, as cited by Kesner \& Sebora, 1994).

Kesner and Sebora (1994) summarized their overall findings:

Succession systems were optimal when they produced a "seamless" continuity in leadership. Ironically, while business leaders were espousing the need for firms to adapt their strategies and structures to rapidly changing environments, when it came to succession they believed that stability was better. Indeed, when compared to the attributes of the incumbent, the history of the job, and the characteristics of the firm, the environment seemed to play only a minor role in understanding succession processes. (p. 360)

They concluded that three issues associated with the actual succession event should be addressed: process, candidate, and choice (Kesner \& Sebora, 1994). In terms of process issues, my focus here, Kesner \& Sebora (1994) found that by the early 1990s the literature had looked at certain characteristics: formality, pattern, rate, stages and type of succession. I searched for similar concepts in later scholarship.

\section{Research Synthesis Findings}

The following sections include a summary of the findings in the scholarly literatures. More detailed information regarding which characteristic was found in specific articles can be found in tables at the end of this document.

\section{Definition of Succession Planning}

The works examined in the literature focused on either organizational- or employeespecific definitions of succession planning. An organizational view focuses on replacement planning to reduce knowledge loss and gaps in employees. It also emphasizes getting the "right" 
people on board, but this is to improve the organization, not necessarily to support the individual employees' needs. The employee view focuses solely on the individual and how to cultivate leadership skills in those employees.

Ten of the 63 articles that included a succession planning definition describe it in a more holistic fashion. This more holistic view looks at the organization's needs and how its human capital should adjust to fit current and future needs. Although the organizational view is similar, a holistic view also looks at the individual employees and how their careers can be developed in conjunction with the strategic plan for the organization. It is more holistic because it considers the needs of both the organization and the people within that organization. (See Table 4 for results related to definitions of succession planning).

Shinn (2006) described a holistic succession process well:

Succession planning focus has changed from the preparation of one person to fill the top leadership position to a more strategic and integrated approach. This approach includes leadership development of individuals at all levels within organizations as the best response to today's ever-changing environment. Developing talented people within an organization is a goal of these planning efforts to ensure that the organization will remain effective or grow by having a stream of ready-prepared individuals to move into new positions or assist in place. Another goal of these planning efforts is to protect and preserve the organization's history and the development of leadership skills at all levels within the organization. (pp. 77-78)

Literature concentrating on educational institutions was similar to the other articles; of the four sources examining higher education that gave a definition for succession planning, three 
take a more organizational view, while one refers to the more holistic view. As already noted, my research promoted a more holistic approach to succession. Such a perspective of succession planning also may help administrators navigate the organizational complexity and the employment requirements related to the university being a public agency.

State agencies are subject to equal employment opportunity regulation, which prohibits them from guaranteeing employees that they will be placed in a management, or higher level positions [in] the future... for this reason, succession planning for state agencies should "focus on preparing staff for assuming a higher leadership level" or career path, rather than on preparing staff for a specific position. (The State of Georgia and the Georgia Merit System, as cited by Whitmore, 2006, p. 21)

In particular, this research relies on William Rothwell's (2001) definition of succession planning:

a deliberate and systematic effort by an organization to ensure leadership continuity in key positions, retain and develop intellectual and knowledge capital for the future, and encourage individual advancement [for all employees in the organization]. (p. 6)

Rothwell and Poduch (2004) described two different kinds of succession planning. The first, management succession planning, stressed getting the right people in the right positions; the second was technical succession planning, getting the right information and organizational knowledge to the right people when they need it (Rothwell \& Poduch, 2004, pp.408-409). The former emphasized people; the latter what the people need to know (Rothwell \& Poduch, 2004). To focus more holistically, this study's conceptualization of succession planning included both 
types, providing a more comprehensive look at the people as well as the organization's knowledge and processes.

Corresponding to the definition of succession planning, scholars defined their terms to help the reader navigate. Shinn (2006) distinguished succession management from succession planning. The former is an "approach to provide a pool of qualified candidates which can build capacity at various levels of management," while the latter "focuses on identifying and developing successors for the executive level of the organization" (p. 28). I used the term succession planning to refer to both areas as well as to strategic management of the organization's human capital. Helton and Jackson (2007) also differentiated between similar terms: workforce planning and succession planning. According to these authors, workforce planning matches an organization's human capital with its strategic plan, while succession planning seeks to develop a pool of talented people to take over leadership positions. Again, this research used the term succession planning in a more holistic way to refer to both areas: aligning human capital with strategic plans as well as developing leaders within an organization.

\section{Decision Makers}

As Table 5 shows, 20 nonprofit, 18 public, 17 for-profit and six educational articles recommended who should take part in decision making in the succession planning process. These articles recommended that five main groups should be the decision makers. First, the executive director or CEO and senior management of the organization should be involved. Second, organizations also should consult with their boards of directors or advisory board members as well as their human resource managers regarding succession planning. Third, several articles added that other stakeholders, such as the organization's line manager or financial officer, should be included in decision making for succession planning. Fourth, if the 
organization pulls together a task force to develop a succession plan, those task force members should participate in decision making. Fifth, a handful of articles suggested staff members should be involved as well.

The educational articles tracked the other sectors well, citing the board of trustees, university president, HR personnel and other executives as the relevant decision makers for succession planning. The educational scholars also warned that the dispersed governance nature of universities may necessitate the inclusion of other people in the university, such as chairs of departments and faculty at all levels.

\section{Participants in Succession Programs}

Forty-nine articles mentioned who should participate in a succession program once it is in place. The research synthesis found that most programs were open for all employees to participate, although each had a nomination and selection process to select which employees would participate annually (see Table 6). This selection process could be focused on pipeline employees, that is, those employees who may be promoted to leaders in the organization. These potential leaders as participants were cited the second most often. Several articles across all three sectors suggested top level administrators and the executive director or CEO should participate. Although line managers should be part of the decision making process, very few articles suggested they should participate in the program once it is in place.

As with the decision makers, the educational literature related to the findings for the other

three sectors. Higher education administrators reported that top level administrators and then the entire staff should be able to participate in succession programs. It is generally believed that everyone in the university should have an opportunity to participate in development activities; then those with a desire or aptitude to lead could be chosen for further mentoring opportunities 
(Clunies, 2004; Van Amburgh, et al., 2010). Clunies (2004) points to a 1992 National Academy of Public Administration study that found organizations that followed this type of approach were more successful.

\section{Stakeholder Perceptions}

Stakeholder perceptions about succession planning seemed to vary a great deal, but seven characteristics did appear across all three sectors. (See Table 7.) Nineteen articles reported that stakeholders think succession planning is a beneficial, strategic tool (seven nonprofit, six public, three for-profit and three education); however, five of those same articles, along with seven others, found that stakeholders have little understanding, or even fear, of succession planning. A total of 16 nonprofit, 14 public, 12 for-profit, and five education articles mentioned the thoughts and comments of stakeholders.

Three of the perceptions evidently were related:

- if organizational leaders do not pay attention to staff members' needs, then staff may leave the organization;

- success of the succession program depends on top level or board support;

- succession plans need to be transparent for staff to feel supported.

Three different articles reported both that a lack of attention to staff members in the process may prompt staff to leave and that transparency is important. One article conveyed both the need for paying attention to needs of staff members while also seeking top level support. Three additional articles focused on staff members' needs, and six others called for support from top level administrators.

Five articles found that stakeholders believe it is quite difficult to plan their own departure: "planning your exit is like scheduling your own funeral; it evokes fears and emotions 
long hidden under layers of defense mechanisms and imperceptible habits" (Cohn, Khurana, \& Reeves, 2005, p. 65). Finally, five articles reported that succession planning requires an honest and thorough assessment of the organization and its people.

Three of the educational articles reported that higher education administrators think succession planning is important and necessary; two others found either negative or neutral perceptions. Four studies, two of which report succession planning is beneficial, noted that respondents think the culture of universities - specifically their dispersed governance and nonhierarchical nature - does not allow for succession planning. The same two articles that reported that succession planning is beneficial also found that respondents think the turnover rate in universities does not allow for effective development of leaders. Three of the five articles showed that administrators reported that support from top executives in the universities is important to the success of the program.

Although some similar characteristics were found across the sectors, most of the perceptions differed. Nonprofit organizations tended to be concerned with the negative aspects of succession planning. Three articles found that nonprofit leaders thought succession planning takes too much time and resources. Two articles reported that they fear appearing disloyal if they bring it up. Three articles indicated that the organization was not big enough to have multiple people who can do the same job. Finally, another three found that many administrators of nonprofit organizations may prefer not to promote from within, bringing outsiders in to encourage organizational change.

Those in public organizations were more positive but their leaders did have some negative comments. Three articles discussed public administrators' belief that there was not enough time and resources for succession planning. One of those articles, along with another 
one, discussed the administrators' worries that succession planning does not fit into their senior managers' responsibilities. Finally, two articles looked at the culture of the public agency and how it may limit the success of a succession program.

The literature examining for-profit organizations was the most positive toward succession planning. Three articles reported that respondents believed succession planning allows the company to take leadership into account when hiring. An additional three articles discussed the stakeholders' beliefs that succession planning is a positive step but it should have top level support. Two articles reviewed how succession planning allows participants to grow and learn, while two others looked at how succession planning promotes both racial and gender diversity.

\section{Context and Impetus for Succession Planning}

Seventeen nonprofit, 22 public, 18 for-profit, and seven educational articles mentioned the impetus for the development of a succession program. Like the stakeholder perceptions, the literature analyzed showed the sectors varying on the reasons why succession programs are implemented. Only four reasons were mentioned across all three sectors: retirements of the baby boomer generation, key leadership transitions, changing work environment, and changing workforce. The majority of leaders in organizations are baby boomers; as these leaders look toward retirement, organizations are beginning to wonder who will take their places. (See Table 8 for information about the articles that mentioned context or impetus of succession programs.)

Beyond retirement, organizations lose their key leaders for other reasons, and organizational leaders are beginning to think about how to deal with gaps in employees. The final two reasons why organizations implement succession plans have to do with the context in which the organization finds itself. Organizations change for many reasons, such as technological advances, responses to client needs, and more global viewpoints; as such, many 
employees within the organization need additional skills to accommodate those changes. The workforce is also changing, becoming more diverse with different work values, forcing organizations to learn how to cope with employment issues related to these new types of employees.

Other reasons that were discussed involving at least two sectors include competiveness in the job market, decreased development opportunities, employee turnover, loss of intellectual capital, need to increase the organization's talent pool, and downsizing or cost cutting. Reasons for employee transitions varied from personal (health, burnout, being overwhelmed, and conflict with board) to external (loss of funding and low salaries or benefits) (Cadmus, 2006; Santora \& Sarros, 1995; Shinn, 2006).

Three reasons rose to the top for educational administrators: retirements of the current top leaders, changing workforce demographics, and changes in the work environment, including funding structures. Two articles reported that education leaders think succession planning should focus on enhancing diversity.

\section{Organizational Placement of Program}

Relatively few articles discussed where in the organization a succession program should be placed - 13 non-profit, 12 public, three for-profit, and three educational. Placement in the organization referred to who is responsible for developing the program and making sure it is implemented. The implementation can be at any level that the organization leaders choose, while coordination relates to the decision makers. The literature showed that most organizations coordinate succession programs at the executive director or human resources levels (see Table 9). Nonprofit organizations also included their boards of directors. 
Bolton and Roy (2004) advanced a very good reason why it is important that human resources management be involved in the process: "When succession planning is integrated into existing HR management systems in a professional practice model, it stands alongside recruitment and retention as part of a comprehensive approach to meeting the organization's workforce needs" (p. 592). Including HR professionals in the process also can help research institute leaders who may not understand how, or have the expertise, to develop succession programs on their own.

Only two of the educational articles spoke about who should coordinate the succession program. Richards (2009) argued it should be jointly coordinated at the board, president and HR levels, while Van Amburgh, et al. (2010) suggested coordination should be the responsibility of the university's senior administrative team.

\section{Timeline}

Like organizational placement, few articles mentioned how long the succession program should last (ten nonprofit, seven public, nine for-profit, and two educational articles). Although small in number, the articles agreed about timing of the succession program: succession programs take months to prepare, with implementation taking one to two years. Although the duration of programs typically is one to two years, the literature did report that it would vary depending on the size, complexity, and needs of the organization. (See Table 10.)

Only two of the educational articles mentioned time. One was similar to the other sectors - two to three years for development. The other article, which focused on national research labs, looked longer term and recommended planning for 10 years forward (Roddy, 2004). 


\section{Other Characteristics}

Although the synthesis focused on specific factors found in the literature, I was open to finding additional characteristics that should be considered in succession planning. Elements that surfaced included what should be in a written plan and how the succession program should be evaluated (Rothwell, 2001). Several articles referred to the written plan of a succession program: six nonprofit, 13 public, 10 for-profit, and three educational articles. Two elements of the written plan, individual employee plans and job descriptions, were found in all three sectors. Two education articles also mentioned job descriptions.

A number of articles described evaluating succession programs: six nonprofit, 16 public, 18 for-profit, and five educational articles. Three characteristics were found in all three sectors as well as in higher education: clear expectations, measures of success for both the program and the participants, and flexibility to incorporate the evaluation findings. Flexibility allows the organization to shift job responsibilities or even outsource some activities. (See Table 11.)

None of the educational articles mentioned planning for individual employees but they did recommend job descriptions and the use of technology and websites to help implement the succession programs. The majority of articles recommended assessing the program and its participants. They also suggested that the program and the university remain flexible to changes in the actual succession plan or job descriptions if an evaluation recommended it.

My research focused on process characteristics across the sectors. I did note, however, examples of specific programmatic elements that articles suggested, including employee opportunities, preparation of the succession program, implementation of the program, and other more general succession planning comments. Table 11 contains details about these elements. 
Most of the organizations examined across the sectors offered leadership development opportunities, mentoring or opportunities to exchange knowledge, and cross-training in different areas of the organization. Several organizations also offered opportunities for current employees to learn management skills and for retired employees to contribute to the organization or field in some fashion.

To prepare for a succession program, decision makers need to analyze current and future organizational needs, identify key positions in the organization that make it successful, and analyze the skills and competencies related to both current and future positions. To implement a succession program, decision makers need to tailor the program to the individual organization and its sector. General comments regarding succession planning focused on the necessity for the succession plan to be linked to the organization's strategic plan, mission and goals. Additionally, five articles reported that organizations need to consider sustainability of the program and make enough resources available to ensure success.

The educational literature closely tracked the findings in other sectors. Development activities should include networking opportunities, mentoring and coaching, cross training, offsite learning (especially through professional association memberships) and opportunities to learn management skills. Universities should conduct analyses of current and future organizational and leadership needs. Most of the articles called for the program to be tailored to the individual university and its mission and suggested that communication with and transparency to faculty and staff were pivotal to its success.

\section{Summary and Conclusion}

Scholarly articles included in the synthesis tended to focus on the content of succession planning rather than the succession process. Key elements of the succession plan, however, were 
similar across the sectors, including institutions of higher education. Each article stressed the need for upper management to be involved and supportive of the succession planning process and emphasized the involvement of employees with high potential or those who may take over such positions as the executive director or senior managers. The succession plan should be linked with the organization's strategic plan, and it should be tailored to the individual organization and its employees. The literature also agreed on the definition of succession planning, the reasons or impetus for designing a program, and the basic time-lines for the development opportunities. Table 12 summarizes the findings of the synthesis on succession planning.

\section{Table 12: Summary of Synthesis Findings}

\begin{tabular}{|c|c|}
\hline Definition & $\begin{array}{l}\text { Holistic View: strategic look at the organization, its programs, and its } \\
\text { current and future needs } \\
\text { Organizational View: replacement planning, meet organizational } \\
\text { needs } \\
\text { Employee View: leadership development }\end{array}$ \\
\hline Decision Makers & $\begin{array}{l}\text { Upper management, including Board, Executive Director, Sr. } \\
\quad \text { Managers, HR Personnel } \\
\text { SP Planning Committee } \\
\text { Staff }\end{array}$ \\
\hline Participants & $\begin{array}{l}\text { Entire staff } \\
\text { Current leaders } \\
\text { Employees with high potential } \\
\text { Those who may take over leadership positions }\end{array}$ \\
\hline Stakeholder Perceptions & $\begin{array}{l}\text { SP is beneficial } \\
\text { Lack of understanding of SP importance } \\
\text { Staff may leave if not given chance to grow or be promoted } \\
\text { Difficult to plan own departures } \\
\text { Success dependent on board of directors } \\
\text { Top level support needed } \\
\text { Requires honest organizational assessments } \\
\text { Should be open and transparent allowing staff to feel supported }\end{array}$ \\
\hline Context or Impetus & $\begin{array}{l}\text { Retirements } \\
\text { Key leadership transitions } \\
\text { Changing work environment / funding structures } \\
\text { Organizational crisis } \\
\text { Changing workforce }\end{array}$ \\
\hline
\end{tabular}




\begin{tabular}{|l|l|}
\hline Organizational Placement & $\begin{array}{l}\text { Executive Director Level } \\
\text { Human Resources Level }\end{array}$ \\
\hline Timeline & $\begin{array}{l}\text { Varies dependent on the needs of the organization, but usually } \\
1-2 \text { years for implementation }\end{array}$ \\
\hline Other Characteristics & $\begin{array}{l}\text { Written Plan: Individual employee plans, Job descriptions } \\
\text { Evaluation: Clear objectives and measurable performance } \\
\text { indicators; Flexible } \\
\text { Employee Opportunities: exchange experience and knowledge } \\
\text { Preparation: Analyze current \& future needs and employee } \\
\text { skills }\end{array}$ \\
$\begin{array}{l}\text { Implementation: Tailored to the organization and its employees } \\
\text { Other: Linked with the organization's strategic plan; Needs } \\
\text { enough time and resources }\end{array}$ \\
\hline
\end{tabular}

Although most articles affirmed that succession planning is a strategic necessity, several articles noted challenges to the process. Ibarra (2005) identified several barriers:

1) the assumption that your employees' retirement options are a don't-ask, don'ttell issue; 2) the perception that predetermining the best candidate for a position resembles favoritism; and 3) the principle of seniority as the primary factor in promotions in both union and nonunion environments. (p. 20)

Rothwell and Poduch (2004) also described challenges:

1) avoiding temptations to clone current job incumbents when future conditions may require different skills; 2) erroneously assuming that successful performance at one layer of the organization's hierarchy automatically guarantees success at higher levels; and 3) ensuring accountability of individuals and their organizational superiors for developing talent and not just handling daily work or managing daily crises. (p. 408)

These challenges can be overcome by remaining open and flexible to new ideas while also assessing any actions taken to ensure they are having a positive impact. 
Other possible barriers related more directly to university settings include culture and the typically dispersed governance structure of higher education institutions. Among the specific challenges were:

- "Faculty tend to be fluid, and one being groomed for leadership management might well leave before his or her time for leadership arrives” (Estepp, 1998, p. 51);

- "Both the uncertainty of the academic and economic environment and the longterm commitment required for employee development make succession planning a high-stakes strategy" (Parkman \& Beard, 2008, p. 29);

- "Higher education operates in a manner of shared governance, meaning that all faculty members and upper administrators play a role in decision making and establishing university policy. Such a self-governing body may perceive the succession planning approach of positioning certain faculty members for leadership roles to be distasteful, connoting favouritism" (Barde, 2009, Parkman \& Beard, 2008, both cited by Van Amburgh, et al., 2010, p. 2); and

- "Transitioning a faculty member to a needed administrative position may also be viewed as punishment for the faculty member not being a productive scholar or top teacher" (Van Amburgh, et al., 2010, p. 2).

These scholars suggest solutions to these challenges: being inclusive in the decision making process, being open and communicative with faculty and staff, and seeking out the "bestqualified candidate... regardless of where he or she currently [works]" (Van Amburgh, et al., 2010, p. 3). 
Overall, several characteristics were found in all three sectors as well as in the educational literature. Each of these characteristics became the basis for questions in my survey, which was the next step in this research. If respondents reported characteristics that were similar to those the reviewed articles found to be important, then those characteristics became part of my proposed succession planning model for university-wide research institutes. Additionally, characteristics that the literature had not emphasized but survey respondents found important received further consideration. 


\section{Chapter 4: Survey Findings}

Everyone takes surveys. Whoever makes a statement about

human behavior has engaged in a survey of some sort.

- Andrew Greeley (1996)

Like many social science researchers, I engage in research to better understand humans and their behavior. Although Andrew Greeley proclaimed this as a sort of survey, my research used "survey" in a more formal sense. I developed a standardized set of questions to better explore how the research synthesis findings might apply to a specific population (Babbie, 2007) and to better understand the "backgrounds, behaviors, beliefs, or attitudes" of participants in my research, or executive directors of university research institutes and their VPs of research (Neuman, 2006, p. 43). Because the participant population was quite large, an electronic survey made it possible to reach those participants in a timely fashion (Neuman, 2006).

Following the synthesis, the next step in my research was to conduct surveys to better understand the context of university-wide research institutes and how succession planning is used in these types of organizations. As Chapter two mentioned, two surveys were administered: one to executive directors of 812 university-wide research institutes and a second to one university-level administrator at the 78 universities that housed the institutes.

\section{Descriptive Information}

Descriptive data were collected for individual respondents, the research institutes, and the universities. Individual characteristics focused on how familiar they were with succession planning processes. Over $60 \%$ of the respondents reported being familiar with succession planning and have considered succession planning, but less than $10 \%$ have succession programs in place. (See Table 13.) 
Characteristics of the research institutes surveyed included budgeting, year created, number of employees, as whether they have strategic plans, how often they are evaluated, and how policies are created and implemented. Approximately twice as many respondents directed hard science institutes as social science institutes. The majority of participating institutes was created after 2000, was interdisciplinary, reported to a university level administrator, and relied on external sponsored research for their budget, which usually ranged from $\$ 1-5$ million. (See Table 14.)

Most research institutes had strategic plans, had missions that were closely related to their home university's mission, created and implemented policies in a collaborative nature, and were evaluated regularly by external reviewers. Most of them did not participate in succession planning activities, but when they did, they focused on mentoring, job enrichment, and stretch assignments. (See Table 15.)

Reported university information focused on size, budget, number of institutes, and other characteristics such as whether they were public or private, were members of the Association of American Universities (AAU), were land grant institutions, or were among the top 30 research institutes (See Appendix I.) All of these dimensions - for individual respondents, research institutes, and universities - were used as filters in analyses of the survey data.

\section{Statistical Analyses}

Initially, I examined frequencies and bivariate crosstabulation tables. These looked for differences in executive directors' and university-level administrators' responses based on variation on the descriptive variables introduced earlier. The second part of the analyses introduced several control variables. Discussion begins with analyses of survey responses based on the process characteristics that the scholarly literature focused upon. Somers' $d$ analysis was 
used to examine the strength of statistically significant relationships because it is a good predictor of the effect size of one variable on another for use with ordinal level data; it is "a 'predictor performance indicator', measuring the performance of $\mathrm{X}$ as a predictor of $\mathrm{Y}$ ', and it measures direction of ordinal data (Newson, 2006, p. 3). I considered statistically significant relationships to be those with $\mathrm{p}$ values of less than 0.10 .

\section{Definition of Succession Planning}

The survey did not ask respondents for their definition of succession planning; I referred them instead to William Rothwell's definition. ${ }^{8}$ Based on this definition, the respondents were asked which characteristics of succession planning they thought were important. Four of the characteristics were positive aspects of succession planning, and three reflected negative features.

Hypotheses. For the executive directors, I developed six hypotheses related to the characteristics of succession planning that respondents would report as important. I expected that executive directors who were more knowledgeable about succession planning; were from older institutes; were from institutes that are larger, in both size and budget; have had more experience with succession planning; and were from institutes that have strategic plans would be more likely to find the positive characteristics of succession planning important and the more negative elements less important.

For the survey of university-level administrators, I formulated four hypotheses. I expected that university administrators who had knowledge of or had considered succession planning, oversaw institutes that have strategic plans, or oversaw institutes that have participated

\footnotetext{
8 "a deliberate and systematic effort by an organization to ensure leadership continuity in key positions, retain and develop intellectual and knowledge capital for the future, and encourage individual advancement" for all employees (Rothwell, 2001, p. 6).
} 
in succession activities would find the positive features important and the negative characteristics unimportant.

I expected that administrators at both the university and institute levels who had more experience with succession planning or were thinking strategically about their organizations would find succession planning beneficial. Additionally, larger institutes may be complex and succession planning may be helpful in planning strategically for the continuation of the institute. Finally, older institutes may have already experienced or be about to experience one or more leadership transitions and therefore administrators would be open to the benefits of succession planning.

Findings. The majority of respondents agreed that the three positive aspects were important and disagreed that the negative aspects were important. Frequency results for both executive directors' and university administrators' responses are shown in Table 16.

Three characteristics from the synthesis were similar to items that both executive directors and university administrators found important: offer development activities, promote leadership continuity, and strategically plan for future employee needs. Negative characteristics related to the definition of succession planning did not appear in the literature.

Replacement planning or naming successors is important in the literature; while the executive directors agreed that this characteristic is important, the university administrators tended to disagree. Perhaps university administrators have a more global view than executive directors and think it is more important to bring in external leaders to continually refresh the ideas in the institute rather than to cultivate similar leaders from within the institute. Another reason may be that university administrators do not find it important for a research institute to continue in the future. Some universities, such as the University of Colorado, have sunset 
policies under which institutes only exist for a certain amount of time and then are closed so that the university can focus its resources on other priorities (Peterson, 2002).

When looking for potential patterns in the responses about important characteristics of succession planning, 32 statistically significant relationships $(\mathrm{p}<0.10)$ emerged. Table 17 displays the relationships between reports of the important characteristics of succession planning and the nature of the respondent, the research institute, and the home university.

Although the frequency data supported my hypotheses, only four of the bivariate relationships were consistent with initial expectations. Executive directors and university administrators who were more knowledgeable about succession planning or were affiliated with institutes that currently take part in succession planning find several of the positive characteristics important and the negative ones less important. There were some interesting relationships to note: executive directors who knew about succession planning find almost all of the positive characteristics of succession planning important, and the negative characteristics not important, while the university administrators who knew about succession planning only report two of the positive characteristics important. If the university administrator has considered succession planning or if succession planning was currently in place, then they also think the negative characteristics were not important.

Two additional relationships beyond those hypothesized emerged: officials at universities with greater numbers of research institutes and at private universities were more likely to report that succession planning encourages a lack of diversity in leaders (Somers' $d=.278$ ). Private universities may be somewhat more limited in the variety of types of people they employ; developing leaders from within may cultivate similar types of people rather than bringing in more diverse leaders from other institutions. 
The responses from participants from universities with more institutes seemed to contradict one another. On the one hand they reported that it is important to promote continuity and name successors; yet on the other they observed that succession planning encourages a lack of diversity. I decided to examine the impact of several control variables to see if other factors may be at play in these relationships. The characteristics that I controlled for included size of both the university and the institute, type of research conducted at the institutes, year the institutes were created, institute budget, whether they currently took part in succession planning activities, and the type of decision making processes that exist in the institute.

Size of university. When controlling for size of the university, 12 statistically significant relationships emerged. These relationships tended to support my original hypotheses. Officials from bigger organizations, in this case larger universities with over 20,000 students, would find the positive characteristics of succession planning important and the negative ones less important (see Table 18). One curious relationship appeared: respondents at universities with 30,000 to 37,999 students and that had greater numbers of institutes reported that succession planning is less likely to promote staff development activities. This may be because such universities already have strong employee development programs in place; therefore, the succession program may not have a major impact in this area. Yet this does not explain why universities with over 38,000 students would not also be less likely to want staff development activities.

Size of institute. Controlling for the size of the institute yielded four statistically significant relationships. Again, these relationships confirmed my hypothesis that respondents from larger organizations would find the positive characteristics important, and those from smaller organizations would think the negative characteristics are more important. Respondents from institutes with more than 20 employees in universities with more institutes were somewhat 
more likely than respondents from smaller institutes in similar universities to report that succession planning promotes continuity (Somers' $\mathrm{d}=.144, \mathrm{p}=.098$ ), helps organizations plan for future employee needs $(.169, \mathrm{p}=.073)$, and helps decision makers name successors $(.199$, $\mathrm{p}=.057)$. Respondents from smaller institutes in universities with greater numbers of institutes were more likely than respondents from larger institutes to say that succession planning takes too much time $(.297, \mathrm{p}=.051)$.

Type of research. Controlling for the type of research the institutes emphasize (hard science or social science), the findings pointed to both similarities and differences from the simple bivariate relationships. Respondents from social science institutes in universities with more institutes were more likely than respondents from hard science institutes to respond that succession planning helps in naming successors (Somers'd=.311, $\mathrm{p}=.036$ ). Yet those same respondents were less likely to report that succession planning takes too much time $(-.243$, $\mathrm{p}=.089$ ). Respondents from both types of research institutes in universities with more research institutes agreed that succession planning helps to promote continuity (hard science: .156, $\mathrm{p}=.078$; soft science: .247, $\mathrm{p}=.049)$.

Year institute was created. Eight statistically significant relationships emerged when I controlled for the year that the institute was created. Each of these relationships confirmed my original hypothesis that officials in older institutes would find the positive characteristics more important than the negative ones (see Table 19).

Institute budget. Only two relationships were significant when I controlled for the institute's budget; neither supported my hypotheses. Respondents from institutes with budgets under $\$ 1$ million in universities with more research institutes were more likely than those with larger budgets to report succession planning helps institutes plan for future employee needs 
(Somers'd $=.324, \mathrm{p}=.009$ ). Similarly, respondents from institutes with budgets ranging from $\$ 1-5$ million in universities with a greater number of research institutes were more likely than others with larger budgets to say that succession planning helps institutes name successors (.295, $\mathrm{p}=.004)$.

Current succession planning activities. When I controlled for institutes that currently take part in succession planning activities, I found two statistically significant relationships that failed to support my hypothesis that respondents in institutes taking part in succession planning would find the positive characteristics more important than those not participating in such activities. Respondents in universities that have more institutes and are not participating in succession planning activities are somewhat more likely than those participating in succession planning to report that succession planning helps to promote continuity (Somers'd $=.181, \mathrm{p}=.006$ ) and that it helps to name successors $(.287, \mathrm{p}=.000)$.

How policies are created and implemented. When I controlled for the final two characteristics, how policies are created and implemented, 18 statistically significant relationships emerged (see Table 20). I chose these characteristics because I thought they might reveal patterns related to who was creating and implementing succession planning policies. It seems that if leaders within the institute work together to both create and implement policies, then they are more likely to think succession planning is important. If policies are created in a more bottom-up fashion or through collaboration among all employees, then succession planning is reported to be less important than if they are only implemented collaboratively. A good illustration of this is that if policies are created bottom-up, respondents are more likely to think succession planning focuses too much on individual development (Somers' $\mathrm{d}=.833, \mathrm{p}=.000$ ). If policies are implemented in a similar bottom-up fashion, respondents are more likely to say 
succession planning promotes continuity in leadership and names successors of key positions; in both cases Somers'd=.667 $(\mathrm{p}=.014)$.

Open-ended comments. Some respondents added comments to their survey responses about the important characteristics of succession planning. Comments referred to the organization itself, succession planning in general, and individual employee positions. All of these observations were similar to the findings of the literature synthesis. Key examples included:

- Succession planning should be based on the needs of the individual institute; it is "dependent on the characteristics of the organization and the context in which is it situated."

- Decision makers should be intentional about the reasons why a succession planning program should be developed; this "assumes that an organization believes it should be perpetual (not all should)."

- Succession planning should have objectives, including diversity; "planning for heterogeneity is part of planning."

- Succession planning should focus on the entire staff and their collective development but not exclude the need for "development of expertise":

- Succession planning should not be about individuals because individuals should not be anointed as the obvious successor to leadership positions. Care must be taken to ensure all potential candidates are encouraged to apply. Therefore, strategic planning about an organization and development of a broad base of current employees is healthy for the organization, not the attempt to single out any individual. 
- Decision makers should understand that there are challenges in the process; it "is often overlooked due to more pressing short term issues," and "the university had complete control of [director's position]."

Based on these comments, I conclude that succession planning should include a process for analyzing why the institute wants to develop a succession program, whether and why it should develop one, the areas of succession planning that should be the focus, and who should be involved.

Summary. The most prominent finding in the survey responses is that respondents, both executive directors and university administrators, who are familiar with succession planning or who work at universities whose institutes are currently participating in succession planning activities support my hypotheses. They think the positive characteristics of succession planning are important and the negative characteristics are less important.

Respondents from newer institutes reported that succession planning takes too much time, which is consistent with my hypothesis. Respondents may believe this because they spend the majority of their time trying to make the institute sustainable in the shorter term rather than focusing on longer term sustainability. They also may think that succession planning takes too much time because they are just getting started and are not yet worried about people leaving or retiring.

No statistically significant relationships appeared between importance of succession planning and the size or type of institute. Contrary to my hypothesis, executive directors who have been in their positions longer do not believe that promoting continuity in leadership is important. Another unexpected relationship is that executive directors who have been in their positions longer do not think that naming successors is important. I find this somewhat 
surprising because I thought executive directors who had been at their institutes longer would be older and might be thinking about retirement, in turn thinking about how the institute may be handed over to another leader. The survey did not ask the respondents for their age or future plans for their institute, which may also have an influence that would not appear in this analysis.

The executive directors who have been at institutes longer may be similar to founders of organizations. Many scholars have written that founders of companies and nonprofit organizations are so invested in the organization that they created that it becomes part of their identity; they may be hesitant to plan for succession for fear of losing part of themselves in the process (Blouin, et al., 2006; Di Re \& Eyberg, 2008). They also could fear looking as if they have failed and are giving up (Cohn, Khurana, \& Reeves, 2005). Similarly, executive directors who have been at institutes longer may have developed strong leadership roles that they find hard to relinquish and allow others to make decisions.

\section{Decision Makers/Stakeholders}

Hypotheses. Based on the literature findings, I expected that respondents would think that administrators involved in the hiring of institute leaders (e.g., executive directors, university administrators, human resources managers) also would participate in the decision making related to succession planning. In particular I developed six hypotheses related to executive director respondents and four related to university administrator respondents.

I expected that executive directors who are more knowledgeable about succession planning, have been in their positions longer, are from institutes that are larger, are from institutes that are older, are from institutes that have some succession activities, or are from institutes that have strategic plans would be more likely to think the senior leaders of their institutes should be part of the decision making process regarding succession planning. 
University administrators who are more knowledgeable about succession planning, have considered succession planning, who are at universities whose institutes have strategic plans, or who have institutes that currently participate in succession activities would be more likely to think people in higher level positions (such as the vice president for research and the executive director) should make decisions regarding succession planning.

Findings. The survey results on the employees who should make decisions are similar to those in the synthesis; respondents believe that executive directors and the university administrator they report to (for example, the university vice-president of research) should be highly involved in decision making about succession planning. The senior managers (or, in the case of institutes, full-time faculty) and the institute's advisory board should be moderately involved in the decision making. Unlike existing research, survey respondents report that human resource managers at the university and institute levels as well as institute staff should not be involved, or involved only to a limited extent. (See Table 21.)

Looking more fully at possible patterns in the desired decision makers, 30 statistically significant relationships emerged (see Table 22). As hypothesized, most respondents believed that the executive director should be involved in the decision making.

Following my expectation, officials of newer institutes were less likely to support the involvement of the executive director in succession planning decisions (Somers'd=-.102). Respondents from newer institutes also are less likely to think institute staff and human resource managers should be involved. These results are consistent with my expectation that respondents from older institutes would be more interested in succession planning. As mentioned earlier, this may indicate the newer institutes' focus on making the institute sustainable in the shorter term, with little time to focus on longer term programming like succession planning. 
If the respondent was a university administrator, they were less likely to respond that executive directors should be involved in the decision making (Somers'd $=.422$ ). This may relate to the reason I mentioned earlier; university administrators may have a more global or holistic view of the institute and may want a greater variety of people to help in the decision making process, perhaps including the university president, members of the institute's advisory board, institute faculty, institute staff, and the university human resource manager.

Although the majority of respondents reported not wanting human resource managers involved, respondents from institutes that are larger, both in size and budget, as well as those that have strategic plans do want human resource managers to help make decisions. Implementing succession planning in larger institutes may become complicated rather quickly. Involving human resource officials, who may have expertise in succession planning, can help the institutes navigate through that complex process.

Another relationship that was contrary to my hypothesis was that social science institutes did not want the university administrator who oversees the institute to be in the decision making process. I originally thought the type of research that the institute conducted would have no effect on their survey responses. After further reflection, it is possible that respondents from social science institutes may believe that they have struggled to garner and retain a status of relevance in large universities whose focus may be more on the amount of external research dollars awarded rather than the actual work conducted. As such, they may be more interested in making their own decisions about succession planning, rather than rely on higher level university administrators.

Because universities tend to be decentralized while also having a formal hierarchy, I am not surprised that most respondents do not think the university president or institute graduate 
students should be involved in the decision making process. More intriguing is that relatively few respondents thought that vice presidents of research, residential faculty of the institute, or human resource managers should be involved. As the formal overseer of the institute, it seems quite appropriate for vice presidents of research to be involved in deciding institutes' direction (especially when hiring new executive directors). Even so, institute officials also can be seen as professionals with views of their own distinctive expertise that organizational superiors almost by definition will not have and therefore may not believe that their superiors should be involved in the decision making. The residential faculty are leaders within the institute because their research is integral to the institute mission and budget; I would expect that they at least would be consulted in the decision making process, however, perhaps, this would not be fully consistent with faculty hiring in extra-departmental settings. Although I understand the importance of the human resource managers being involved since succession planning is a human capital planning process, I also understand that many smaller institutes may not have HR managers on staff to be consulted.

Open-ended comments. Some respondents commented that university succession planning is not relevant to their institute because it is part of a larger national lab or a separate 501(c)3 operating in partnership with the university. Three respondents reported that the provost, dean or vice president of research would be involved in the decision making while another noted that the faculty of science and engineering departments should be involved in decisions. Two others were not sure who should be involved:

- "The field is small and there aren't many possible candidates outside my colleague who has to get tenure first." 
- "I cannot answer these questions because to my knowledge my university does not have a succession plan. I am not certain a succession plan would not run counter to the requirements for a fair and open search based on merit."

\section{Participants in Succession Program}

Hypothesis. I expected that survey respondents would report that full-time employees of the institute participated in succession planning programs. In particular, I developed six hypotheses: respondents, both executive directors and university administrators, who have knowledge of succession planning and whose institutes currently take part in succession planning, and executive directors from institutes that are older or larger would prefer to have senior leaders (e.g., executive directors), managers, and residential faculty participate in a succession planning process once it was put in place. I also expected that the type of institute would have no influence on respondents' views of who should participate.

Additionally, I hypothesized that older and larger institutes that currently take part in succession planning and executive directors who have knowledge of succession planning would think development methods such as job rotation, stretch assignments and job enrichment are more important than training.

Findings. The survey results largely confirmed my hypotheses. (See Table 23.) Both executive directors and university administrators reported that senior leaders such as the executive director, managers, staff and residential faculty should participate in succession planning programs when they are implemented. University administrators provided somewhat different responses regarding residential faculty participation: one-third reported residential faculty should be involved to a "small extent" and another to a "great extent." Perhaps administrators are concerned that residential faculty members should focus more on their 
research rather than on preparing to become administrative leaders in the institute. Residential faculty usually are full-time faculty employed by the institute, and many do not have responsibilities in their home departments as their time there frequently is bought out by the institute's research grants.

When looking at bivariate relationships, only respondents who are familiar with succession planning, whose institutes currently participate in succession planning, or whose institutes have strategic plans supported the hypotheses that all full-time employees should participate in the succession planning program. Other respondents focused more on senior leaders or managers as participants. (See Table 24.) Faculty in universities and research institutes tend to occupy a different status than other employees, which may have affected respondents' answers. Respondents may not view faculty as administrative leaders and therefore may not think that they should participate in succession planning programs.

Respondents from newer institutes were slightly less likely to want managers to be involved in succession planning. There may be several reasons why they would not middle managers to be involved. As mentioned previously, newer institutes may be focused on garnering greater prestige on campus and therefore may want to bring high level research in to the institute rather than promote middle managers up to director. As newer institutes, they may not have middle managers who would be available to participate in succession programs.

University administrators were less likely to choose senior institute leaders and managers to participate in succession planning. Perhaps this reflected the administrators' focus on the longer term sustainability of the institute and their desire for other people to move up in the leadership ranks; they also may want to bring new people into the institute to help energize or reenergize it. 
One flaw in the survey was that the category "post-docs" was left out of the possible responses to this question; however, I expect the respondents' answers would be similar to those for graduate students: they should not participate in succession planning programs. I am not surprised by the respondents leaving graduate students and affiliated faculty out of succession planning; however, I did anticipate that residential faculty would be included. Such faculty and their research are integral to the institute's mission; as such, it would make sense that they be included in planning for future employees.

Contrary to my expectation, respondents from social science institutes are more likely to think senior leaders and managers should participate in succession planning. I was not sure why this relationship appeared, and so I examined several control variables to try to better understand these relationships. I controlled for university size, institute budget, number of institute employees, which institutes currently participate in succession planning activities, and how policies are created and implemented. Several statistically significant relationships emerged; further confirming my hypotheses (see Table 25). Social science respondents from larger universities, from institutes with more faculty and staff, from institutes with larger budgets, and from institutes that currently take part in succession planning activities are more likely to report that senior leaders should participate in succession programs. Some of those same respondents also agree that managers should participate.

When ranking development methods for participants, executive directors responded that three types of development opportunities are important to research institutes: mentoring, job enrichment, and stretch assignments. Executive directors reported that job rotation and training related to succession planning are least important. In contrast, the university administrators believed that all of the methods are important, with job enrichment and mentoring the most 
important. Their responses were split on training related to succession planning $-22.7 \%$ said it was least important and $27.3 \%$ said it was most important.

Only one statistically significant relationship appeared: university administrators who are more knowledgeable about succession planning were more likely than administrators who know nothing about succession planning to think job enrichment is the most important method of development (Somers'd $=.466, \mathrm{p}=.006$ ).

Open-ended comments. Several survey respondents were not sure they could answer the question of who should participate in succession planning, because they "don't have all these categories of people." Other respondents included participants that do not seem to make sense given the definition of university-wide research institutes that the survey referred: to "Dean and Associate Deans," and "external search committee." Another clarified their answer: "At this center, graduate students and affiliated faculty are linked to their primary departments, not to the Center for decision-making purposes."

\section{Stakeholder Perceptions}

To capture stakeholder perceptions of succession planning in the survey, I focused on features that the respondents thought might inhibit or benefit succession planning and on the characteristics of succession planning that would be important to their particular institute.

Hypotheses. I expected that officials at older or larger institutes, respondents from institutes currently participating in succession planning activities, as well as respondents who know more about succession planning would find aspects in the university and institute more beneficial than inhibiting. I also expected them to find succession planning characteristics to be more important. 
Findings. The majority of the respondents, both executive directors and university administrators, reported that specific items neither inhibited nor benefitted succession planning but some of the executive directors' answers leaned toward features that inhibited succession planning while others leaned toward those that benefitted it (see Table 26.)

Executive directors were more negative than university administrators about university policies and procedures. They may think this because the larger university system is more complex and harder to navigate in a timely manner. The university policies themselves may be more favorable to traditional university departments compared to somewhat autonomous research institutes, which are a newer phenomenon. As mentioned earlier, some universities have sunset policies under which all institutes must close down after a certain amount of time unless they receive special permission to remain open. This certainly would inhibit succession planning within institutes.

The executive directors were more positive about policies and procedures within the research institutes themselves and about support by current university and institute leaders. They may think internal institute policies are more beneficial because as executive director they already think about the human capital in their organization. They also have more control over their own policies, which may help them plan for succession. Support by current leaders at both the university and institute levels is key to implementing a successful succession program. Such leaders want the best for their university and its institutes, even if other priorities may get in the way.

I was surprised to see that institute priorities did not appear to be inhibiting factors. Many executive directors seemed quite busy, based on emails I received when sending out the 
survey invitations, and it would appear that succession planning would not be an immediate priority.

When looking at bivariate correlations related to factors that might benefit or inhibit succession planning, 40 statistically significant relationships emerged. Most confirm my hypotheses. (See Table 27.)

Respondents who are knowledgeable about succession planning or are currently participating in succession planning activities seem to think the items were more beneficial. Respondents from larger institutes find both university and research institute policies and procedures beneficial. This may suggest that university administrators acknowledge the influence that large institutes have on the university, particularly its budget and prestige as a research university and may encourage institute administrators to consider succession planning.

Only two types of respondents reported that consulting with succession planning experts would be beneficial - university administrators who had considered succession planning and respondents at universities with more research institutes. This may show that administrators acknowledge the importance of succession planning but also understand that they do not have enough knowledge to make it happen, especially when there are more institutes for which to plan.

Two surprising relationships relate to social science institutes and respondents who are university administrators. Respondents at social science institutes are $26.2 \%$ less likely than those from hard science institutes to think university policies and procedures are beneficial to succession planning. Again, this may be further evidence that social science institutes struggle for prestige and importance on their university campuses. It may be that since social science institutes tend to bring in fewer sponsored dollars that university policies and procedures focus 
more on hard science institutes. It also could suggest specific characteristics about the nature of faculty from different disciplines and how they value university policies and procedures.

University administrators are more likely to think university policies, procedures, and priorities are beneficial and less likely to think institute priorities and leadership support are beneficial. This could be further evidence that university administrators are thinking holistically and longer term, and they do not think institute leaders focus sufficiently on longer term sustainability. It also, of course, could mean that higher level administrators both have other priorities and make more centralized decisions.

Another question about perceptions asked respondents which characteristics of succession planning were important to their research institutes. These characteristics are more specific to what a succession program includes, such as establishing individual development plans and clarifying position responsibilities; characteristics at the beginning of the survey related more to abstract features of succession plans. Respondents reported that five of the six characteristics are quite important. Only devising a means to keep records for individuals identified as successors was reported as only "slightly" or "fairly" important. (See Table 28.)

Seventeen statistically significant relationships appeared when examining which characteristics were important to institutes (see Table 29). I was surprised by the negative relationships between executive directors' tenure and the importance of clarifying present position responsibilities and keeping individual records. I expected that they would find these characteristics important because they might have had more time to think about planning for the future.

I also was surprised that the type of institute was related to the importance of identifying which groups the succession plan would serve. I expected this to be important in both types of 
institutes, not just to social science institutes. Looking at partial correlations did little to provide insight into these unexpected results.

I was not surprised that administrators who have considered succession planning and respondents from institutes currently participating in succession planning would find the characteristics important. It seems that those who know about succession planning have a positive view of the process in general. As the synthesis showed, succession planning is an important part of strategic planning for any organization in any sector; the problem is trying to persuade current administrators and directors that it is important and therefore should be a higher priority. Once they begin to experience succession planning, they become convinced of its importance.

In addition to their general thoughts about succession planning, one survey question asked the respondents to rank the importance of the methods of staff development that a succession plan might include. Mentoring was indicated as being most important, with stretch assignments and job enrichment tied for second in importance. The respondents were split on the importance of job rotation and training. (See Table 30.)

Open-ended comments. Several written comments better explain respondents' perceptions of succession planning. Succession planning is important but it depends on continuous funding:

- “We don’t want to pre-empt search processes, but succession planning is indeed critical to research institutes largely supported by external funding."

- "Succession planning in a research center depends on on-going and new grants, linked to the mission of the center." 
- "Succession of leaders is linked to funding for particular programs/projects. Faculty are reviewed annually for productivity. Staff are reviewed annually for productivity. Future leaders emerge with funding."

Contrary to these comments, one respondent believed succession is a more natural process, and formal succession planning may not be needed:

In more than 30 years experience, I have seen people self-nominate or selfpromote themselves as "interested" or available for promotion. Some employees do not rise above or do not show interest in advancement. Perhaps it is because I have been in this work for so long and have seen mostly good decisions being made concerning leadership appointments. I think people with what it takes to lead show themselves [by] virtue of their knowledge, experience, career choices, success in work and projects, and personality to make a good leader. Some employees no matter what their training is or has been could successfully lead an organization, others seem to naturally assume and have people follow them because of their qualities. Over these many years, the process of doing [well] at what you have to do, having the kind of behavior people naturally admire, and making good choices usually leads to a position that one has earned.

\section{Context and Impetus for Succession Planning}

Several questions in the survey related to the context and impetus for establishing succession plans. Context questions asked about the expected percentage of growth in the number of employees at the institute and how many of those employees would retire in the next five or ten years. Additionally, the respondents were asked about the reasons they thought were important for establishing a succession plan. 
Hypotheses. I expected that officials at older or larger institutes, respondents from institutes currently participating in succession planning activities, as well as respondents who know more about succession planning would find the reasons for establishing succession plans to be important. I also expected that respondents from institutes that had strategic plans or were currently participating in succession planning activities would find more characteristics of succession planning important to their institutes.

Findings. Respondents from over three-fourths of the institutes (77.2\%) predicted that they would need more employees in the future but that growth would be minimal, ranging from $1-25 \%$ increases in administrators, full-time faculty, and staff. Respondents reported even smaller amounts of expected growth in post-docs and graduate students. A majority of respondents said that between one and five full time employees would retire in five years, with a similar number expected to retire in 10 years. Respondents from several larger institutes added that they lose 5-10\% of their employees annually, about 35-75 employees depending on the institute. Officials from two different institutes reported that they expect to lose between 400 and 650 employees in the next 10 years. Those from several institutes anticipate that between 10 and $25 \%$ of their employees, including faculty, will retire in 10 years. (See Table 31.) The survey respondents said seven reasons were important for establishing succession plans and one reason was not important. (See Table 32.) The important reasons were to:

- Contribute to implementing the organization's strategic plan;

- Help individuals realize their career plans within the organization;

- Encourage the advancement of diverse groups - such as minorities or women in future jobs within the organization;

- Preserve institutional knowledge as our workforce evolves; 
- Provide increased opportunities for "high potential" workers;

- Prepare for immediate loss of key employees in critical positions; and

- Improve employee retention.

Although a few mentioned that succession planning is helpful for downsizing, the majority of respondents reported that a final reason, to help downsize or reduce staffing, was "not at all important." This is a noteworthy characteristic of succession planning but many managers may not like to think negatively, or to plan for layoffs, for fear of upsetting current employees. These responses could also be a result of a socially desirable response: what leader wants to look like they are planning for failure?

Several questions arise regarding three of the reasons. Why did executive directors' responses to planning for the immediate loss of key employees range from slightly to very important? As executive directors, it would seem that planning for the future of their institutes would be important, especially when it comes to thinking about to emergency transitions. Similarly, why did university administrators consider preserving institutional knowledge or helping individuals realize their career plans of varying degrees of importance? Responses that rated helping individual career plans as being "slightly important" might be explained by administrators' more global perspectives. Responses that found preserving institutional knowledge to be only "slightly important" evidently are more problematic in relation to succession planning more generally; these administrators may also believe that succession planning is only slightly important. The survey data did show that administrators who think succession planning is less relevant to their institutes are also less likely to think succession planning helps to preserve institution knowledge. 
When looking at bivariate relationships, I found 34 statistically significant relationships related to context and impetus for establishing a succession planning program (see Table 33). Most supported my hypotheses. Respondents who were more knowledgeable about succession planning or were from institutes that were larger or had larger budgets were more likely than others to find most of the reasons for establishing a succession plan to be important.

It is not surprising that officials from newer institutes were less likely to find using succession planning to downsize to be important; they are most likely looking to expand their operations to achieve their goals. Of greater interest is that social science institutes and institutes with larger budgets are less likely to report using succession planning for downsizing. Institutes with larger budgets may be able to weather more fluctuations in their budgets; therefore, they may not think about downsizing. Yet if social science institutes need to struggle for prestige on campus, using succession planning to plan for possible downsizing may be appropriate.

However, their officials may be so focused on staying relevant to campus priorities that they do not think about planning for employee reductions, and/or they are so small, that it makes little sense.

Open-ended comments. Respondents wrote in additional reasons for why succession programs should be implemented, including dealing with budget cuts, continuing the institute's mission, better preparing internal candidates to compete for positions, and preparing for immediate loss of people:

- "Because of the economic situation in the nation and the state and budget cuts are cutting staff so any new hiring is contingent upon an improvement in the economy."

- "Continuity of mission and goals" 
- "Universities usually hold an open search either regionally or nationally focused to attract someone at the director level. Sometimes an inside candidate will compete with an external candidate for the position. In my opinion, if the university feels the organization is well managed then an inside candidate has a greater chance. If the university feels the unit is poorly managed, then they will often go for the external candidate."

- "Provides continuity in vision."

- "Ensures that efforts can continue whenever a person leaves, not just immediate loss."

Succession planning allows the institutes to strategically plan for the future to ensure continuity in vision and goals as well as to assure that the "right" employees are in the "right" positions.

When asked about the types of succession planning activities their research institute currently takes part, several respondents wrote they use merit and committee assignments:

- "We use merit for advancement nothing more to add."

- "Establishing rules and by-laws for the organization, including succession rules.”

- "Incorporation in strategic planning."

- "We seek future leaders from across the entire campus."

- "Committee assignments." 


\section{Organizational Placement of Program}

Organizational placement of the succession program refers to the personnel or unit in the institute or university that would coordinate program activities and evaluate it to make sure program objectives were met.

Hypotheses. I expected that officials at older or larger institutes, respondents from institutes currently participating in succession planning activities, as well as respondents who know more about succession planning would prefer higher level internal units, such as the executive director's office or the human resources office in the institute to coordinate the succession program. Many of these respondents would understand that succession planning is important and might receive greater attention and priority if it were coordinated at a higher level in the university or institute.

Findings. The survey responses agreed with the synthesis results. Most executive directors believed that succession planning should be located at the senior executive level in the institute (59.3\%), but another third believed it should be placed at a senior executive level in the university (36.4\%). University administrators' responses were the opposite; most university administrators believed it should be located at the senior executive level of the university $(54.5 \%)$, with one-third reporting it should be at the senior executive level in the institute (31.8\%). No statistically significant relationships involving where succession planning programs should be located appeared.

Open-ended comments. Some of the written comments suggest that the succession program should be lodged at multiple levels in a university. Five respondents suggest "collaboration" between both the university and research institute senior executive levels. Two think the program should be jointly coordinated by senior executives and human resources staff. 
Two others think it should be handled at a lower level within the "unit" or "laboratory." Another four looked to academic departments or college deans to coordinate succession planning in consultation with the institutes. Finally, some commented that the question did not apply to them because they are "part of a national lab," are "a 501(c)3 that works with universities, and is not itself a university entity," or are required to "[coalesce] with another center." Finally, three respondents noted that they "don't know," and another indicated that the word "program seems too formal" but that "planning by someone is key."

\section{Timeline}

During the pretesting of the surveys, I found that university administrators think of development timelines in terms of number of development opportunities over a certain amount of time rather than in months and years for the design and implementation of the program. The options for timing related to the succession planning process in the final survey were "none, one time experience, multiple experiences over one year, or multiple experiences over multiple years".

Hypotheses. I expected that officials from larger and older institutes and respondents who know more about succession planning would think senior leaders, managers and residential faculty should receive more development opportunities.

Findings. As seen in Table 34, respondents believe that senior leaders and managers should receive multiple experiences over multiple years. Yet staff should only have one-time development experiences. Residential faculty, affiliated faculty, post-docs, and graduate students should receive no development opportunities. If residential faculty receive any development opportunities, then it should be only a one time experience. 
A greater amount of variation appeared in the university administrators' responses about opportunities for senior leadership. The majority responded that senior leaders should receive only a one time experience, while another third responded multiple experiences over multiple years, and one-quarter of the responses said multiple experiences over one year. These respondents may believe that senior leaders already are the leaders of the institute and do not need additional development opportunities to move up in the institute or the university generally.

When reviewing bivariate relationships, 23 statistically significant relationships emerged (see Table 35). It is quite evident that most respondents, no matter the type of institute they come from or how long they have been there, believe that senior executives, or those who may take over these positions at the institute, should receive multiple development opportunities over multiple years. The exceptions are respondents who are university administrators and those from newer institutes or from universities with more institutes. Overall, university administrators were less likely than executive directors to respond that all employees should have multiple development experiences. The administrators may be more focused on bringing in new employees rather than on developing current staff. Again, executive directors from newer institutes may focus more on the short-term viability of the institute rather than on longer term sustainability, which would include developing employees. Universities with a greater number of institutes may have a similar emphasis as that on executive directors; they are already the senior leaders of the institute and development opportunities should be reserved for employees below the level of senior leader.

Open-ended comments. Unfortunately, at least seven of the respondents did not understand this question. Several other comments suggested that respondents do not have resources to think about succession planning or are not familiar enough to answer. Such 
responses indicate that development of employees varies across institutes or is linked to available funding:

- "We do not have the staff or resources for this."

- "Have no idea not having done this."

- "Development is linked to funding or to periodic meetings about future funding with an appropriate Dean.”

- "Depends on the institutes. Ours are so varied in composition and mission that one size does not fit all.”

\section{Other Characteristics}

Although I focused on specific elements of succession planning in the research synthesis, such as definition, decision makers, and participants, I was open to letting the literature suggest additional elements that should be considered in the succession planning model. Features that came to the surface included what should be in a written plan and how the succession program should be evaluated (Rothwell, 2001). Additionally, the pre-survey process raised the question of where current key hires come from. I also reviewed characteristics of the respondents and institutes themselves.

\section{Written plan}

Survey respondents reported that linking the succession plan to the research institute's strategic plan is very important and that it being tied to the university's strategic plan is quite important as well. Most of the respondents said the other characteristics of the succession plan are fairly important with the exception of having an established schedule of program events, which was seen as only slightly important. Not having a scheduled program of events within the 
actual succession plan can be a positive characteristic because it allows the plan to be nimble and alter as necessary over time. (See Table 36.)

\section{Evaluating the Succession Program}

Survey respondents cited four of the characteristics of succession program evaluation as being fairly to quite important, including measurable program objectives, a means to appraise individual performance, a means to compare individual skills to the future job requirements, and an annual review of organizational talent. (See Table 37.) The final characteristic that was reported to be only slightly to fairly important was tracking development activities for specific successors for eventual advancement. Respondents may not have considered this as important because they may already have a means in their human relations system of tracking individual employees, making an additional system unnecessary. That suggests in turn that it may be important for institute leaders to ensure their current system of tracking employee development can be linked to the succession program.

\section{Current Key Hires}

The survey respondents were asked where their current key employees came from, including candidates externally and internally from the institute, university, or from industry, and what if any changes they would make in the current configuration. Executive directors reported that roughly $26-50 \%$ of current key employees come internally from the research institute, internally from the university, and externally from the university but from another university (see Table 38). University administrators report that roughly $11-25 \%$ of current key employees come internally from the research institute, internally from the university, and externally from other universities; another 1-10\% come externally from private industry (see Table 39 ). These responses evidently contradict earlier responses in which they said leaders in the institute should 
be external candidates. It could be that respondents consider key personnel to be lower level leaders, which could be internal candidates, while they believe that higher level executive directors should come from external sources.

When asked how they would change the percentages of where key employees came from, $88.8 \%$ of executive directors reported no changes. Of the other $21.2 \%$, most would reduce the percentage of employees who come either internally from the research institute or externally from industry. University administrators' responses differed: $77.8 \%$ reported no changes while the other $22.2 \%$ would increase the number of key employees from other universities. (See Tables 38 and 39 and Figures 5 and 6.)

Open-ended comments. In answering closed-ended questions, respondents reported that less than one-quarter of current institute leaders came from industry; their write-in answers showed greater variation. Five noted that their leaders came from industry; one came from a non-governmental organization, from a national laboratory, and two from state or federal government. One respondent wrote that all of its leaders have been internal but that "in better times, we might look outside." Another respondent suggested that where the leaders come from "varies greatly by period, program, and projects." Others recognized leaders outside the institute with whom they partner but who do not work directly for the university.

\section{Other Findings}

When looking at characteristics of research institutes, I found that officials in institutes in public universities reported being evaluated more often than those at private universities. This could be related to the push for accountability and transparency in the public sector.

Moreover, when a university had a greater number of research institutes, the mission of those institutes related less to the university's mission than at those universities with fewer 
research institutes. On a somewhat contrary note, larger universities had research institutes with missions that were more related to the university's mission. It would seem that as universities developed a larger number of research institutes, those institutes might drift away from the university's core mission. Historically, the main mission of universities was to teach and convey knowledge; as research universities develop a greater interest in research and create institutes, that mission shifts more to creating and distributing that knowledge, maybe even selling it, through technology transfers with industry partners.

Respondents from larger universities were more likely than respondents from smaller institutions to be knowledgeable about succession planning (Somers'd $=.212, \mathrm{p}=.063$ ). Those at universities with more research institutes are more likely than respondents from schools with fewer institutes to report that they had considered succession planning $(.950, \mathrm{p}=.073)$.

\section{General Comments}

Although the survey responses to individual questions indicate that respondents consider succession planning to be relatively important, their more general comments exhibited more variation and intensity. Some highly recommend succession planning as a key ingredient in strategic planning and professional development, while others think it is not only unnecessary but could actually be detrimental to the flexibility that research institutes need to stay constantly relevant. It is also clear from the general comments that most think of succession planning as replacement planning rather than providing a more holistic plan for their human capital. The respondents' comments recognize that a difference between succession planning for faculty and for administrative employees. They are not sure how to develop succession programs for tenured faculty. Finally, most smaller institutes, with between one and five employees, find the 
idea of succession planning too daunting because they do not have the resources, both financial and staffing, to consider it a worthwhile undertaking.

\section{Positive Comments}

There were eight very positive comments related to succession planning. First, these respondents said that "succession planning is vital" in helping the leaders "continue to grow" their institutes and to strategically plan for the future by "[maintaining] continuity and direction." Not only is succession planning "critical to maintain the momentum and continuity of successful centers," it is also helpful to the university to "preserve/grow the investments made in the institute over the years."

Second, succession planning helps potential leaders learn skills needed to take on senior management position, such as "human resources and business" skills. It "trains employees" in the fundamentals of working for a research institute and publishing, while also helping directors and employees "[establish] a reputation for the group through participation in workshops, review meetings, symposia, and through leading conferences." Another respondent agreed: "These skills are required for these senior level management/director positions and appropriate education is required. On the job training is very stressful."

Third, although respondents from many smaller institutes seem negative about succession planning, other center directors believe that succession planning is important to help develop the person who may take over one day: "I hope the person I recruited six years ago will get tenure and grow into this role."

Fourth, even though succession planning may seem hard for smaller institutes, one respondent is hopeful that succession planning can allow for both internal and external candidates: 
Succession planning is driven by the strategic plan for the institute. As a small facility, we are only one or two deep in any particular skill, so succession is rather straightforward except that skill level of "deputy" may be inadequate to succeed, and outside recruitment becomes important.

\section{Negative Comments}

Many more respondents, a total of 30, expressed concerns about succession planning at the research institute level. Their comments noted several common themes: 1) succession planning should never be done, 2) succession planning is important but there are not enough resources, 3) university and faculty culture does not allow for it, 4) succession planning is not possible because the state mandates open searches, and 5) it is not applicable.

Should never be done. Six respondents gave four different reasons why succession planning should not be done in research institutes. First, cited by three respondents, institutes need to conduct nationwide, external searches to "attract 'stars' to the university." The external search process also is "very valuable in re-calibrating organizational mission."

Second, "too much emphasis on succession planning can make any enterprise stale and inflexible, because it reduces the enterprise's ability to respond quickly to changing boundary conditions and new challenges." Several of the negative comments seem to contradict one another in regards to flexibility - one calls for flexibility because the institute should constantly bring in new leaders to refresh the institute and another justifies flexibility because one should not lock people into career tracks when leaders do not leave very often.

Third, succession planning is "not altogether appropriate for universities compared to industry." This respondent calls for additional research and data on the "impact of relatively 
minimal planning" on universities. In other words, this respondent is not convinced that planning for human capital has worked and is necessary.

Finally, one respondent questioned the idea that organizations below the overall university level should assume perpetuity:

In a research/innovation environment of rapid and dramatic change, it seems the burden of proof should be on why a given institute should not sunset after 5 years (10 at most). After all, its purpose shouldn't be job security for management.

Not enough resources. Twelve different respondents argued that a lack of resources that hinders succession planning, including funding issues, employee capacity, other priorities, and high turnover of junior faculty. Nine of the respondents focused on tight budgets as the reason they do not plan for succession programs, even though several of the directors recognized the importance of it. Funding issues fell into five categories:

1. Lack of resources to continue the center - "Succession planning is essential for economically viable institutes, but probably a moot point for institutes that are at the end of their lifecycle."

2. Lack of resources to hire replacement employees - "Recent rounds of budget cuts mean that most vacated positions have simply disappeared and we either abandon positions and responsibilities or re-train existing staff."

3. Lack of funding to design a succession program - "The lack of budgets (especially in light of multiple years of recent budget cuts) makes such planning very difficult to justify and/or accomplish.”

4. Lack of funding to implement a succession program - The "lack of funding is a clear barrier to a robust succession plan. The Universities are strapped for 
any kind of meaningful succession plan and the research institutes are more so."

5. Inability to transfer research contracts between faculty - "Succession planning is extraordinarily difficult under these circumstances because funding is not easily transferred from one investigator to another. Each principal investigator is forced to raise their own support for their own research.”

The next prevalent comment referred to a lack of resources due to a small staff, in one case an institute with only one employee. Three respondents report not having the capacity to plan succession activities because they are stretched very thin as it is; it also may not be relevant because there is only one staff member - due to "the small size of most research institutes, I'm not sure how important succession planning is to such organizations."

One respondent commented that the focus of the institute is "on the academic quality/usefulness of our research and on garnering resources to do our work"; as such, succession planning is not a priority and resources would not be devoted to it. This person continued: "Time and energy devoted to succession planning would be counterproductive and lessen our ability to accomplish our primary mission."

Despite having a lack of resources to conduct their own succession plan, one respondent suggested that institute employees should take advantage of current training programs, such as the Academic Leadership Program offered by the Big Ten Conference's Committee on Institutional Cooperation.

University and faculty cultures. The comments of 11 respondents focused on the inability to participate in succession planning because of the constraints put on them by the culture of the university or the nature of being a faculty member. The most cited reason, with 
three mentions, was the hierarchical nature of universities and the differences among tenured faculty, research faculty, and administrative/professional staff: “A technical or clerical member of the institute will not be accepted in a leadership position for a research institute. Thus, it will be disingenuous to suggest that there are no limits to advancement."

Other comments citing the university culture as a challenge to succession planning include the executive director's lack of authority to hire faculty, his or her influence over faculty members' promotion and tenure, and his or her perception of little support from the university administration to develop succession programs. Although some respondents are beginning to think about succession in light of their own retirements, they are finding it hard to "figure out what I could have and should do given that research institutes at my institution do not have the authority to hire faculty and have little influence over promotion and tenure. Consequently, I am very powerless in identifying and planning for future leadership. This is a significant problem." Even if the institute directors want to implement succession planning, some find it a challenge because “there isn't too much support for it, as it isn't part of the culture here."

Another challenge related to the university and research institute cultures is that the respondents say the institutions have never done it before or have a laissez-faire attitude toward it. For example:

Succession planning is, in my view, rare or absent for faculty, and definitely for staff. An organization may encourage staff advancement, but not with a strategic basis. If my answers to the questions above seem odd, it's probably because I've never seen any of this done (in 35 years).

Two respondents underscored a laissez-faire attitude as a constraint. One wrote, it is "generally a non-issue, up to the discretion of the current director. Some do it, and others don't. 
University administration above centers and institutes are not involved." Another focused on a more as-needed rationale: "filling position appears to be primarily triggered by 'on-demand' events, such as a surprise departure or the acquisition of a new, major source of funding."

Other respondents saw the nature of being a tenured faculty member as a challenge. Eight respondents give five different reasons why succession planning would not work with such faculty members:

1. It is too difficult to replicate one faculty member's research interests "Researchers are affiliated with a line of activity based on strong personal preference and expertise built over a long period of time. Consequently, mobility within the institution can be low." Another agrees, "It is often difficult to find a successor that can take over the center effectively."

2. Faculty are promoted based on their academic work, not management training - "Faculty almost always have a key, if not definitive, role in individual selection processes and few have formalized management planning training demonstrated management abilities are often considered second-tier priorities compared to academic stature."

3. Like the institute priorities are focused on other things, individual faculty have other priorities - "In our institute the senior management positions are held by faculty with many other responsibilities, and [succession] strategies are far down their list of importance."

4. Faculty report to departments, not the institute - "The research director is usually a tenured faculty member, so he/she reports to two persons, an academic unit head (for tenure and salary issues) and a senior university 
official (for institute issues). This system makes succession planning extraordinarily complicated, to the point of near impossibility."

5. Faculty have self-preservation challenges - "Faculty affiliates and senior research staff do not see the benefits of succession planning because they raise their own money and control their own research projects."

Open search requirements. Three respondents commented that their hands are tied regarding succession planning because their state or university mandates open searches for leadership positions, with both internal and external candidates encouraged to apply. One of these respondents also noted that he worries succession planning might "cause morale problems" because it "[promotes] some at the expense of others" and that "all employees deserve professional development and the chance to prove themselves as worthy of promotion."

Not applicable. Two participants responded that succession planning is "not applicable where I work." One explained the answer further: "Ours is a rather democratic organization where members elect leaders, but tend to do so only when a vacancy occurs."

While most of these comments were negative and point to several major challenges to succession planning, many of the respondents genuinely were interested in the concept but could not figure out how it could be implemented in their institute. Of the 30 respondents, only five stated that succession planning should not be conducted at research institutes.

\section{Other Comments}

An additional 30 comments were neither positive nor negative but rather made suggestions about the succession planning process. The first suggestion was that succession planning should be used in conjunction with an evaluation of the institute and strategic planning for the future. 
Similar to previous comments, the second suggestion reiterates that succession planning is important but the biggest challenge will be "identifying people who are both technically strong and have leadership skills." Once these people are identified, they should receive stretch assignments and mentoring opportunities.

Next, some respondents wrote that succession planning should involve the universitylevel administrator the institute reports to as well as deans of affiliated departments. According to one, "The success of this approach depends on how well the VP-R understands the research institute, and the type of relationship between the current ED and the current VP-R. Succession planning needs to focus on making this process a bit more robust."

Two other suggestions seem to contradict one another. Two respondents commented that succession planning is for the entire organization - "there is a need to help all employees develop their abilities to serve effectively and be available for promotion." To the contrary, another maintained that succession planning should be only for the senior leaders and not the people underneath them:

I am more concerned with succession planning for leaders than for the folks below them, including staff. We don't even do an adequate job of succession planning for the leadership of our major research institutes.

Ten different participants emphasized another point: "succession planning is important but it should be an informal, organic and simple process. This informal process helps keep the institute flexible and avoids the "strong status quo biases." One participant summed up the concerns nicely:

In my jobs over the last 2 decades, as dean of a school, as director of a large interdisciplinary research project, and now as director of a newly established 
research institute, I have in each of them identified people early on who have the potential to replace me and worked to place them in positions in which they would have to learn what they would need to know to be able to fill my job should they be chosen. There is a delicate balance here of observing how people perform in these positions (how well they work with others, how diplomatically they resolve conflicts, and how well they listen to those around them) and working with them to develop those skills through mentoring. In my institution, this is done mostly informally by senior leaders who know the faculty and staff and their capabilities. Given the modest number of positions for which this sort of planning is appropriate in my university, I'm not sure that a formal, codified, written plan would work as well as a less formal ongoing evaluation of individuals with potential coupled with opportunities for assignments that provide breadth of useful experience. That is the approach we use now, and while it no doubt could be improved, I think adding formal requirements in this area should be approached with caution. Whether or not succession planning is formalized, it is an important part of the job of institute leaders.

Eight different respondents focused on the next suggestion. The succession plan should be tailored to the context of individual research institutes as well as to individual employees and faculty. "Succession planning needs to be closely tailored to the character of each institute and its circumstances. Important elements are preserving key skills, identifying likely successors to key positions, and making sure star performances are not lost inadvertently during a downsizing episode." Several participants wrote that it not only should be situated in the "context of our 
Institute, but in the context of the field," because they are preparing leaders for the field whether they work for this particular institute or another.

Another suggestion emphasized the timing of succession plans. Succession planning should be considered with enough time to invest in the program and not during a crisis or time of transition.

One respondent suggested that succession planning should only occur for university-wide research institutes that the university wants to continue when the leader leaves. The university should be strategic in choosing which institutes should embark on succession planning processes.

The final suggestion related to communicating and sharing information more readily across institutes. One responder commented that "outside consultation is helpful." Another looked to "best practices across research institutions," and a third suggested "[bringing] in leaders of similar institutes to talk to staff."

All of these suggestions seem important and relevant without being deterrents to succession planning for university-wide research institutes. I tried to incorporate them into my proposed succession planning model that was the next step in this research.

\section{Summary and Discussion}

\section{Summary}

Using the survey findings to test the hypotheses, I found that a little over half of the hypotheses were supported. It seems that respondents who reported being familiar with succession planning or came from institutes that are larger, older, or currently have some type of succession planning activities in place are more favorable toward characteristics of succession planning or find that succession planning would be beneficial. (See Table 40 below.) 


\section{Table 40: Summary: Survey Support for Hypotheses}

\section{Definition:}

The following respondents were likely to find the positive characteristics of succession planning more important and the more negative characteristics less important:

1. Executive Directors familiar with succession planning

2. Executive Directors from older institutes

3. Executive Directors from institutes with larger budgets

4. Executive Directors from bigger institutes

5. Executive Directors from institutes that have strategic plans

6. Executive Directors whose institute currently participates in succession planning activities

7. University Administrators familiar with succession planning

8. University Administrators who had considered succession planning

Supported

Supported

Not supported

Not supported

Not supported

Supported

Supported

Supported

9. University Administrators whose institutes have strategic plans

10. University Administrators whose institutes currently participate in succession planning activities

\section{Decision Makers:}

The following respondents would think that senior leaders of the institute should be involved in the decision making for succession planning:

1. Executive Directors familiar with succession planning

2. Executive Directors who have been in their positions longer

3. Executive Directors from older institutes

4. Executive Directors from bigger institutes

5. Executive Directors from institutes that have strategic plans

6. Executive Directors whose institute currently participates in succession planning activities

7. University Administrators familiar with succession planning

8. University Administrators who had considered succession planning

9. University Administrators whose institutes have strategic plans

10. University Administrators whose institutes currently participate in succession planning activities

\section{Supported}

Not supported

Supported

Not supported

Supported

Not supported

Supported

Supported

Supported
Not supported 


\begin{tabular}{|c|c|}
\hline $\begin{array}{l}\text { Participants: } \\
\text { The following respondents would think that senior leaders, managers, } \\
\text { and residential faculty should participate in succession planning once it is } \\
\text { in place: }\end{array}$ & \\
\hline 1. Executive Directors familiar with succession planning & $\begin{array}{c}\text { Supported } \\
\text { (Not Res. Faculty) }\end{array}$ \\
\hline 2. Executive Directors from older institutes & Not supported \\
\hline 3. Executive Directors from bigger institutes & $\begin{array}{c}\text { Supported } \\
\text { (Not Res. Faculty) }\end{array}$ \\
\hline $\begin{array}{l}\text { 4. Executive Directors whose institute currently participates in } \\
\text { succession planning activities }\end{array}$ & $\begin{array}{l}\text { Supported } \\
\text { (Not Res. Faculty/ } \\
\text { Add Staff) }\end{array}$ \\
\hline 5. University Administrators familiar with succession planning & Not supported \\
\hline $\begin{array}{l}\text { 6. University Administrators whose institute currently } \\
\text { participates in succession planning activities }\end{array}$ & $\begin{array}{c}\text { Supported } \\
\text { (Not Sr. Leaders) }\end{array}$ \\
\hline $\begin{array}{l}\text { Stakeholder Perceptions: } \\
\text { The following respondents would think that aspects of the university and } \\
\text { institute are more beneficial for succession planning than inhibiting: }\end{array}$ & \\
\hline 1. Executive Directors familiar with succession planning & $\begin{array}{l}\text { Somewhat } \\
\text { Supported }\end{array}$ \\
\hline 2. Executive Directors from older institutes & Not supported \\
\hline 3. Executive Directors from bigger institutes & $\begin{array}{l}\text { Somewhat } \\
\text { Supported }\end{array}$ \\
\hline 4. Executive Directors from institutes with larger budgets & $\begin{array}{l}\text { Somewhat } \\
\text { Supported }\end{array}$ \\
\hline $\begin{array}{l}\text { 5. Executive Directors whose institute currently participates in } \\
\text { succession planning activities }\end{array}$ & Supported \\
\hline 6. University Administrators familiar with succession planning & $\begin{array}{l}\text { Somewhat } \\
\text { Supported }\end{array}$ \\
\hline $\begin{array}{l}\text { 7. University Administrators whose institute currently } \\
\text { participates in succession planning activities }\end{array}$ & Supported \\
\hline $\begin{array}{l}\text { Context or Impetus: } \\
\text { The following respondents would find the reasons for establishing } \\
\text { succession plans to be important: }\end{array}$ & \\
\hline 1. Executive Directors familiar with succession planning & Supported \\
\hline 2. Executive Directors from older institutes & Not supported \\
\hline 3. Executive Directors from bigger institutes & Supported \\
\hline 4. Executive Directors from institutes with larger budgets & Supported \\
\hline $\begin{array}{l}\text { 5. Executive Directors whose institute currently participates in } \\
\text { succession planning activities }\end{array}$ & $\begin{array}{l}\text { Somewhat } \\
\text { Supported }\end{array}$ \\
\hline University Administrators familiar with succession planning & Not supported \\
\hline
\end{tabular}




\begin{tabular}{|c|c|}
\hline $\begin{array}{l}\text { 7. University Administrators whose institute currently participates } \\
\text { in succession planning activities }\end{array}$ & Not supported \\
\hline \multicolumn{2}{|l|}{$\begin{array}{l}\text { Organizational Placement: } \\
\text { The following respondents would prefer high level internal units to } \\
\text { coordinate the succession program: }\end{array}$} \\
\hline 1. Executive Directors familiar with succession planning & Not supported \\
\hline 2. Executive Directors from older institutes & Not supported \\
\hline 3. Executive Directors from bigger institutes & Not supported \\
\hline 4. Executive Directors from institutes with larger budgets & Not supported \\
\hline $\begin{array}{l}\text { 5. Executive Directors whose institute currently participates in } \\
\text { succession planning activities }\end{array}$ & Not supported \\
\hline 6. University Administrators familiar with succession planning & Not supported \\
\hline $\begin{array}{l}\text { 7. University Administrators whose institute currently participates } \\
\text { in succession planning activities }\end{array}$ & Not supported \\
\hline \multicolumn{2}{|l|}{$\begin{array}{l}\text { Timeline: } \\
\text { The following respondents would think that senior leaders, managers, } \\
\text { and residential faculty should receive more development opportunities: }\end{array}$} \\
\hline 1. Executive Directors familiar with succession planning & $\begin{array}{c}\text { Supported } \\
\text { (Not Res. Faculty) }\end{array}$ \\
\hline 2. Executive Directors from older institutes & Not supported \\
\hline 3. Executive Directors from bigger institutes & $\begin{array}{l}\text { Supported } \\
\text { (Not Res. Faculty/ } \\
\text { Not Managers) }\end{array}$ \\
\hline 4. Executive Directors from institutes with larger budgets & $\begin{array}{c}\text { Supported } \\
\text { (Not Managers) }\end{array}$ \\
\hline 5. University Administrators familiar with succession planning & Not supported \\
\hline
\end{tabular}

\section{Proposed Succession Planning Process Model}

As Chapter one discussed, the survey was a vehicle to situate existing scholarship in a real world context. Based on the survey results, it seems that there are similarities between university-wide research institutes and organizations across the public, nonprofit, and for-profit sectors. Because few university research institutes reported participating in succession planning, my expectation was that characteristics that were found in all three sectors could serve as benchmarks for the institutes. These benchmark characteristics, which executive directors and 
university administrators also identified as important in the surveys, became the characteristics I focused on in the proposed succession planning model that was the next step in the research.

Among the model characteristics were elements such as the following. Regarding definition and important succession planning characteristics, three features rose to the top. Succession programs in research institutes are tools to plan for transitions of key leaders, to plan for recruitment of employees, and to develop a pool of better prepared employees and future leaders.

For decision making, three types of people were identified in the synthesis and the survey. The CEO, executive director, and human resource manager should be involved in the decision making. ${ }^{9}$ I interpret the $\mathrm{CEO}$ as being a position similar to the university's vicepresident of research. As for participants, the executive director, top-level administrators, managers and some key staff should participate in the succession plan once it is in place. Because of their influence and role in research in the institute, I consider residential faculty of the research institute to be top-level administrators for that sub-organization of the university.

The stakeholder perceptions uncovered in the research synthesis seemed more negative than those of the executive directors but there was some overlap. The institute should be assessed, particularly in relation to current and future job responsibilities. The succession planning program should be geared toward individual career and development needs.

Additionally, the succession planning process should be mindful of developing resources for the succession program and make sure all leaders and administrators understand the process.

\footnotetext{
${ }^{9}$ University-wide research institutes typically report to a university-level administrator who oversees the institute to make sure that it follows research protocols and stays connected to the mission of the university. Although this administrator does not control day-to-day operations of the institute like an executive director, he or she does have some power over decision-making, especially as related to hiring replacement leaders for the institute.
} 
In regards to context and impetus, the succession plan is developed as a guide to help institutes navigate executive director transitions, to plan for retirements of key leaders, to overcome training and development deficiencies, and to encourage retention or to mitigate the loss of employees. The succession plan should not be used as a guide to help downsize or reduce costs.

The succession plan should be placed at the executive director and management levels of the research institute. The plan also should include both limited and more extensive development opportunities. Limited development opportunities, such as a one-time workshop, should be available for staff and residential faculty. More extensive development opportunities that may involve multiple experiences over a year or more should be for executive directors and senior leaders who might become executive directors in the future.

\section{Limitations}

The survey had several limitations. As chapter two discussed, surveys may be inflexible, force respondents into answer categories they would not normally choose, and not allow for special circumstances confronted by an institute. I sought to compensate for these limitations by offering open-ended questions and opportunities for respondents to write in their own answers. Additionally, all survey responses were confidential, which may have helped secure more open and honest answers from participants.

Similarly, although the survey questions were vetted through a pre-survey, the questions may not have been as relevant or as clear as they could have been. The survey also relied on electronic communication, which may have faults, such as the email invitation going to a spam folder or being lost in a sea of other emails. I reduced this concern by contacting each potential 
participant four different times, once per week, with two different methods including three emails and one postcard.

Beyond the survey design, limitations may be related to the response rate, which is relatively low and not representative of the entire population. I tried to mitigate this concern by inviting the entire university-wide research institute population to participate in my survey research.

\section{Conclusion}

Although there is some overlap in succession planning characteristics among the various sectors, administrators in higher education and university-wide research institutes should be wary of trying to change their organizational processes inappropriately to mirror for-profit norms of efficiency and effectiveness (Lumby, 1999). Instead, by focusing on succession planning in a more holistic sense similar to organizations from other sectors, universities as a whole can plan for future workforce needs. Lumby (1999) praises strategic planning in colleges because it allowed colleges in England to become more "business-like" in a positive way - not in terms of bottom lines but rather in becoming "more sure and more committed to what their business was" (p. 81). Succession planning might well have similar effects in U.S. universities. It can help university administrators become more aware of and more committed to the institution and their work, promote a dialogue about the institutes' human capital needs and the administrators' needs through more open communication, and encourage developing a plan to achieve both.

Although succession planning does have positive gains for higher education institutions that implement it, John Heuer (2003) found internal impediments that prevented universities from fully implementing succession plans. The planning that is required for succession management is difficult to implement in any university culture that may resist change. 
Succession planning may be an alien concept to higher level administrators who may not believe that training or development will help (Heuer, 2003). A final impediment is the frequent myth that it is necessary to conduct national or even international searches to find experts while ignoring internal candidates who may be qualified (Heuer, 2003, pp. 62-70). Heuer continues by suggesting strategies to overcome these impediments: involve senior leadership, eliminate blockages in promotions, begin career coaching, give employees opportunities for development, and understand the organization's demographics and how the institution's labor supply is changing.

Whereas impediments can be detrimental to implementing succession planning, Heuer's findings were similar to mine. Cautioning that one succession planning model will not fit every university (or university research institute here), he posits that successful succession planning processes may include: "a talent planning initiative identifying the best people, developmental needs, career aspirations and the types of jobs for the future"; identifying the individuals in the university "who are believed to be the future leaders and a discussion to try to determine what the gaps are in their knowledge and skills"; support and funding from top leadership including direct supervisors; and cross-university sector mentoring, training and networks (Heuer, 2003, p. 73-74).

Further research on organizational cultural and learning in the context of higher education can help illuminate how the succession planning characteristics identified here might apply to research institutes. Additional questions that might be addressed include:

- Whose responsibility is it to assess leadership skills and needs and to seek development opportunities - the employee or the employer? 
- How is a balance struck between the institution's needs and those of the employees?

- What will succession plans include in five to ten years from now when a new generation of workers is ready for leadership development?

- For-profit institutions are beginning to move away from a traditional succession planning process focused on replacement planning to a process that guides and develops all of their employees; is it appropriate for universities to follow their lead?

According to scholars, the demographics of the workforce are changing (Pynes, 2004a). Discussions about the changing workforce and the ever-evolving careers of newer generations may become important. Not only must universities start planning for their futures, especially with the flood of retirements that began in 2008, administrators need to begin discussing their future needs within the context of what the future labor supply will look like. Universities cannot use today's standards, norms and habits to plan for the future; administrators must learn from today but be willing and open to developing plans that can be flexible and adapt to tomorrow's generation's needs, standards, norms and habits. 


\section{Chapter 5: Development and Review of the Proposed Succession Planning Model}

There is no success without a successor.

- Peter Drucker (Maxwell, 1995)

As the survey results suggest, university and research institute administrators are aware of the benefits of succession planning for their university-wide research institutes; yet, many do not fully understand or may even fear succession planning. To help reduce this fear, I developed a proposed model to guide administrators through the process of developing a succession plan that is appropriate for their institutes (see Appendix J). I then interviewed executive directors of institutes to see if they found the model helpful and relevant to their work. This chapter examines the model, the findings from and limitations of the interviews, and the overall findings of this phase of my research.

\section{Model Description}

This model focuses on directing decision makers through the development of a plan, not on specific elements of the plan itself. Although some recommendations appear toward the end of the model, an actual succession program would be based on the decisions of those involved and the context of the institute and its university.

The model was based on a synthesis of scholarly literatures related to succession planning and on the results of surveys of executive directors of university-wide research institutes as well as university-level administrators at universities with very high research activity, as described earlier. Although how a particular institute's stakeholders define the elements may change depending on the nature of their specific institute, the model is designed to help decision makers better understand these elements and to define them based on their own needs and on the context in which the institute finds itself, all while using the literature and 
survey results as benchmarks. The model uses context variables such as an institute's mission, size, budget, decision processes, typical methods of policy implementation, and relationship with its home university.

Figure 7 shows a conceptual view of the model. The succession planning model proposed here is an organic one that has the institute's strategic plan at its core and is surrounded by the context in which it is developed. The model is circular, or spiraling over time, because the process of succession is not a single event but a program that continues and evolves over time through repetition of steps. The purpose of the model is to help decision makers think strategically about the employee needs of their institute. It is a tool to prompt intentional strategic thinking regarding their human resource needs now and in the future. 


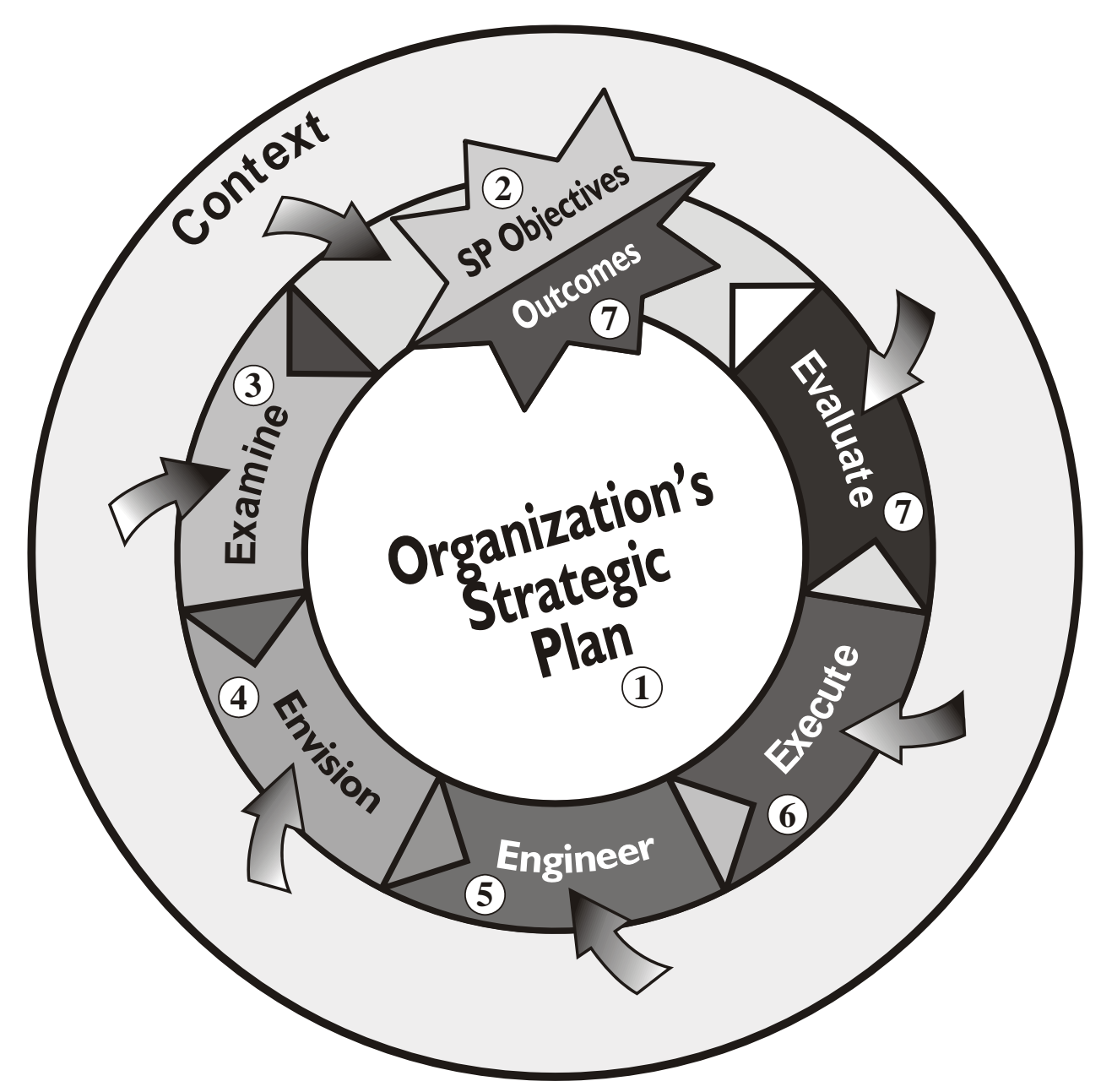

Figure 7. Conceptual model for succession planning in university-wide research institutes.

\section{Navigating the model}

There are seven steps in the succession planning process. The first five steps make up the planning phase and should take approximately six to nine months to complete, according to the literature. Step 6 is the implementation phase of the program, which should take approximately one to two years to fully put into practice based on programs in other sectors. The final step, evaluation, is an annual activity that begins one year after the program is first implemented. The goal of step 7 is to analyze whether or not the program meets its stated objectives developed in step 2. 
The planning phase begins in the core of the circle. In step 1, Strategic Plan, institute leaders decide who will make up their succession planning development team. They also review their institute's strategic plan, which will guide them in writing objectives in step 2. In the second step, Succession Planning Objectives, the development team writes specific objectives for the succession program. In step 3, Examine, decision makers ask how far their institute is from its stated objectives. They then review current employee strengths and competencies that may enhance their objectives and develop a list of strengths that need further development. The final step in the planning phase, Envision, is a time for decision makers to decide how best to bridge the gap between current strengths and future needs.

The implementation phase includes the final two steps of the model. Decisions makers and program coordinators start the program that they have designed - Execute - and analyze it annually to see if the outcomes match the stated objectives developed at the beginning of the planning process - Evaluate/Outcomes.

The arrows coming into the model are inputs related to each phase - available resources, skills and talents of current employees, goals and vision for the future of the organization, future organizational and employee needs. These arrows come from the context in which the institute is situated and vary depending on the university it is affiliated with, the influences of that university's policies and politics, and the connection to the institute's broader field of research.

\section{Interview Findings}

My main research question asked about the processes of succession planning that are relevant in a model of succession planning for university-wide research institutes in four-year, public doctoral universities with very high research activity. Among the secondary questions were whether and why leaders in university-wide research institutes found this model relevant to 
the strategic planning of research institutes within their organization. Also of concern was how this model might be best implemented in university-wide research institutes.

To answer these questions, I asked ten executive directors who responded to the surveys and volunteered to participate in follow-up interviews to validate the model for relevance to their institutes. Forty-two directors from hard science institutes and 16 directors from social science institutes agreed to follow-up interviews. Using a similar ratio of hard science to social science institutes, I randomly selected six directors from hard science institutes and four from social science institutes to contact for interviews. If the respondent did not respond to my interview inquiry, declined to participate, or was out of the office for an extended period of time, I selected the next director on my list to contact. Of the hard science institutes, three never responded to my inquiry, and one declined because she had retired as director of her institute. Of the social science institutes, one never replied, two replied that they did not have time, one replied no and gave no reason, and one was out of the office for an extended period of time.

Interview questions can be found in Appendix H. The questions were semi-structured, allowing for additional questions to be asked depending on the nature of the answers to the initial questions. The interviews were not recorded.

The actual model (in Appendix J) was set up in booklet format with questions to help guide a development team through the process of making decisions based on benchmarks found in scholarly literature as well as survey results from similar institutes. If the institutes' administrators were to complete the booklet in its entirety it would take six to nine months; instead, I asked each executive director to read and review the model to help me determine whether the right questions were being asked. Each of the executive directors received a printed copy of the model and then participated in a 30-minute telephone interview with me. 
I grouped the interview notes into themes, with some overlapping responses among respondents. Table 41 details which directors mentioned which themes.

\section{Demographics}

I interviewed directors at 10 university-wide institutes, six institutes categorized as being involved in hard science research and four institutes in social science research. All of the interviewees were men. Nine of the directors were their institute's executive director and one was a project director. Two of the executive directors were their institutes' founding directors.

\section{Question 1: Relevance of Succession Planning}

The first interview question referred back to the directors' answers to a survey question regarding whether they thought succession planning was relevant to the strategic planning of their institutes. A majority of the directors interviewed thought succession planning was directly relevant to strategic planning (see Table 42).

When respondents were asked to elaborate, two themes emerged most frequently, with five directors mentioning each. Those who mentioned aspects of these first two themes responded in the survey that succession planning was relevant to strategic planning, rating it a 3 , 4 , or 5 out of 5 .

The first theme looks at the funding of their institutes. One director succinctly summed up this theme: "[Succession planning is] relevant but in a crazy environment of funding." The directors described constantly changing funding sources and other resources and the need to be "nimble" to follow where the funding and the evolving research needs in their fields take them. Four of the five directors were from hard science institutes, and one was from a social science institute. 
In the second theme, directors discussed how succession planning is helpful in combating the effects of retirements and sudden employee turnovers. Three directors acknowledged that they are older, around 70 years old, and have been looking at retirement. Two other directors told me that "a lot of head hunting is going on for top people," and there "can be a great deal of turnover and immediate change." As such, they think succession planning can help an institute prepare for turnover. Again, four of the five directors were from hard science institutes and one from a social science institute.

A third theme, also mentioned by directors who gave succession planning a 3 or 5 in relevance to strategic planning, focused on the formality of succession planning programs. Four directors reported that succession planning occurs informally. One of those directors said their planning is an "ad hoc process," while two others reported that it is part of their everyday planning: "it's not a big deal, it's just something you have to keep in mind on a regular basis." All four directors were from hard science institutes.

Other themes emerged but with less frequency. One was whether to focus on the organization or the individual: one director focused on the organization, one on his employees, and a third on both. Three directors believed that succession planning had some challenges but it was relevant to strategic planning. "It's always relevant - there are some issues but it's relevant." Two directors liked the idea of succession planning but they did not think it would work because they have no authority to hire their replacements. Two directors observed that succession planning is less relevant because what drives the organization is its people, technology, and the strategic plan; "succession planning is part of what we do but not what drives [the institute]." Finally, one director noted that succession planning is not a priority, and another director told me that it was "not totally clear to me there is a long term benefit." 
As many of the themes suggest, the directors thought that succession planning was relevant to strategic planning in their institutes but expressed difficulties related to its application, including funding, retirements and turnovers, and the informal nature of their planning.

\section{Question 2: Reaction to the Proposed Model}

Similarly to the first question, two themes emerged with five directors mentioning them; four directors noted two more, and several other themes received mentions from three or fewer directors (see Table 41). The first theme focused on the clarity of the model; three social science and two hard science directors discussed this. Three directors thought the model was very clear, one to the point that "it seemed like a lot of common sense." Although the model was clear, one of those directors was confused by some of the wording related to types of development opportunities. Two other directors wondered about the model's practical application. Five directors mentioned constraints and lack of resources related to implementing the model, changing funding models, or hiring individuals. Generally, these directors liked the proposed model but wanted it to better address these constraints: "funding so constrains how to do succession planning. You have the budget as a variable; to me it is the variable right now."

Four directors mentioned that the strategic plan and mission of the organization were most important and that the model needed to further highlight them. The model should address the "execution of the mission," allow for "changes in direction," and "draw in someone with an understanding of that mission."

Another theme noted by four directors related to the context or external environment in which the institute was located. A social science director in this theme thought the model was "very systematic" and took the university context into account. The other three directors 
believed the model was "not broad enough," and that it should look at critical positions within the constraints of the budget, highlight external partnerships as well as the percentage of internal and external hires, and yet emphasize national searches.

When discussing the connection to the university, a social science director thought it was important to include senior administrators of the university but the two hard science directors who mentioned the university connection were more negative. One said he has "no involvement of university administration or HR," while the other described a tenure system that currently does not apply to institute employees but noted that he is working informally to change that system.

Other initial reactions that emerged included focusing the model on critical positions, making it less structured and emphasizing in the summary that many institutes already may be doing some of these activities, which would help to alleviate some concern over the scope of the model. One social science director liked that the model focused on both the employees and the institute. Another social science director thought the model was flexible enough to use in a variety of institutes, while a hard science director suggested looking at the metrics of success that institutes must follow, such as funding and number of students, and incorporating those into the succession plan. Yet another hard science director thought that the examination and evaluation sections were important: "Part of the way forward to the future is to look at optimizing by merging with other institutes... We need to look at not just surviving in this turf but evolving, not just holding our ground. Too often institutes become resilient to change."

\section{Question 3: Relevance of Model to Institute}

Eight out of the ten interviewees (four social science and four hard science directors) agreed that the model was relevant to their institutes. Six of those, however, couched their 
answer with changes that they would make to the model. Such changes included emphasizing the broader research community, describing how to navigate limited resources, and allowing institutes to be flexible in response to research needs in their fields. One of the eight directors said it was relevant but not a priority at the moment. (See Table 41.) Only two directors, both hard scientists, stated that the model was not relevant to their institutes. Both directors said that succession planning is "so ingrained in what [they] do" and that a structured model like mine is not needed because "it's something [they] incorporate into [their] everyday work." They reported that they do succession planning but it is not a formal program or process; it is something they think about constantly.

\section{Question 4: Strengths of the Model}

Two strengths rose to the top with this question - the model's structure is logical and coherent, and it forces institute directors to think about succession planning. Five directors mentioned the first strength. In particular, they liked that the model had a structure: there is "something about having printed questions rather than a faculty group saying 'let's do a search'." Four directors mentioned the second strength. One of them said that he himself would not use the model, but that "it's good for up and coming leaders to learn and to get them thinking about succession planning." (See Table 41 for more details on which directors mentioned which theme.)

Other strengths that were mentioned included long term development of employees, the fact that the model is being developed with institute directors, its relationship to strategic plans, its focus on all employees and not just the executive director, and its emphasis on evaluation. 


\section{Question 5: Suggested Changes to the Model}

The suggested changes to the model varied more. Only one or two directors mentioned most themes, with one theme appearing in three directors' remarks. Three hard science directors suggested that the model should concentrate on the constraints of the resources that they have and that "a strategic plan [and succession plan] could come after resources." These directors discussed resources related to continuing the institute in general, conducting a succession plan, and considering how quickly someone should be hired after someone leaves.

Two directors, one from a social science and one from a hard science institute, wanted the model to require people in an institute to conduct a strategic plan before beginning the succession plan. Similar to earlier remarks, two directors wanted the model to better emphasize the institute's context because the "institute is in a changing environment." Two other directors thought the model was too long. One suggested cutting out extraneous language and the references to scholarship to reduce the length. The other suggested having both short and long versions and emphasizing in the summary at the beginning that institutes already may be involved in some of the activities. Other ideas included highlighting HR policies more, incorporating sponsors or funders in the decision making group, and focusing on critical positions that are necessary for the institute's success, not just "key" positions.

\section{Question 6: Knowing succession planning was successful}

This question asked the interviewees what they thought the metrics would be by which they would evaluate a succession program once it was put in place. All ten said that the metrics would be more long-term (e.g., five to ten years), and three suggested some short-term ones as well (one to three years). When asking this question, I used the term "metric"; however, the interviewees answered with more general methods of evaluating success rather than suggesting 
exact measures. Success was not defined in the interviews; therefore, each participant likely had a different opinion of what success meant to them.

Answers that focused more on long-term success included that the research institute:

- Remain open,

- Retain employees,

- Receive positive feedback from employees,

- Maintain current funding levels, or even leverage it for additional funding,

- Maintain current number of publications,

- Meet its mission,

- Receive positive feedback from institute clients,

- Develop internal candidates who are competitive for open positions, and

- Actually implement the succession plan.

Shorter term success "would be difficult to know," but respondents said they would examine whether the numbers of grants and publications remained steady, the leadership at the university "goes through the steps [of the succession model] with all stakeholders as a management exercise," and there is "no down time in productivity" when positions are filled.

\section{Question 7: Additional Comments}

As expected, the open comment question produced very different responses; however, multiple directors mentioned several of the same things. Three directors, all hard scientists, said that the succession planning process had to be "current, alive, and vibrant." To them, this evidently meant that it has to be continuously updated, responsive to changes in the context, and flexible. 
One hard scientist and two social scientists remarked that the process as captured in the model is helpful but that it may be too thorough: "almost more thorough than people have time to think about. It's so thorough it may be intimidating, given how busy everyone is." One director suggested developing a shorter version "to make it not so daunting."

Two directors differed over the model's emphasis on the development needs of the organization versus those of individual employees. One, a social science director, believed that "people are more important than the organization." The other, a hard science director, said that "you have to put personal feelings aside and make good business decisions."

Two directors, one from each type of institute, noted that they liked the model overall and would like to share it with their executive team members. The respondents suggested several questions as additions or changes to the proposed model:

- How do you prepare a future leader to deal with HR issues?

- What percentage of hires should be internal versus external? Both directors who mentioned this only hire externally to their institute.

- How do you find administrators when researchers do not want to be trained to be administrators?

- How do you deal with the "founder's syndrome" related to the first director not wanting to hand over the reins?

- What do you do when others do not find it important, especially the university administrator to whom the director reports?

- How can you develop employees to be future leaders when the institute director him- or herself does not believe in developing his or her employees? 
- How do you deal with different classifications of faculty (e.g., tenured research faculty versus administrative/professional faculty)?

\section{Limitations}

There may be some limitations to the generalizability of these findings. First, I interviewed only 10 people; this low number of participants may not reflect the entire population. Second, I secured participants through what might be considered a form of convenience sampling, those who responded "yes" in the survey to be contacted for a follow-up interview. The bias here could be that those who said yes to a follow-up interview may be participants who are more interested in succession planning to begin with and may find the model relevant to their work more so than those who do not agree to a follow-up interview. Third, some respondents may have been hesitant to criticize or give negative feedback about the model to its author. Finally, I did not record the interviews, and the notes may be biased because of my own filter when writing them.

I tried to limit these biases by randomly selecting participants who replied "yes" to further contact in the survey. I also kept the ratio of directors interviewed from social science institutes to those from hard science institutes similar to those who agreed to be interviewed (40:60, social science to hard science responses). Although I did use a convenience sample, this sample of participants was a portion of the entire population of directors of university-wide research institutes who all had equal opportunity to participate in the survey. To reduce biases in my own note-taking, I tried to write as many direct quotes from the directors as possible. I also repeated my notes to directors when I missed a phrase or misunderstood the interviewees' comments, to make sure that I actually captured what each participant was trying to convey. 
Additionally, I typed up my notes immediately after each interview to produce a more accurate record.

\section{Summary}

Although the directors suggested changes and additions, overall they found the model relevant to their work and institutes. (See Table 43 below.) On the whole, there seemed to be no major differences in the comments between the directors from hard science institutes and those from social science institutes.

\section{Table 43: Summary of Interview Findings}

\begin{tabular}{|c|c|}
\hline $\begin{array}{l}\text { Relevance of Succession } \\
\text { Planning, in general }\end{array}$ & $\begin{array}{l}\text { All ten agreed that succession planning is important for various } \\
\text { reasons. One relied on informal succession planning and would } \\
\text { not use a formal model. Another said the institute priorities } \\
\text { prevent him from focusing on succession planning at this time. } \\
\text { Two others said they have no authority to hire replacements. }\end{array}$ \\
\hline Reaction to Model & $\begin{array}{l}\text { Model is clear } \\
\text { Constraints and lack of resources to implement model needs to } \\
\quad \text { be addressed } \\
\text { Model should further highlight institute's mission } \\
\text { Model should further highlight external partnerships and the } \\
\text { internal/external hire percentage }\end{array}$ \\
\hline Relevance of Model & $\begin{array}{l}\text { Eight out of ten agreed the model is relevant to their institute. } \\
\text { Four of them agreed the model is relevant but they would } \\
\text { make some changes first. } \\
\text { Two of the ten reported not needing a formal model because } \\
\text { they do succession planning informally. }\end{array}$ \\
\hline Strengths of Model & $\begin{array}{l}\text { Logical and coherent } \\
\text { Forces directors to think about it }\end{array}$ \\
\hline $\begin{array}{l}\text { Suggested Changes to } \\
\text { Model }\end{array}$ & Focus on constraints of resources \\
\hline $\begin{array}{l}\text { Know that succession } \\
\text { program was successful }\end{array}$ & $\begin{array}{l}\text { Long term measures (remain open, retain employees, meet its } \\
\text { mission, receive positive feedback, maintain funding) } \\
\text { Short term measures (maintain grants, implement succession } \\
\text { model, no down time in productivity) }\end{array}$ \\
\hline Other Comments & $\begin{array}{l}\text { Succession program should be continuously updated, responsive } \\
\text { to changes, and flexible. } \\
\text { Model is too thorough, almost intimidating. }\end{array}$ \\
\hline
\end{tabular}


To better highlight any particular patterns in the interview comments, I decided to compare data based on size of the institute, size of the institute's budget, and age of the institute. When I controlled for size, tapped by the number of faculty and staff employed at the institutes, several patterns emerged in questions two, three, and four. Question two asked respondents about their initial reaction to the model. Directors from smaller institutes tended to say that the model was clear, while directors from larger institutes reported confusion over certain parts of the model or that it seemed more like common sense. Those from larger institutes also emphasized the mission or strategic plan of their institutes and noted that institutes may already be doing certain types of succession activities, even if they do not call it succession planning.

Question three asked interviewees if the model was relevant to their institute; directors from smaller institutes tended to agree that it was, while directors from larger institutes said it was relevant but would face challenges or that it was not relevant at all. Question four asked interviewees about the model's strengths. Respondents from larger organizations reported that the model's ability to force directors to think about succession planning and its focus on longterm development needs were strengths of the model. Respondents from smaller organizations responded more than those from larger institutes that one of the strengths was the development of the model in collaboration with others. These patterns seem to match the survey results; respondents from larger organizations may oversee more complex operations that may make a general model less relevant to their organization.

When controlling for budget, I found similar patterns in the directors' comments. Directors with larger budgets underscored their reliance on funding, the constraints on resources, the institutes' mission, and current activities which may be considered succession planning. They also highlighted the institutes' reliance on its people and technology, confirming that one 
of the model's strengths was its long-term focus. There seemed to be one contradiction when controlling for budget - on the one hand directors from institutes with larger budgets like that the model looks at the long-term and is attentive to more than one person; one the other hand directors from institutes with larger budgets do not think that the model is relevant to their institute. This contradiction seems strange but it could be that these directors' are already doing some forms of succession planning and, therefore, they do not think that a formal plan is needed.

When I looked at the age of the institute, it seemed that directors of older institutes found the model clear, agreed that it was relevant to their institutes, and discussed short-term metrics of success. These directors also said that the model was too long and that they had no authority to hire people for their positions. Directors from newer institutes focused more on their people, technology, and strategic planning as drivers of the organization.

Some of these patterns match the survey data, and some do not. The survey hypotheses posited that directors from older and larger institutes (in both size and budget) would find succession planning important to their organizations. The comments from directors from older institutes followed this pattern, while the comments from those from larger institutes did not. It could be that these directors are so engrossed in continuing to find funding for their institutes that they do not think about other aspects of keeping their institutes alive and thriving.

Generally, however, the respondents indicated that the model would be very helpful. This confirms that the model's processes, which were chosen from across all three sectors and from the survey results, appear relevant to university-wide research institutes. Several of the directors wanted particular characteristics, such as HR issues and funding constraints, to be highlighted more but as a rule they deemed all of the characteristics to be applicable. A majority of the directors also reported that the model was relevant to their own institute. 
When attention turns to implementation, the responses suggest that the structure of the model is good, but it may be somewhat overwhelming for people who already are quite busy in their research and proposal writing. As such, future editions of the model may include a more detailed explanation in the beginning summary, especially pointing out that some institutes may be already being doing some of the activities, as well as a shorter version of the model. Because these suggestions for changes were more related to the presentation and structure rather than to substantive content, I decided that an additional version of the model was not needed at this time for this research.

Confirming a positive result for my main research question, I turn now to the final chapter in which I discuss implications of these findings and recommendations for future research. 


\section{Chapter 6: Concluding Remarks}

One thing at a time, all things in succession. That which grows fast

withers as rapidly; and that which grows slow endures.

- J. G. Holland (1862)

For myriad reasons that Chapter One discussed, I recommend that university-wide research institutes prepare for their futures by strategically planning for their current and future employee needs through the development and implementation of succession programs. Work environments are changing, requiring organizations to constantly update and renew their processes. Public organizations, including university-wide research institutes, must prepare for major advances in technology, increases in global initiatives and partnerships, shifts in employee demographics and values, and imminent retirements of faculty and staff who are the current leaders of these organizations. If university research institutes do not prepare for these changes, they may not stay relevant in today's educational and research spheres and may be shuttered.

Some universities have sunset policies for individual institutes because they want to ensure that each institute is purposeful in its mission and current in its research. Top research is important to universities, however; it helps the institution stay attractive to current and future faculty and students. Introducing organizational change to current institutes to match contemporary research needs may be more cost effective and successful than developing wholly new institutes because already established institutes have a track record of research as well as familiarity with university culture and governance methods.

Research institutes typically are funded through external sponsored research, which helps universities acquire and retain comparative advantage with their peers. Despite the "great recession" of 2008, research funding has increased, and this trend is predicted to continue. 
Administrators who want to keep or increase their university's prestige should be mindful of these trends and position their universities to continually compete for research dollars. Preparing universities to meet these challenges involves planning both the type of research that institutes will conduct as well as who will lead and eventually sustain that research. Succession planning is the process by which universities focus on the employees in their organizations to better meet research challenges: "all successful enterprises are engaged in some sort of talent management, whether they do it openly or in secret" (González, 2010, p. 2). As some of the interview comments indicated, succession planning can be an informal process or a more formal one. A more formal process, such as the model that this research proposed, may be more intentional in its strategic planning for the organization and its people. I worry that a more informal process may get pushed to the side when the executive director or other senior level administrators become too busy with other work to think strategically about their employee needs.

PriceWaterhouseCoopers (2006) describes well what could happen if the U.S. federal government does not implement formal succession programs in government agencies:

Without strong leaders, there are no strong nations. Although this has been true since time immemorial, never in recent history has the need for outstanding government leaders been more accurate than it is today. In the midst of global political uncertainty and threats to national security, the US government urgently needs leaders who think creatively, strategize effectively and respond with speed and competence to high-pressure situations. But if its current talent development practices do not change quickly, the government will soon boast few such leaders. Federal agencies' succession planning, which relies on traditional training methods, is barely adequate to do the job. The gap between those in senior 
executive positions and those prepared to move into them is widening by the day. And just at the federal government is beginning to recognize the problem, it is running into new demographic and workforce challenges that make the leadership crisis all the more challenging. (p. 1)

This description also could apply to public universities and their university-wide research institutes: the United States is beginning to lag behind other countries in granting higher education degrees, especially graduate degrees, and in developing innovative and groundbreaking research (Duderstadt, 2009; Plume, 2011; Wildavsky, 2010). U.S. higher education, including institutions in both the private and public sectors, arguably needs to reposition itself as a leader in global research; one way to do this is to focus on its research leaders.

Public agencies need leaders and other employees with the appropriate skill sets to continually improve their organizations. Unfortunately, some scholars, like Henry Mintzberg (1994), have found that the strategic planning process can get bogged down in the formal process itself. He argues that a strategic planning process, or a strategic planner, should "use provocation or shock tactics like raising difficult questions and challenging conventional assumptions," all while remaining broad and general "to adapt to changing environments" (Mintzberg, 1994, pp. 112-114). The proposed model in this research does just that - it leads decision makers through a series of questions to prompt discussion and strategic thinking but remains flexible enough to adapt to multiple situations. The model also guides institute leaders through an evaluation phase to see if the planning is accomplishing what it set out to do, rather than sitting on a shelf gathering dust and not prompting institutional adaptation that is needed to continually stay relevant. 
This chapter returns to the "so what?" question - why, and for whom, are these findings important? It begins by recapturing the opening discussion about the study's significance and continues by reviewing the research questions and hypotheses and summarizing the main findings. I then look to the future by discussing implications of the research, recommendations from the findings, and suggestions for future research.

\section{Summary of the Study}

Previous chapters reviewed reasons for succession planning in university-wide research institutes and analyzed findings from a qualitative synthesis of scholarly literatures, two surveys conducted with research institute directors and university-level administrators, and follow-up interviews with the institute directors.

\section{Reviewing Research Questions}

This dissertation research had one primary question and three secondary ones. The primary question asked about the relevance of a model of succession planning to leaders of university-wide research institutes in four-year, public doctoral universities with very high research activity. To develop this model (and answer the first secondary question), I began with a qualitative synthesis of scholarship on succession planning in the public, private, and nonprofit sectors.

Seven characteristics of succession planning were mentioned most frequently:

- Upper management needs to be involved and supportive of the succession program.

- Employees with high potential should be identified and involved in the succession program.

- The succession program should be linked to the organization's strategic plan. 
- The succession program should be tailored specifically to the individual organization, its employees, and their needs.

- The definition of succession planning should be holistic in nature, encompassing all aspects of talent management such as replacement planning, employee development, and organizational talent needs.

- Four reasons for designing a program include the forthcoming retirements of the baby boomer generation, key leadership transitions, changing work environments, and a changing workforce.

- The basic time-line for the succession program is six to nine months to prepare the plan with one to two years to fully implement it.

I then explored the relevance of these processes to university research institutes following a two-step process. First, I administered an on-line survey to research institute directors and one university administrator at each of 78 U.S. doctoral universities, classified by the Carnegie Foundation as having very high research activity.

The second secondary question inquired about the processes of succession planning engaged in by leaders of complex public organizations generally and university-wide research institutes specifically. Two-thirds of the respondents to the on-line survey reported not being involved in succession planning activities at all. This number is not shocking; the majority of public organizations also seem not to engage in succession planning. The 2009 International Public Management Association for Human Resources (IPMA-HR) Benchmarking Committee Survey on Workforce found that fewer than 80 out of 310 public organizations reporting had formal plans (IMPA-HR \& CPS Human Resource Services, 2009). These authors also infer that 
many of the rest of the 8,000 members did not complete the survey because they do not have formal succession plans (IMPA-HR \& CPS Human Resource Services, 2009).

The $34 \%$ of research institutes in my surveys that reported involvement in succession planning engaged in mentoring, job enrichment, and stretch assignments. Most of this latter group reported that these activities are informal and not related to a formal written succession plan.

The third secondary question focused on how the model might best be implemented in university-wide research institutes. Many of the respondents' answers were consistent with extant scholarship:

- The succession plan should be related to the institute's strategic plan.

- It should be located at the senior executive level of the institute in partnership with the senior executives of the university.

- It should recognize actual constraints, such as available funding and public agency hiring policies, and it needs to remain flexible to changes in the future.

- The succession plan's focus should be on the individual needs of the specific institute for which it is being designed.

- The institute's executive director should be involved in the decision making related to the design of the program.

- Senior leaders, such as the executive director, managers, staff and residential faculty, should participate in the program once the succession plan is implemented.

- The actual program should be coordinated at the senior executive level of the institute. 
- Senior institute executives should have multiple development experiences over multiple years, while other employees should receive multiple experiences over one year or only one experience.

Based on the survey responses, I developed a model for succession planning and asked ten of the executive directors surveyed to review the model for relevance to their institutes. Eight of the 10 executive directors agreed that the model was relevant; two of these indicated they would use the model as is, while six offered suggestions for changes and additional questions. Several expressed surprise at how relevant the succession planning model was to their institute.

Generally, the institutes' executive directors reported that the proposed succession planning model was relevant and necessary for their institutes. In some ways, the survey answers seem to contradict one another. On the one hand, respondents reported that the reasons for succession planning are to plan for transitions of key leaders, to plan for recruitment of employees, and to develop a pool of better prepared employees and future leaders. On the other hand, they want only senior level administrators to participate in succession programs and not those who would transition into leadership roles. They also warned that a succession program would not work because they are constrained by policies related to hiring practices, which require open, nation-wide searches for the director's position. Directors reported that they worry about funding and acceptances of grant proposals to keep the doors open before they focus on employee development needs.

These comments and others show that directors may be overly focused on:

- Replacement planning for the director's position and not preparing the entire institute for the future; 
- Individual skills they currently have, with less attention to skills that they can help their employees develop for the future;

- Budgeting, funding cuts, and sustainability, which limits their ability to envision future organizational and employee needs and growth potential.

Having confirmed that succession planning is relevant to universities and their universitywide research institutes, I return to the "so what?" question. What really do these data mean, and why does it matter?

\section{So What? Implications, Recommendations, and Future Research Implications for Research Institutes and Public Universities}

As universities look to the future, many administrators are focused on increasing the prominence of their institutions' funded research and their standing compared to other universities with very high research activity. Increasing prestige may involve greater amounts of research funding, which also may mean an increase or growth of research institutes. Administrators may look as well at enhancing the institutes they currently have rather than creating new ones.

While administrators may say they are planning for the future, it seems my data confirm White and Eckel's (2008) argument that, when resources are tight, priorities and planning become very short-sighted. Funding concerns are a real anxiety for university administrators; however, if longer term issues, such as employee development and strategic planning, are ignored on a regular basis, the concern over funding eventually will become a moot point.

When administrators do plan for employee development it usually is focused only on the top employees. Consequently, the institute may not "grow" as well as it could because lower level employees are not being developed and given skills that the institute will need to be better 
prepared for the future. Mihn (2003) recommends emphasizing multiple levels in the organization: "effective succession planning and management initiatives identify highperforming employees from multiple levels in the organization and still early in their careers" (p. 4).

Other concerns of participants in this study related to priorities and lack of experience with succession planning. Yet, many did not think consulting with a succession planning expert would be helpful. There may be a lack of appreciation of the role of human resources or other succession planning expertise in university settings, which may lead many institute directors to fail to promote or participate in succession planning. "Succession planning and management can help an organization become what it needs to be, rather than simply to recreate the existing organization" (Mihn, 2003, \1). Realizing the need, directors may engage in succession planning on their own but the programs may not be as successful as they otherwise could be. If it is not conducted, most organizations will continue a long a trajectory of not planning for the future. Consequently, employees may leave because there are fewer developmental or promotional opportunities. Eventually, the institutes may not have the talent or skills they need for future activities and research, and the institutes' relevance and competiveness may become hampered.

As previously argued, work environments, priorities, and workforce demographics are all changing. In turn, universities and research institutes must make efforts to develop and change to remain a viable player in the creation of knowledge. If not, they may begin to lose the necessary skills to conduct good research, lacking the ability to carry out the universities' and institutes' missions. In extreme cases, accountability issues may arise as there are no persons 
remaining in the institute who can complete grants and projects to which the institute was already committed.

Unfortunately, my research also shows that many institutions may not be capable of making necessary changes, much as Frank T. Rhodes (2001) has observed. The attention of the administrators in this research seemed to be on the constraints they see in planning for the future, such as funding and hiring practices. For the funding constraints, although predictions from the BLS show a need for more researchers, there are rumors that the National Science Foundation (NSF) and other federal agencies that award major research grants may have their funding slashed in the near future, which may have dire consequences for research institutes that rely on such funding (Hand, 2011). It is understandable that the executive directors and other administrators may fear for the sustainability of their institutes, which rely on this money. As seen in their survey answers, many of the respondents do not acknowledge that succession planning can help them plan through tough economic times. A succession plan should be directly related to the institute's strategic planning process; succession planning is the strategic process used to make intentional decisions related to the institute's current and future employee needs. If the institute needs to alter its mission or research focus due to funding priorities, its succession plan should follow suit, helping administrators think about the future of their staffs and the employee needs at the institute. Succession planning can be used to work through budget cuts by reorganizing job responsibilities, making sure the right employees, both faculty and staff, are in appropriate positions, and even letting employees go when cuts are needed. The other major constraint that many respondents focused on was their universities' hiring practices. Some directors reported that they have no authority to plan for who will lead their institutes. Some worry that the tenured/non-tenured faculty hierarchy or the faculty/staff 
dichotomy would hinder some of the planning that is needed. I wonder if there is a need for new models of governance of university administration, including research institutes, which would break down these hierarchical boundaries. New governance models could include flattening the hierarchy by reducing levels, reorganizing or eliminating departments, or aligning the institutes, departments and administrators in different ways. In large research universities, these new governance models may be hard to implement because of entrenched values, cultures, and structures found in and outside of the university. On the contrary, W. Richard Scott (2001) argues that institutions can and do change through processes of destructuration as people within institutions mold and amend processes to ameliorate internal and external tensions.

Worrying about the future, thinking about how to sustain the university's prestige, and making strategic decisions to better the institution's future can be significant forms of tension that may provoke needed change. Frank T. Rhodes's (2001) research shows that universities have drastically changed their missions since the early $11^{\text {th }}$ century but their organizational, management and governance structures have stagnated. In the $21^{\text {st }}$ century, it may be time for a drastic change to these structures to better match and solve today's issues.

\section{Implications for Public Administration}

As Chapter One mentioned, public universities are linked organizationally, financially, and theoretically to the field of public administration. Research institutes have become an important node in a very complex system of research in the U.S. Some might argue that, beyond the national laboratories, university research has become the most important aspect of basic and applied research in the country:

Universities performed 56 percent of the nation's basic research in 2008, or about $\$ 39$ billion of the national total of $\$ 69$ billion. For applied research, universities 
performed 12 percent of the nation's total in 2008 , or about $\$ 11$ billion of the national total of $\$ 89$ billion. (Association of American Universities, 2011)

Reviewing the network in which research institutes sit, I see a real dilemma here:

research institutes seem to be an important node in an interconnected web; yet there are no plans or even mention, of how and why these organizations will continue into the future beyond the current research faculty. Policymakers push for measures of accountability and effectiveness, but they frequently appear to forget one of the most important assets in the organization - the human capital, the researchers who produce the work that is funded so heavily year after year.

Data show that research institutes within public universities are increasing in number as well as research activity; if this trend continues such institutes will need greater numbers of employees to meet demand (Hedblad, 2003; NSF, 2009a; NSF, 2009b; NIH, 2009). In addition, many organizations, including universities and research institutes, will lose their top executives in the next five to ten years due to the retirements and career changes of individuals in the baby boomer generation (BLS, 2007; Toossi, 2007). Following suit, it is necessary to think about leadership transitions and the associated planning and organizational development that are essential in preparation for those transitions (Teegarden, 2004).

Succession planning is important for universities and research institutes because it helps them to prepare for the future by giving them a process through which to think strategically about their future labor needs, thereby sustaining the services that they offer without becoming hollowed out organizations. It also helps them to "anticipate the need for leaders and other key employees with the necessary competencies to successfully meet the complex challenges of the 21st century" (Mihn, 2003, p. 8). 
If research in universities generally, and in research institutes specifically, were allowed to diminish due to a lack of skills and abilities of their employees, there would be major consequences at the state, federal and even global levels. At the state level, if many public universities lose prestige they would have a difficult time attracting and retaining top notch faculty and students. Reductions in out-of-state faculty and students would reduce economies in many fields, such as tourism, restaurant and hospitality, and arts and culture. At the federal level, reductions in the majority of basic research would push the nation on a downward drop in rankings and prestige, leading many international students to seek their education in other countries. Consequently, the United States power as a global partner in addressing world issues would also slip. Although these are extreme examples of the implications of not preparing university research institutes for their future employee needs, they are real illustrations of some of the effects that could happen because of research institutes' place in this interconnected web.

Beyond actual consequences, this research has implications theoretically for public administrators, particularly related to organizational learning and change. To survive and prosper in this varying world, public organizations must learn from their experiences, altering their belief systems, culture, traditions, and behavior. Organizational learning, defined by Hatch, is "organizations once again.... defin[ing] their own change processes, but not in the direct, controlling, and top-down ways... [in] more democratic processes... [relying] on pluralism, diversity and freedom (Hatch, 1997, p. 352). My data show that executive directors want their institutes to stay relevant and viable in the coming years, including implementing succession programs; however, many of them feel constrained by external forces related to funding and public policies. It is important for any organizational learning and change processes to take into account the context that an organization inhabits. Ferris et al.'s (1998) social context theory 
proposes that "the social context [of HR management] encompasses culture, climate, politics, and social interaction processes, as well as concern with both substance and form" (p. 239). Not only must administrators assess critical skills and competencies but they must take into account "attitudes, beliefs, values, and political issues that make up the organizational culture" (Ferris et al., 1998, p. 241).

Context refers to objective realities (e.g., actual policies that public agencies must follow, like the hiring policies many directors refer to) and subjective realities (e.g., perceived notions of a lack of research funding.) Although many of the executive directors found this research's model relevant to their work, they were cautious of both objective and subjective realities. By acknowledging these objective and subjective realities and the complex nature in which our organizations sit, public administrators, including university administrators, can begin to make necessary changes and plans for the future of their organizations. W. Richard Scott (2008) agrees:

It is important that we recognize and publicize the more complex view of institutions as a double-edged sword. By stressing the role of institutions as curbing and constraining choice and action, we ignore the way in which institutions also empower actors and enable actions. Those interested in redressing inequalities or pursuing other types of reforms can find inspiration and support from surveying and making judicious use of the variety of schemas, resources, and mechanisms that are to be found in any complex institutional field. Institutional forces can liberate as well as constrain. They can both enable and disarm the efforts of those seeking change. We must call attention to these possibilities in our scholarship. (p. 220) 
I cannot say it better than Scott - public administrators must be willing to broaden their focus and include the complexities associated with organizations and their ability to learn. As such, further iterations of the model should better incorporate these realities as well as the complex organizational structures and decision-making of the public university. Additionally, the process model should consider whether the university culture is ready for this change; if they are not, how might public universities prepare to make such changes, if needed?

\section{Recommendations}

Not only did this research help me to develop a proposed model for succession planning but it also further emphasized the importance and need for succession programs within universities. Based on this study, my first recommendation is general in nature: all university administrators and research institute leaders should begin the process of developing their own succession programs. Whether they use a model similar to the one advanced here or develop their own, I am convinced of the need for succession programs in higher education. My research was based on the Virginia Tech's Office of the Senior Fellow for Resource Development's recommendation that university-wide research institutes should develop succession planning programs. The findings support this recommendation in several ways:

- Executive directors' comments focus on replacement planning rather than holistic strategic planning, rarely mentioning how their employees could help better the future of the institute.

- Executive directors' comments about bringing in outside expertise limit their capacity to see the skills and abilities of current employees, thereby constraining the overall successfulness of their institute generally. 
- Executive directors' concerns regarding funding issues may lead them to overemphasize budgetary matters and not the development of employees within their institutes, when those same employees may be used to help generate additional funding support.

- While many of the executive directors worry about keeping the doors open, their survey responses show that participants do not perceive succession planning as helpful in planning for reductions in forces. Participating in a succession planning process may help them realize that succession planning is beneficial in reducing and reorganizing their institute as well as sustaining and growing it.

The follow-up interviews gave me several recommendations that will be useful to implement in future editions of the model. Several directors were concerned about the length and comprehensiveness of the model. If the model seems like a burden to undertake, then the leaders of institutes will drag their feet; their negative attitude could become a self-fulfilling prophecy and the program would not be successful. As such, a second recommendation is that a shorter version of the model be developed to help ease decision makers into the process rather than turning them away.

My third recommendation relates to the comprehensiveness of the model. The model includes a two-part process that focuses on the short-term leadership needs of an institute as well as longer term development of employee skills that are not necessarily related to particular positions. Consequently, the model may appear to be too thorough. Future versions should include a more refined argument for why a holistic succession program is important. Such an argument should appear in the executive summary or the beginning section to help institute 
leaders better understand the need for broad thinking in this area. In return, it may reduce apprehension about the length and scope of the model.

Fourth, directors suggested content changes to further highlight the importance and feasibility of the model. Directors face real constraints related to funding and hiring practices in public agencies, and they wanted the model to better address these issues and how they might overcome them before they embark on developing their employees. The model includes most of these content suggestions but they could be further emphasized in the executive summary or model sections, helping decision makers understand how succession planning fits within these very real constraints.

The final recommendation involves the conclusion of the model. In the future, the model should encourage institute leaders to work to implement their program, and it should give them resources to consult when they struggle with pursuing succession planning. A better argument for why consulting with succession planning experts is important also might be included. This resources section would better help decision makers seek additional assistance when needed.

\section{Future Research}

Looking to the future, suggestions for future research fall into two categories. One is directly related to this research - what type of research is needed to better understand succession planning in university-wide research institutes? The other takes a broader focus, looking at succession planning in public administration more generally - what type of research is needed to better understand the effects of succession planning in the field of public administration?

Specific Suggestions. While more and more businesses and other public agencies are focusing their attention on succession planning, universities and their research institutes seem to be ignoring the issue, at least at the moment. As some of the interview comments suggested, 
many university leaders think that bringing in outside talent is more important than developing leaders from within. They also focused almost exclusively on the directorship position rather than on developing all of the institutes' employees. I contended at the beginning of the study that succession planning in research institutes was needed, based on demographic and other trends; however, comments from directors showed that they do not all share this view. Future research should be undertaken that focuses on the need for and success of succession planning in universities and research institutes. This research, in turn, may help persuade institute leaders of the need for formal succession programs.

Additional research also would involve the implementation and evaluation of the proposed model. My current research relied on the perceptions of institute experts; actual implementation of the model may further confirm its relevance as well as possibly point to other necessary changes.

Because the study did not include all types of institutes, future research might compare university-wide research institutes with college- and department-level research centers. The proposed model is relevant to university-wide institutes, is it also relevant to college- or department-level centers?

The opening argument for the need for succession planning cited changes in organizational environments and the institutes' constant need to adapt. Additional research should be conducted in this area to better understand how succession programs in universities and institutes do and should adapt over time. Questions could include:

- How might a succession planning model change in 5-10 years when new or younger leaders take over the leadership of universities and institutes? How will their developmental needs differ? 
- As universities and research projects work on a more global scale, how might a succession program incorporate a more global perspective itself, particularly related to potential research partners or employees from other countries?

- Could the succession program incorporate researchers in multiple locations?

- If an institute were to sunset, how could the university use a succession program to shift and incorporate those employees into other university activities, if desired?

General Suggestions. As the implications section mentioned, this research has consequences to the broader field of public administration, particularly as it relates to organization learning and change. Future research should look more at how succession planning helps public organizations manage change. Questions could include:

- What particular organizational change theories help to explain succession planning?

- How would the succession planning model change given the various foci of these theories?

- Reviewing public network theories, how would the network posited in chapter one alter to overcome possible gaps in research if research institutes were to close?

Other areas of research could explore the various ways that public agencies adapt to pressures from environmental forces when they employ succession planning processes. For instance, does succession planning fit into Meier and O'Toole's $(2001,2011)$ model of public management and program performance, and if so how? Additionally, research could focus on 
universities' generally weak reliance on human resources management and how that affects their ability to prosper compared to other public agencies.

Future research could address many new and exciting questions. For now, I am content that my proposed succession planning model is relevant to university-wide research institutes, reinforced by one of the survey respondent's comments:

Succession planning is absolutely critical to maintain the momentum and continuity of successful centers, and to thereby preserve/grow the investments made in the institute over the years. I would strongly encourage my University to incorporate succession planning as part of its long-term strategy.

If public agencies, including universities and research institutes, do not incorporate succession planning as part of their long-term strategies, they are effectively mimicking the Wizard of Oz: "Pay no attention to [the people] behind the curtain." It is the people behind the scenes that help make research institutes as successful as they can be; if these people are ignored and not given opportunities for development and growth, the institute can become stunted in its capacities and may cease to be relevant or prestigious. In turn, other public agencies in the web can be negatively affected. Succession planning is an initiative of helping make sure the institute node in this public agency web stays strong and vibrant. 


\section{References}

Adams, T. (2005). Founder transitions: Creating good endings and new beginnings, a guide for executive directors and boards. In Executive Transitions Monograph Series. Retrieved from: http://www.transitionguides.com/resources/docs/Founders_final.pdf

Adams, T. (2006). Staying engaged, stepping up: Succession planning and executive transition management for nonprofit boards of directors. In Executive Transitions Monograph Series. Retrieved from: http://www.transitionguides.com/resources/docs/ETMBoard.pdf

Adams and Associates \& Management Performance Concepts, (2003). Community based organizations and executive leadership transitions: A survey of Annie E. Casey community based grantees. Retrieved from: http://www.transitionguides.com/resources/docs/aecf_grantees.pdf

AdvancED. (2009). Standards assessment report template: AdvancED school accreditation for NCA CASI and SACS CASI schools. Retrieved from jc-schools.net/SACS/SACSStandards.pdf

AdvancED. (2010). Standards, indicators, and impact statements for quality schools. Retrieved from http://www.advanc-ed.org/webfm_send/10

Allison, M. (2002). Into the fire: Boards and executive transitions. Nonprofit Management \& Leadership, 12(4), 341-351.

Arnone, W. J. (2006). Are employers prepared for the aging of the U.S. workforce? Benefits Quarterly, 22(4), 7-12.

Association of American Universities. (2001). America's research universities: Institutions in service to the nation. Retrieved from http://www.aau.edu/WorkArea/DownloadAsset.aspx?id=1130 
Association of American Universities. (2011). University research: Understanding its role. Retrieved from www.aau.edu/WorkArea/DownloadAsset.aspx?id=11590

Babbie, E. R. (2007). The practice of social research (1 $1^{\text {th }}$ ed.). Belmont, CA: Thomson Wadsworth.

Berchelman, D. K. (2005). Succession planning. The Journal for Quality and Participation, 28(3), 11-12.

Bleak, J. L., \& Fulmer, R. M. (2009). Strategically developing strategic leaders. Duke Corporate Education. Excerpted from D. Giber, L. Carter, \& M. Goldsmith (Eds.), Linkage Inc's, Best practices in leadership development handbook: Case studies, instruments, training (2nd ed.). San Francisco: Pfeiffer. Retrieved from http://www.dukece.com/newsmedia/documents/Strategic_Leaders_000.pdf

Blouin, A. S., McDonagh, K. J., Neistadt, A. M., \& Helfand, B. (2006). Leading tomorrow's healthcare organizations: Strategies and tactics for effective succession planning. Journal of Nursing Administration, 36(6), 325-330.

Bolton, J. \& Roy, W. (2004). Succession planning: Securing the future. Journal of Nursing Administration, 34(12), 589-593.

Bower, F. L. (2000). Succession planning: A strategy for taking charge. Nursing Leadership Forum, 4(4), 110-114.

Brown, P. T. (2010). Making training strategic. The Public Manager, 39(2), p. 38-42. Retrieved from http://www.thepublicmanager.org/docs_articles/current/Vol39,2010/Vol39,Issue02/Vol3 9N2_MakingTrainingStrategic_Brown.pdf 
Bryson, J. M. (2004). Strategic planning for public and nonprofit organizations: A guide to strengthening and sustaining organizational achievement (3rd ed.). San Francisco: Jossey-Bass.

Bureau of Labor Statistics (BLS). (2009a). Employment projections: 2008-18 summary. Retrieved from http://www.bls.gov/news.release/ecopro.nr0.htm

Bureau of Labor Statistics (BLS). (2009b). Table 1.2 Employment by occupation, 2008 and projected 2018. Retrieved from http://www.bls.gov/emp/ep_table_102.htm

Bureau of Labor Statistics (BLS). (2009c). Table 3. The 10 industries with the largest wage and salary employment growth, 2008-18. Retrieved from http://www.bls.gov/news.release/ecopro.t03.htm

Bureau of Labor Statistics (BLS). (2009d). Table 9. Employment and total job openings by postsecondary education or training category, 2008-18. Retrieved from http://www.bls.gov/news.release/ecopro.t09.htm

Cadmus, E. (2006). Succession planning: Multilevel organizational strategies for the new workforce. Journal of Nursing Administration, 36(6), 298-303.

Cairns, T. D. (2009). Talent management at homeland security: A corporate model suggests a recipe for success. Employment Relations Today, 36(3), 19-26.

Cappelli, P. (2008, March). Talent management for the twenty-first century. Harvard Business Review, 86(3), 74-81.

Carman, J. G., Leland, S. M., \& Wilson, A. J. (2010). Crisis in leadership or failure to plan? Insights from Charlotte, North Carolina. Nonprofit Management \& Leadership, 21(1), 93111. 
Carnegie Foundation for the Advancement of Teaching (2007). Classifications. Retrieved from http://www.carnegiefoundation.org/classifications/index.asp?key=782

Carriere, B. K., Cummings, G., Muise, M., \& Newburn-Cook, C. (2009). Healthcare succession planning: An integrative review. Journal of Nursing Administration, 39(2), 548-555.

Creswell, J. W., \& Plano Clark, V. L. (2007). Designing and conducting mixed methods research. Thousand Oaks, CA: Sage Publications.

Choudhury, E. H. (2007). Workforce planning in small local governments. Review of Public Personnel Administration, 27(3), 264-280.

Christie, D. (2005). Learning to grow our own: A study of succession planning at Douglas College (Masters of Arts thesis, Royal Roads University at Victoria, British Columbia, Canada). Retrieved from http://www.jimforce.ca/christie05MALTthesis.pdf

Clemmens, D. (2003). Adolescent motherhood: A meta-synthesis of qualitative studies. MCN, the American journal of maternal child nursing, 28(2), 93-99.

Clunies, J. P. (2004). Benchmarking succession planning \& executive development in higher education: Is the academy ready now to employ these corporate paradigms? Academic Leadership, 2(4). Retrieved from: http://academicleadership.org/article/Benchmarking_Succession_Planning_Executive_De velopment_in_Higher_Education/benchmarking

Cohen, W. M., Nelson, R. R., \& Walsh, J. P. (2002). Links and impacts: The influence of public research on industrial R\&D. Management Science, 48(1), 1-23.

Cohn, J. M., Khurana, R., \& Reeves, L. (2005). Growing talent as if your business depended on it. Harvard Business Review, 83(10), 62-70. 
Collins, J. C. (2001). Good to great: Why some companies make the leap...and others don't. New York, NY: HarperBusiness.

CompassPoint (2004). Capturing the power of leadership change: Using Executive Transition Management to strengthen organizational capacity. Baltimore, MD: The Annie. E. Casey Foundation.

Considine, M. \& Lewis, J. M. (1999). Governance at ground level: The frontline bureaucrat in the age of markets and networks. Public Administration Review, 59(6), 467-480.

Dalton, C. M. (2006). A recipe for success in succession planning. Business Horizons, 49, 175177.

Day, D. (2000). Leadership development: A review in context. Leadership Quarterly, 11(4), $581-613$.

Department of Human Resource Management [DHRS]. (2003). Policy number 1.90: Workforce planning. Retrieved from http://www.dhrm.virginia.gov/hrpolicy/policy/pol1_90WorkforcePlanning.pdf

Di Re, E., \& Eyberg, T. (2008, October 21). Psychology of succession planning. Forbes.com. Retrieved from http://www.forbes.com/2008/10/21/intergenerational-successionplanning-pf-ii-in_ed_1021succession_inl.html

Dillman, D. A., Smyth, J. D., \& Christian, L. M. (2009). Internet, mail, and mixed-mode surveys: The tailored design method. Hoboken, N.J: Wiley \& Sons.

Drew, G., \& Ehrich, L. C. (2010). A model of organizational leadership development informing succession development: Elements and practices. Academic Leadership Live: The Online Journal, 8(4). Retrieved from: http://www.academicleadership.org/article/a-model-of- 
organisational-leadership-development-informing-succession-development-elementsand-practices

Drucker, P. F., \& Wartzman, R. (2010) The Drucker lectures: Essential lessons on management, society, and economy. New York: McGraw-Hill.

Duderstadt, J. J. (2009). Current global trends in higher education and research: Their impact on Europe. Address given at Dies Academicus 2009, Universität Wien, Vienna, Austria. Retrieved from www.aplu.org/document.doc?id=1969

Duta, A. C. (2008). Leadership succession: A discourse analysis of governance dialectics in two nonprofit organizations. (Unpublished doctoral dissertation). Texas A\&M University, College Station, TX.

Endres, G. \& Alexander, J. (2006). Two government agencies look at succession planning. Organization Development Journal, 24(2), 23-32.

Estepp, J. M. (1998). Succession planning in university-level technology programs. Journal of Technology Studies, 24(2), 48-51. Retrieved from: http://scholar.lib.vt.edu/ejournals/JOTS/Summer-Fall-1998/PDF/estepp.pdf

Fairweather, V. (2000). Succession planning pays off. Civil Engineering, 70(2), 56-59.

Falleti, T. G., \& Lynch, J. F. (2009). Context and causal mechanisms in political analysis. Comparative Political Studies, 42(9), 1143-1166.

Ferris, G., Arthur, M. M., Berkson, H. M., Kaplan, D. M., Harrell-Cook, G., \& Frink, D. D. (1998). Toward a social context theory of the human resource management-organization effectiveness relationship. Human Resource Management Review, 8(3), 235-264. 
Fisher, M. (2010). Passing the torch: An exploration of leadership succession in nonprofit performing arts organizations in Oregon. (Unpublished master's thesis). University of Oregon, Portland, OR.

Folkers, D. R. (2008). Succession planning and management in Nebraska state government: Perceptions, experiences, and barriers. (Unpublished doctoral dissertation). University of Phoenix, Phoenix, AZ.

Fowler, F. J. (2002). Survey research methods ( $3^{\text {rd }}$ ed.). Thousand Oaks, CA: Sage Publications.

Frauenheim, E. (2006). Succession progression. Workforce Management, January, 31-35.

Fullan, M., Miles, M. B., \& Taylor, G. (1980). Organization development in schools: The state of the art. Review of Educational Research, 50(1), 121-183. doi: $10.3102 / 00346543050001121$

Gaffney, S. (2005). Career development as a retention and succession planning tool. The Journal for Quality and Participation, 28(3), 7-10.

Gamble, J. L. (2008). Leadership trends in the non-profit sector: A North American sample of United Way executive directors. (Unpublished doctoral dissertation). University of Louisville, Louisville, KY.

Gandossy, R., \& Kao, T. (2004). Talent wars: Out of mind, out of practice. HR: Human Resource Planning, 27(4), 15-19.

Gandz, J. (2006). Talent development: The architecture of a talent pipeline that works. Ivey Business Journal, January/February, 1-4.

Gebbie, K. M., \& Turnock, B. J. (2006). The public health workforce, 2006: New challenges. Health Affairs, 25(4), 923-933. 
Goodsell, C. T. (2001, March 11). Public administration's soul reincarnated. Sixty-Second National Conference of American Society for Public Administration. Concurrent Panel, Newark, New Jersey.

González, C. (2010). Leadership, diversity and succession planning in academia. Center for Studies in Higher Education. Retrieved from http://cshe.berkeley.edu/publications/publications.php?id=360

Goudreau, K. A. \& Hardy, J. (2006). Succession planning and individual development. Journal of Nursing Administration, 36(6), 313-318.

Gowdy, H., Hildebrand, A., La Piana, D., \& Mendes Campos, M. (2009). Convergence: How five trends will reshape the social sector. Emeryville, CA: La Piana Consulting

Greeley, A. (1996). In defense of surveys. Society, 33(4), 26-29.

Greer, C. R., \& Virick, M. (2008). Diverse succession planning: Lessons from the industry leaders. Human Resource Management, 47(2), 351-367.

Guba, E. G., \& Lincoln, Y. S. (1994). Competing paradigms in qualitative research. In N. K. Denzin \& Y. S. Lincoln (Eds.), Handbook of qualitative research (105-117). Thousand Oaks, CA: Sage Publications.

Hand, E. (2011, August 9). U.S. debt deal could dramatically slash science funding in 2013: US science agencies avoid immediate pain but could be devastated by automatic cuts in 2013. Scientific American. Retrieved from http://www.scientificamerican.com/article.cfm?id=us-debt-deal-could-dramatically-slashscience-funds-in-2013 
Hanna, D. E. (2003). Building a leadership vision: Eleven strategic challenges for higher education. Educause Review, 38(4), 25-34. Retrieved from http://net.educause.edu.ezproxy.lib.vt.edu:8080/ir/library/pdf/ERM0341.pdf

Haworth, M. (2005). Tips for better succession planning. The Journal for Quality and Participation, 28(3), 13-15.

Haynes, R. K., \& Ghosh, R. (2008). Mentoring and succession management: An evaluative approach to the strategic collaboration model. Review of Business, 28(2), 3-12.

Heinen, J. S., \& O'Neill, C. (2004). Managing talent to maximize performance. Employment Relations Today, 31(2), 67-82.

Helton, K. A., \& Jackson, R. D. (2007). Navigating Pennsylvania's dynamic workforce: Succession planning in a complex environment. Public Personnel Management, 36(4), $335-347$.

Herrera, F. (2002). Demystifying succession planning. Employment Relations Today, 29(2), 2531.

Heuer, J. J. (2003). Succession planning for key administrators at ivy-plus universities. Unpublished doctoral dissertation, University of Pennsylvania, Philadelphia, PA. Hiteshew, R. (2009). Attrition of leadership within the Henrico County Division of Fire: Are we ready for the future? Retrieved from http://www.usfa.dhs.gov/pdf/efop/efo44174.pdf Holland, J. G. (1862). Friends' intelligencer, volume 18. An Association of Friends (Eds.). Philadelphia, PA: T. Ellwood Zell.

Holinsworth, S. R. (2004). Case study: Henrico County, Virginia: Succession management: A developmental approach. Public Personnel Management, 33(4), 475-486. 
Horrigan, M. W. (2004, February). Employment projections to 2012: Concepts and context. Monthly Labor Review, 127(2), 3-22. Retrieved from http://www.bls.gov/opub/mlr/2004/02/art1 full.pdf

HRM Guide Network (2008a). Aging workforces. Retrieved from http://www.hrmguide.com/strategy/aging-workforce.htm

HRM Guide Network (2008b). Finding talent increasingly difficult. Retrieved from http://www.hrmguide.com/recruitment/finding-talent.htm

Huang, T.C. (2001). Succession management systems and human resources outcomes. International Journal of Manpower, 22(7/8), 736-747.

Hughes Butts, M. A. (2008). A descriptive quantitative study of credit union succession planning. (Unpublished doctoral dissertation). University of Phoenix, Phoenix, AZ.

Hurston, Z. N. (1942). Dust Tracks on a Road. Philadelphia, PA: J. B. Lippincott.

Huselid, M. A. (1993). The impact of environmental volatility on human resource planning and strategic human resource management. HR: Human Resource Planning, 16(3), 35-51.

Ibarra, P. (2005). Succession planning: An idea whose time has come. Public Management, 87(1), 18-24.

Ibrahim, T, O'Connell, J. B., LaRusso, N. F., Meyers, F. J., \& Crist, T. B. (2003). Centers, institutes, and the future of clinical departments: Part 1. The American Journal of Medicine, 115, 337-341. doi:10.1016/S0002-0343(03)00419-4

Ingraham, P. W., \& Getha-Taylor, H. (2004). Leadership in the public sector: Models and assumptions for leadership development in the federal government. Review of Public Personnel Administration, 24(2), 95-112. 
International Public Management Association for Human Resources [IPMA-HR], \& CPS Human Resource Services. (2009). Benchmarking report 2009: Workforce and succession planning. Alexandria, VA.: Authors. Retrieved from http://www.ipmahr.org/sites/default/files/pdf/BestPractices/2009Bench.pdf

Ip, B. (2009). Planning and controlling business succession planning using quality function deployment. Total Quality Management, 20(4), 363-379.

Janosik, S. (2006). Policy making: A matrix perspective [Lecture handout]. Blacksburg, Virginia: Virginia Tech, School of Education, Educational Leadership \& Policy Studies.

Jarrell, K. M., \& Pewitt, K. C. (2007). Succession planning in government: Case study of a medium-sized city. Review of Public Personnel Administration, 27(3), 297-309.

Kaplan, R. S. (2007, January). What to ask the person in the mirror. Harvard Business Review, 85(1), 86-95.

Karaevli, A. \& Hall, D. T. (2003). Growing leaders for turbulent times: Is succession planning up to the challenge? Organizational Dynamics, 32(1), 62-79. doi: 10.1016/S00902616(02)00138-9

Keast, R., Mandell, M.P., Brown, K., \& Woolcock, G. (2004). Network structures: Working differently and changing expectations. Public Administration Review, 64(3), 363-371.

Kesner, I. F., \& Sebora, T. C., (1994). Executive succession: Past, present \& future. Journal of Management, 20(2), 327-372.

Kim, S. (2003). Linking employee assessments to succession planning. Public Personnel Management, 32(4), 533-547.

Kim, Y. (2010). Measuring the value of succession planning and management: A qualitative study of multinational companies. Performance Improvement Quarterly, 23(2), 5-31). 
Kunreuther, F. (2005). Up next: Generation change and the leadership of nonprofit organizations. Baltimore, MD: The Annie E. Casey Foundation.

Kur, E., \& Bunning, R. (2002). Assuring corporate leadership for the future. Journal of Management Development, 21(10), 761-778.

Langley, A. (1999). Strategies for theorizing from process data. Academy of Management Review, 24(4), 691-710.

Latif, M. (2010). Succession planning: Another look. Journal of Nonprofit Management, 14(1), $2-7$.

Leibman, M., Bruer, R. A., \& Maki, B. R. (1996). Succession management: The next generation of succession planning. Human Resource Planning, 19(3), 16-29.

Levin, S. Z. (2010). Deans of career and technical education: Charting the course to senior administration. (Unpublished doctoral dissertation). National-Louis University, Chicago, IL.

Ley, S. (2002). An assessment of succession planning at the State Bar of Texas. (Unpublished master's thesis). Southwest Texas State University, San Marcos, TX.

Liebowitz, J. (2004). Bridging the knowledge and skills gap: Tapping federal retirees. Public Personnel Management, 33(4), 421-448.

Lombardi, J. V. (2005, December 15). Paying for the Research Juggernaut. Inside Higher Ed. Retrieved from http://www.insidehighered.com/views/2005/12/15/lombardi

Love, J. (2010). Approaching 65: A survey of boomers turning 65 years old. Washington, DC: AARP. Retrieved from http://www.aarp.org/personal-growth/transitions/info-122010/approaching-65.html 
Lumby, J. (1999). Strategic planning in further education. Educational Management \& Administration, 27(1), 71-83.

Lynn, L. E. (1998). The new public management: How to transform a theme into a legacy. Public Administration Review, 58(3), 231-237.

Lynn, D. B. (2001). Succession management strategies in public sector organizations: Building leadership capital. Review of Public Personnel Administration, 21(2), 114-132.

Mallon, W. (2004). Disjointed governance in university centers and institutes. New Directions for Higher Education, 127, 61-74.

Mallon, W. T. (2006). The benefits and challenges of research centers and institutes in academic medicine: Findings from six universities and their medical schools. Academic Medicine, 81(6), 502-512.

Mallon, W. T., \& Bunton, S. A. (2005). Research centers and institutes in U.S. medical schools: A descriptive analysis. Academic Medicine, 80(11), 1005-1011.

Maxwell, J. C. (1995). Developing the leaders around you: How to help others reach their full potential. Nashville, TN: Thomas Nelson.

McCallin, A., Bamford-Wade, A., \& Frankson, C. (2009). Leadership succession planning: A key issue for the nursing profession. Nurse Leader, 7(6), 40-44. Retrieved from: http://www.nurseleader.com/article/S1541-4612\%2809\%2900188-8/abstract

McKinney, J. B., \& Howard, L. C. (1998). Public administration: Balancing power and accountability. Westport, CT: Praeger Publishers.

Meier, K. J., \& O’Toole, L. J. (2001). Managerial strategies and behavior in networks: A model with evidence from U.S. public education. Journal of Public Administration Research and Theory, 11(3), 271-293. 
Mihn, J. C. (2003). Human capital: Succession planning and management is critical driver of organizational transition. (GAO Publication No. GAO-04-127T). Washington, DC: U.S. General Accounting Office. Retrieved from www.gao.gov/new.items/d04127t.pdf

Mike, H. (2004). Executive transitions and leadership development. Unpublished manuscript, Hunter College, New York, New York.

Milward, H. B., \& Provan, K. G. (2000). Governing the hollow state. Journal of Public Administration Research and Theory, 10(2), 359-380.

Mintzberg, H. (1994). The fall and rise of strategic planning. Harvard Business Review, 72(1), $107-114$.

Mir, R., \& Watson, A. (2001). Critical realism and constructivism in strategy research: Toward a synthesis. Strategic management journal, 22(12), 1169-1173.

Morgan, G. (1981). The schismatic metaphor and its implications for organizational analysis. Organization Studies, 2(1), 23-44.

Naquin, S. S., \& Holton, E. F. (2003). Redefining state government leadership and management development: A process for competency-based development. Public Personnel Management, 32(1), 23-46.

Narin, F., Hamilton, K. S., \& Olivastro, D. (1997). The increasing linkage between U.S. technology and public science. Research Policy, 26(3), 317-330.

National Institutes of Health [NIH]. (2009). The NIH almanac - Appropriations. Retrieved from http://www.nih.gov/about/almanac/appropriations/index.htm

National Science Board. (2010). Science and engineering indicators 2010. Retrieved from http://www.nsf.gov/statistics/seind10/c/cs1.htm 
National Science Foundation [NSF]. (2009a). Award search [Data file]. Retrieved from http://www.nsf.gov/awardsearch/

National Science Foundation [NSF]. (2009b). Federal government is largest source of university $R \& D$ funding in S\&E: Share drops in FY 2008. Retrieved from http://www.nsf.gov/statistics/infbrief/nsf09318/?org=NSF

National Science Foundation [NSF]. (2009c). NSF by account. Retrieved from http://dellweb.bfa.nsf.gov/NSFHist.htm

National Science Foundation [NSF]. (2010). Universities report \$55 billion in science and engineering R\&D spending for FY 2009: Redesigned survey to launch in 2010. Retrieved from http://www.nsf.gov/statistics/infbrief/nsf10329/

Naveen, L. (2000). Management turnover and succession planning in firms. (Unpublished manuscript). Arizona State University, Tempe, AZ.

Neuman, W. L. (2006). Social research methods: Qualitative and quantitative approaches $\left(6^{\text {th }}\right.$ ed.). Boston: Allyn and Bacon.

Newson, R. (2006). Confidence intervals for rank statistics: Somers'd and extensions. Stata Journal, 6, 309-334.

Novak, M. J., \& Beckman, T. (2008, April). A multi-tiered competency-based approach to knowledge retention in organizations. Paper presented at the Knowledge Management Conference, Washington, DC.

Office of Budget and Financial Planning. (2010). FAQs. Retrieved from http://www.obfp.vt.edu/FAQ/FAQs.html

Parkman, A., \& Beard, R. (2008). Succession planning and the imposter phenomenon in higher education. CUPA-HR Journal, 59(2), 29-36. Retrieved from: 
http://jamiesmithportfolio.com/EDTE800/wpcontent/Imposter\%20Syndrome/Parkman.pdf

Partnership for Public Service. (2009). Where the jobs are 2009: Mission-critical opportunities for America (3rd ed.). Washington, D.C.: Author. Retrieved from http://data.wherethejobsare.org/wtja/home

Pennell, K. (2010). The role of flexible job descriptions in succession management. Library Management, 31(4/5), 279-290.

Peterson, R. J. (2002). Reauthorization of centers, bureaus and laboratories. Retrieved from http://www.colorado.edu/policies/reauthorize.html

Pink, D. H. (2005). A whole new mind: Why right-brainers will rule the future. New York: Penguin Group.

Plume, A. (2011). Tipping the balance: The rise of China as a science superpower. Research Trends. Retrieved from http://www.researchtrends.com/category/issue22-march-2011/

PriceWaterhouseCoopers. (2006). The crisis in federal government succession planning: What's being done about it. Retrieved from http://www.pwc.com/us/en/publicsector/publications/federal-government-succession-planning.jhtml

Pynes, J. E. (2004a). Human resource management for public and nonprofit organizations. San Francisco: John Wiley \& Sons.

Pynes, J. E. (2004b). The implementation of workforce and succession planning in the public sector. Public Personnel Management, 33(4), 389-404.

Quint, M. (2009). Developing a succession plan for the Watertown Fire Department. Retrieved from http://www.usfa.dhs.gov/pdf/efop/efo42934.pdf 
Ready, D. A., \& Conger, J. A. (2007). Make your company a talent factory. Harvard Business Review, 85(6), 68-77.

Redman, R. W. (2006). Leadership succession planning: An evidence-based approach for managing the future. Journal of Nursing Administration, 36(6), 292-297.

Richards, C. L. (2009). A new paradigm: Strategies for succession planning in higher education. (Unpublished doctoral dissertation). Capella University, Minneapolis, MN.

Rhodes, F. H. T. (2001). The university at the millennium: Missions and responsibilities of research universities. In W. Z. Hirsch \& L. E. Weber (Eds.), Governance in higher education: The university in a state of flux (3-14). Paris: Economica.

Roddy, N. (2004). Leadership capacity building model: Developing tomorrow's leadership in science and technology: An example in succession planning and management. Public Personnel Management, 33(4), 487-496.

Rosenbloom, D. H. \& Piotrowski, S. J. (2005). Outsourcing the constitution and administrative law norms. American Review of Public Administration 35(2), 103-121.

Romejko, M. A. (2008). Key characteristics of a succession planning program at a government research center. (Unpublished doctoral dissertation). Pepperdine University, Malibu, CA. Rothwell, W. J. (2001). Effective succession planning: Ensuring leadership continuity and building talent from within (2nd ed.). New York: AMACOM.

Rothwell, W. J. (2010). Effective succession planning: Ensuring leadership continuity and building talent from within (4th ed.). New York: AMACOM.

Rothwell, W. J., \& Poduch, S. (2004). Introducing technical (not managerial) succession planning. Public Personnel Management, 33(4), 405-418. 
Rudis, E. V. (2006). Succession planning for top management remains a major issue for global companies. Employment Relations Today, Autumn, 51-59.

Santora, J. C. \& Sarros, J. C. (1995). Mortality and leadership succession: A case study. Leadership \& Organization Development Journal, 16(7), 29-32.

Santora, J. C., \& Sarros, J. C. (2001). CEO succession in nonprofit community-based organizations: Is there room for insiders at the top? Career Development International, $6(2), 107-110$.

Scheerens, J. (1990). School effectiveness research and the development of process indicators of school functioning. School Effectiveness and School Improvement, 1(1), 61-80.

Schmalzried, H. \& Fallon, L. F. (2007). Succession planning for local health department top executives: Reducing risk to communities. Journal of Community Health, 32(3), 169-180.

Scott, W. R. (2001). Institutions and organizations. Thousand Oaks, CA: Sage Publications.

Shinn, J. (2006). Preparing small non-profit organizations for leadership transition: An examination of effective succession planning strategies. (Unpublished Master of Arts thesis). Saint Mary's University of Minnesota, Winona, MN.

Siau, K., \& Long, Y. (2005). Synthesizing e-government stage models: A meta-synthesis based on meta- ethnography approach. Industrial Management + Data Systems, 105(3/4), 443458.

Slaughter, S., \& Leslie, L. L. (1997). Academic capitalism: Politics, policies, and the entrepreneurial university. Baltimore: The Johns Hopkins University Press.

Spanier, G. B. (1999). Enhancing the quality of life: A model for the 21st-century land-grant university. Applied Developmental Science, 3(4), 199-205. 
Stahler, G. J., \& Tash, W. R. (1994). Centers and institutes in the research university: Issues, problems, and prospects. The Journal of Higher Education, 65(5), 540-554. doi: $10.2307 / 2943777$

Swain, J., \& Turpin, W. (2005). The new world of CEO succession. Ivey Business Journal Online, September/October, 1-5.

Teegarden, P. H. (2004). Nonprofit executive leadership and transitions survey 2004. Retrieved from: http://www.aecf.org/upload/PublicationFiles/executive_transition_survey_report2004.pdf

Thomas, D. R. (2006). A general inductive approach for analyzing qualitative evaluation data. American Journal of Evaluation, 27(2), 237-246.

Toossi, M. (2009, November). Labor force projections to 2018: older workers staying more active. Monthly Labor Review, 132(11), 30-51. Retrieved from http://www.bls.gov/opub/mlr/2009/11/art3full.pdf

Valentine, J. A. (2000). Strategic management and health workforce policy. Journal of Health and Human Services Administration, 23(3), 361-378.

Van Amburgh, J., Surratt, C. K., Green, J. S., Gallucci, R., M., Colbert, J., Zatopek, S. L., \& Blouin, R. A. (2010). Succession planning in US pharmacy schools. American Journal of Pharmaceutical Education, 74(5), 1-7.

Van de Ven, A. H. (1992). Suggestions for studying strategy process: A research note. Strategic Management Journal, 13(special issue), 169-191.

Virginia Polytechnic Institute and State University [VPI\&SU]. (2008). Policy and procedures: Subject: Centers financial and administrative policy and procedures. Retrieved from: http://www.policies.vt.edu/3020.pdf 
White, B. P., \& Eckel, P. D. (2008). Collective foresight: The leadership challenges for higher education's future. Washington, D.C.: American Council on Education.

Whitmore, M. A. (2006). Success through succession: Implementing succession planning at the Texas Department of Insurance. (Unpublished master's thesis). Texas State University, San Marcos, TX.

Wildavsky, B. (2010, August 22). University globalization is here to stay. The Chronicle of Higher Education. Retrieved from http://chronicle.com.ezproxy.lib.vt.edu:8080/article/Almanac-2010-International/123922/

Witt/Keiffer. (2008). Succession planning gaining support in higher education. Oak Brook, IL: Author.

Wright, F. L. (1953). The future of architecture. New York: Horizon Press.

Young, D. L. (2008). Maximizing Army's return on investment in civilian development. Retrieved from http://oai.dtic.mil/oai/oai?verb=getRecord\&metadataPrefix $=$ html\&identifier=ADA48145 1 


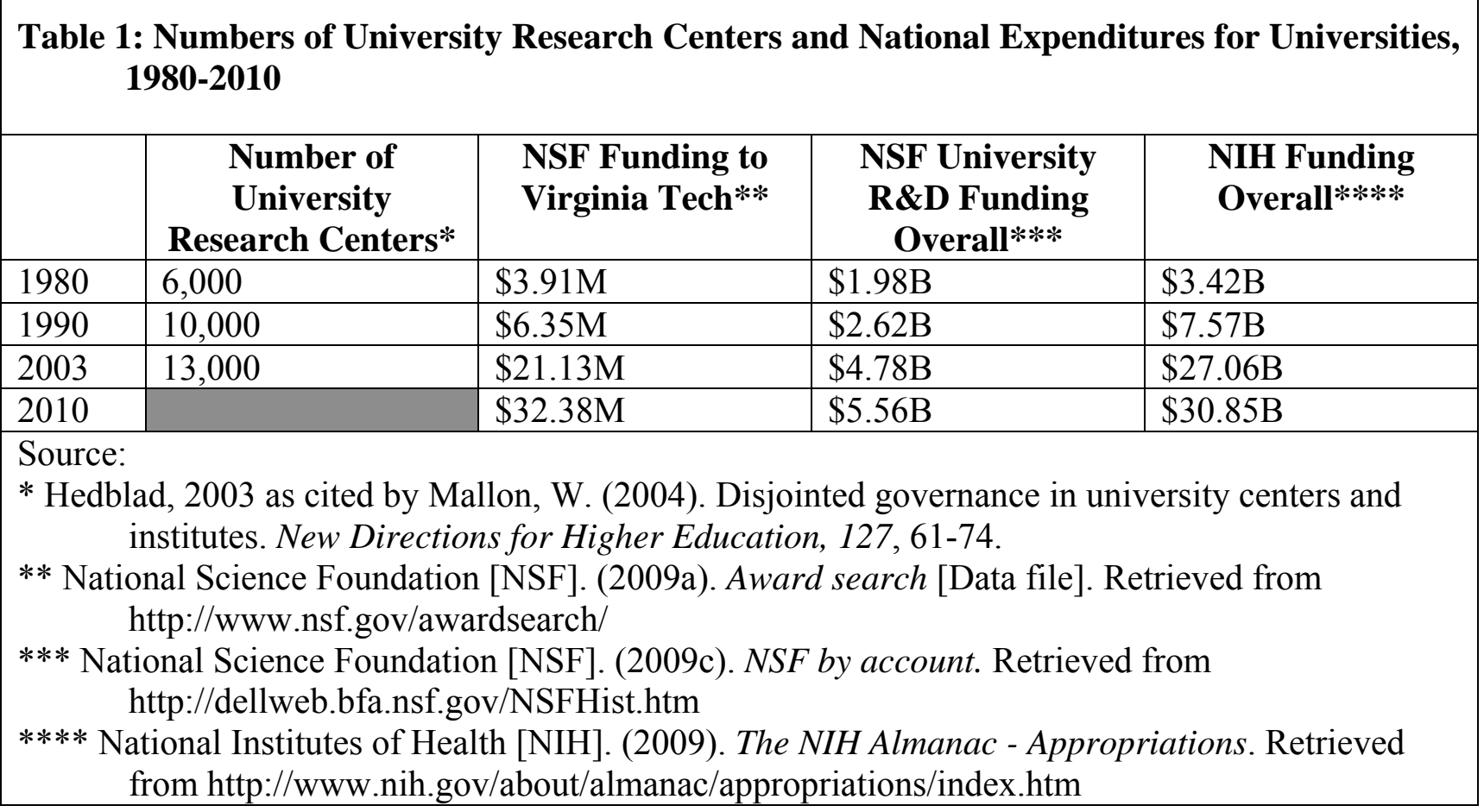




\section{Table 2: Characteristics of drivers.}

\section{Categories of concepts related to current succession planning models (PROCESS CHARACTERISTICS)}

- Definition of succession planning

- Decision makers/stakeholders

- Participants in succession program

- Participant and stakeholder perceptions

- Reason for succession planning, including impetus for program development

- Level at which program placed in organization

- Timeline

- Other concepts that although linked to particular plans might apply to succession planning processes in higher education institutions

Characteristics of university-wide research institutes (CONTEXT)

- Mission

- Number of staff and nature of structure (separate center, under provost, under department)

- Relationship to university (mission/vision)

- Budget

- Oversight, evaluation

Characteristics of policy implementation in university-wide research institutes (CONTEXT)

- Decision processes

- Leadership style (related to succession planning) 


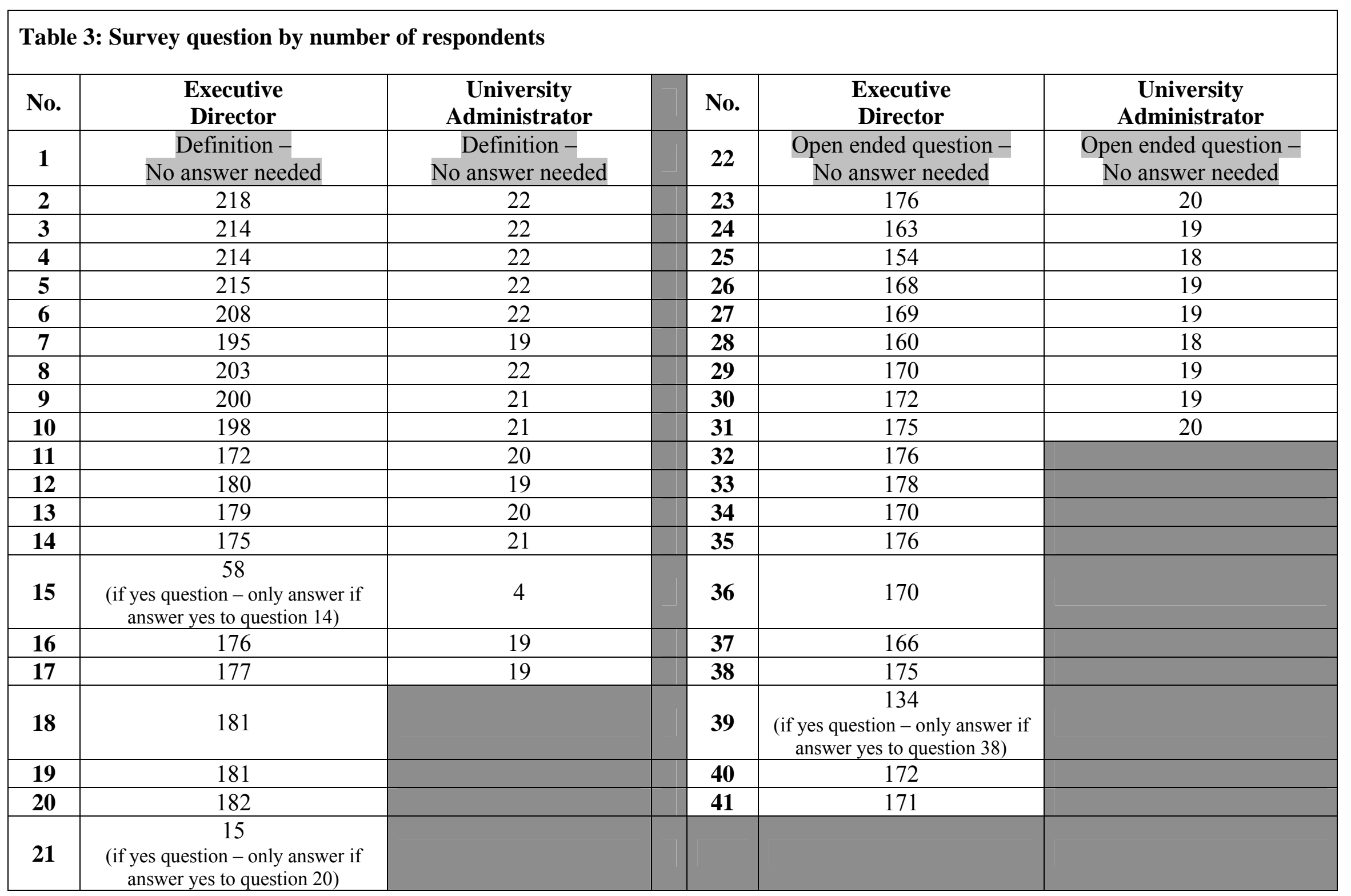


Table 4: Definition of Succession Planning across Three Sectors

\begin{tabular}{|c|c|c|c|c|}
\hline & $\begin{array}{c}\text { Nonprofit } \\
(\mathrm{n}=21 / 84.0 \%)^{*}\end{array}$ & $\begin{array}{c}\text { Public } \\
(\mathrm{n}=21 / 75.0 \%)^{*}\end{array}$ & $\begin{array}{c}\text { For-profit } \\
(\mathrm{n}=17 / 60.7 \%)^{*}\end{array}$ & $\begin{array}{c}\text { Education } \\
(\mathrm{n}=4 / 50.0 \%)^{*}\end{array}$ \\
\hline \multicolumn{5}{|c|}{ HOLISTIC SUCCESSION PLANNING } \\
\hline $\begin{array}{l}\text { Holistic, strategic look at the } \\
\text { organization, its programs, and its } \\
\text { current and future needs }\end{array}$ & $\begin{array}{l}\text { Adams (2005) } \\
\text { Cadmus (2006) } \\
\text { Hughes Butts (2008) } \\
\text { Latif (2010) }\end{array}$ & $\begin{array}{l}\text { Folkers (2008) } \\
\text { Ley (2002) } \\
\text { Pennell (2010) } \\
\text { Rothwell \& Poduch (2004) } \\
\end{array}$ & $\begin{array}{l}\text { Haynes \& Ghosh (2008) } \\
\text { Kim (2010) }\end{array}$ & Richards (2009) \\
\hline $\begin{array}{l}\text { Management of individual employees' } \\
\text { careers in order to "optimize the } \\
\text { organization's needs and the } \\
\text { individual's aspirations" }\end{array}$ & $\begin{array}{l}\text { Carman, Leland, \& Wilson } \\
\text { (2010) }\end{array}$ & & Huang (2001, p. 736) & \\
\hline $\begin{array}{l}\text { Assessment of HR strengths and } \\
\text { weaknesses to strategic plan } \\
\text { Opportunity to learn how to implement } \\
\text { the strategic plan }\end{array}$ & & Pynes (2004b) & Huselid (1993) & \\
\hline \multicolumn{5}{|l|}{ ORGANIZATIONAL VIEW } \\
\hline $\begin{array}{l}\text { Written plan to prepare executive } \\
\text { transitions of key leaders } \\
\text { Replacement planning }\end{array}$ & $\begin{array}{l}\text { Adams (2005, 2006) } \\
\text { Adams and Associates \& } \\
\text { Management } \\
\text { Performance Concepts } \\
\text { (2003) } \\
\text { Bolton \& Roy (2004) } \\
\text { Bower (2000) } \\
\text { Carman, Leland, \& Wilson } \\
\text { (2010) } \\
\text { CompassPoint (2004) } \\
\text { Fisher (2010) } \\
\text { Gamble (2008) } \\
\text { Redman (2006) } \\
\text { Santora \& Sarros (1995, } \\
\text { 2001) } \\
\text { Shinn (2006) } \\
\text { Teegarden (2004) }\end{array}$ & $\begin{array}{l}\text { Herrera (2002) } \\
\text { Ibarra (2005) } \\
\text { Jarrell \& Pewitt (2007) } \\
\text { Schmalzried \& Fallon } \\
\quad(2007) \\
\text { Whitmore (2006) }\end{array}$ & $\begin{array}{l}\text { Carriere, Cummings, } \\
\quad \text { Muise, \& Newburn-Cook } \\
(2009) \\
\text { Huang }(2001) \\
\text { Ip (2009) } \\
\text { Kim (2010) } \\
\text { Naveen }(2000)\end{array}$ & Van Amburgh, et al. (2010) \\
\hline
\end{tabular}




\begin{tabular}{|c|c|c|c|c|}
\hline $\begin{array}{l}\text { Opportunity to meet organizational } \\
\text { needs } \\
\text { Ability to ensure suitable supply of } \\
\text { employees that match current and } \\
\text { future job needs }\end{array}$ & $\begin{array}{l}\text { Gowdy, et al. (2009) } \\
\text { Redman (2006) }\end{array}$ & Choudhury (2007) & $\begin{array}{l}\text { Cappelli (2008) } \\
\text { Gaffney (2005) } \\
\text { Huang (2001) } \\
\text { Huselid (1993) } \\
\text { Ready \& Conger (2007) }\end{array}$ & Roddy (2004) \\
\hline $\begin{array}{l}\text { Opportunity to prepare for knowledge } \\
\text { loss and retain business wisdom }\end{array}$ & Adams (2006) & $\begin{array}{l}\text { Rothwell \& Poduch (2004) } \\
\text { Whitmore (2006) }\end{array}$ & Arnone (2006) & Van Amburgh, et al. (2010) \\
\hline $\begin{array}{l}\text { Manage talent } \\
\text { Get the right people in right job and } \\
\text { keep them there }\end{array}$ & & Whitmore (2006) & $\begin{array}{l}\text { Cairns (2009) } \\
\text { Frauenheim (2006) } \\
\text { Gandossy \& Kao (2004) } \\
\text { Heinen \& O’Neill (2004) } \\
\text { Rudis (2006) } \\
\end{array}$ & \\
\hline Organizational development & CompassPoint (2004) & $\begin{array}{l}\text { Goudreau \& Hardy (2006) } \\
\text { Helton \& Jackson (2007) } \\
\text { Lynn (2001) }\end{array}$ & & \\
\hline $\begin{array}{l}\text { Plan for recruitment } \\
\text { Recruit and train "high potentials" }\end{array}$ & $\begin{array}{l}\text { Duta }(2008) \\
\text { Shinn }(2006)\end{array}$ & $\begin{array}{l}\text { Rothwell \& Poduch (2004) } \\
\text { Schmalzried \& Fallon } \\
\text { (2007) }\end{array}$ & & $\begin{array}{l}\text { Parkman \& Beard (2008) } \\
\text { Van Amburgh, et al. (2010) }\end{array}$ \\
\hline \multicolumn{5}{|l|}{ EMPLOYEE VIEW } \\
\hline $\begin{array}{l}\text { Leadership development } \\
\text { Enhance leadership capabilities }\end{array}$ & $\begin{array}{l}\text { Adams }(2005,2006) \\
\text { Blouin, et. al }(2006) \\
\text { Bower }(2000) \\
\text { Redman }(2006) \\
\text { Shinn }(2006) \\
\end{array}$ & $\begin{array}{l}\text { Hiteshew (2009) } \\
\text { Ibarra (2005) } \\
\text { Kim (2003) } \\
\text { Quint (2009) } \\
\text { Young (2008) } \\
\end{array}$ & $\begin{array}{l}\text { Kim }(2010) \\
\text { Kur \& Bunning (2002) }\end{array}$ & \\
\hline $\begin{array}{l}\text { Develop a pool of better prepared } \\
\text { candidates } \\
\text { Groom employees and build bench } \\
\text { strength }\end{array}$ & $\begin{array}{l}\text { Blouin, et. al (2006) } \\
\text { Bolton \& Roy (2004) } \\
\text { Bower (2000) } \\
\text { McCallin, Bamford-Wade, } \\
\text { \& Frankson (2009) } \\
\text { Shinn (2006) }\end{array}$ & $\begin{array}{l}\text { Helton \& Jackson (2007) } \\
\text { Romejko (2008) } \\
\text { Rothwell \& Poduch (2004) } \\
\text { Young (2008) }\end{array}$ & & \\
\hline Staff development & $\begin{array}{l}\text { Adams }(2005,2006) \\
\text { Cadmus }(2006)\end{array}$ & $\begin{array}{l}\text { Goudreau \& Hardy (2006) } \\
\text { Novak \& Beckman (2008) } \\
\text { Romejko (2008) } \\
\text { Rothwell \& Poduch (2004) } \\
\text { Valentine (2000) } \\
\end{array}$ & & \\
\hline Enhance employee performance & & $\begin{array}{l}\text { Ibarra (2005) } \\
\text { Kim (2003) }\end{array}$ & & \\
\hline Develop teams or cohorts of employees & & & Kur \& Bunning (2002) & \\
\hline
\end{tabular}




\section{Table 5: Decision Makers}

\begin{tabular}{|c|c|c|c|c|}
\hline & $\begin{array}{c}\text { Nonprofit } \\
(\mathrm{n}=20 / 80.0 \%)^{*}\end{array}$ & $\begin{array}{c}\text { Public } \\
(\mathrm{n}=18 / 64.2 \%)^{*}\end{array}$ & $\begin{array}{c}\text { For-Profit } \\
(\mathrm{n}=17 / 60.7 \%) *\end{array}$ & $\begin{array}{c}\text { Education } \\
(\mathrm{n}=6 / 75.0 \%) *\end{array}$ \\
\hline Board of Directors & $\begin{array}{l}\text { Adams }(2005,2006) \\
\text { Adams and Associates \& } \\
\quad \text { Management Performance } \\
\text { Concepts (2003) } \\
\text { Allison (2002) } \\
\text { Blouin, et al. (2006) } \\
\text { Carman, Leland, \& Wilson } \\
\quad \text { (2010) } \\
\text { CompassPoint (2004) } \\
\text { Duta (2008) } \\
\text { Fisher (2010) } \\
\text { Gamble (2008) } \\
\text { Hughes Butts (2008) } \\
\text { Mike (2004) } \\
\text { Redman (2006) } \\
\text { Santora \& Sarros (2001) } \\
\text { Shinn (2006) } \\
\text { Teegarden (2004) }\end{array}$ & $\begin{array}{l}\text { Jarrell \& Pewitt (2007) } \\
\text { Ley (2002) } \\
\text { Schmalzried \& Fallon (2007) }\end{array}$ & $\begin{array}{l}\text { Arnone (2006) } \\
\text { Cohn, Khurana, \& Reeves } \\
\quad(2005) \\
\text { Ip }(2009) \\
\text { Kim }(2010) \\
\text { Ready \& Conger (2007) } \\
\text { Swain \& Turpin }(2005)\end{array}$ & $\begin{array}{l}\text { Clunies (2004) } \\
\text { Richards (2009) }\end{array}$ \\
\hline $\begin{array}{l}\text { CEO } \\
\text { Executive Directors }\end{array}$ & $\begin{array}{l}\text { Adams (2005) } \\
\text { Adams and Associates \& } \\
\quad \text { Management Performance } \\
\text { Concepts (2003) } \\
\text { Blouin, et al. (2006) } \\
\text { Bolton \& Roy (2004) } \\
\text { Cadmus (2006) } \\
\text { Duta (2008) } \\
\text { Fisher (2010) } \\
\text { Gamble (2008) } \\
\text { Hughes Butts (2008) } \\
\text { Redman (2006) } \\
\text { Santora \& Sarros (1995) } \\
\text { Shinn (2006) }\end{array}$ & $\begin{array}{l}\text { Choudhury (2007) } \\
\text { Endres \& Alexander (2006) } \\
\text { Folkers (2008) } \\
\text { Hiteshew (2009) } \\
\text { Jarrell \& Pewitt (2007) } \\
\text { Kim (2003) } \\
\text { Ley (2002) } \\
\text { Lynn (2001) } \\
\text { Novak \& Beckman (2008) } \\
\text { Rothwell \& Poduch (2004) } \\
\text { Whitmore (2006) }\end{array}$ & $\begin{array}{l}\text { Arnone (2006) } \\
\text { Cairns (2009) } \\
\text { Carriere, Cummings, Muise, } \\
\quad \text { \& Newburn-Cook (2009) } \\
\text { Gaffney (2005) } \\
\text { Gandossy \& Kao (2004) } \\
\text { Gandz (2006) } \\
\text { Greer \& Virick (2008) } \\
\text { Heinen \& O'Neill (2004) } \\
\text { Huang (2001) } \\
\text { Ip (2009) } \\
\text { Kim (2010) } \\
\text { Kur \& Bunning (2002) } \\
\text { Rudis (2006) } \\
\text { Swain \& Turpin (2005) }\end{array}$ & $\begin{array}{l}\text { Clunies (2004) - Executives } \\
\text { Drew \& Ehrich (2010) } \\
\text { Richards (2009) } \\
\text { Roddy (2004) } \\
\text { Van Amburgh, et al. (2010) }\end{array}$ \\
\hline
\end{tabular}




\begin{tabular}{|c|c|c|c|c|}
\hline Senior management & $\begin{array}{l}\text { Adams and Associates \& } \\
\text { Management Performance } \\
\text { Concepts (2003) } \\
\text { Blouin, et al. (2006) } \\
\text { Bolton \& Roy (2004) } \\
\text { Cadmus (2006) } \\
\text { Fisher (2010) } \\
\text { Hughes Butts (2008) } \\
\text { Latif (2010) } \\
\text { Redman (2006) } \\
\text { Shinn (2006) }\end{array}$ & $\begin{array}{l}\text { Brown (2010) } \\
\text { Choudhury (2007) } \\
\text { Endres \& Alexander (2006) } \\
\text { Folkers (2008) } \\
\text { Hiteshew (2009) } \\
\text { Jarrell \& Pewitt (2007) } \\
\text { Kim (2003) } \\
\text { Ley (2002) } \\
\text { Lynn (2001) } \\
\text { Romejko (2008) } \\
\text { Rothwell \& Poduch (2004) } \\
\text { Valentine (2000) } \\
\text { Whitmore (2006) }\end{array}$ & $\begin{array}{l}\text { Arnone (2006) } \\
\text { Carriere, Cummings, Muise, } \\
\quad \text { \& Newburn-Cook (2009) } \\
\text { Cohn, Khurana, \& Reeves } \\
\quad(2005) \\
\text { Gaffney (2005) } \\
\text { Gandossy \& Kao (2004) } \\
\text { Gandz (2006) } \\
\text { Greer \& Virick (2008) } \\
\text { Heinen \& O'Neill (2004) } \\
\text { Huang (2001) } \\
\text { Kim (2010) } \\
\text { Kur \& Bunning (2002) } \\
\text { Ready \& Conger (2007) }\end{array}$ & $\begin{array}{l}\text { Clunies (2004) - Deans } \\
\text { Drew \& Ehrich (2010) } \\
\text { Van Amburgh, et al. (2010) }\end{array}$ \\
\hline Human resource personnel & $\begin{array}{l}\text { Bolton \& Roy (2004) } \\
\text { Hughes Butts (2008) } \\
\text { Latif (2010) }\end{array}$ & $\begin{array}{l}\text { Jarrell \& Pewitt (2007) } \\
\text { Lynn (2001) } \\
\text { Pynes (2004b) } \\
\text { Romejko (2008) } \\
\text { Whitmore (2006) }\end{array}$ & $\begin{array}{l}\text { Arnone (2006) } \\
\text { Cairns (2009) } \\
\text { Gandz (2006) } \\
\text { Huang (2001) } \\
\text { Huselid (1993) } \\
\text { Ip (2009) } \\
\text { Karaevli \& Hall (2002) } \\
\text { Kur \& Bunning (2002) }\end{array}$ & $\begin{array}{l}\text { Levin (2010)- HR exec. } \\
\text { Richards (2009) }\end{array}$ \\
\hline $\begin{array}{l}\text { Succession planning task } \\
\text { force / planning committee }\end{array}$ & $\begin{array}{l}\text { Duta }(2008) \text { - search } \\
\text { committee } \\
\text { Fisher }(2010) \text { - transition } \\
\text { team }\end{array}$ & $\begin{array}{l}\text { Endres \& Alexander (2006) } \\
\text { Goudreau \& Hardy (2006) } \\
\text { Pynes (2004b) } \\
\text { Quint (2009) }\end{array}$ & $\begin{array}{l}\text { Cohn, Khurana, \& Reeves } \\
(2005) \\
\text { Kur \& Bunning (2002) }\end{array}$ & \\
\hline Staff & $\begin{array}{l}\text { McCallin, Bamford-Wade, \& } \\
\text { Frankson (2009) } \\
\text { Shinn (2006) }\end{array}$ & Lynn (2001) - key personnel & $\begin{array}{l}\text { Ip (2009) - key personnel } \\
\text { Kim (2010) - succession } \\
\text { candidates }\end{array}$ & $\begin{array}{l}\text { Clunies (2004) - all levels } \\
\text { Richards (2009) - faculty }\end{array}$ \\
\hline $\begin{array}{l}\text { Other stakeholders (line } \\
\text { manager, financial officer, } \\
\text { staff, funders, service } \\
\text { recipients, and the } \\
\text { community-at-large) }\end{array}$ & $\begin{array}{l}\text { Latif (2010) } \\
\text { Shinn (2006) }\end{array}$ & $\begin{array}{l}\text { Folkers (2008) } \\
\text { Ley (2002) } \\
\text { Valentine }(2000)\end{array}$ & $\begin{array}{l}\text { Arnone (2006) } \\
\text { Cairns (2009) } \\
\text { Cohn, Khurana, \& Reeves } \\
\quad(2005) \\
\text { Gandz (2006) } \\
\text { Heinen \& O'Neill (2004) } \\
\text { Huang (2001) } \\
\text { Ready \& Conger (2007) }\end{array}$ & $\begin{array}{l}\text { Van Amburgh, et al. (2010) - } \\
\text { assistant deans \& dept. } \\
\text { chairs }\end{array}$ \\
\hline
\end{tabular}


Table 6: Participants in Succession Planning Programs.

\begin{tabular}{|c|c|c|c|c|}
\hline & $\begin{array}{c}\text { Nonprofit } \\
(\mathrm{n}=12 / 48.0 \%) *\end{array}$ & $\begin{array}{c}\text { Public } \\
(\mathrm{n}=20 / 71.4 \%)^{*}\end{array}$ & $\begin{array}{c}\text { For-Profit } \\
(\mathrm{n}=13 / 46.4 \%) *\end{array}$ & $\begin{array}{c}\text { Education } \\
(n=4 / 50.0 \%)^{*}\end{array}$ \\
\hline $\begin{array}{l}\text { Entire staff } \\
\text { New employees }\end{array}$ & $\begin{array}{l}\text { Adams (2005) } \\
\text { Bower (2000) } \\
\text { Cadmus (2006) } \\
\text { Carman, Leland, \& Wilson } \\
\quad(2010) \\
\text { Gamble (2008) } \\
\text { Kunreuther (2005) } \\
\text { Latif (2010) } \\
\text { McCallin, Bamford-Wade, \& } \\
\quad \text { Frankson (2009) }\end{array}$ & $\begin{array}{l}\text { Endres \& Alexander (2006) } \\
\text { Folkers (2008) } \\
\text { Gebbie \& Turnock (2006) } \\
\text { Goudreau \& Hardy (2006) } \\
\text { Holinsworth (2004) } \\
\text { Ingraham \& Getha-Taylor } \\
\quad(2004) \\
\text { Kim (2003) } \\
\text { Ley (2002) } \\
\text { Novak \& Beckman (2008) } \\
\text { Romejko (2008) } \\
\text { Rothwell \& Poduch (2004) } \\
\text { Valentine (2000) } \\
\text { Whitmore (2006) }\end{array}$ & $\begin{array}{l}\text { Gaffney (2005) } \\
\text { Gandz (2006) } \\
\text { Haynes \& Ghosh (2008) } \\
\text { Huselid (1993) } \\
\text { Kim (2010) } \\
\text { Kur \& Bunning (2002) }\end{array}$ & $\begin{array}{l}\text { Clunies (2004) } \\
\text { Van Amburgh, et al. (2010) }\end{array}$ \\
\hline $\begin{array}{l}\text { CEO } \\
\text { Executive Director }\end{array}$ & $\begin{array}{l}\text { Blouin, et al. (2006) } \\
\text { Hughes Butts (2008) } \\
\text { Kunreuther (2005) } \\
\text { McCallin, Bamford-Wade, \& } \\
\text { Frankson (2009) } \\
\text { Redman (2006) }\end{array}$ & Quint (2009) & Haynes \& Ghosh (2008) & Drew \& Ehrich (2010) \\
\hline Top level administrators & $\begin{array}{l}\text { Blouin, et al. (2006) } \\
\text { Hughes Butts (2008) } \\
\text { McCallin, Bamford-Wade, \& } \\
\text { Frankson (2009) } \\
\text { Redman (2006) }\end{array}$ & $\begin{array}{l}\text { Folkers (2008) } \\
\text { Goudreau \& Hardy (2006) } \\
\text { Holinsworth (2004) } \\
\text { Ibarra (2005) } \\
\text { Jarrell \& Pewitt (2007) } \\
\text { Kim (2003) } \\
\text { Lynn (2001) } \\
\text { Schmalzried \& Fallon (2007) }\end{array}$ & $\begin{array}{l}\text { Greer \& Virick (2008) } \\
\text { Haynes \& Ghosh (2008) }\end{array}$ & $\begin{array}{l}\text { Clunies (2004) - VPs } \\
\text { Drew \& Ehrich (2010) } \\
\text { Van Amburgh, et al. (2010) }\end{array}$ \\
\hline
\end{tabular}




\begin{tabular}{|c|c|c|c|c|}
\hline Pipeline or potential leaders & $\begin{array}{l}\text { Mike (2004) } \\
\text { Redman (2006) }\end{array}$ & $\begin{array}{l}\text { Ibarra (2005) } \\
\text { Kim (2003) } \\
\text { Lynn (2001) } \\
\text { Pennell (2010) } \\
\text { Schmalzried \& Fallon (2007) }\end{array}$ & $\begin{array}{l}\text { Berchelman (2005) } \\
\text { Cohn, Khurana, \& Reeves } \\
\quad(2005) \\
\text { Frauenheim (2006) } \\
\text { Gandossy \& Kao (2004) } \\
\text { Greer \& Virick (2008) } \\
\text { Heinen \& O'Neill (2004) } \\
\text { Ready \& Conger (2007) }\end{array}$ & Van Amburgh, et al. (2010) \\
\hline $\begin{array}{l}\text { First line manager } \\
\text { Beginning manager }\end{array}$ & $\begin{array}{l}\text { Cadmus (2006) } \\
\text { Hughes Butts (2008) } \\
\text { McCallin, Bamford-Wade, \& } \\
\text { Frankson (2009) }\end{array}$ & $\begin{array}{l}\text { Kim }(2003) \\
\text { Quint }(2009) \text { - middle } \\
\text { managers }\end{array}$ & & $\begin{array}{l}\text { Roddy (2004) - project } \\
\quad \text { directors }\end{array}$ \\
\hline High performing employees & & $\begin{array}{l}\text { Jarrell \& Pewitt (2007) } \\
\text { Naquin \& Holton (2003) }\end{array}$ & & \\
\hline
\end{tabular}


Table 7: Stakeholder Perceptions of Succession Planning

\begin{tabular}{|c|c|c|c|c|}
\hline & $\begin{array}{c}\text { Nonprofit } \\
(\mathrm{n}=16 / 64.0 \%)^{*}\end{array}$ & $\begin{array}{c}\text { Public } \\
(\mathrm{n}=14 / 50.0 \%)^{*} \\
\end{array}$ & $\begin{array}{c}\begin{array}{c}\text { For-Profit } \\
(\mathrm{n}=12 / 42.8 \%)^{*}\end{array} \\
\end{array}$ & $\begin{array}{c}\begin{array}{c}\text { Education } \\
(\mathrm{n}=5 / 62.5 \%)^{*}\end{array} \\
\end{array}$ \\
\hline \multicolumn{5}{|l|}{ Positive Perceptions } \\
\hline $\begin{array}{l}\text { SP is beneficial } \\
\text { SP is needed / opportunity } \\
\text { SP is a successful strategic } \\
\text { tool }\end{array}$ & $\begin{array}{l}\text { Allison (2002) } \\
\text { Bolton \& Roy (2004) } \\
\text { Duta (2008) } \\
\text { Fisher (2010) } \\
\text { Gowdy, et al. (2009) } \\
\text { Redman (2006) } \\
\text { Shinn (2006) }\end{array}$ & $\begin{array}{l}\text { Choudhury (2007) } \\
\text { Folkers (2008) } \\
\text { Goudreau \& Hardy (2006) } \\
\text { Helton \& Jackson (2007) } \\
\text { Liebowitz (2004) } \\
\text { Rothwell \& Poduch (2004) }\end{array}$ & $\begin{array}{l}\text { Frauenheim (2006) } \\
\text { Kim (2010) } \\
\text { Kur \& Bunning (2002) }\end{array}$ & $\begin{array}{l}\text { Estepp (1998) } \\
\text { Roddy (2004) } \\
\text { Van Amburgh, et al. (2010) }\end{array}$ \\
\hline $\begin{array}{l}\text { SP allows company to take } \\
\text { into account potential } \\
\text { leadership qualities when } \\
\text { hiring }\end{array}$ & & $\begin{array}{l}\text { Choudhury }(2007) \text { - match } \\
\text { org. values }\end{array}$ & $\begin{array}{l}\text { Fairweather (2000) } \\
\text { Gandossy \& Kao (2004) } \\
\text { Rudis (2006) }\end{array}$ & \\
\hline $\begin{array}{l}\text { SP programs allow } \\
\text { participants to learn to } \\
\text { adapt quickly to changing } \\
\text { environments } \\
\text { SP reduces unproductive } \\
\text { breaking-in period for new } \\
\text { employees }\end{array}$ & & Rothwell \& Poduch (2004) & $\begin{array}{l}\text { Gandossy \& Kao (2004) } \\
\text { Karaevli \& Hall (2002) }\end{array}$ & \\
\hline SP enhances diversity & & & $\begin{array}{l}\text { Greer \& Virick (2008) } \\
\text { Kim (2010) }\end{array}$ & \\
\hline $\begin{array}{l}\text { Emergency SP / replacement } \\
\text { planning should be used } \\
\text { for every position in org. }\end{array}$ & Shinn (2006) & & & \\
\hline $\begin{array}{l}\text { SP helps improve org. } \\
\text { processes }\end{array}$ & & Rothwell \& Poduch (2004) & & \\
\hline $\begin{array}{l}\text { SP programs are positive step } \\
\text { but need to be linked to } \\
\text { strategic plan }\end{array}$ & & & Karaevli \& Hall (2002) & \\
\hline
\end{tabular}




\begin{tabular}{|c|c|c|c|c|}
\hline $\begin{array}{l}\text { SP programs reduce brain } \\
\text { drain when leaders retire }\end{array}$ & & Liebowitz (2004) & & \\
\hline \multicolumn{5}{|l|}{ Negative Perceptions } \\
\hline $\begin{array}{l}\text { Lack of understanding of } \\
\text { importance of SP } \\
\text { Fear SP } \\
\text { Not all leaders see need for } \\
\text { SP }\end{array}$ & $\begin{array}{l}\text { Adams (2005) } \\
\text { Allison (2002) } \\
\text { Carman, Leland, \& Wilson (2010) } \\
\text { Duta (2008) } \\
\text { Fisher (2010) } \\
\text { Gamble (2008) } \\
\text { Shinn (2006) }\end{array}$ & $\begin{array}{l}\text { Ley (2002) } \\
\text { Liebowitz (2004) } \\
\text { Schmalzried \& Fallon } \\
\quad(2007)\end{array}$ & $\begin{array}{l}\text { Cohn, Khurana, \& Reeves } \\
\quad(2005) \\
\text { Huang (2001) }\end{array}$ & \\
\hline $\begin{array}{l}\text { Lack of attention to staff } \\
\text { concerns disrupts } \\
\text { performance and morale } \\
\text { Staff may leave if not given } \\
\text { opportunities to grow or } \\
\text { are not promoted }\end{array}$ & $\begin{array}{l}\text { Adams (2005) } \\
\text { Bolton \& Roy (2004) } \\
\text { Carman, Leland, \& Wilson (2010) }\end{array}$ & $\begin{array}{l}\text { Jarrell \& Pewitt (2007) } \\
\text { Ley (2002) }\end{array}$ & $\begin{array}{l}\text { Gaffney (2005) } \\
\text { Gandossy \& Kao (2004) }\end{array}$ & \\
\hline $\begin{array}{l}\text { Difficult to plan own } \\
\text { departures }\end{array}$ & $\begin{array}{l}\text { Blouin, et al. (2006) } \\
\text { Shinn (2006) }\end{array}$ & Liebowitz (2004) & $\begin{array}{l}\text { Cohn, Khurana, \& Reeves } \\
\quad(2005) \\
\text { Frauenheim (2006) }\end{array}$ & Estepp (1998) \\
\hline Lack of time and resources & $\begin{array}{l}\text { Adams (2006) } \\
\text { Mike (2004) } \\
\text { Shinn (2006) }\end{array}$ & $\begin{array}{l}\text { Folkers (2008) } \\
\text { Ley (2002) } \\
\text { Liebowitz (2004) }\end{array}$ & & $\begin{array}{l}\text { Estepp (1998) } \\
\text { Van Amburgh, et al. (2010) }\end{array}$ \\
\hline $\begin{array}{l}\text { Organization is not big } \\
\text { enough to have two people } \\
\text { qualified to act as } \\
\text { ED/leader }\end{array}$ & $\begin{array}{l}\text { Adams (2006) } \\
\text { Fisher (2010) } \\
\text { Gamble (2008) }\end{array}$ & & & \\
\hline $\begin{array}{l}\text { Job responsibility prohibiting } \\
\text { staff training opportunities } \\
\text { Senior managers should } \\
\text { remain responsive to } \\
\text { environment and needs of } \\
\text { org. }\end{array}$ & Mike (2004) & $\begin{array}{l}\text { Endres \& Alexander (2006) } \\
\text { Ley (2002) }\end{array}$ & & \\
\hline $\begin{array}{l}\text { Promoting from within is not } \\
\text { always preferred } \\
\text { Want outsiders to promote } \\
\text { organizational change }\end{array}$ & $\begin{array}{l}\text { Carman, Leland, \& Wilson (2010) } \\
\text { Duta (2008) } \\
\text { Santora \& Sarros (2001) }\end{array}$ & & & Estepp (1998) \\
\hline $\begin{array}{l}\text { Will appear disloyal to org. if } \\
\text { brought up SP }\end{array}$ & $\begin{array}{l}\text { Adams (2005) } \\
\text { Carman, Leland, \& Wilson (2010) }\end{array}$ & & & \\
\hline
\end{tabular}




\begin{tabular}{|c|c|c|c|c|}
\hline $\begin{array}{l}\text { Reluctance to lose staff to } \\
\text { other orgs. after they have } \\
\text { been trained }\end{array}$ & $\begin{array}{l}\text { Bolton \& Roy (2004) } \\
\text { Mike (2004) }\end{array}$ & & & Van Amburgh, et al. (2010) \\
\hline $\begin{array}{l}\text { Boards are not prepared } \\
\text { No experience or training } \\
\text { related to succession } \\
\text { planning } \\
\end{array}$ & Allison (2002) & Folkers (2008) & & \\
\hline $\begin{array}{l}\text { Organizational culture } \\
\text { inhibits succession } \\
\text { planning }\end{array}$ & & $\begin{array}{l}\text { Folkers (2008) } \\
\text { Hiteshew (2009) }\end{array}$ & & $\begin{array}{l}\text { Clunies (2004) } \\
\text { Estepp (1998) } \\
\text { Richards (2009) } \\
\text { Van Amburgh, et al. (2010) }\end{array}$ \\
\hline $\begin{array}{l}\text { SP is ad-hoc and reactive } \\
\text { SP is too slow and not } \\
\text { successful in long term }\end{array}$ & & Lynn (2001) & & \\
\hline $\begin{array}{l}\text { Perceived competition from } \\
\text { other employees is obstacle }\end{array}$ & & Liebowitz (2004) & & Estepp (1998) \\
\hline $\begin{array}{l}\text { May not be able to predict } \\
\text { future needs }\end{array}$ & Duta (2008) & & & Estepp (1998) \\
\hline \multicolumn{5}{|l|}{ Other Perceptions } \\
\hline $\begin{array}{l}\text { Transition success dependent } \\
\text { on board of directors or } \\
\text { focus on entire org. } \\
\text { Top level support needed }\end{array}$ & $\begin{array}{l}\text { Adams (2006) } \\
\text { Adams and Associates \& } \\
\text { Management Performance } \\
\text { Concepts (2003) } \\
\text { Mike (2004) } \\
\end{array}$ & $\begin{array}{l}\text { Ingraham \& Getha-Taylor } \\
\text { (2004) }\end{array}$ & $\begin{array}{l}\text { Cohn, Khurana, \& Reeves } \\
\quad(2005) \\
\text { Huang (2001) } \\
\text { Ready \& Conger (2007) }\end{array}$ & $\begin{array}{l}\text { Clunies (2004) } \\
\text { Richards (2009) } \\
\text { Van Amburgh, et al. (2010) }\end{array}$ \\
\hline $\begin{array}{l}\text { SP programs require honest } \\
\text { org. assessments }\end{array}$ & Adams (2005) & $\begin{array}{l}\text { Endres \& Alexander (2006) } \\
\text { Liebowitz (2004) }\end{array}$ & $\begin{array}{l}\text { Fairweather (2000) } \\
\text { Frauenheim (2006) }\end{array}$ & \\
\hline $\begin{array}{l}\text { SP should be open and } \\
\text { transparent allowing staff } \\
\text { to feel supported }\end{array}$ & Bolton \& Roy (2004) & Jarrell \& Pewitt (2007) & Gaffney (2005) & \\
\hline $\begin{array}{l}\text { SP program should be } \\
\text { adapted to agency's } \\
\text { context and needs } \\
\text { SP should include both } \\
\text { current knowledge and } \\
\text { skills and future needs }\end{array}$ & & $\begin{array}{l}\text { Choudhury (2007) } \\
\text { Endres \& Alexander (2006) } \\
\text { Hiteshew (2009) } \\
\text { Ley (2002) }\end{array}$ & & Clunies (2004) \\
\hline
\end{tabular}




\begin{tabular}{|c|l|l|l|}
\hline $\begin{array}{c}\text { Interest in continuation of } \\
\text { executive director's vision }\end{array}$ & $\begin{array}{l}\text { Duta (2008) } \\
\text { Santora \& Sarros (1995, 2001) }\end{array}$ & & \\
\hline $\begin{array}{c}\text { Interest in preserving org. or } \\
\text { its mission }\end{array}$ & $\begin{array}{l}\text { Santora \& Sarros (1995) } \\
\text { Shinn (2006) }\end{array}$ & Quint (2009) & \\
\hline $\begin{array}{l}\text { Employees should define } \\
\text { their own development } \\
\text { needs }\end{array}$ & Fisher (2010) & & \\
\hline $\begin{array}{l}\text { Management favorable } \\
\text { towards SP when ED } \\
\text { creates own plan }\end{array}$ & & & \\
\hline
\end{tabular}




\section{Table 8: Context and Impetus for Succession Planning}

\begin{tabular}{|c|c|c|c|c|}
\hline & $\begin{array}{c}\text { Nonprofit } \\
(\mathrm{n}=17 / 68.0 \%) *\end{array}$ & $\begin{array}{c}\text { Public } \\
(\mathrm{n}=22 / 78.5 \%) *\end{array}$ & $\begin{array}{c}\text { For-Profit } \\
(\mathrm{n}=18 / 64.2 \%) *\end{array}$ & $\begin{array}{c}\text { Education } \\
(\mathrm{n}=7 / 87.5 \%) *\end{array}$ \\
\hline Retirements & $\begin{array}{l}\text { Blouin, et al. (2006) } \\
\text { Cadmus (2006) } \\
\text { Carman, Leland, \& Wilson } \\
\quad(2010) \\
\text { CompassPoint (2004) } \\
\text { Duta (2008) } \\
\text { Gamble (2008) } \\
\text { Hughes Butts (2008) } \\
\text { Redman (2006) } \\
\text { Shinn (2006) }\end{array}$ & $\begin{array}{l}\text { Endres \& Alexander (2006) } \\
\text { Folkers (2008) } \\
\text { Gebbie \& Turnock (2006) } \\
\text { Goudreau \& Hardy (2006) } \\
\text { Helton \& Jackson (2007) } \\
\text { Herrera (2002) } \\
\text { Holinsworth (2004) } \\
\text { Ibarra (2005) } \\
\text { Jarrell \& Pewitt (2007) } \\
\text { Kim (2003) } \\
\text { Ley (2002) } \\
\text { Liebowitz (2004) } \\
\text { Pennell (2010) } \\
\text { Pynes (2004b) } \\
\text { Quint (2009) } \\
\text { Romejko (2008) } \\
\text { Rothwell \& Poduch (2004) }\end{array}$ & $\begin{array}{l}\text { Arnone }(2006) \\
\text { Fairweather }(2000) \\
\text { Frauenheim }(2006) \\
\text { Ready \& Conger }(2007)\end{array}$ & $\begin{array}{l}\text { Drew \& Ehrich (2010) } \\
\text { Levin (2010) } \\
\text { Parkman \& Beard (2008) } \\
\text { Roddy (2004) } \\
\text { Van Amburgh, et al. (2010) }\end{array}$ \\
\hline $\begin{array}{l}\text { CEO or ED transitions } \\
\text { Key leadership transitions }\end{array}$ & $\begin{array}{l}\text { Adams (2006) } \\
\text { Adams and Associates \& } \\
\quad \text { Management Performance } \\
\text { Concepts (2003) } \\
\text { Bolton \& Roy (2004) } \\
\text { Carman, Leland, \& Wilson } \\
\quad(2010) \\
\text { CompassPoint (2004) } \\
\text { Duta (2008) } \\
\text { Fisher (2010) } \\
\text { Santora \& Sarros (1995, 2001) } \\
\text { Shinn (2006) } \\
\text { Teegarden (2004) }\end{array}$ & $\begin{array}{l}\text { Hiteshew (2009) } \\
\text { Lynn (2001) } \\
\text { Romejko (2008) }\end{array}$ & $\begin{array}{l}\text { Dalton (2006) } \\
\text { Fairweather (2000) } \\
\text { Kaplan (2007) } \\
\text { Ready \& Conger (2007) }\end{array}$ & \\
\hline
\end{tabular}




\begin{tabular}{|c|c|c|c|c|}
\hline $\begin{array}{l}\text { Changing work environment } \\
\text { / funding structures } \\
\text { Organizational crisis }\end{array}$ & $\begin{array}{l}\text { Cadmus (2006) } \\
\text { CompassPoint (2004) } \\
\text { Duta (2008) } \\
\text { Gamble (2008) } \\
\text { Mike (2004) }\end{array}$ & $\begin{array}{l}\text { Pynes }(2004 b) \\
\text { Romejko (2008) } \\
\text { Valentine }(2000)\end{array}$ & $\begin{array}{l}\text { Gaffney (2005) } \\
\text { Karaevli \& Hall (2002) } \\
\text { Kur \& Bunning (2002) } \\
\text { Ready \& Conger (2007) } \\
\text { Rudis (2006) }\end{array}$ & $\begin{array}{l}\text { Parkman \& Beard (2008) } \\
\text { Van Amburgh, et al. (2010) }\end{array}$ \\
\hline Changing workforce & $\begin{array}{l}\text { Cadmus (2006) } \\
\text { Gamble (2008) }\end{array}$ & $\begin{array}{l}\text { Gebbie \& Turnock (2006) } \\
\text { Helton \& Jackson (2007) } \\
\text { Holinsworth (2004) } \\
\text { Pynes (2004b) } \\
\text { Romejko (2008) }\end{array}$ & $\begin{array}{l}\text { Arnone (2006) } \\
\text { Gaffney (2005) } \\
\text { Ready \& Conger (2007) }\end{array}$ & $\begin{array}{l}\text { Parkman \& Beard (2008) } \\
\text { Richards (2009) } \\
\text { Roddy (2004) }\end{array}$ \\
\hline $\begin{array}{l}\text { Employee turnover } \\
\text { Forecasted talent gap }\end{array}$ & & $\begin{array}{l}\text { Choudhury (2007) } \\
\text { Gebbie \& Turnock (2006) } \\
\text { Kim (2003) } \\
\text { Lynn (2001) } \\
\text { Pennell (2010) }\end{array}$ & $\begin{array}{l}\text { Carriere, Cummings, Muise, } \\
\text { \& Newburn-Cook (2009) } \\
\text { Frauenheim (2006) } \\
\text { Heinen \& O'Neill (2004) }\end{array}$ & \\
\hline $\begin{array}{l}\text { Competiveness } \\
\text { Tight job market }\end{array}$ & $\begin{array}{l}\text { Blouin, et al. (2006) } \\
\text { Fisher (2010) } \\
\text { Hughes Butts (2008) }\end{array}$ & & $\begin{array}{l}\text { Gaffney (2005) } \\
\text { Heinen \& O'Neill (2004) } \\
\text { Huang (2001) } \\
\text { Rudis (2006) } \\
\end{array}$ & Richards (2009) \\
\hline $\begin{array}{l}\text { Need for strong leaders } \\
\text { Increase talent pool }\end{array}$ & & $\begin{array}{l}\text { Folkers (2008) } \\
\text { Ingraham \& Getha-Taylor } \\
\quad(2004) \\
\text { Romejko (2008) } \\
\text { Young (2008) }\end{array}$ & $\operatorname{Kim}(2010)$ & Drew \& Ehrich (2010) \\
\hline $\begin{array}{l}\text { Loss of intellectual capital } \\
\text { Want continuity in } \\
\text { intellectual capital }\end{array}$ & & $\begin{array}{l}\text { Folkers (2008) } \\
\text { Holinsworth (2004) }\end{array}$ & $\begin{array}{l}\text { Carriere, Cummings, Muise, } \\
\& \text { Newburn-Cook (2009) }\end{array}$ & \\
\hline Downsizing / cost cutting & & $\begin{array}{l}\text { Kim }(2003) \\
\text { Pynes }(2004 b)\end{array}$ & Gandossy \& Kao (2004) & \\
\hline $\begin{array}{l}\text { Decreased development or } \\
\text { recognition opportunities }\end{array}$ & Blouin, et al. (2006) & Gebbie \& Turnock (2006) & & \\
\hline Reduced loyalty & & Ley $(2002)$ & Kaplan (2007) & \\
\hline Mandates & & $\begin{array}{l}\text { Goudreau \& Hardy (2006) } \\
\text { Romejko (2008) }\end{array}$ & & \\
\hline $\begin{array}{l}\text { Increase unionization and } \\
\text { professionalization of } \\
\text { personnel } \\
\end{array}$ & & $\begin{array}{l}\text { Choudhury (2007) } \\
\text { Helton \& Jackson (2007) }\end{array}$ & & \\
\hline
\end{tabular}




\begin{tabular}{|l|l|l|l|}
\hline $\begin{array}{c}\text { Expenses related to hiring } \\
\text { and training external } \\
\text { candidates }\end{array}$ & & $\begin{array}{l}\text { Frauenheim (2006) } \\
\text { Heinen \& O'Neill (2004) }\end{array}$ \\
\hline Enhance diversity & & $\begin{array}{l}\text { Greer \& Virick (2008) } \\
\text { Kim (2010) }\end{array}$ & $\begin{array}{l}\text { Estepp (1998) } \\
\text { Roddy (2004) }\end{array}$ \\
\hline $\begin{array}{l}\text { Need for a new type of SP } \\
\text { that focuses on team } \\
\text { building vs. individual } \\
\text { development }\end{array}$ & Folkers (2008) & Bunning (2002) \\
\hline $\begin{array}{l}\text { Support / implement } \\
\text { strategic plan }\end{array}$ & & Berchelman (2005, p. 11) \\
\hline $\begin{array}{c}\text { "We hope for sunshine and } \\
\text { plan for rain. Such is the } \\
\text { impetus for sound } \\
\text { succession planning" }\end{array}$ & & \\
\hline
\end{tabular}


Table 9: Organizational Placement of Program

\begin{tabular}{|c|c|c|c|c|}
\hline & $\begin{array}{c}\text { Nonprofit } \\
(\mathrm{n}=13 / 52.0 \%)^{*}\end{array}$ & $\begin{array}{c}\text { Public } \\
(\mathrm{n}=12 / 42.8 \%)^{*}\end{array}$ & $\begin{array}{c}\text { For-Profit } \\
(n=3 / 10.7 \%) *\end{array}$ & $\begin{array}{c}\text { Education } \\
(\mathrm{n}=2 / 25.0 \%) *\end{array}$ \\
\hline Board Level & $\begin{array}{l}\text { Adams (2006) } \\
\text { CompassPoint (2004) } \\
\text { Duta (2008) } \\
\text { Gamble (2008) } \\
\text { Santora \& Sarros (2001) } \\
\text { Shinn (2006) } \\
\text { Teegarden (2004) }\end{array}$ & & & Richards (2009) \\
\hline Executive Director Level & $\begin{array}{l}\text { Carman, Leland, \& Wilson } \\
(2010) \\
\text { Duta (2008) } \\
\text { Gamble (2008) } \\
\text { Hughes Butts (2008) } \\
\text { Mike (2004) } \\
\text { Santora \& Sarros (1995) } \\
\text { Shinn (2006) }\end{array}$ & $\begin{array}{l}\text { Gebbie \& Turnock (2006) } \\
\text { Holinsworth (2004) } \\
\text { Ley (2002) } \\
\text { Whitmore (2006) }\end{array}$ & Cairns (2009) - with HR help & $\begin{array}{l}\text { Richards (2009) } \\
\text { Van Amburgh, et al. (2010) - } \\
\text { senior admin team }\end{array}$ \\
\hline Human Resources Level & Bolton \& Roy (2004) & $\begin{array}{l}\text { Choudry (2007) } \\
\text { Gebbie \& Turnock (2006) } \\
\text { Ingraham \& Getha-Taylor } \\
(2004) \\
\text { Kim (2003) } \\
\text { Liebowitz (2004) } \\
\text { Lynn (2001) } \\
\text { Naquin \& Holton (2003) } \\
\text { Pynes (2004b) }\end{array}$ & Huselid (1993) & Richards (2009) \\
\hline Line manager & & & $\begin{array}{l}\text { Cohn, Khurana, \& Reeves } \\
(2005)\end{array}$ & \\
\hline All levels, including staff & Redman (2006) & Goudreau \& Hardy (2006) & & \\
\hline
\end{tabular}


Table 10: Timeline of Succession Program

\begin{tabular}{|c|c|c|c|c|}
\hline & $\begin{array}{c}\text { Nonprofit } \\
(\mathrm{n}=10 / 40.0 \%)^{*}\end{array}$ & $\begin{array}{c}\text { Public } \\
(\mathrm{n}=7 / 25.0 \%)^{*}\end{array}$ & $\begin{array}{c}\text { For-Profit } \\
(\mathrm{n}=9 / 36.0 \%)^{*}\end{array}$ & $\begin{array}{c}\text { Education } \\
(\mathrm{n}=2 / 25.0 \%)^{*}\end{array}$ \\
\hline \multicolumn{5}{|l|}{ Planning / Preparation } \\
\hline month to years & $\begin{array}{l}\text { Adams (2005) } \\
\text { CompassPoint (2004) } \\
\text { Mike (2004) }\end{array}$ & Goudreau \& Hardy (2006) & & \\
\hline 2-4 months & & & Kur \& Bunning (2002) & \\
\hline 9 months & & Jarrell \& Pewitt (2007) & & \\
\hline 1 year & & Valentine (2000) & & \\
\hline \multicolumn{5}{|l|}{ Implementation } \\
\hline 6-9 months & $\begin{array}{l}\text { Adams (2005) - if already } \\
\text { planned }\end{array}$ & & Kur \& Bunning (2002) & \\
\hline 1-2 years & $\begin{array}{l}\text { Adams (2006) } \\
\text { Duta (2008) } \\
\text { Hughes Butts (2008) } \\
\text { Mike (2004) }\end{array}$ & $\begin{array}{l}\text { Ingraham \& Getha-Taylor } \\
(2004) \\
\text { Romejko (2008) }\end{array}$ & Ip (2009) & \\
\hline 3 years & $\begin{array}{l}\text { Fisher (2010) } \\
\text { Gamble (2008) - 24-36 } \\
\text { months }\end{array}$ & & Naveen (2000) & Clunies (2004) - 2-3 years \\
\hline $\begin{array}{l}\text { Varies depending on } \\
\text { needs of the } \\
\text { organization }\end{array}$ & Fisher (2010) & $\begin{array}{l}\text { Romejko (2008) - look at } \\
\text { short term project needs }\end{array}$ & $\begin{array}{l}\text { Carriere, Cummings, Muise, } \\
\& \text { Newburn-Cook (2009) }\end{array}$ & \\
\hline Long-term & $\begin{array}{l}\text { Fisher (2010) } \\
\text { Redman (2006) }\end{array}$ & & $\begin{array}{l}\text { Fairweather (2000) } \\
\text { Gandossy \& Kao (2004) } \\
\text { Greer \& Virick (2008) } \\
\text { Swain \& Turpin }(2005)-7 \\
\text { years }\end{array}$ & Roddy (2004) - 10 years \\
\hline $\begin{array}{l}\text { Related to Short- and } \\
\text { Long-Term Goals }\end{array}$ & $\begin{array}{l}\text { McCallin, Bamford-Wade, \& } \\
\text { Frankson (2009) }\end{array}$ & $\begin{array}{l}\text { Brown (2010) } \\
\text { Endres \& Alexander (2006) }\end{array}$ & & \\
\hline Early & & & $\begin{array}{l}\text { Carriere, Cummings, Muise, } \\
\& \text { Newburn-Cook (2009) } \\
\text { Cohn, Khurana, \& Reeves } \\
(2005)\end{array}$ & \\
\hline
\end{tabular}


Table 11: Types and Elements of Succession Plans

\begin{tabular}{|c|c|c|c|c|}
\hline & Nonprofit & Public & For-Profit & Education \\
\hline Written Plan & $(\mathrm{n}=6 / 24.0 \%)^{*}$ & $(n=13 / 46.4 \%)^{*}$ & $(n=10 / 35.7 \%)^{*}$ & $(\mathrm{n}=3 / 37.5 \%)^{*}$ \\
\hline Individual employee plans & $\begin{array}{l}\text { Cadmus (2006) } \\
\text { Latif (2010) } \\
\text { McCallin, Bamford-Wade, } \\
\text { Frankson (2009) } \\
\text { Redman (2006) }\end{array}$ & $\begin{array}{l}\text { Endres \& Alexander (2006) } \\
\text { Folkers (2008) } \\
\text { Goudreau \& Hardy (2006) } \\
\text { Holinsworth (2004) } \\
\text { Ingraham \& Getha-Taylor } \\
\text { (2004) } \\
\text { Ley (2002) } \\
\text { Pynes (2004b) } \\
\text { Romejko (2008) } \\
\text { Whitmore (2006) }\end{array}$ & $\begin{array}{l}\text { Cairns (2009) } \\
\text { Gaffney (2005) } \\
\text { Haworth (2005) } \\
\text { Huang (2001) } \\
\text { Karaevli \& Hall (2002) }\end{array}$ & \\
\hline Job descriptions & $\begin{array}{l}\text { Fisher }(2010) \\
\text { Redman }(2006) \\
\text { Shinn }(2006)\end{array}$ & $\begin{array}{l}\text { Brown (2010) } \\
\text { Folkers (2008) } \\
\text { Helton \& Jackson (2007) } \\
\text { Holinsworth (2004) } \\
\text { Pynes (2004b) } \\
\text { Quint (2009) } \\
\text { Rothwell \& Poduch (2004) } \\
\end{array}$ & Huselid (1993) & $\begin{array}{l}\text { Clunies (2004) } \\
\text { Van Amburgh, et al. (2010) }\end{array}$ \\
\hline $\begin{array}{l}\text { Use technology } \\
\text { Keep records }\end{array}$ & & $\begin{array}{l}\text { Endres \& Alexander (2006) } \\
\text { Folkers (2008) } \\
\text { Pynes (2004b) }\end{array}$ & $\begin{array}{l}\text { Arnone (2006) } \\
\text { Frauenheim (2006) } \\
\text { Heinen \& O’Neill (2004) } \\
\text { Karaevli \& Hall (2002) }\end{array}$ & $\begin{array}{l}\text { Clunies (2004) } \\
\text { Roddy (2004) - Website } \\
\text { Van Amburgh, et al. (2010) }\end{array}$ \\
\hline $\begin{array}{l}\text { Readiness indicators (ready } \\
\text { now, ready in } 1 \text { year, ready } \\
\text { in future) }\end{array}$ & & Endres \& Alexander (2006) & Greer \& Virick (2008) & \\
\hline Establish event schedule & & Folkers (2008) & & \\
\hline
\end{tabular}




\begin{tabular}{|c|c|c|c|c|}
\hline Evaluation / Accountability & $(n=6 / 24.0 \%)^{*}$ & $(n=16 / 57.1 \%)^{*}$ & $(n=18 / 64.2 \%)^{*}$ & $(n=5 / 62.5 \%)^{*}$ \\
\hline $\begin{array}{l}\text { Clear expectations } \\
\text { Measures of success (of SP) } \\
\text { Accountability }\end{array}$ & $\begin{array}{l}\text { Adams (2006) } \\
\text { Redman (2006) } \\
\text { Shinn (2006) }\end{array}$ & $\begin{array}{l}\text { Choudry (2007) } \\
\text { Endres \& Alexander (2006) } \\
\text { Folkers (2008) } \\
\text { Herrera (2002) } \\
\text { Hiteshew (2009) } \\
\text { Holinsworth (2004) } \\
\text { Ibarra (2005) } \\
\text { Jarrell \& Pewitt (2007) } \\
\text { Lynn (2001) } \\
\text { Romejko (2008) } \\
\text { Rothwell \& Poduch (2004) }\end{array}$ & $\begin{array}{l}\text { Bleak \& Fulmer (2009) } \\
\text { Carriere, Cummings, Muise, } \\
\text { \& Newburn-Cook (2009) } \\
\text { Dalton (2006) } \\
\text { Haynes \& Ghosh (2008) } \\
\text { Heinen \& O’Neill (2004) } \\
\text { Huang (2001) } \\
\text { Ip (2009) } \\
\text { Karaevli \& Hall (2002) } \\
\text { Kim (2010) } \\
\text { Ready \& Conger (2007) }\end{array}$ & $\begin{array}{l}\text { Clunies (2004) } \\
\text { Drew \& Ehrich (2010) } \\
\text { Parkman \& Beard (2008) } \\
\text { Richards (2009) } \\
\text { Van Amburgh, et al. (2010) }\end{array}$ \\
\hline $\begin{array}{l}\text { Measurable indicators of } \\
\text { performance (of employee) } \\
\text { Process to track performance }\end{array}$ & $\begin{array}{l}\text { Fisher (2010) } \\
\text { McCallin, Bamford-Wade, \& } \\
\text { Frankson (2009) } \\
\text { Redman (2006) } \\
\text { Shinn (2006) }\end{array}$ & $\begin{array}{l}\text { Endres \& Alexander (2006) } \\
\text { Folkers (2008) } \\
\text { Helton \& Jackson (2007) } \\
\text { Holinsworth (2004) } \\
\text { Ibarra (2005) } \\
\text { Lynn (2001) } \\
\text { Pennell (2010) } \\
\text { Quint (2009) }\end{array}$ & $\begin{array}{l}\text { Berchelman (2005) } \\
\text { Bleak \& Fulmer (2009) } \\
\text { Cairns (2009) } \\
\text { Dalton (2006) } \\
\text { Gandz (2006) } \\
\text { Heinen \& O’Neill (2004) } \\
\text { Huang (2001) } \\
\text { Ip (2009) } \\
\text { Karaevli \& Hall (2002) } \\
\text { Swain \& Turpin (2005) }\end{array}$ & $\begin{array}{l}\text { Drew \& Ehrich (2010) } \\
\text { Parkman \& Beard (2008) } \\
\text { Richards (2009) } \\
\text { Van Amburgh, et al. (2010) }\end{array}$ \\
\hline $\begin{array}{l}\text { Allow flexibility (of SP and to } \\
\text { redefine vacant positions, } \\
\text { reallocate employees, } \\
\text { outsource jobs) }\end{array}$ & $\begin{array}{l}\text { Fisher (2010) } \\
\text { Hughes Butts (2008) }\end{array}$ & $\begin{array}{l}\text { Hiteshew (2009) } \\
\text { Jarrell \& Pewitt (2007) } \\
\text { Pennell (2010) } \\
\text { Romejko (2008) } \\
\text { Young (2008) }\end{array}$ & $\begin{array}{l}\text { Bleak \& Fulmer (2009) } \\
\text { Gandossy \& Kao (2004) } \\
\text { Huselid (1993) } \\
\text { Kur \& Bunning (2002) }\end{array}$ & $\begin{array}{l}\text { Clunies (2004) } \\
\text { Drew \& Ehrich (2010) } \\
\text { Van Amburgh, et al. (2010) }\end{array}$ \\
\hline Recognize and reward & & $\begin{array}{l}\text { Folkers }(2008) \\
\text { Pynes }(2004 b)\end{array}$ & $\begin{array}{l}\text { Gandossy \& Kao (2004) } \\
\text { Haworth (2005) } \\
\text { Heinen \& O’Neill (2004) }\end{array}$ & \\
\hline
\end{tabular}




\begin{tabular}{|c|c|c|c|c|}
\hline Employee Opportunities & $(n=15 / 60.0 \%)^{*}$ & $(n=22 / 78.5 \%)^{*}$ & $(n=17 / 60.7 \%)^{*}$ & $(n=7 / 87.5 \%)^{*}$ \\
\hline $\begin{array}{l}\text { Training and expanding } \\
\text { network opportunities of } \\
\text { current and potential } \\
\text { executives } \\
\text { Development opportunities } \\
\text { Leadership development }\end{array}$ & $\begin{array}{l}\text { Adams and Associates \& } \\
\text { Management Performance } \\
\text { Concepts (2003) } \\
\text { Blouin, et al. (2006) } \\
\text { Bolton \& Roy (2004) } \\
\text { Bower (2000) } \\
\text { Hughes Butts (2008) } \\
\text { Kunreuther (2005) } \\
\text { Latif (2010) } \\
\text { McCallin, Bamford-Wade, } \\
\text { Frankson (2009) } \\
\text { Redman (2006) }\end{array}$ & $\begin{array}{l}\text { Folkers (2008) } \\
\text { Gebbie \& Turnock (2006) } \\
\text { Helton \& Jackson (2007) } \\
\text { Hiteshew (2009) } \\
\text { Holinsworth (2004) } \\
\text { Ibarra (2005) } \\
\text { Jarrell \& Pewitt (2007) } \\
\text { Ley (2002) } \\
\text { Lynn (2001) } \\
\text { Naquin \& Holton (2003) } \\
\text { Pennell (2010) } \\
\text { Quint (2009) } \\
\text { Romejko (2008) } \\
\text { Whitmore (2006) } \\
\text { Young (2008) }\end{array}$ & $\begin{array}{l}\text { Arnone (2006) } \\
\text { Berchelman (2005) } \\
\text { Carriere, Cummings, Muise, } \\
\text { \& Newburn-Cook (2009) } \\
\text { Frauenheim (2006) } \\
\text { Gandossy \& Kao (2004) } \\
\text { Gandz (2006) } \\
\text { Haworth (2005) - offer but } \\
\text { don't make promises } \\
\text { Karaevli \& Hall (2002) } \\
\text { Kim (2010) } \\
\text { Ready \& Conger (2007) }\end{array}$ & $\begin{array}{l}\text { Estepp (1998) } \\
\text { Parkman \& Beard (2008) } \\
\text { Richards (2009) } \\
\text { Roddy (2004) } \\
\text { Van Amburgh, et al. (2010) }\end{array}$ \\
\hline $\begin{array}{l}\text { Opportunities to exchange } \\
\text { experience and knowledge } \\
\text { Intergenerational dialogue } \\
\text { Mentoring } \\
\text { Coaching }\end{array}$ & $\begin{array}{l}\text { Adams (2005) } \\
\text { Adams and Associates \& } \\
\text { Management Performance } \\
\text { Concepts (2003) } \\
\text { Bower (2000) } \\
\text { Cadmus (2006) } \\
\text { Gamble (2008) } \\
\text { Kunreuther (2005) } \\
\text { Latif (2010) } \\
\text { McCallin, Bamford-Wade, } \\
\text { Frankson (2009) } \\
\text { Redman (2006) } \\
\text { Teegarden (2004) }\end{array}$ & $\begin{array}{l}\text { Brown (2010) } \\
\text { Endres \& Alexander (2006) } \\
\text { Folkers (2008) } \\
\text { Goudreau \& Hardy (2006) } \\
\text { Ingraham \& Getha-Taylor } \\
\text { (2004) } \\
\text { Kim (2003) } \\
\text { Ley (2002) } \\
\text { Pennell (2010) } \\
\text { Pynes (2004b) } \\
\text { Quint (2009) } \\
\text { Romejko (2008) } \\
\text { Young (2008) }\end{array}$ & $\begin{array}{l}\text { Arnone (2006) } \\
\text { Carriere, Cummings, Muise, } \\
\text { \& Newburn-Cook (2009) } \\
\text { Cohn, Khurana, \& Reeves } \\
\text { (2005) } \\
\text { Greer \& Virick (2008) } \\
\text { Haworth (2005) } \\
\text { Haynes \& Ghosh (2008) } \\
\text { Heinen \& O’Neill (2004) } \\
\text { Karaevli \& Hall (2002) }\end{array}$ & $\begin{array}{l}\text { Levin (2010) } \\
\text { Parkman \& Beard (2008) } \\
\text { Roddy (2004) } \\
\text { Van Amburgh, et al. (2010) }\end{array}$ \\
\hline $\begin{array}{l}\text { Cross training } \\
\text { Opportunities to gain } \\
\text { experience across } \\
\text { organization } \\
\text { Special job assignments }\end{array}$ & $\begin{array}{l}\text { Carman, Leland, \& Wilson } \\
\text { (2010) } \\
\text { Latif (2010) }\end{array}$ & $\begin{array}{l}\text { Brown (2010) } \\
\text { Endres \& Alexander (2006) } \\
\text { Folkers (2008) } \\
\text { Helton \& Jackson (2007) } \\
\text { Pennell (2010) } \\
\text { Pynes (2004b) }\end{array}$ & $\begin{array}{l}\text { Cohn, Khurana, \& Reeves } \\
(2005) \\
\text { Gandossy \& Kao (2004) } \\
\text { Haworth (2005) } \\
\text { Haynes \& Ghosh (2008) } \\
\text { Heinen \& O’Neill (2004) } \\
\text { Huselid (1993) } \\
\text { Karaevli \& Hall (2002) } \\
\text { Kur \& Bunning (2002) } \\
\text { Ready \& Conger (2007) }\end{array}$ & $\begin{array}{l}\text { Clunies (2004) } \\
\text { Estepp (1998) - leadership } \\
\text { rotations } \\
\text { Levin (2010) } \\
\text { Roddy (2004) } \\
\text { Van Amburgh, et al. (2010) }\end{array}$ \\
\hline
\end{tabular}




\begin{tabular}{|c|c|c|c|c|}
\hline $\begin{array}{l}\text { Opportunities to learn } \\
\text { management skills }\end{array}$ & $\begin{array}{l}\text { Mike (2004) } \\
\text { Redman (2006) }\end{array}$ & $\begin{array}{l}\text { Folkers (2008) } \\
\text { Ibarra (2005) }\end{array}$ & Arnone (2006) & $\begin{array}{l}\text { Roddy (2004) } \\
\text { Van Amburgh, et al. (2010) }\end{array}$ \\
\hline $\begin{array}{l}\text { Offer opportunities for } \\
\text { retired employees to reduce } \\
\text { hours but still contribute to } \\
\text { field }\end{array}$ & Teegarden (2004) & Liebowitz (2004) & Arnone (2006) & \\
\hline $\begin{array}{l}\text { Opportunities for sabbaticals } \\
\text { Off-site learning (i.e., } \\
\text { degrees; association } \\
\text { memberships) }\end{array}$ & $\begin{array}{l}\text { Adams and Associates \& } \\
\text { Management Performance } \\
\text { Concepts (2003) }\end{array}$ & $\begin{array}{l}\text { Folkers }(2008) \\
\text { Pynes }(2004 b)\end{array}$ & & $\begin{array}{l}\text { Levin (2010) } \\
\text { Roddy (2004) } \\
\text { Van Amburgh, et al. (2010) }\end{array}$ \\
\hline $\begin{array}{l}\text { Retain relationship with } \\
\text { former employees in case } \\
\text { they may return }\end{array}$ & & & Cappelli (2008) & \\
\hline Encourage self-development & & & Cappelli (2008) & \\
\hline Preparation & $(\mathrm{n}=8 / 32.0 \%)^{*}$ & $(n=22 / 78.5 \%)^{*}$ & $(n=19 / 67.8 \%)^{*}$ & $(\mathrm{n}=7 / 87.5 \%)^{*}$ \\
\hline $\begin{array}{l}\text { Analyze current leadership } \\
\text { skills and future leadership } \\
\text { needs } \\
\text { Competency-based program }\end{array}$ & $\begin{array}{l}\text { Adams (2006) } \\
\text { Bolton \& Roy (2004) } \\
\text { Cadmus (2006) } \\
\text { Latif (2010) } \\
\text { McCallin, Bamford-Wade, } \\
\text { Frankson (2009) } \\
\text { Redman (2006) }\end{array}$ & $\begin{array}{l}\text { Choudry (2007) } \\
\text { Herrera (2002) } \\
\text { Hiteshew (2009) } \\
\text { Ibarra (2005) } \\
\text { Jarrell \& Pewitt (2007) } \\
\text { Novak \& Beckman (2008) } \\
\text { Pennell (2010) } \\
\text { Pynes (2004b) } \\
\text { Quint (2009) } \\
\end{array}$ & $\begin{array}{l}\text { Arnone (2006) } \\
\text { Carriere, Cummings, Muise, } \\
\text { \& Newburn-Cook (2009) } \\
\text { Haynes \& Ghosh (2008) } \\
\text { Huang (2001) } \\
\text { Huselid (1993) } \\
\text { Ip (2009) } \\
\text { Kur \& Bunning (2002) }\end{array}$ & $\begin{array}{l}\text { Clunies (2004) } \\
\text { Drew \& Ehrich (2010) } \\
\text { Richards (2009) } \\
\text { Roddy (2004) }\end{array}$ \\
\hline $\begin{array}{l}\text { Analyze current and future } \\
\text { organization needs }\end{array}$ & $\begin{array}{l}\text { Allison (2002) } \\
\text { Fisher (2010) }\end{array}$ & $\begin{array}{l}\text { Herrera (2002) } \\
\text { Hiteshew (2009) } \\
\text { Jarrell \& Pewitt (2007) } \\
\text { Ley (2002) } \\
\text { Lynn (2001) } \\
\text { Naquin \& Holton (2003) } \\
\text { Pynes (2004b) } \\
\text { Whitmore (2006) }\end{array}$ & $\begin{array}{l}\text { Dalton (2006) } \\
\text { Gaffney (2005) } \\
\text { Gandz (2006) } \\
\text { Haworth (2005) } \\
\text { Haynes \& Ghosh (2008) } \\
\text { Heinen \& O’Neill (2004) } \\
\text { Ip (2009) } \\
\text { Kim (2010) } \\
\text { Ready \& Conger (2007) } \\
\end{array}$ & $\begin{array}{l}\text { Clunies (2004) } \\
\text { Drew \& Ehrich (2010) }\end{array}$ \\
\hline
\end{tabular}




\begin{tabular}{|c|c|c|c|c|}
\hline $\begin{array}{l}\text { Identify key positions at all } \\
\text { levels that are essential for } \\
\text { org. success }\end{array}$ & Redman (2006) & $\begin{array}{l}\text { Herrera (2002) } \\
\text { Hiteshew (2009) } \\
\text { Holinsworth (2004) } \\
\text { Ibarra (2005) } \\
\text { Kim (2003) } \\
\text { Ley (2002) } \\
\text { Rothwell \& Poduch (2004) } \\
\text { Whitmore (2006) } \\
\end{array}$ & $\begin{array}{l}\text { Carriere, Cummings, Muise, } \\
\& \text { Newburn-Cook (2009) } \\
\text { Kim (2010) }\end{array}$ & Van Amburgh, et al. (2010) \\
\hline $\begin{array}{l}\text { Analyze workforce } \\
\text { composition (attrition } \\
\text { forecast; supply \& demand } \\
\text { and gap analyses) }\end{array}$ & & $\begin{array}{l}\text { Brown (2010) } \\
\text { Choudry (2007) } \\
\text { Gebbie \& Turnock (2006) } \\
\text { Helton \& Jackson (2007) } \\
\text { Herrera (2002) } \\
\text { Ibarra (2005) } \\
\text { Kim (2003) } \\
\text { Pennell (2010) } \\
\text { Pynes (2004b) } \\
\text { Romejko (2008) } \\
\text { Rothwell \& Poduch (2004) }\end{array}$ & $\begin{array}{l}\text { Arnone (2006) } \\
\text { Cohn, Khurana, \& Reeves } \\
(2005) \\
\text { Frauenheim (2006) } \\
\text { Gaffney (2005) } \\
\text { Haworth (2005) } \\
\text { Huselid (1993) }\end{array}$ & \\
\hline $\begin{array}{l}\text { Participant identification } \\
\text { process }\end{array}$ & & $\begin{array}{l}\text { Folkers (2008) } \\
\text { Hiteshew (2009) } \\
\text { Ibarra (2005) } \\
\text { Kim (2003) } \\
\text { Lynn (2001) } \\
\text { Pennell (2010) } \\
\text { Quint (2009) } \\
\text { Romejko (2008) } \\
\text { Young (2008) } \\
\end{array}$ & $\begin{array}{l}\text { Arnone (2006) } \\
\text { Berchelman (2005) } \\
\text { Carriere, Cummings, Muise, } \\
\text { \& Newburn-Cook (2009) } \\
\text { Huang (2001) } \\
\text { Karaevli \& Hall (2002) - } \\
\text { opposite what traditionally do } \\
\text { Kim (2010) } \\
\text { Kur \& Bunning (2002) } \\
\end{array}$ & $\begin{array}{l}\text { Roddy (2004) } \\
\text { Van Amburgh, et al. (2010) }\end{array}$ \\
\hline $\begin{array}{l}\text { Identify process to transfer } \\
\text { knowledge }\end{array}$ & & $\begin{array}{l}\text { Folkers (2008) } \\
\text { Hiteshew (2009) } \\
\text { Rothwell \& Poduch (2004) }\end{array}$ & $\begin{array}{l}\text { Arnone (2006) } \\
\text { Ip (2009) }\end{array}$ & \\
\hline $\begin{array}{l}\text { Incorporate employee input } \\
\text { Employee career plans and } \\
\text { goals included in plan }\end{array}$ & & Holinsworth (2004) & $\begin{array}{l}\text { Frauenheim (2006) } \\
\text { Huang (2001) }\end{array}$ & $\begin{array}{l}\text { Levin (2010) } \\
\text { Roddy (2004) }\end{array}$ \\
\hline $\begin{array}{l}\text { Identify opportunities for } \\
\text { growth }\end{array}$ & Bolton \& Roy (2004) & & & \\
\hline Link to HR activities & & Romejko (2008) & & $\begin{array}{l}\text { Clunies (2004) } \\
\text { Parkman \& Beard (2008) }\end{array}$ \\
\hline
\end{tabular}




\begin{tabular}{|c|c|c|c|c|}
\hline $\begin{array}{l}\text { Underestimate future needs / } \\
\text { hire externally to cover } \\
\text { gaps }\end{array}$ & & & Cappelli (2008) & \\
\hline Implementation & $(\mathrm{n}=8 / 32.0 \%)^{*}$ & $(\mathrm{n}=8 / 28.5 \%)^{*}$ & $(n=3 / 10.7 \%)^{*}$ & $(n=6 / 75.0 \%)^{*}$ \\
\hline $\begin{array}{l}\text { Tailored to the individual } \\
\text { organization and its sector }\end{array}$ & $\begin{array}{l}\text { Blouin, et al. (2006) } \\
\text { McCallin, Bamford-Wade, \& } \\
\text { Frankson (2009) } \\
\text { Mike (2004) } \\
\text { Shinn (2006) }\end{array}$ & $\begin{array}{l}\text { Endres \& Alexander (2006) } \\
\text { Herrera (2002) } \\
\text { Holinsworth (2004) } \\
\text { Pynes (2004b) } \\
\text { Quint (2009) } \\
\text { Whitmore (2006) }\end{array}$ & $\begin{array}{l}\text { Heinen \& O’Neill (2004) } \\
\text { Ip (2009) } \\
\text { Karaevli \& Hall (2002) }\end{array}$ & $\begin{array}{l}\text { Clunies (2004) } \\
\text { Drew \& Ehrich (2010) } \\
\text { Richards (2009) }\end{array}$ \\
\hline $\begin{array}{l}\text { Focus on recruitment and } \\
\text { retention of young leaders } \\
\text { Proactive in promotion }\end{array}$ & $\begin{array}{l}\text { Kunreuther (2005) } \\
\text { Teegarden (2004) }\end{array}$ & $\begin{array}{l}\text { Choudry (2007) } \\
\text { Young (2008) }\end{array}$ & & \\
\hline $\begin{array}{l}\text { Guidance on how to manage } \\
\text { transitions }\end{array}$ & $\begin{array}{l}\text { Allison (2002) } \\
\text { Fisher (2010) } \\
\text { Shinn (2006) }\end{array}$ & & & \\
\hline Promote work-life balance & Kunreuther (2005) & & & Parkman \& Beard (2008) \\
\hline $\begin{array}{l}\text { Communication and } \\
\text { transparency is important }\end{array}$ & & & & $\begin{array}{l}\text { Drew \& Ehrich (2010) } \\
\text { Levin (2010) } \\
\text { Richards (2009) } \\
\text { Van Amburgh, et al. (2010) } \\
\end{array}$ \\
\hline $\begin{array}{l}\text { Succession Planning - } \\
\text { General }\end{array}$ & $(n=6 / 24.0 \%)^{*}$ & $(n=18 / 64.2 \%)^{*}$ & $(\mathrm{n}=11 / 39.2 \%)^{*}$ & $(n=6 / 75.0 \%)^{*}$ \\
\hline $\begin{array}{l}\text { Link to org. strategic plan, } \\
\text { mission and goals }\end{array}$ & $\begin{array}{l}\text { Hughes Butts (2008) } \\
\text { Latif (2010) } \\
\text { McCallin, Bamford-Wade, \& } \\
\text { Frankson (2009) }\end{array}$ & $\begin{array}{l}\text { Brown (2010) } \\
\text { Choudry (2007) } \\
\text { Endres \& Alexander (2006) } \\
\text { Folkers (2008) } \\
\text { Hiteshew (2009) } \\
\text { Holinsworth (2004) } \\
\text { Jarrell \& Pewitt (2007) } \\
\text { Ley (2002) } \\
\text { Lynn (2001) } \\
\text { Pennell (2010) } \\
\text { Quint (2009) } \\
\text { Romejko (2008) } \\
\text { Rothwell \& Poduch (2004) } \\
\text { Whitmore (2006) }\end{array}$ & $\begin{array}{l}\text { Bleak \& Fulmer (2009) } \\
\text { Frauenheim (2006) } \\
\text { Gaffney (2005) } \\
\text { Heinen \& O’Neill (2004) } \\
\text { Huselid (1993) } \\
\text { Ready \& Conger (2007) }\end{array}$ & $\begin{array}{l}\text { Clunies (2004) } \\
\text { Drew \& Ehrich (2010) } \\
\text { Estepp (1998) } \\
\text { Richards (2009) }\end{array}$ \\
\hline
\end{tabular}




\begin{tabular}{|c|c|c|c|c|}
\hline $\begin{array}{l}\text { Consider sustainability of SP } \\
\text { Enough time and resources }\end{array}$ & Hughes Butts (2008) & $\begin{array}{l}\text { Folkers (2008) } \\
\text { Jarrell \& Pewitt (2007) } \\
\text { Pynes (2004b) }\end{array}$ & $\begin{array}{l}\text { Carriere, Cummings, Muise, } \\
\& \text { Newburn-Cook (2009) }\end{array}$ & $\begin{array}{l}\text { Clunies (2004) } \\
\text { Parkman \& Beard (2008) }\end{array}$ \\
\hline $\begin{array}{l}\text { Need to focus on } \\
\text { underperformers as well as } \\
\text { high potentials }\end{array}$ & $\begin{array}{l}\text { McCallin, Bamford-Wade, \& } \\
\text { Frankson (2009) }\end{array}$ & & $\begin{array}{l}\text { Gaffney (2005) } \\
\text { Heinen \& O’Neill (2004) }\end{array}$ & \\
\hline Emergency Plan & $\begin{array}{l}\text { Carman, Leland, \& Wilson } \\
(2010) \\
\text { Fisher (2010) } \\
\text { Gamble (2008) } \\
\text { Hughes Butts (2008) } \\
\text { McCallin, Bamford-Wade, } \\
\text { Frankson (2009) }\end{array}$ & & & Van Amburgh, et al. (2010) \\
\hline $\begin{array}{l}\text { SP used for lateral job moves } \\
\text { as well as executive } \\
\text { replacement }\end{array}$ & & $\begin{array}{l}\text { Ingraham \& Getha-Taylor } \\
(2004) \\
\text { Kim (2003) }\end{array}$ & & Van Amburgh, et al. (2010) \\
\hline $\begin{array}{l}\text { Look at team development } \\
\text { over individual } \\
\text { development }\end{array}$ & & & $\begin{array}{l}\text { Kur \& Bunning (2002) } \\
\text { Rudis (2006) }\end{array}$ & \\
\hline $\begin{array}{l}\text { Learning should occur at } \\
\text { multiple levels (individual, } \\
\text { team, and organizational) }\end{array}$ & & Naquin \& Holton (2003) & & \\
\hline $\begin{array}{l}\text { SP should be targeted / not } \\
\text { for entire staff }\end{array}$ & Latif (2010) & & & \\
\hline Ensure ethical practices & & Romejko (2008) & & \\
\hline $\begin{array}{l}\text { Develop or strengthen pool of } \\
\text { candidates }\end{array}$ & & & $\operatorname{Kim}(2010)$ & $\begin{array}{l}\text { Estepp (1998) } \\
\text { Richards (2009) }\end{array}$ \\
\hline $\begin{array}{l}\text { Consider organizational-wide } \\
\text { talent pool for all units to } \\
\text { tap when needed }\end{array}$ & & & Cappelli (2008) & Clunies (2004) \\
\hline
\end{tabular}


Table 13: Characteristics of Survey Respondents (\% respondents [N])*

\begin{tabular}{|l|c|c|}
\hline Moderate knowledge about & Executive Directors & University Administrator \\
succession planning & $62.8 \%[137]$ & $81.8 \%[18]$ \\
\hline $\begin{array}{l}\text { Extent to which considered } \\
\text { succession planning }\end{array}$ & $\begin{array}{c}63.6 \%[136] \\
\text { moderate extent }\end{array}$ & $\begin{array}{c}54.5 \%[12] \\
\text { small extent }\end{array}$ \\
\hline $\begin{array}{l}\text { Been in position more than } 5 \\
\text { years }\end{array}$ & $47.5 \%[86]$ & \\
\hline $\begin{array}{l}\text { Succession program not in } \\
\text { place when took position }\end{array}$ & $91.2 \%[166]$ & \\
\hline $\begin{array}{l}\text { Helpfulness of succession } \\
\text { program if in place }\end{array}$ & $\begin{array}{c}80 \%[12] \\
\text { (of } 8.8 \% \text { who had } \\
\text { succession program) }\end{array}$ & \\
\hline
\end{tabular}

*Percentage is based on the number of respondents who answered each individual question. 


\section{Table 14: Descriptive Characteristics of Research Institutes (\% respondents [N])*}

\begin{tabular}{|c|c|}
\hline Reporting Line & $\begin{array}{l}68.8 \%[117] \text { report to university administrator, usually the } \\
\text { vice president of research }\end{array}$ \\
\hline Human Resources & $\begin{array}{l}66.8 \% \text { [117] do not have their own human resources } \\
\text { function within the institute }\end{array}$ \\
\hline Budget & $\begin{array}{l}20.9 \% \text { [36] have budgets under } \$ 1 \text { million } \\
41.9 \% \text { [72] have budgets from } \$ 1-5 \text { million } \\
21.5 \% \text { [37] have budgets greater than } \$ 10 \text { million } \\
56.0 \% \text { [98] have fairly independent budgets }\end{array}$ \\
\hline Sponsored Research & $82.8 \%$ [145] rely on external sponsored research funds \\
\hline Administration & $\begin{array}{l}51.1 \%[89] \text { are not independent of university administration } \\
\text { and rely on university for administrative services } \\
48.9 \% \text { [85] are independent of university administration }\end{array}$ \\
\hline Interdisciplinary & $96.6 \%$ [169] consider themselves interdisciplinary \\
\hline Year Created & $\begin{array}{l}34.1 \%[60] \text { created since } 2000 \\
17.0 \%[30] \text { created in the } 1990 \mathrm{~s} \\
19.3 \%[34] \text { created in the } 1980 \mathrm{~s} \\
11.9 \% \text { [21] created in the } 1960 \mathrm{~s}\end{array}$ \\
\hline Category/Type of Research & $\begin{array}{l}\text { 18.0\% [32] Physical Sciences } \\
15.2 \% \text { [27] } \text { Biological Sciences } \\
10.1 \% \text { [18] } \\
\text { Social Sciences } \\
9.0 \% \text { [16] Engineering }\end{array}$ \\
\hline Number of staff & $\begin{array}{l}37.5 \% \text { [66] } 1-5 \text { staff } \\
30.7 \% \text { [54] more than } 20\end{array}$ \\
\hline Number of faculty & $\begin{array}{l}29.0 \%[51] 1-5 \text { faculty } \\
19.3 \%[34] 6-10 \\
19.9 \%[35] \text { more than } 20\end{array}$ \\
\hline Number of post-docs & $\begin{array}{l}31.8 \%[56] 1-5 \text { post-docs } \\
10.8 \%[19] 6-10 \\
24.4 \%[43] \text { none }\end{array}$ \\
\hline Number of grad students & $\begin{array}{l}26.7 \%[47] 1-5 \text { graduate students } \\
13.1 \%[23] 6-10 \\
10.8 \%[19] 11-15 \\
22.7 \%[40] \text { more than } 20 \\
13.6 \%[24] \text { none }\end{array}$ \\
\hline
\end{tabular}


Table 15: Contextual Characteristics of Research Institutes* (\% respondents [N])**

\begin{tabular}{|c|c|}
\hline Have Strategic Plans & $70.2 \%[151]$ \\
\hline $\begin{array}{l}\text { Take part in succession planning } \\
\text { activities }\end{array}$ & Over $69 \%$ do not $[121]$ \\
\hline Types of succession planning activities & $\begin{array}{l}\text { Mentoring } \\
\text { Job Enrichment } \\
\text { Stretch Assignments }\end{array}$ \\
\hline How policies are created & $\begin{array}{l}52.9 \% \text { [90] Collaboration among research } \\
\text { institute leaders } \\
22.9 \% \text { [39] Top-down } \\
22.4 \% \text { [38] Collaboration with employees }\end{array}$ \\
\hline How policies are implemented & $\begin{array}{l}\text { 34.3\% [59] Collaboration with employee } \\
33.1 \% \text { [57] Collaboration among research } \\
\text { institute leaders } \\
31.4 \% \text { [54] Top-down approach }\end{array}$ \\
\hline Evaluation & $\begin{array}{l}\text { Most institutes are evaluated either annually or } \\
\text { on a regular cycle (e.g., every } 5 \text { years.) } \\
\text { Most evaluated by external reviewers from } \\
\text { industry and other universities }\end{array}$ \\
\hline
\end{tabular}




\begin{tabular}{|c|c|c|}
\hline \multicolumn{3}{|c|}{$\begin{array}{l}\text { Table 16: Characteristics of Succession Planning Reported as Important by Respondent (\% } \\
\text { respondents }[\mathrm{N}]) *\end{array}$} \\
\hline $\begin{array}{l}\text { Characteristics of Succession } \\
\text { Planning: }\end{array}$ & Executive Directors & University Administrators \\
\hline $\begin{array}{l}\text { Offers development or } \\
\text { educational activities for } \\
\text { current employees }\end{array}$ & $\begin{array}{l}54.5 \% \text { agree } \\
25.3 \% \text { strongly agree } \\
{[178]}\end{array}$ & $\begin{array}{l}22.7 \% \text { neither agree/disagree } \\
54.5 \% \text { agree } \\
22.7 \% \text { strongly agree } \\
{[22]}\end{array}$ \\
\hline $\begin{array}{l}\text { Promotes continuity in } \\
\text { leadership }\end{array}$ & $\begin{array}{l}44.2 \% \text { agree } \\
49.7 \% \text { strongly agree } \\
{[181]}\end{array}$ & $\begin{array}{l}50.0 \% \text { agree } \\
45.5 \% \text { strongly agree } \\
{[22]}\end{array}$ \\
\hline $\begin{array}{l}\text { Strategically plans for } \\
\text { employment needs for the } \\
\text { future }\end{array}$ & $\begin{array}{l}58.9 \% \text { agree } \\
31.1 \% \text { strongly agree } \\
{[180]}\end{array}$ & $\begin{array}{l}22.7 \% \text { neither agree/disagree } \\
45.5 \% \text { agree } \\
31.8 \% \text { strongly agree } \\
{[22]}\end{array}$ \\
\hline $\begin{array}{l}\text { Names successors of } \\
\text { key/critical positions }\end{array}$ & $\begin{array}{l}31.3 \% \text { neither agree/disagree } \\
39.6 \% \text { agree } \\
{[179]}\end{array}$ & $\begin{array}{l}18.2 \% \text { disagree } \\
50.0 \% \text { neither agree/disagree } \\
13.6 \% \text { agree } \\
{[22]}\end{array}$ \\
\hline Takes too much time & $\begin{array}{l}47.7 \% \text { disagree } \\
32.4 \% \text { neither agree/disagree } \\
{[176]}\end{array}$ & $\begin{array}{l}52.4 \% \text { disagree } \\
33.3 \% \text { neither agree/disagree } \\
{[21]}\end{array}$ \\
\hline $\begin{array}{l}\text { Focuses too much on } \\
\text { individual dev. and not on } \\
\text { org. planning }\end{array}$ & $\begin{array}{l}52.3 \% \text { disagree } \\
33.5 \% \text { neither agree/disagree } \\
{[176]}\end{array}$ & $\begin{array}{l}45.5 \% \text { disagree } \\
13.6 \% \text { neither agree/disagree } \\
31.8 \% \text { agree } \\
{[22]}\end{array}$ \\
\hline $\begin{array}{l}\text { Encourages a lack of } \\
\text { diversity as leaders are } \\
\text { created in the same image as } \\
\text { other leaders }\end{array}$ & $\begin{array}{l}46.3 \% \text { disagree } \\
30.3 \% \text { neither agree/disagree } \\
{[175]}\end{array}$ & $\begin{array}{l}40.9 \% \text { disagree } \\
32.8 \% \text { neither agree/disagree } \\
22.7 \% \text { agree } \\
{[22]}\end{array}$ \\
\hline
\end{tabular}




\section{Table 17: “Important” Characteristics of Succession Planning by Type of Respondent, Institute, and University*}

\begin{tabular}{|c|c|c|c|c|c|c|c|c|c|c|c|c|}
\hline $\begin{array}{l}\text { Characteristics of } \\
\text { Succession Planning: }\end{array}$ & $\begin{array}{c}\text { ED } \\
\text { Knowledge } \\
\text { of SP }\end{array}$ & $\begin{array}{l}\text { How long } \\
\text { ED in } \\
\text { position }\end{array}$ & $\begin{array}{c}\text { Institutes } \\
\text { had SP in } \\
\text { place } \\
\text { when ED } \\
\text { hired }\end{array}$ & $\begin{array}{c}\text { ED } \\
\text { Reports } \\
\text { Institutes } \\
\text { currently } \\
\text { doing SP } \\
\text { activities }\end{array}$ & $\begin{array}{c}\text { Social } \\
\text { Science } \\
\text { Institutes }\end{array}$ & $\begin{array}{l}\text { Newer } \\
\text { Institutes }\end{array}$ & $\begin{array}{l}\text { Respondent } \\
\text { is UA }\end{array}$ & $\begin{array}{c}\text { UA } \\
\text { Knowledge } \\
\text { of SP }\end{array}$ & $\begin{array}{c}\text { UA } \\
\text { Considered } \\
\text { SP }\end{array}$ & $\begin{array}{c}\text { UA } \\
\text { Reports } \\
\text { RI } \\
\text { currently } \\
\text { doing SP } \\
\text { Activities } \\
\end{array}$ & $\begin{array}{l}\text { Univ. has } \\
\text { greater } \\
\text { number of } \\
\text { RIs }\end{array}$ & $\begin{array}{l}\text { Univ. is } \\
\text { Private }\end{array}$ \\
\hline $\begin{array}{l}\text { Offers development } \\
\text { activities for current } \\
\text { employees }\end{array}$ & $\begin{array}{c}.249 \\
(p=.000)\end{array}$ & & & $\begin{array}{c}.150 \\
(\mathrm{p}=.088)\end{array}$ & & & & $\begin{array}{c}.388 \\
(\mathrm{p}=.012)\end{array}$ & $\begin{array}{c}.460 \\
(p=.010)\end{array}$ & $\begin{array}{c}.464 \\
(p=.030)\end{array}$ & & \\
\hline $\begin{array}{l}\text { Strategically plans } \\
\text { for future employee } \\
\text { needs }\end{array}$ & $\begin{array}{c}.158 \\
(p=.011)\end{array}$ & & & & & & & & $\begin{array}{c}.559 \\
(p=.001)\end{array}$ & $\begin{array}{c}.536 \\
(\mathrm{p}=.008)\end{array}$ & & \\
\hline $\begin{array}{l}\text { Names successors of } \\
\text { key positions }\end{array}$ & & $\begin{array}{c}-.140 \\
(p=.080)\end{array}$ & & & $\begin{array}{c}.219 \\
(p=.065)\end{array}$ & & $\begin{array}{c}-.282 \\
(p=.025)\end{array}$ & & & & $\begin{array}{c}.188 \\
(p=.001)\end{array}$ & \\
\hline Takes too much time & $\begin{array}{c}-.251 \\
(p=.000)\end{array}$ & & $\begin{array}{c}-.275 \\
(\mathrm{p}=.010)\end{array}$ & & & $\begin{array}{c}.128 \\
(p=.037)\end{array}$ & & & $\begin{array}{c}-.367 \\
(p=.026)\end{array}$ & & & \\
\hline $\begin{array}{l}\text { Focuses too much on } \\
\text { individual dev. and } \\
\text { not on org. }\end{array}$ & $\begin{array}{c}-.231 \\
(p=.000)\end{array}$ & & $\begin{array}{c}-.240 \\
(p=.072)\end{array}$ & & & & & & $\begin{array}{c}-.478 \\
(p=.013)\end{array}$ & $\begin{array}{c}-.527 \\
(p=.001)\end{array}$ & & \\
\hline $\begin{array}{l}\text { Encourages a lack of } \\
\text { diversity }\end{array}$ & $\begin{array}{c}-.135 \\
(\mathrm{p}=.031)\end{array}$ & & & $\begin{array}{c}-.200 \\
(\mathrm{p}=.031)\end{array}$ & $\begin{array}{c}-.225 \\
(\mathrm{p}=.040)\end{array}$ & & & & $\begin{array}{c}-.509 \\
(p=.001)\end{array}$ & $\begin{array}{c}-.636 \\
(\mathrm{p}=.000)\end{array}$ & $\begin{array}{c}.131 \\
(\mathrm{p}=.018)\end{array}$ & $\begin{array}{c}.278 \\
(p=.002)\end{array}$ \\
\hline
\end{tabular}


Table 18: Important Characteristics of Succession Planning by Universities with More Research Institutes, Controlling for University Size*

\begin{tabular}{|c|c|c|c|c|c|c|c|}
\hline $\begin{array}{l}\text { Characteristics of } \\
\text { Succession Planning: }\end{array}$ & $\begin{array}{l}<20,000 \\
\text { Students }\end{array}$ & $\begin{array}{c}20,000- \\
22,999 \\
\text { Students }\end{array}$ & $\begin{array}{c}23,000- \\
27,999 \\
\text { Students }\end{array}$ & $\begin{array}{c}28,000- \\
29,999 \\
\text { Students }\end{array}$ & $\begin{array}{c}30,000- \\
37,999 \\
\text { Students }\end{array}$ & $\begin{array}{c}38,000- \\
43,999 \\
\text { Students }\end{array}$ & $\begin{array}{l}44,000+ \\
\text { Students }\end{array}$ \\
\hline $\begin{array}{l}\text { Offers development } \\
\text { activities for current } \\
\text { employees }\end{array}$ & & & & & $\begin{array}{c}-.327 \\
(p=.041)\end{array}$ & & \\
\hline $\begin{array}{l}\text { Promotes continuity in } \\
\text { leadership }\end{array}$ & & $\begin{array}{c}.297 \\
(p=.023)\end{array}$ & $\begin{array}{c}.253 \\
(p=.037)\end{array}$ & & & & \\
\hline $\begin{array}{l}\text { Strategically plans for } \\
\text { future employee needs }\end{array}$ & $\begin{array}{c}.296 \\
(p=.033)\end{array}$ & & & & & & \\
\hline $\begin{array}{l}\text { Names successors of key } \\
\text { positions }\end{array}$ & & $\begin{array}{c}.344 \\
(p=.019)\end{array}$ & $\begin{array}{c}.341 \\
(p=.016)\end{array}$ & & $\begin{array}{c}.327 \\
(p=.027)\end{array}$ & & $\begin{array}{c}.413 \\
(p=.002)\end{array}$ \\
\hline Takes too much time & & $\begin{array}{c}-.270 \\
(p=.022)\end{array}$ & & & & & \\
\hline $\begin{array}{l}\text { Focuses too much on } \\
\text { individual dev. and not on } \\
\text { org. }\end{array}$ & & $\begin{array}{c}-.312 \\
(p=.030)\end{array}$ & & $\begin{array}{c}-.327 \\
(p=.037)\end{array}$ & & & \\
\hline $\begin{array}{l}\text { Encourages a lack of } \\
\text { diversity }\end{array}$ & & $\begin{array}{c}-.398 \\
(\mathrm{p}=.002)\end{array}$ & & & & & \\
\hline
\end{tabular}




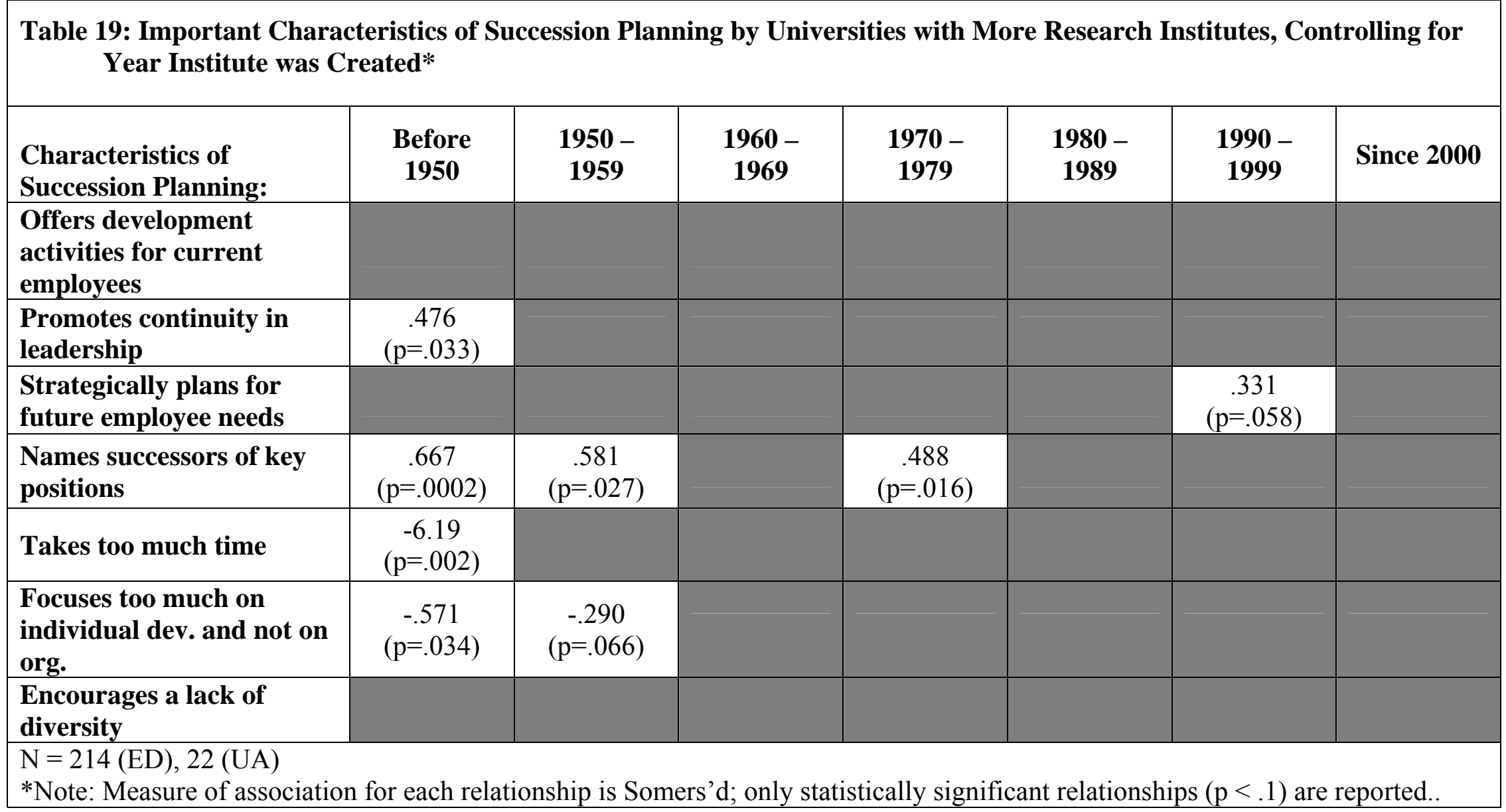


Table 20: Important Characteristics of Succession Planning by Universities with More Research Institutes, Controlling for How Policies are Created and Implemented*

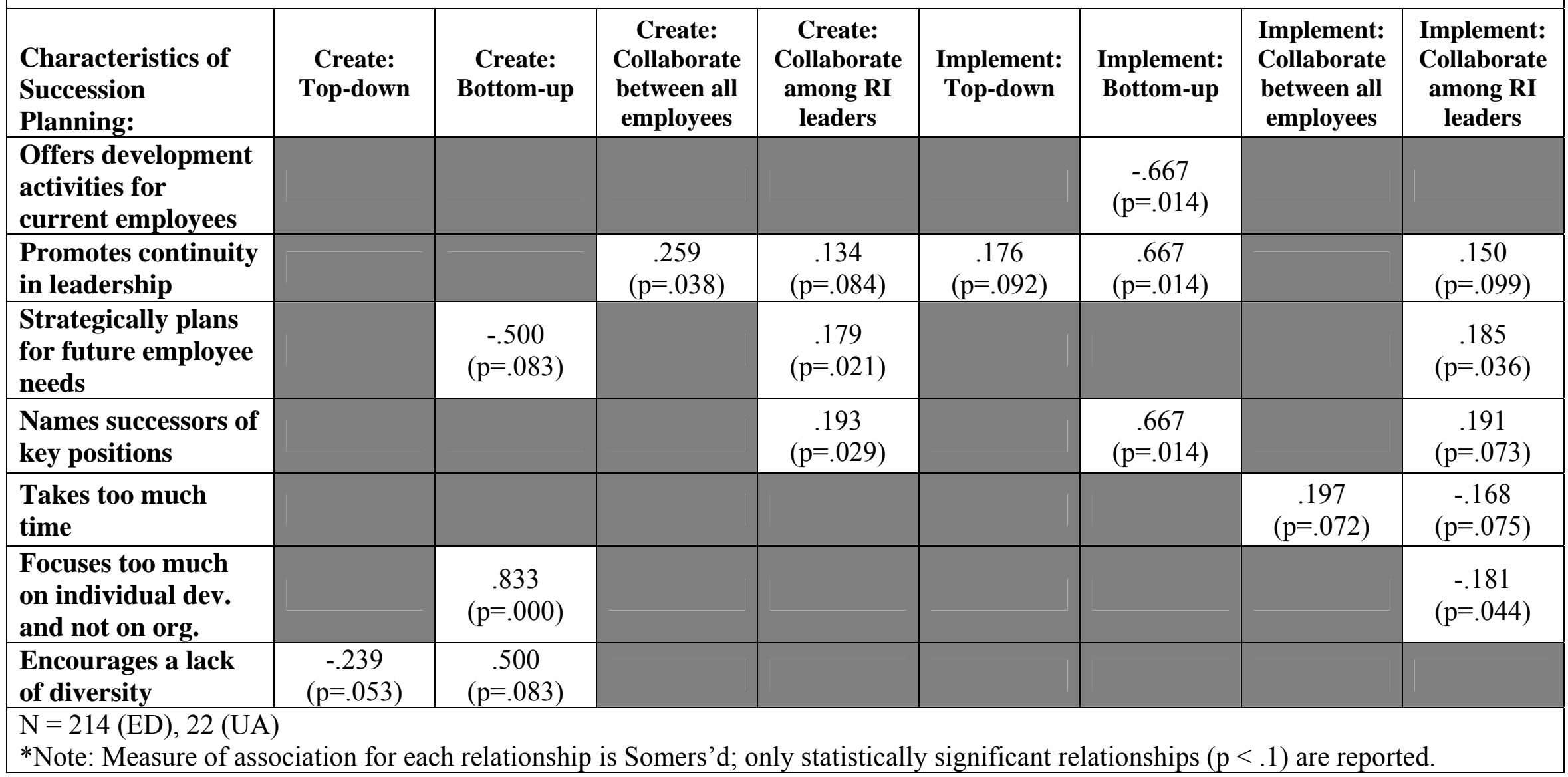



Table 21: Desired Decision Makers in Succession Planning Processes by Respondent (\%
respondents $[\mathrm{N}]$ )*

\begin{tabular}{|c|c|c|}
\hline Decision Makers: & Executive Directors & University Administrators \\
\hline University President & $\begin{array}{l}54.8 \% \text { not at all } \\
21.7 \% \text { small extent } \\
{[166]}\end{array}$ & $\begin{array}{l}30.0 \% \text { great extent } \\
20.0 \% \text { not at all; small extent; } \\
\text { and very great extent } \\
{[20]}\end{array}$ \\
\hline University VP of Research & $\begin{array}{l}21.6 \% \text { moderate extent } \\
28.7 \% \text { great extent } \\
23.4 \text { very great extent } \\
{[167]}\end{array}$ & $\begin{array}{l}19.0 \% \text { small extent } \\
14.3 \% \text { moderate extent } \\
33.3 \% \text { great extent } \\
28.6 \% \text { very great extent } \\
{[21]}\end{array}$ \\
\hline $\begin{array}{l}\text { Research Institute Advisory } \\
\text { Board }\end{array}$ & $\begin{array}{l}27.3 \% \text { small extent } \\
25.5 \% \text { moderate extent } \\
23.6 \% \text { great extent } \\
{[165]}\end{array}$ & $\begin{array}{l}25.0 \% \text { small extent } \\
55.0 \% \text { moderate extent } \\
{[20]}\end{array}$ \\
\hline Executive Director & $\begin{array}{l}32.9 \% \text { great extent } \\
49.1 \% \text { very great extent } \\
{[167]}\end{array}$ & $\begin{array}{l}38.1 \% \text { moderate extent } \\
28.6 \% \text { great extent } \\
19.0 \% \text { very great extent } \\
{[21]}\end{array}$ \\
\hline Institute Faculty & $\begin{array}{l}18.7 \% \text { small extent } \\
33.1 \% \text { moderate extent } \\
28.3 \% \text { great extent } \\
{[166]}\end{array}$ & $\begin{array}{l}23.8 \% \text { small extent } \\
38.1 \% \text { moderate extent } \\
23.8 \% \text { great extent } \\
{[21]}\end{array}$ \\
\hline Institute Staff & $\begin{array}{l}18.2 \% \text { not at all } \\
35.8 \% \text { small extent } \\
32.1 \% \text { moderate extent } \\
{[165]}\end{array}$ & $\begin{array}{l}33.3 \% \text { not at all } \\
42.9 \% \text { small extent } \\
23.8 \% \text { moderate extent } \\
{[21]}\end{array}$ \\
\hline Institute Post-Docs & $\begin{array}{l}58.2 \% \text { not at all } \\
33.3 \% \text { small extent } \\
{[165]}\end{array}$ & $\begin{array}{l}61.9 \% \text { not at all } \\
28.6 \% \text { small extent } \\
{[21]}\end{array}$ \\
\hline Institute Grad Students & $\begin{array}{l}65.9 \% \text { not at all } \\
26.3 \% \text { small extent } \\
{[167]}\end{array}$ & $\begin{array}{l}61.9 \% \text { not at all } \\
23.8 \% \text { small extent } \\
{[21]}\end{array}$ \\
\hline University HR Manager & $\begin{array}{l}49.7 \% \text { not at all } \\
34.7 \% \text { small extent } \\
{[167]}\end{array}$ & $\begin{array}{l}28.6 \% \text { not at all; small extent } \\
23.8 \% \text { moderate extent } \\
19.0 \% \text { great extent } \\
{[21]}\end{array}$ \\
\hline Institute HR Manager & $\begin{array}{l}47.8 \% \text { not at all } \\
22.4 \% \text { small extent } \\
19.3 \% \text { moderate extent } \\
{[161]}\end{array}$ & $\begin{array}{l}28.6 \% \text { not at all } \\
47.6 \% \text { small extent } \\
19.0 \% \text { moderate extent } \\
{[21]}\end{array}$ \\
\hline
\end{tabular}




\begin{tabular}{|c|c|c|c|c|c|c|c|c|c|c|c|c|c|c|c|}
\hline $\begin{array}{l}\text { Decision } \\
\text { Makers: }\end{array}$ & $\begin{array}{c}\text { ED } \\
\text { Knows } \\
\text { SP }\end{array}$ & $\begin{array}{l}\text { How } \\
\text { long ED } \\
\text { in } \\
\text { position }\end{array}$ & $\begin{array}{l}\text { RI had } \\
\text { SP in } \\
\text { place } \\
\text { when } \\
\text { ED } \\
\text { hired }\end{array}$ & $\begin{array}{l}\text { RI doing } \\
\text { SP }\end{array}$ & $\begin{array}{c}\text { RI has } \\
\text { Strategic } \\
\text { Plan }\end{array}$ & $\begin{array}{c}\text { Social } \\
\text { Science } \\
\text { RI }\end{array}$ & $\begin{array}{l}\text { Larger } \\
\text { RI }\end{array}$ & $\begin{array}{c}\text { Newer } \\
\text { RI }\end{array}$ & $\begin{array}{l}\text { RI with } \\
\text { Larger } \\
\text { Budgets }\end{array}$ & $\begin{array}{c}\text { UA } \\
\text { Knows } \\
\text { SP }\end{array}$ & $\begin{array}{c}\text { UA } \\
\text { Conside } \\
\text { red SP }\end{array}$ & $\begin{array}{l}\text { Respon- } \\
\text { dent is } \\
\text { UA }\end{array}$ & $\begin{array}{c}\text { Larger } \\
\text { Univ. }\end{array}$ & $\begin{array}{l}\text { Univ. is } \\
\text { Private }\end{array}$ & $\begin{array}{l}\text { Univ. } \\
\text { has } \\
\text { greater } \\
\text { \# of RIs }\end{array}$ \\
\hline $\begin{array}{l}\text { University } \\
\text { President }\end{array}$ & & & & $\begin{array}{l}\text { UA: } .495 \\
(p=.010)\end{array}$ & & & & & $\begin{array}{c}.143 \\
(\mathrm{p}=.038)\end{array}$ & & & $\begin{array}{c}.491 \\
(\mathrm{p}=.001)\end{array}$ & & & \\
\hline $\begin{array}{l}\text { University VP } \\
\text { of Research }\end{array}$ & & & & & & $\begin{array}{c}-.321 \\
(\mathrm{p}=.010)\end{array}$ & & $\begin{array}{c}.189 \\
(\mathrm{p}=.003)\end{array}$ & & & & & & & $\begin{array}{c}-.250 \\
(\mathrm{p}=.000)\end{array}$ \\
\hline $\begin{array}{l}\text { RI Advisory } \\
\text { board }\end{array}$ & & $\begin{array}{c}-.122 \\
(\mathrm{p}=.091)\end{array}$ & & & & & & & & $\begin{array}{c}.560 \\
(\mathrm{p}=.007)\end{array}$ & $\begin{array}{c}.496 \\
(p=.000)\end{array}$ & & & & \\
\hline $\begin{array}{l}\text { Exec. } \\
\text { Director }\end{array}$ & $\begin{array}{c}.216 \\
(\mathrm{p}=.000)\end{array}$ & & & $\begin{array}{l}\text { ED:.231 } \\
(p=.007) \\
\text { UA: } .491 \\
(p=.028)\end{array}$ & $\begin{array}{l}\text { UA: } .563 \\
(\mathrm{p}=.014)\end{array}$ & $\begin{array}{c}.251 \\
(\mathrm{p}=.018)\end{array}$ & & $\begin{array}{c}-.102 \\
(\mathrm{p}=.096)\end{array}$ & & & $\begin{array}{c}.796 \\
(\mathrm{p}=.000)\end{array}$ & $\begin{array}{c}-.422 \\
(\mathrm{p}=.002)\end{array}$ & & & \\
\hline RI faculty & & & & $\begin{array}{l}\text { UA: } .464 \\
(\mathrm{p}=.051)\end{array}$ & & & & & & & $\begin{array}{c}.429 \\
(\mathrm{p}=.022)\end{array}$ & & & $\begin{array}{c}-.176 \\
(\mathrm{p}=.097)\end{array}$ & \\
\hline RI staff & & & & & & & & $\begin{array}{c}-.132 \\
(\mathrm{p}=.039)\end{array}$ & & & $\begin{array}{c}.327 \\
(\mathrm{p}=.048)\end{array}$ & $\begin{array}{c}-.297 \\
(\mathrm{p}=.014)\end{array}$ & & & \\
\hline RI post-docs & & & $\begin{array}{c}-.304 \\
(p=.021)\end{array}$ & & & & & & & & & & & & \\
\hline $\begin{array}{l}\text { RI grad } \\
\text { students }\end{array}$ & & & & & & & & & & & & & $\begin{array}{c}-.079 \\
(\mathrm{p}=.098)\end{array}$ & & \\
\hline $\begin{array}{l}\text { Univ. HR } \\
\text { mgr }\end{array}$ & & & & & $\begin{array}{c}.154 \\
(\mathrm{p}=.092)\end{array}$ & & & & & & & $\begin{array}{c}.326 \\
(p=.021)\end{array}$ & & & \\
\hline RI HR mgr & & & & & & & $\begin{array}{c}.202 \\
(p=.003)\end{array}$ & $\begin{array}{c}-.142 \\
(\mathrm{p}=.031)\end{array}$ & $\begin{array}{c}.189 \\
(p=.011)\end{array}$ & & & & & & \\
\hline \multicolumn{16}{|c|}{$\begin{array}{l}\mathrm{N}=200(\mathrm{ED}), 21(\mathrm{UA}) \\
* \text { Note: Measure of association for each relationship is Somers'd; only statistically significant relationships }(\mathrm{p}<.1) \text { are reported.. } \\
\mathrm{UA}=\text { University Administrator } \\
\mathrm{ED}=\text { Executive Director }\end{array}$} \\
\hline
\end{tabular}




\begin{tabular}{|c|c|c|}
\hline Participants: & Executive Directors & University Administrators \\
\hline Senior Leaders (ex: ED) & $\begin{array}{l}37.6 \% \text { great extent } \\
50.3 \% \text { very great extent } \\
{[165]}\end{array}$ & $\begin{array}{l}61.9 \% \text { great extent } \\
19.0 \% \text { very great extent } \\
{[21]}\end{array}$ \\
\hline Managers & $\begin{array}{l}26.8 \% \text { moderate extent } \\
39.6 \% \text { great extent } \\
{[164]}\end{array}$ & $\begin{array}{l}19.0 \% \text { small extent } \\
42.9 \% \text { moderate extent } \\
19.0 \% \text { great extent } \\
{[21]}\end{array}$ \\
\hline Staff & $\begin{array}{l}30.3 \% \text { small extent } \\
40.6 \% \text { moderate extent } \\
14.5 \% \text { great extent } \\
{[165]}\end{array}$ & $\begin{array}{l}14.3 \% \text { not at all } \\
42.9 \% \text { small extent } \\
33.3 \% \text { moderate extent } \\
{[21]}\end{array}$ \\
\hline Residential Faculty & $\begin{array}{l}16.1 \% \text { not at all } \\
19.3 \% \text { small extent } \\
35.4 \% \text { moderate extent } \\
21.1 \% \text { great extent } \\
{[161]}\end{array}$ & $\begin{array}{l}14.3 \% \text { not at all } \\
38.1 \% \text { small extent } \\
33.3 \% \text { great extent } \\
{[21]}\end{array}$ \\
\hline Adjunct / Affiliated Faculty & $\begin{array}{l}42.7 \% \text { not at all } \\
33.5 \% \text { small extent } \\
15.2 \% \text { moderate extent } \\
{[164]}\end{array}$ & $\begin{array}{l}47.6 \% \text { not at all } \\
38.1 \% \text { small extent } \\
{[21]}\end{array}$ \\
\hline Graduate Students & $\begin{array}{l}58.5 \% \text { not at all } \\
33.3 \% \text { small extent } \\
{[159]}\end{array}$ & $\begin{array}{l}66.7 \% \text { not at all } \\
28.6 \% \text { small extent } \\
{[21]}\end{array}$ \\
\hline
\end{tabular}




\begin{tabular}{|c|c|c|c|c|c|c|c|c|c|c|c|}
\hline Participants: & $\begin{array}{c}\text { ED } \\
\text { Knowledge } \\
\text { of SP }\end{array}$ & $\begin{array}{l}\text { RI doing } \\
\text { SP } \\
\text { activities }\end{array}$ & $\begin{array}{c}\text { Social } \\
\text { Science } \\
\text { RI }\end{array}$ & $\begin{array}{l}\text { Larger } \\
\text { RI }\end{array}$ & Newer RI & $\begin{array}{c}\text { ED } \\
\text { Consider } \\
\text { ed SP }\end{array}$ & $\begin{array}{l}\text { RI have } \\
\text { Strategic } \\
\text { Plans }\end{array}$ & \begin{tabular}{c}
\multicolumn{1}{c}{ RI } \\
currently \\
doing SP \\
activities
\end{tabular} & $\begin{array}{l}\text { Respondent } \\
\text { is UA }\end{array}$ & $\begin{array}{l}\text { Larger } \\
\text { Univ. }\end{array}$ & $\begin{array}{c}\text { Univ. has } \\
\text { greater \# } \\
\text { of RIs }\end{array}$ \\
\hline $\begin{array}{l}\text { Senior Leaders } \\
\text { (ex: ED) }\end{array}$ & $\begin{array}{c}.143 \\
(p=.016)\end{array}$ & $\begin{array}{c}.189 \\
(p=.037) \\
\end{array}$ & $\begin{array}{c}.237 \\
(\mathrm{p}=.032) \\
\end{array}$ & $\begin{array}{c}.116 \\
(p=.084)\end{array}$ & & & & & $\begin{array}{c}-.314 \\
(\mathrm{p}=.009) \\
\end{array}$ & & \\
\hline Managers & $\begin{array}{c}.189 \\
(p=.006)\end{array}$ & $\begin{array}{c}.245 \\
(p=.010)\end{array}$ & $\begin{array}{c}.239 \\
(p=.041)\end{array}$ & $\begin{array}{c}.159 \\
(p=.017)\end{array}$ & $\begin{array}{c}-.110 \\
(p=.091)\end{array}$ & $\begin{array}{c}.578 \\
(p=.000)\end{array}$ & $\begin{array}{c}.563 \\
(p=.020)\end{array}$ & $\begin{array}{c}.491 \\
(p=.016)\end{array}$ & $\begin{array}{c}-.293 \\
(p=.026)\end{array}$ & $\begin{array}{c}.095 \\
(p=.074)\end{array}$ & \\
\hline Staff & & $\begin{array}{c}.210 \\
(p=.031)\end{array}$ & & & & $\begin{array}{c}.510 \\
(\mathrm{p}=.001)\end{array}$ & $\begin{array}{c}.525 \\
(p=.019)\end{array}$ & $\begin{array}{c}.455 \\
(p=.034)\end{array}$ & & & \\
\hline Residential Faculty & & & & & & $\begin{array}{c}.646 \\
(p=.000)\end{array}$ & $\begin{array}{c}.575 \\
(p=.012)\end{array}$ & $\begin{array}{c}.655 \\
(p=.001)\end{array}$ & & & \\
\hline $\begin{array}{l}\text { Adjunct / } \\
\text { Affiliated Faculty }\end{array}$ & & & & & & $\begin{array}{c}.544 \\
(p=.000)\end{array}$ & $\begin{array}{c}.688 \\
(p=.002) \\
\end{array}$ & $\begin{array}{c}.645 \\
(p=.002)\end{array}$ & & & $\begin{array}{c}-.147 \\
(p=.010)\end{array}$ \\
\hline Graduate Students & & & & & & & $\begin{array}{c}.438 \\
(p=.010)\end{array}$ & $\begin{array}{c}.600 \\
(p=.004)\end{array}$ & & & \\
\hline
\end{tabular}


Table 25: Desired Participants in Succession Planning by Social Science Institutes, Controlling for University Size, Institute Size, Year Institute was Created, Institute Budget, Current Succession Planning Activities, How Polices Created and Implemented*

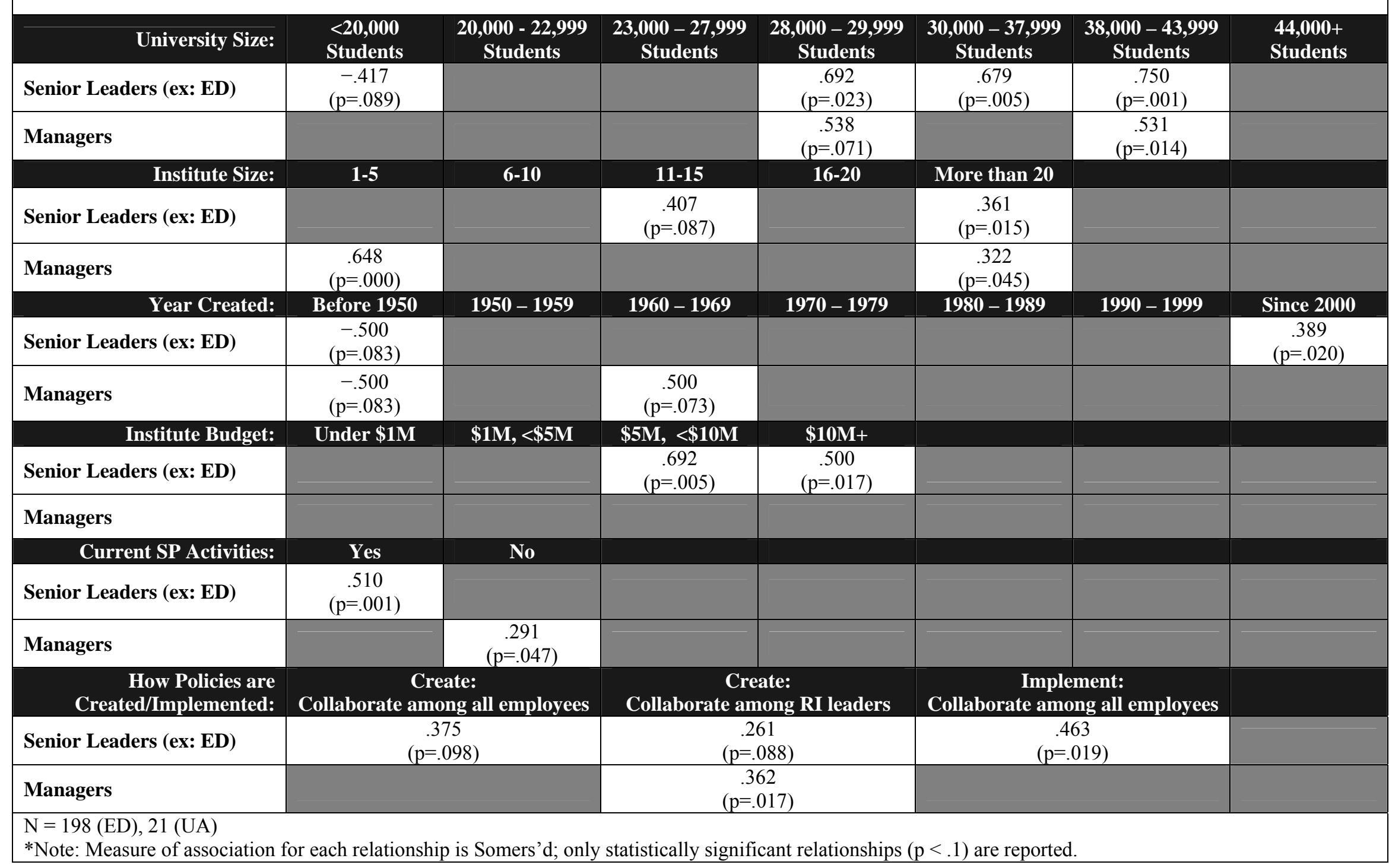




\begin{tabular}{|c|c|c|}
\hline \multicolumn{3}{|c|}{$\begin{array}{l}\text { Table 26: Items Inhibiting/Benefitting Succession Planning Processes by Respondent (\% } \\
\text { respondents [N])* }\end{array}$} \\
\hline & Executive Directors & University Administrators \\
\hline University policy/procedures & $\begin{array}{l}15.3 \% \text { inhibit } \\
18.8 \% \text { slightly inhibit } \\
54.1 \% \text { neither } \\
{[170]}\end{array}$ & $\begin{array}{l}86.4 \% \text { neither } \\
{[22]}\end{array}$ \\
\hline $\begin{array}{l}\text { Research institute } \\
\text { policy/procedures }\end{array}$ & $\begin{array}{l}64.5 \% \text { neither } \\
18.9 \% \text { somewhat benefit } \\
{[169]}\end{array}$ & $\begin{array}{l}81.8 \% \text { neither } \\
9.1 \% \text { somewhat benefit } \\
\text { [22] }\end{array}$ \\
\hline University priorities & $\begin{array}{l}15.9 \% \text { slightly inhibit } \\
44.1 \% \text { neither } \\
24.1 \% \text { somewhat benefit } \\
{[170]}\end{array}$ & $\begin{array}{l}45.5 \% \text { neither } \\
36.4 \% \text { somewhat benefit } \\
{[22]}\end{array}$ \\
\hline Research institute priorities & $\begin{array}{l}24.7 \% \text { neither } \\
35.3 \% \text { somewhat benefit } \\
32.9 \% \text { benefit } \\
{[170]}\end{array}$ & $\begin{array}{l}45.5 \% \text { neither } \\
31.8 \% \text { somewhat benefit }\end{array}$ \\
\hline $\begin{array}{l}\text { Support by current university } \\
\text { senior leadership }\end{array}$ & $\begin{array}{l}28.8 \% \text { neither } \\
34.1 \% \text { somewhat benefit } \\
24.7 \% \text { benefit } \\
{[170]}\end{array}$ & $\begin{array}{l}40.9 \% \text { neither } \\
45.5 \% \text { somewhat benefit } \\
{[22]}\end{array}$ \\
\hline $\begin{array}{l}\text { Support by current senior } \\
\text { leaders in research institute }\end{array}$ & $\begin{array}{l}23.1 \% \text { neither } \\
33.7 \% \text { somewhat benefit } \\
39.6 \% \text { benefit } \\
{[169]}\end{array}$ & $\begin{array}{l}45.5 \% \text { neither } \\
36.4 \% \text { somewhat benefit } \\
{[22]}\end{array}$ \\
\hline $\begin{array}{l}\text { Support by current faculty in } \\
\text { research institute }\end{array}$ & $\begin{array}{l}38.1 \% \text { neither } \\
32.1 \% \text { somewhat benefit } \\
24.4 \% \text { benefit } \\
{[168]}\end{array}$ & $\begin{array}{l}54.5 \% \text { neither } \\
22.7 \% \text { somewhat benefit } \\
{[22]}\end{array}$ \\
\hline $\begin{array}{l}\text { Support by current staff in } \\
\text { research institute }\end{array}$ & $\begin{array}{l}39.4 \% \text { neither } \\
35.3 \% \text { somewhat benefit } \\
20.6 \% \text { benefit } \\
{[170]}\end{array}$ & $\begin{array}{l}59.1 \% \text { neither } \\
22.7 \% \text { somewhat benefit } \\
{[22]}\end{array}$ \\
\hline Financial resources & $\begin{array}{l}22.3 \% \text { inhibit } \\
19.9 \% \text { slightly inhibit } \\
27.7 \% \text { neither } \\
17.5 \% \text { somewhat benefit } \\
12.7 \% \text { benefit } \\
{[166]}\end{array}$ & $\begin{array}{l}42.9 \% \text { slightly inhibit } \\
23.8 \% \text { neither } \\
19.0 \% \text { somewhat benefit } \\
{[21]}\end{array}$ \\
\hline $\begin{array}{l}\text { Ability to consult with } \\
\text { succession planning experts }\end{array}$ & $\begin{array}{l}60.7 \% \text { neither } \\
17.2 \% \text { somewhat benefit } \\
{[163]}\end{array}$ & $\begin{array}{l}14.3 \% \text { slightly inhibit } \\
71.4 \% \text { neither } \\
{[21]}\end{array}$ \\
\hline
\end{tabular}


Table 27: Items Inhibiting/Benefitting Succession Planning Processes by Respondent, Institute, and University*

\begin{tabular}{|c|c|c|c|c|c|c|c|c|c|c|c|c|c|c|c|}
\hline Benefit: & $\begin{array}{c}\text { ED } \\
\text { knows } \\
\text { SP }\end{array}$ & $\begin{array}{c}\text { How } \\
\text { long ED } \\
\text { in } \\
\text { position }\end{array}$ & $\begin{array}{l}\text { RI had } \\
\text { SP in } \\
\text { place }\end{array}$ & $\begin{array}{l}\text { RI doing } \\
\text { SP }\end{array}$ & $\begin{array}{l}\text { Social } \\
\text { Science } \\
\text { RI }\end{array}$ & $\begin{array}{l}\text { Larger } \\
\text { RI }\end{array}$ & $\begin{array}{l}\text { Newer } \\
\text { RI }\end{array}$ & $\begin{array}{l}\text { RI with } \\
\text { Larger } \\
\text { Budgets }\end{array}$ & $\begin{array}{c}\text { UA } \\
\text { knows } \\
\text { SP }\end{array}$ & $\begin{array}{l}\text { UA } \\
\text { Conside } \\
\text { red SP }\end{array}$ & $\begin{array}{l}\text { RI have } \\
\text { Strategic } \\
\text { Plans }\end{array}$ & $\begin{array}{l}\text { \# of RIs } \\
\text { at Univ. }\end{array}$ & $\begin{array}{l}\text { Larger } \\
\text { Univ. }\end{array}$ & $\begin{array}{l}\text { Respon- } \\
\text { dent is a } \\
\text { UA }\end{array}$ & $\begin{array}{l}\text { Univ. is } \\
\text { Public }\end{array}$ \\
\hline $\begin{array}{l}\text { University policy \& } \\
\text { procedures }\end{array}$ & & & & $\begin{array}{l}\text { UA: } .209 \\
(p=.056)\end{array}$ & $\begin{array}{c}-.262 \\
(\mathrm{p}=.021)\end{array}$ & & $\begin{array}{c}.118 \\
(\mathrm{p}=.053)\end{array}$ & & & $\begin{array}{c}.161 \\
(\mathrm{p}=.013)\end{array}$ & & & & $\begin{array}{c}.171 \\
(\mathrm{p}=.044)\end{array}$ & \\
\hline $\begin{array}{l}\text { Institute policy\& } \\
\text { procedures }\end{array}$ & & & & & & & & & & & & & & & $\begin{array}{c}.177 \\
(\mathrm{p}=.043)\end{array}$ \\
\hline University priorities & & & & $\begin{array}{l}\text { UA: } .527 \\
(p=.018)\end{array}$ & & $\begin{array}{c}.122 \\
(\mathrm{p}=.057)\end{array}$ & & $\begin{array}{c}.203 \\
(p=.001)\end{array}$ & $\begin{array}{c}.414 \\
(\mathrm{p}=.013)\end{array}$ & & & & & $\begin{array}{c}.219 \\
(p=.055)\end{array}$ & \\
\hline Institute priorities & $\begin{array}{c}.158 \\
(\mathrm{p}=.018)\end{array}$ & & & $\begin{array}{l}\begin{array}{l}\text { ED: .232 } \\
(p=.018)\end{array} \\
\text { UA: } .491 \\
(p=.013)\end{array}$ & & $\begin{array}{c}.168 \\
(\mathrm{p}=.010)\end{array}$ & & $\begin{array}{c}.139 \\
(\mathrm{p}=.049)\end{array}$ & & & & & & $\begin{array}{c}-.350 \\
(p=.004)\end{array}$ & \\
\hline $\begin{array}{l}\text { Support by current } \\
\text { university senior } \\
\text { leadership }\end{array}$ & $\begin{array}{c}.172 \\
(p=.012)\end{array}$ & & $\begin{array}{c}.358 \\
(\mathrm{p}=.012)\end{array}$ & $\begin{array}{l}\begin{array}{l}\text { ED: } .386 \\
(p=.000)\end{array} \\
\text { UA: } .482 \\
(p=.032)\end{array}$ & & & & & & $\begin{array}{c}.640 \\
(\mathrm{p}=.000)\end{array}$ & & & & & \\
\hline $\begin{array}{l}\text { Support by current } \\
\text { institute senior leaders }\end{array}$ & & & & $\begin{array}{l}\begin{array}{l}\text { ED: } .326 \\
(p=.000)\end{array} \\
\text { UA: } .491 \\
(p=.016)\end{array}$ & & & & & & & & & & $\begin{array}{c}-.396 \\
(\mathrm{p}=.001)\end{array}$ & \\
\hline $\begin{array}{l}\text { Support by current } \\
\text { institute faculty }\end{array}$ & & & $\begin{array}{c}.447 \\
(\mathrm{p}=.026)\end{array}$ & $\begin{array}{l}\begin{array}{l}\text { ED: } .305 \\
(p=.002)\end{array} \\
\text { UA: } .509 \\
(p=.052)\end{array}$ & & & & $\begin{array}{c}.126 \\
(\mathrm{p}=.070)\end{array}$ & & & & & & & \\
\hline $\begin{array}{l}\text { Support by current } \\
\text { institute staff }\end{array}$ & & $\begin{array}{c}.136 \\
(\mathrm{p}=.075)\end{array}$ & & $\begin{array}{l}\begin{array}{l}\text { ED: } .277 \\
(p=.006)\end{array} \\
\text { UA: } .709 \\
(p=.000)\end{array}$ & & & & & & & $\begin{array}{c}.376 \\
(p=.073)\end{array}$ & & $\begin{array}{c}-.083 \\
(\mathrm{p}=.093)\end{array}$ & $\begin{array}{c}-.346 \\
(p=.004)\end{array}$ & \\
\hline Financial resources & & & & $\begin{array}{l}\begin{array}{l}\text { ED: } .188 \\
(p=.060)\end{array} \\
\text { UA: } .408 \\
(p=.064)\end{array}$ & & & & & & & $\begin{array}{c}.463 \\
(\mathrm{p}=.053)\end{array}$ & & & & \\
\hline $\begin{array}{l}\text { Ability to consult with } \\
\text { succession planning } \\
\text { experts }\end{array}$ & & & & & & & & & & $\begin{array}{c}.279 \\
(\mathrm{p}=.033)\end{array}$ & & $\begin{array}{c}.125 \\
(\mathrm{p}=.014)\end{array}$ & & & \\
\hline
\end{tabular}




\begin{tabular}{|c|c|c|}
\hline The succession plan would: & Executive Directors & University Administrators \\
\hline $\begin{array}{l}\text { Identify the groups that the } \\
\text { program would serve, in } \\
\text { priority order }\end{array}$ & $\begin{array}{l}11.8 \% \text { slightly important } \\
25.0 \% \text { fairly important } \\
38.9 \% \text { quite important } \\
17.4 \% \text { very important } \\
{[144]}\end{array}$ & $\begin{array}{l}15.0 \% \text { slightly important } \\
35.0 \% \text { fairly important } \\
25.0 \% \text { quite important } \\
15.0 \% \text { very important } \\
{[20]}\end{array}$ \\
\hline $\begin{array}{l}\text { Devise a means to keep } \\
\text { records for individuals who } \\
\text { are designated as successors }\end{array}$ & $\begin{array}{l}14.5 \% \text { not at all important } \\
28.3 \% \text { slightly important } \\
29.0 \% \text { fairly important } \\
24.8 \% \text { quite important } \\
{[145]}\end{array}$ & $\begin{array}{l}26.3 \% \text { slightly important } \\
42.1 \% \text { fairly important } \\
26.3 \% \text { quite important } \\
{[19]}\end{array}$ \\
\hline $\begin{array}{l}\text { Establish a means to clarify } \\
\text { present position } \\
\text { responsibilities }\end{array}$ & $\begin{array}{l}11.6 \% \text { slightly important } \\
25.3 \% \text { fairly important } \\
40.4 \% \text { quite important } \\
17.8 \% \text { very important } \\
{[146]}\end{array}$ & $\begin{array}{l}36.8 \% \text { fairly important } \\
47.4 \% \text { quite important } \\
{[19]}\end{array}$ \\
\hline $\begin{array}{l}\text { Establish a means to clarify } \\
\text { future position } \\
\text { responsibilities }\end{array}$ & $\begin{array}{l}22.1 \% \text { fairly important } \\
48.3 \% \text { quite important } \\
15.9 \% \text { very important } \\
{[145]}\end{array}$ & $\begin{array}{l}36.8 \% \text { fairly important } \\
47.4 \% \text { quite important } \\
{[19]}\end{array}$ \\
\hline $\begin{array}{l}\text { Establish a way to forecast } \\
\text { future talent needs }\end{array}$ & $\begin{array}{l}10.3 \% \text { slightly important } \\
30.1 \% \text { fairly important } \\
45.2 \% \text { quite important } \\
{[146]}\end{array}$ & $\begin{array}{l}21.1 \% \text { slightly important } \\
21.1 \% \text { fairly important } \\
42.1 \% \text { quite important } \\
10.5 \% \text { very important } \\
{[19]}\end{array}$ \\
\hline $\begin{array}{l}\text { Establish individual } \\
\text { employee development plans }\end{array}$ & $\begin{array}{l}18.5 \% \text { slightly important } \\
32.2 \% \text { fairly important } \\
34.2 \% \text { quite important } \\
10.3 \% \text { very important } \\
{[146]}\end{array}$ & $\begin{array}{l}10.5 \% \text { slightly important } \\
31.6 \% \text { fairly important } \\
42.1 \% \text { quite important } \\
10.5 \% \text { very important } \\
{[19]}\end{array}$ \\
\hline
\end{tabular}




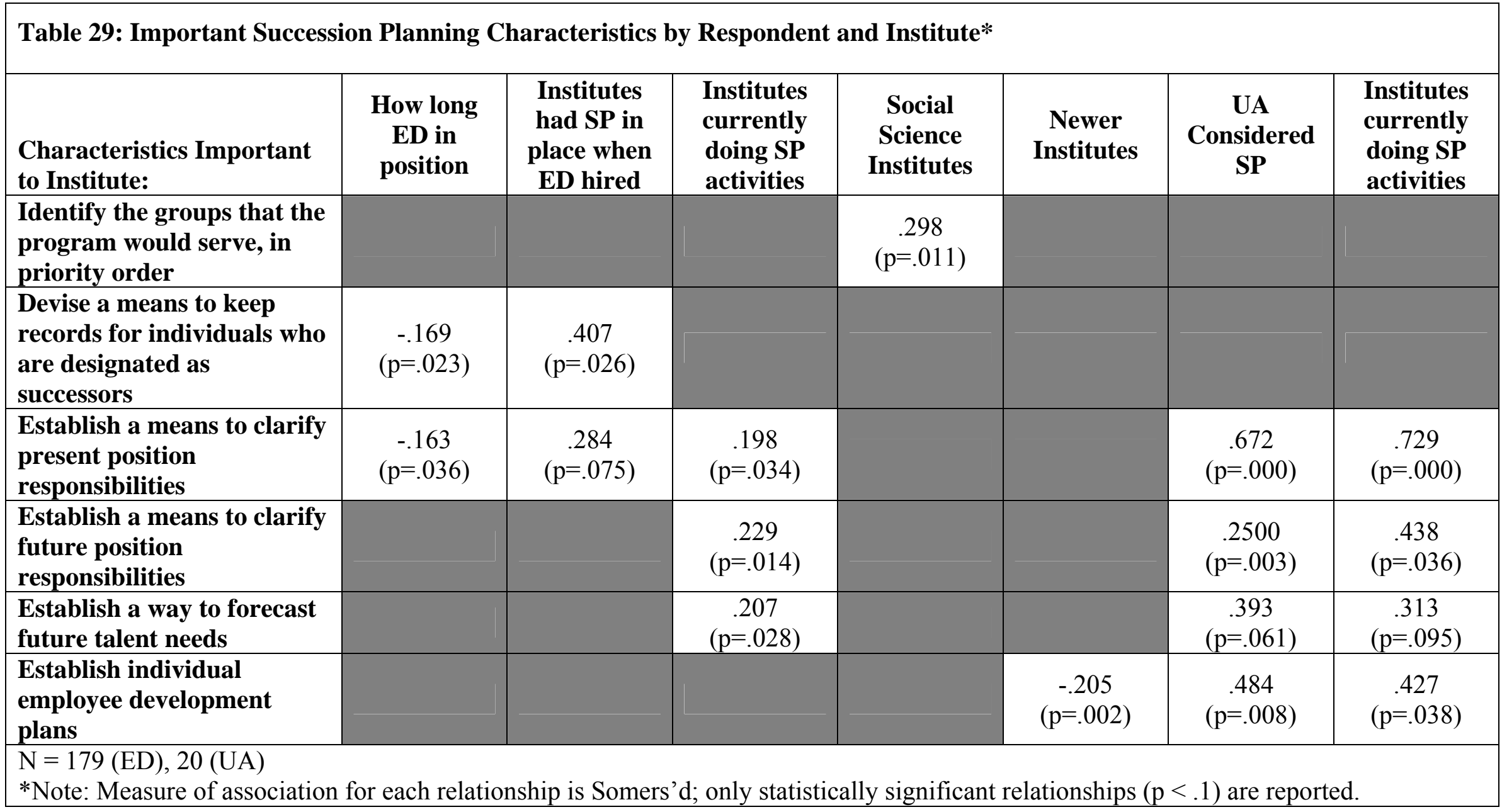




\begin{tabular}{|c|c|c|}
\hline & Executive Directors & University Administrators \\
\hline Job rotation & $\begin{array}{l}32.0 \% \text { Least Important } \\
19.0 \% \text { fourth important } \\
16.3 \% \text { third important } \\
17.7 \% \text { second in importance } \\
15.0 \% \text { Most Important } \\
{[147]}\end{array}$ & $\begin{array}{l}21.1 \% \text { Least Important } \\
15.8 \% \text { fourth important } \\
21.1 \% \text { third important } \\
15.8 \% \text { second in importance } \\
26.3 \% \text { Most Important } \\
{[19]}\end{array}$ \\
\hline Stretch assignments & $\begin{array}{l}10.9 \% \text { Least Important } \\
15.6 \% \text { fourth important } \\
27.2 \% \text { third important } \\
27.9 \% \text { second in importance } \\
18.4 \% \text { Most Important } \\
\text { [147] }\end{array}$ & $\begin{array}{l}15.8 \% \text { fourth important } \\
42.1 \% \text { third important } \\
31.6 \% \text { second in importance } \\
10.5 \% \text { Most Important } \\
{[19]}\end{array}$ \\
\hline Job enrichment & $\begin{array}{l}19.7 \% \text { fourth important } \\
19.7 \% \text { third important } \\
32.0 \% \text { second in importance } \\
19.0 \% \text { Most Important } \\
\text { [147] }\end{array}$ & $\begin{array}{l}\text { 10.5\% Least Important } \\
21.1 \% \text { fourth important } \\
31.6 \% \text { third important } \\
36.8 \% \text { second in importance } \\
{[19]}\end{array}$ \\
\hline Mentoring & $\begin{array}{l}12.2 \% \text { Least Important } \\
19.0 \% \text { fourth important } \\
16.3 \% \text { third important } \\
25.2 \% \text { second in importance } \\
27.2 \% \text { Most Important } \\
\text { [147] }\end{array}$ & $\begin{array}{l}21.1 \% \text { Least Important } \\
10.5 \% \text { fourth important } \\
10.5 \% \text { third important } \\
31.6 \% \text { second in importance } \\
26.3 \% \text { Most Important } \\
\text { [19] }\end{array}$ \\
\hline $\begin{array}{l}\text { Training related to } \\
\text { succession development }\end{array}$ & $\begin{array}{l}28.6 \% \text { Least Important } \\
20.4 \% \text { fourth important } \\
18.4 \% \text { third important } \\
14.3 \% \text { second in importance } \\
18.4 \% \text { Most Important } \\
\text { [147] }\end{array}$ & $\begin{array}{l}26.3 \% \text { Least Important } \\
15.8 \% \text { fourth important } \\
10.5 \% \text { third important } \\
15.8 \% \text { second in importance } \\
31.6 \% \text { Most Important } \\
\text { [19] }\end{array}$ \\
\hline
\end{tabular}




\begin{tabular}{|c|c|c|c|}
\hline \multicolumn{2}{|l|}{ Growth } & \multicolumn{2}{|l|}{ Retiring } \\
\hline Administration & $\begin{array}{l}31.8 \% \text { report } 0 \% \text { growth } \\
52.3 \% \text { report } 10 \% \text { or less } \\
10.3 \% \text { report } 11-25 \% \text { growth } \\
{[145]}\end{array}$ & $\begin{array}{l}\text { \# Retire in } 5 \\
\text { years }\end{array}$ & $\begin{array}{l}19.3 \% \text { report } 0 \\
65.0 \% \text { report } 1 \text { to } 5 \\
{[140]}\end{array}$ \\
\hline Faculty & $\begin{array}{l}18.1 \% \text { report no growth } \\
33.3 \% \text { report } 10 \% \text { or less } \\
25.7 \% \text { report } 11-25 \% \\
17.1 \% \text { report } 25-50 \% \\
{[107]}\end{array}$ & $\begin{array}{l}\text { \# Retire in } 10 \\
\text { years }\end{array}$ & $\begin{array}{l}53.3 \% \text { report } 1-5 \\
24.1 \% \text { report } 6-10 \\
12.4 \% \text { report } 16-20 \\
{[137]}\end{array}$ \\
\hline Staff & $\begin{array}{l}37.1 \% \text { report } 10 \% \text { or less } \\
35.2 \% \text { report } 11-25 \% \\
13.3 \% \text { report } 26-50 \% \\
{[105]}\end{array}$ & & \\
\hline Post-Docs & $\begin{array}{l}20.2 \% \text { report no growth } \\
33.7 \% \text { report } 10 \% \text { or less } \\
22.1 \% \text { report } 11-25 \% \\
12.5 \% \text { report } 26-50 \% \\
{[104]}\end{array}$ & & \\
\hline Graduate Students & $\begin{array}{l}20.8 \% \text { report no growth } \\
29.2 \% \text { report } 10 \% \text { or less } \\
21.7 \% \text { report } 11-25 \% \\
17.9 \% \text { report } 26-50 \% \\
{[106]}\end{array}$ & & \\
\hline
\end{tabular}


Table 32: Importance of Reasons for Succession Planning by Respondent (\% respondents [N])*

\begin{tabular}{|c|c|c|}
\hline The succession plan would: & Executive Directors & University Administrators \\
\hline $\begin{array}{l}\text { Contribute to implementing } \\
\text { the organization's strategic } \\
\text { plan }\end{array}$ & $\begin{array}{l}12.7 \% \text { slightly important } \\
31.8 \% \text { fairly important } \\
34.7 \% \text { quite important } \\
16.8 \% \text { very important } \\
{[173]}\end{array}$ & $\begin{array}{l}31.8 \% \text { slightly important } \\
31.8 \% \text { fairly important } \\
22.7 \% \text { quite important } \\
{[22]}\end{array}$ \\
\hline $\begin{array}{l}\text { Help downsize / reduce } \\
\text { staffing }\end{array}$ & $\begin{array}{l}58.4 \% \text { not at all important } \\
21.4 \% \text { slightly important } \\
16.8 \% \text { fairly important } \\
{[173]}\end{array}$ & $\begin{array}{l}71.4 \% \text { not at all important } \\
19.0 \% \text { slightly important } \\
{[21]}\end{array}$ \\
\hline $\begin{array}{l}\text { Help individuals realize their } \\
\text { career plans within the org }\end{array}$ & $\begin{array}{l}17.1 \% \text { slightly important } \\
30.9 \% \text { fairly important } \\
36.6 \% \text { quite important } \\
10.3 \% \text { very important } \\
{[175]}\end{array}$ & $\begin{array}{l}31.8 \% \text { slightly important } \\
27.3 \% \text { fairly important } \\
31.8 \% \text { quite important } \\
{[22]}\end{array}$ \\
\hline $\begin{array}{l}\text { Encourage the advancement } \\
\text { of diverse groups - such as } \\
\text { minorities or women - in } \\
\text { future jobs within the org }\end{array}$ & $\begin{array}{l}22.9 \% \text { slightly important } \\
35.4 \% \text { fairly important } \\
28.6 \% \text { quite important } \\
{[175]}\end{array}$ & $\begin{array}{l}22.7 \% \text { slightly important } \\
45.5 \% \text { fairly important } \\
18.2 \% \text { quite important } \\
{[22]}\end{array}$ \\
\hline $\begin{array}{l}\text { Preserve institutional } \\
\text { knowledge as our workforce } \\
\text { evolves }\end{array}$ & $\begin{array}{l}19.4 \% \text { fairly important } \\
46.9 \% \text { quite important } \\
25.7 \% \text { very important } \\
{[175]}\end{array}$ & $\begin{array}{l}27.3 \% \text { slightly important } \\
36.4 \% \text { fairly important } \\
18.2 \% \text { quite important } \\
18.2 \% \text { very important } \\
{[22]}\end{array}$ \\
\hline $\begin{array}{l}\text { Provide increased } \\
\text { opportunities for “high } \\
\text { potential” workers }\end{array}$ & $\begin{array}{l}24.1 \% \text { fairly important } \\
45.4 \% \text { quite important } \\
21.8 \% \text { very important } \\
{[174]}\end{array}$ & $\begin{array}{l}22.7 \% \text { fairly important } \\
36.4 \% \text { quite important } \\
31.8 \% \text { very important } \\
{[22]}\end{array}$ \\
\hline $\begin{array}{l}\text { Prepare for immediate loss } \\
\text { of key employees in critical } \\
\text { positions }\end{array}$ & $\begin{array}{l}13.8 \% \text { slightly important } \\
28.2 \% \text { fairly important } \\
33.9 \% \text { quite important } \\
21.8 \% \text { very important } \\
{[174]}\end{array}$ & $\begin{array}{l}27.3 \% \text { fairly important } \\
22.7 \% \text { quite important } \\
36.4 \% \text { very important } \\
{[22]}\end{array}$ \\
\hline Improve employee retention & $\begin{array}{l}19.3 \% \text { slightly important } \\
35.1 \% \text { fairly important } \\
31.6 \% \text { quite important } \\
{[171]}\end{array}$ & $\begin{array}{l}31.8 \% \text { fairly important } \\
31.8 \% \text { quite important } \\
18.2 \% \text { very important } \\
{[22]}\end{array}$ \\
\hline
\end{tabular}




\begin{tabular}{|c|c|c|c|c|c|c|c|c|c|}
\hline Impetus for Succession Plan: & $\begin{array}{c}\text { ED } \\
\text { Knowledge } \\
\text { of SP }\end{array}$ & $\begin{array}{l}\text { RIs } \\
\text { currently } \\
\text { doing SP } \\
\text { activities }\end{array}$ & $\begin{array}{l}\text { RI have } \\
\text { Strategic } \\
\text { Plan }\end{array}$ & $\begin{array}{c}\text { Social } \\
\text { Science RI }\end{array}$ & Larger RI & Newer RI & $\begin{array}{l}\text { RIs with } \\
\text { Larger } \\
\text { Budgets }\end{array}$ & $\begin{array}{l}\text { UA } \\
\text { Considered } \\
\text { SP }\end{array}$ & $\begin{array}{l}\text { Respondent } \\
\text { is UA }\end{array}$ \\
\hline $\begin{array}{l}\text { Contribute to implementing the } \\
\text { strategic plan }\end{array}$ & $\begin{array}{c}.238 \\
(\mathrm{p}=.000)\end{array}$ & $\begin{array}{l}\text { ED: } .326 \\
(p=.000) \\
\text { UA: } .500 \\
(p=.012)\end{array}$ & $\begin{array}{l}\text { ED: } .203 \\
(p=.029)\end{array}$ & & $\begin{array}{c}.139 \\
(p=.046)\end{array}$ & & & $\begin{array}{c}.503 \\
(\mathrm{p}=.002)\end{array}$ & $\begin{array}{c}-.258 \\
(\mathrm{p}=.049)\end{array}$ \\
\hline Help downsize / reduce staffing & & & & $\begin{array}{c}-.196 \\
(p=.040)\end{array}$ & & $\begin{array}{c}-.120 \\
(\mathrm{p}=.051)\end{array}$ & $\begin{array}{c}-.128 \\
(\mathrm{p}=.056)\end{array}$ & & \\
\hline $\begin{array}{l}\text { Help individuals realize their } \\
\text { career plans within the } \\
\text { organization }\end{array}$ & $\begin{array}{c}.189 \\
(p=.003)\end{array}$ & & & & $\begin{array}{c}.194 \\
(\mathrm{p}=.003)\end{array}$ & & $\begin{array}{c}.146 \\
(p=.046)\end{array}$ & $\begin{array}{c}.410 \\
(\mathrm{p}=.046)\end{array}$ & \\
\hline $\begin{array}{l}\text { Encourage the advancement of } \\
\text { diverse groups in future jobs } \\
\text { within the organization }\end{array}$ & $\begin{array}{c}.109 \\
(p=.094)\end{array}$ & & & & $\begin{array}{c}.127 \\
(p=.045)\end{array}$ & & $\begin{array}{c}.203 \\
(p=.004)\end{array}$ & & \\
\hline $\begin{array}{l}\text { Preserve institutional knowledge } \\
\text { as our workforce evolves }\end{array}$ & $\begin{array}{c}.148 \\
(\mathrm{p}=.021) \\
\end{array}$ & & & & $\begin{array}{c}.108 \\
(\mathrm{p}=.088) \\
\end{array}$ & & & $\begin{array}{c}.373 \\
(p=.036) \\
\end{array}$ & $\begin{array}{c}-.344 \\
(\mathrm{p}=.018)\end{array}$ \\
\hline $\begin{array}{l}\text { Provide increased opportunities } \\
\text { for "high potential" workers }\end{array}$ & $\begin{array}{c}.213 \\
(p=.001)\end{array}$ & & $\begin{array}{l}\text { UA: } .541 \\
(p=.026)\end{array}$ & & $\begin{array}{c}.152 \\
(p=.023)\end{array}$ & & $\begin{array}{c}.155 \\
(\mathrm{p}=.036)\end{array}$ & $\begin{array}{c}.466 \\
(p=.006)\end{array}$ & \\
\hline $\begin{array}{l}\text { Prepare for immediate loss of } \\
\text { key employees in critical } \\
\text { positions }\end{array}$ & & $\begin{array}{l}\text { ED: . .173 } \\
(p=.062)\end{array}$ & & & $\begin{array}{c}.121 \\
(\mathrm{p}=.092)\end{array}$ & & & & \\
\hline Improve employee retention & $\begin{array}{c}.193 \\
(p=.003)\end{array}$ & $\begin{array}{l}\text { ED: .168 } \\
(p=.082)\end{array}$ & $\begin{array}{l}\text { UA: .506 } \\
(\mathrm{p}=.048)\end{array}$ & & $\begin{array}{c}.206 \\
(\mathrm{p}=.004) \\
\end{array}$ & & $\begin{array}{c}.149 \\
(\mathrm{p}=.043)\end{array}$ & $\begin{array}{c}.547 \\
(p=.006)\end{array}$ & \\
\hline \multicolumn{10}{|c|}{$\begin{array}{l}\mathrm{N}=208(\mathrm{ED}), 22(\mathrm{UA}) \\
* \text { Note: Measure of association for each relationship is Somers'd; only statistically significant relationships }(\mathrm{p}<.1) \text { are reported. } \\
\mathrm{ED}=\text { Executive Director } \\
\mathrm{UA}=\text { University Administrator }\end{array}$} \\
\hline
\end{tabular}



Table 34: Frequency of Development Programs by Type of Employee and Respondent (\%
respondents $[\mathrm{N}])^{*}$

\begin{tabular}{|c|c|c|}
\hline & Executive Directors & University Administrators \\
\hline Senior Leaders (ex: ED) & $\begin{array}{l}\text { 16.7\% One Time } \\
\text { 18.8\% Multiple Experiences } \\
\text { over 1 Year } \\
55.8 \% \text { Multiple experiences } \\
\text { over multiples years } \\
{[138]}\end{array}$ & $\begin{array}{l}45.0 \% \text { One Time } \\
25.0 \% \text { Multiple Experiences } \\
\text { over 1 Year } \\
\text { 30.0\% Multiple Experiences } \\
\text { over Multiple Years } \\
\text { [20] }\end{array}$ \\
\hline Managers & $\begin{array}{l}\text { 14.0\% None } \\
23.5 \% \text { One Time } \\
26.5 \% \text { Multiple Experiences } \\
\text { over 1 Year } \\
\text { 36.0\% Multiple experiences } \\
\text { over multiples years } \\
{[136]}\end{array}$ & $\begin{array}{l}\text { 10.0\% None } \\
30.0 \% \text { One Time } \\
35.0 \% \text { Multiple Experiences } \\
\text { over 1 Year } \\
\text { 25.0\% Multiple Experiences } \\
\text { over Multiple Years } \\
\text { [20] }\end{array}$ \\
\hline Staff & $\begin{array}{l}26.3 \% \text { None } \\
35.8 \% \text { One Time } \\
\text { 19.7\% Multiple Experiences } \\
\text { over 1 Year } \\
\text { 18.2\% Multiple experiences } \\
\text { over multiples years } \\
\text { [137] }\end{array}$ & $\begin{array}{l}35.0 \% \text { None } \\
30.0 \% \text { One Time } \\
20.0 \% \text { Multiple Experiences } \\
\text { over 1 Year } \\
\text { 15.0\% Multiple experiences } \\
\text { over multiples years } \\
\text { [20] }\end{array}$ \\
\hline Residential Faculty & $\begin{array}{l}39.7 \% \text { None } \\
28.2 \% \text { One Time } \\
\text { 17.6\% Multiple Experiences } \\
\text { over 1 Year } \\
\text { 14.5\% Multiple experiences } \\
\text { over multiples years } \\
{[131]}\end{array}$ & $\begin{array}{l}40.0 \% \text { None } \\
30.0 \% \text { One Time } \\
\text { 15.0\% Multiple Experiences } \\
\text { over 1 Year } \\
\text { 15.0\% Multiple experiences } \\
\text { over multiples years } \\
\text { [20] }\end{array}$ \\
\hline $\begin{array}{l}\text { Adjunct/Affiliated } \\
\text { Faculty }\end{array}$ & $\begin{array}{l}62.2 \% \text { None } \\
24.4 \% \text { One Time } \\
{[135]}\end{array}$ & $\begin{array}{l}75.0 \% \text { None } \\
20.0 \% \text { One Time } \\
{[20]}\end{array}$ \\
\hline Post-Docs & $\begin{array}{l}70.6 \% \text { None } \\
\text { 19.9\% One Time } \\
{[136]}\end{array}$ & $\begin{array}{l}90.0 \% \text { None } \\
{[20]}\end{array}$ \\
\hline Graduate Students & $\begin{array}{l}75.6 \% \text { None } \\
16.0 \% \text { One Time } \\
{[131]}\end{array}$ & $\begin{array}{l}90.0 \% \text { None } \\
{[20]}\end{array}$ \\
\hline
\end{tabular}


Table 35: Frequency and Target of Development Opportunities by Respondent, Institute, and University*

\begin{tabular}{|c|c|c|c|c|c|c|c|c|c|c|}
\hline $\begin{array}{l}\text { Type of } \\
\text { Development } \\
\text { Program: }\end{array}$ & $\begin{array}{c}\text { ED } \\
\text { Knowled } \\
\text { ge of SP }\end{array}$ & $\begin{array}{l}\text { How long } \\
\text { ED in } \\
\text { position }\end{array}$ & $\begin{array}{l}\text { RI doing } \\
\text { SP } \\
\text { activities }\end{array}$ & $\begin{array}{c}\text { Larger } \\
\text { RI }\end{array}$ & Newer RI & $\begin{array}{l}\text { RI with } \\
\text { Larger } \\
\text { Budgets }\end{array}$ & $\begin{array}{l}\text { RI have } \\
\text { Strategic } \\
\text { Plans }\end{array}$ & $\begin{array}{l}\text { Respon- } \\
\text { dent is } \\
\text { UA }\end{array}$ & $\begin{array}{c}\text { Larger } \\
\text { Univ. }\end{array}$ & $\begin{array}{c}\text { Univ. has } \\
\text { greater } \\
\text { number } \\
\text { of RI }\end{array}$ \\
\hline $\begin{array}{l}\text { Senior Leaders } \\
\text { (ED) }\end{array}$ & $\begin{array}{c}.220 \\
(p=.001)\end{array}$ & $\begin{array}{c}.137 \\
(p=.066)\end{array}$ & $\begin{array}{l}\text { ED: } .169 \\
(p=.075)\end{array}$ & $\begin{array}{c}.142 \\
(p=.032)\end{array}$ & $\begin{array}{c}-.110 \\
(p=.079)\end{array}$ & $\begin{array}{c}.118 \\
(p=.078)\end{array}$ & & $\begin{array}{c}-.667 \\
(p=.000)\end{array}$ & $\begin{array}{c}.098 \\
(p=.087)\end{array}$ & $\begin{array}{c}-.115 \\
(p=.073)\end{array}$ \\
\hline Managers & $\begin{array}{c}.194 \\
(p=.009)\end{array}$ & & & & $\begin{array}{c}-.119 \\
(p=.078)\end{array}$ & & $\begin{array}{l}.408 \\
(p=.080)\end{array}$ & $\begin{array}{c}-.524 \\
(p=.000)\end{array}$ & & \\
\hline Staff & & & $\begin{array}{l}\text { ED: . } 192 \\
(p=.054)\end{array}$ & & & & & $\begin{array}{c}-.529 \\
(p=.001)\end{array}$ & & \\
\hline Residential Faculty & & & & & & $\begin{array}{c}.131 \\
(p=.075)\end{array}$ & $\begin{array}{l}.466 \\
(p=.042)\end{array}$ & $\begin{array}{c}-.489 \\
(p=.002)\end{array}$ & & \\
\hline $\begin{array}{l}\text { Adjunct / Affiliated } \\
\text { Faculty }\end{array}$ & & & $\begin{array}{r}\text { UA: } .313 \\
(p=.046)\end{array}$ & & & & $\begin{array}{l}.485 \\
(p=.022)\end{array}$ & $\begin{array}{c}-.785 \\
(p=.000)\end{array}$ & & \\
\hline Post-Docs & & & & & & & & $\begin{array}{c}-.871 \\
(\mathrm{p}=.000)\end{array}$ & & \\
\hline Graduate Students & & & & & & & & $\begin{array}{c}-.869 \\
(p=.000)\end{array}$ & & \\
\hline \multicolumn{11}{|c|}{$\begin{array}{l}\mathrm{N}=172(\mathrm{ED}), 20(\mathrm{UA}) \\
* \text { Note: Measure of association for each relationship is Somers'd; only statistically significant relationships }(\mathrm{p}<.1) \text { are reported. } \\
\mathrm{ED}=\text { Executive Director } \\
\mathrm{UA}=\text { University Administrator } \\
\text { Positive Relationships correlate with greater number of development opportunities over longer time periods. }\end{array}$} \\
\hline
\end{tabular}


Table 36: Contents of Written Succession Plan by Respondent (\% respondents [N])*

\begin{tabular}{|c|c|c|}
\hline $\begin{array}{l}\text { A written succession plan } \\
\text { would: }\end{array}$ & Executive Director & University Administrator \\
\hline $\begin{array}{l}\text { Be tied to the research } \\
\text { center's strategic plans }\end{array}$ & $\begin{array}{l}13.9 \% \text { fairly important } \\
33.3 \% \text { quite important } \\
43.1 \% \text { very important } \\
{[144]}\end{array}$ & $\begin{array}{l}15.8 \% \text { slightly important } \\
21.1 \% \text { fairly important } \\
36.8 \% \text { quite important } \\
26.3 \% \text { very important } \\
{[19]}\end{array}$ \\
\hline $\begin{array}{l}\text { Be tied to the university's } \\
\text { strategic plans }\end{array}$ & $\begin{array}{l}\text { 15.3\% slightly important } \\
26.4 \% \text { fairly important } \\
35.4 \% \text { quite important } \\
16.0 \% \text { very important } \\
{[144]}\end{array}$ & $\begin{array}{l}21.1 \% \text { slightly important } \\
21.1 \% \text { fairly important } \\
31.6 \% \text { quite important } \\
21.1 \% \text { very important } \\
{[19]}\end{array}$ \\
\hline $\begin{array}{l}\text { Be tied to employee training } \\
\text { programs }\end{array}$ & $\begin{array}{l}13.9 \% \text { not at all important } \\
30.6 \% \text { slightly important } \\
34.7 \% \text { fairly important } \\
17.4 \% \text { quite important } \\
{[144]}\end{array}$ & $\begin{array}{l}10.5 \% \text { not at all important } \\
42.1 \% \text { slightly important } \\
21.1 \% \text { fairly important } \\
15.8 \% \text { quite important } \\
10.5 \% \text { very important } \\
{[19]}\end{array}$ \\
\hline $\begin{array}{l}\text { Have a prepared written } \\
\text { purpose statement }\end{array}$ & $\begin{array}{l}21.7 \% \text { slightly important } \\
30.1 \% \text { fairly important } \\
25.9 \% \text { quite important } \\
14.7 \% \text { very important } \\
{[143]}\end{array}$ & $\begin{array}{l}10.5 \% \text { not at all important } \\
26.3 \% \text { slightly important } \\
31.6 \% \text { fairly important } \\
26.3 \% \text { quite important } \\
\text { [19] }\end{array}$ \\
\hline $\begin{array}{l}\text { Have prepared written } \\
\text { program goals }\end{array}$ & $\begin{array}{l}18.1 \% \text { slightly important } \\
30.6 \% \text { fairly important } \\
29.2 \% \text { quite important } \\
16.7 \% \text { very important } \\
{[144]}\end{array}$ & $\begin{array}{l}10.5 \% \text { not at all important } \\
42.1 \% \text { fairly important } \\
36.8 \% \text { quite important } \\
{[19]}\end{array}$ \\
\hline $\begin{array}{l}\text { Have an established } \\
\text { schedule of program events }\end{array}$ & $\begin{array}{l}16.2 \% \text { not at all important } \\
28.2 \% \text { slightly important } \\
28.2 \% \text { fairly important } \\
25.4 \% \text { quite important } \\
{[142]}\end{array}$ & $\begin{array}{l}15.8 \% \text { not at all important } \\
47.4 \% \text { slightly important } \\
26.3 \% \text { fairly important } \\
{[19]}\end{array}$ \\
\hline $\begin{array}{l}\text { Develop a means to budget } \\
\text { for a succession program }\end{array}$ & $\begin{array}{l}24.5 \% \text { slightly important } \\
23.1 \% \text { fairly important } \\
32.2 \% \text { quite important } \\
12.6 \% \text { very important } \\
{[143]}\end{array}$ & $\begin{array}{l}15.8 \% \text { not at all important } \\
21.1 \% \text { slightly important } \\
47.4 \% \text { fairly important } \\
10.5 \% \text { quite important } \\
{[19]}\end{array}$ \\
\hline
\end{tabular}




\section{Table 37: Characteristics Succession Plan Evaluation by Respondent (\% respondents}

[N])*

\begin{tabular}{|c|c|c|}
\hline $\begin{array}{l}\text { A succession program would } \\
\text { establish: }\end{array}$ & Executive Director & University Administrator \\
\hline $\begin{array}{l}\text { Measurable objectives for } \\
\text { program operation }\end{array}$ & $\begin{array}{l}13.4 \% \text { slightly important } \\
29.6 \% \text { fairly important } \\
34.5 \% \text { quite important } \\
15.5 \% \text { very important } \\
{[142]}\end{array}$ & $\begin{array}{l}10.5 \% \text { not at all important } \\
26.3 \% \text { fairly important } \\
47.4 \% \text { quite important } \\
10.5 \% \text { very important } \\
{[19]}\end{array}$ \\
\hline $\begin{array}{l}\text { A means to appraise } \\
\text { individual performance }\end{array}$ & $\begin{array}{l}11.9 \% \text { slightly important } \\
28.0 \% \text { fairly important } \\
40.6 \% \text { quite important } \\
16.1 \% \text { very important } \\
{[143]}\end{array}$ & $\begin{array}{l}10.5 \% \text { slightly important } \\
15.8 \% \text { fairly important } \\
52.6 \% \text { quite important } \\
15.8 \% \text { very important } \\
{[19]}\end{array}$ \\
\hline $\begin{array}{l}\text { A means to compare } \\
\text { individual skills to the } \\
\text { requirements of a future } \\
\text { position }\end{array}$ & $\begin{array}{l}14.0 \% \text { slightly important } \\
27.3 \% \text { fairly important } \\
39.2 \% \text { quite important } \\
17.5 \% \text { very important } \\
{[143]}\end{array}$ & $\begin{array}{l}10.5 \% \text { slightly important } \\
15.8 \% \text { fairly important } \\
57.9 \% \text { quite important } \\
10.5 \% \text { very important } \\
{[19]}\end{array}$ \\
\hline $\begin{array}{l}\text { A way to review } \\
\text { organizational talent at least } \\
\text { annually }\end{array}$ & $\begin{array}{l}35.7 \% \text { fairly important } \\
37.8 \% \text { quite important } \\
12.6 \% \text { very important } \\
{[143]}\end{array}$ & $\begin{array}{l}21.1 \% \text { slightly important } \\
36.8 \% \text { fairly important } \\
21.1 \% \text { quite important } \\
15.8 \% \text { very important } \\
{[19]}\end{array}$ \\
\hline $\begin{array}{l}\text { A means to track } \\
\text { development activities to } \\
\text { prepare successors for } \\
\text { eventual advancement }\end{array}$ & $\begin{array}{l}12.6 \% \text { slightly important } \\
37.8 \% \text { fairly important } \\
32.9 \% \text { quite important } \\
12.6 \% \text { very important } \\
{[143]}\end{array}$ & $\begin{array}{l}11.1 \% \text { not at all important } \\
16.7 \% \text { slightly important } \\
33.3 \% \text { fairly important } \\
22.2 \% \text { quite important } \\
16.7 \% \text { very important } \\
{[18]}\end{array}$ \\
\hline
\end{tabular}


Table 38: Sources of Key Hires (Executive Director Reports) (\% respondents [N])*

\begin{tabular}{|c|c|c|c|}
\hline & $\begin{array}{c}\text { Where Key } \\
\text { Employees Currently } \\
\text { Come From }\end{array}$ & $\begin{array}{c}\text { Desired Changes } \\
\text { from Where they } \\
\text { Come From }\end{array}$ & $\begin{array}{l}\text { Where Current } \\
\text { Leaders Came From }\end{array}$ \\
\hline $\begin{array}{l}\text { Internal to Research } \\
\text { Institute }\end{array}$ & $\begin{array}{l}22.1 \% \text { report } 0 \% \\
21.2 \% \text { report } 1-10 \% \\
18.6 \% \text { report } 11-25 \% \\
23.0 \% \text { report } 26-50 \% \\
{[113]}\end{array}$ & $\begin{array}{l}26.4 \% \text { report } 0 \% \\
11.3 \% \text { report } 1-10 \% \\
28.3 \% \text { report } 11-25 \% \\
26.4 \% \text { report } 26-50 \% \\
{[53]}\end{array}$ & $\begin{array}{l}33.6 \% \\
{[137]}\end{array}$ \\
\hline $\begin{array}{l}\text { Internal to } \\
\text { University }\end{array}$ & $\begin{array}{l}11.9 \% \text { report } 0 \% \\
13.5 \% \text { report } 1-10 \% \\
22.2 \% \text { report } 11-25 \% \\
27.0 \% \text { report } 26-50 \% \\
10.3 \% \text { report } 100 \% \\
{[126]}\end{array}$ & $\begin{array}{l}16.9 \% \text { report } 0 \% \\
20.3 \% \text { report } 1-10 \% \\
20.3 \% \text { report } 11-25 \% \\
28.8 \% \text { report } 26-50 \% \\
{[59]}\end{array}$ & $\begin{array}{l}36.5 \% \\
{[137]}\end{array}$ \\
\hline $\begin{array}{l}\text { External to } \\
\text { University but from } \\
\text { Another University }\end{array}$ & $\begin{array}{l}14.7 \% \text { report } 0 \% \\
12.9 \% \text { report } 1-10 \% \\
24.1 \% \text { report } 11-25 \% \\
32.8 \% \text { report } 26-50 \% \\
{[116]}\end{array}$ & $\begin{array}{l}16.4 \% \text { report } 0 \% \\
10.9 \% \text { report } 1-10 \% \\
32.7 \% \text { report } 11-25 \% \\
36.4 \% \text { report } 26-50 \% \\
{[55]}\end{array}$ & $\begin{array}{l}24.1 \% \\
{[137]}\end{array}$ \\
\hline $\begin{array}{l}\text { External to } \\
\text { University but from } \\
\text { Industry }\end{array}$ & $\begin{array}{l}31.5 \% \text { report } 0 \% \\
27.0 \% \text { report } 1-10 \% \\
23.4 \% \text { report } 11-25 \% \\
16.2 \% \text { report } 26-50 \% \\
{[111]}\end{array}$ & $\begin{array}{l}30.9 \% \text { report } 0 \% \\
20.0 \% \text { report } 1-10 \% \\
32.7 \% \text { report } 11-25 \% \\
16.4 \% \text { report } 26-50 \% \\
{[55]}\end{array}$ & \\
\hline No Change & & $\begin{array}{l}88.8 \% \text { report No } \\
\text { changes } \\
{[80]}\end{array}$ & \\
\hline
\end{tabular}




\begin{tabular}{|c|c|c|c|}
\hline & $\begin{array}{c}\text { Where Key } \\
\text { Employees Currently } \\
\text { Come From }\end{array}$ & $\begin{array}{c}\text { Desired Changes } \\
\text { from Where they } \\
\text { Come From }\end{array}$ & $\begin{array}{c}\text { Where Current } \\
\text { Leaders Came From }\end{array}$ \\
\hline $\begin{array}{l}\text { Internal to Research } \\
\text { Institute }\end{array}$ & $\begin{array}{l}10.5 \% \text { report } 0 \% \\
15.8 \% \text { report } 1-10 \% \\
31.6 \% \text { report } 11-25 \% \\
21.1 \% \text { report } 26-50 \% \\
21.1 \% \text { report } 51-75 \% \\
{[19]}\end{array}$ & & $\begin{array}{l}26.3 \% \\
{[19]}\end{array}$ \\
\hline $\begin{array}{l}\text { Internal to } \\
\text { University }\end{array}$ & $\begin{array}{l}21.1 \% \text { report } 1-10 \% \\
42.1 \% \text { report } 11-25 \% \\
26.3 \% \text { report } 26-50 \% \\
{[19]}\end{array}$ & $\begin{array}{l}21.4 \% \text { report } 0 \% \\
21.4 \% \text { report } 1-10 \% \\
42.9 \% \text { report } 11-25 \% \\
14.3 \% \text { report } 26-50 \% \\
{[14]}\end{array}$ & $\begin{array}{l}52.6 \% \\
{[19]}\end{array}$ \\
\hline $\begin{array}{l}\text { External to } \\
\text { University but from } \\
\text { Another University }\end{array}$ & $\begin{array}{l}15.8 \% \text { report } 1-10 \% \\
31.6 \% \text { report } 11-25 \% \\
15.8 \% \text { report } 26-50 \% \\
26.3 \% \text { report } 51-75 \% \\
10.5 \% \text { report } 76-99 \% \\
{[19]}\end{array}$ & $\begin{array}{l}21.4 \% \text { report } 0 \% \\
28.6 \% \text { report } 11-25 \% \\
35.7 \% \text { report } 26-50 \% \\
{[14]}\end{array}$ & $\begin{array}{l}21.1 \% \\
{[19]}\end{array}$ \\
\hline $\begin{array}{l}\text { External to } \\
\text { University but from } \\
\text { Industry }\end{array}$ & $\begin{array}{l}62.5 \% \text { report } 1-10 \% \\
25.0 \% \text { report } 11-25 \% \\
{[16]}\end{array}$ & $\begin{array}{l}23.1 \% \text { report } 0 \% \\
38.5 \% \text { report } 1-10 \% \\
30.8 \% \text { report } 11-25 \% \\
{[13]}\end{array}$ & \\
\hline No Change & & $\begin{array}{l}77.8 \% \text { report No } \\
\text { changes } \\
{[9]}\end{array}$ & \\
\hline
\end{tabular}


Table 41: Responses and Themes by Director and Institute Type

\begin{tabular}{|c|c|c|c|c|c|c|c|c|c|c|}
\hline & $\begin{array}{c}1 \\
\text { Hard } \\
\text { Science }\end{array}$ & $\begin{array}{c}2 \\
\text { Hard } \\
\text { Science }\end{array}$ & $\begin{array}{c}3 \\
\text { Hard } \\
\text { Science }\end{array}$ & $\begin{array}{c}4 \\
\text { Hard } \\
\text { Science }\end{array}$ & $\begin{array}{c}7 \\
\text { Hard } \\
\text { Science }\end{array}$ & $\begin{array}{c}8 \\
\text { Hard } \\
\text { Science }\end{array}$ & $\begin{array}{c}5 \\
\text { Social } \\
\text { Science }\end{array}$ & $\begin{array}{c}6 \\
\text { Social } \\
\text { Science } \\
\end{array}$ & $\begin{array}{c}9 \\
\text { Social } \\
\text { Science }\end{array}$ & $\begin{array}{c}10 \\
\text { Social } \\
\text { Science }\end{array}$ \\
\hline \multicolumn{11}{|c|}{ Question 1: Succession planning relevance } \\
\hline Funding & Yes & Yes & Yes & Yes & & & Yes & & & \\
\hline Turnover & Yes & & Yes & Yes & Yes & & & Yes & & \\
\hline Informal & Yes & Yes & & & & Yes & & Yes & & \\
\hline Org vs. Ind. & Yes & & Yes & & & & & & Yes & \\
\hline $\begin{array}{l}\text { Both Relevant and } \\
\text { Not Relevant }\end{array}$ & & & Yes & Yes & Yes & & & & & \\
\hline No Authority & & & & & & & & Yes & Yes & \\
\hline What drives Org & & Yes & & & & & Yes & & & \\
\hline Priority & & & & & & & & & & Yes \\
\hline Benefit of SP? & Yes & & & & & & & & & \\
\hline \multicolumn{11}{|c|}{ Question 2: Reaction to the proposed model } \\
\hline Clarity of Model & & & & Yes & Yes & & & Yes & Yes & Yes \\
\hline Resources & Yes & & Yes & Yes & & & Yes & & & Yes \\
\hline Org's Mission & Yes & Yes & & Yes & & & Yes & & & \\
\hline $\begin{array}{l}\text { Connection to } \\
\text { University } \\
\end{array}$ & & Yes & & Yes & & & & & Yes & \\
\hline Model Focus & & & Yes & & & Yes & & & Yes & \\
\hline Context & & & Yes & & & & & & Yes & \\
\hline External Env. & Yes & Yes & & & & & & & & \\
\hline Already Doing It & & & & & & Yes & & & Yes & \\
\hline $\begin{array}{l}\text { Focus on Org and } \\
\text { Ind. }\end{array}$ & & & & & & & Yes & & Yes & \\
\hline $\begin{array}{l}\text { Metrics for } \\
\text { success }\end{array}$ & Yes & & & & & & & & & \\
\hline $\begin{array}{l}\text { Model's } \\
\text { Flexibility }\end{array}$ & & & & & & & & Yes & & \\
\hline Org. Resiliency & & & Yes & & & & & & & \\
\hline \multicolumn{11}{|c|}{ Question 3: Relevance of model to institute } \\
\hline Relevant & & & Yes & & & & Yes & Yes & Yes & \\
\hline Relevant, but... & Yes & & & Yes & Yes & & & & & Yes \\
\hline Not Relevant & & Yes & & & & Yes & & & & \\
\hline
\end{tabular}




\begin{tabular}{|c|c|c|c|c|c|c|c|c|c|c|}
\hline & $\begin{array}{c}1 \\
\text { Hard } \\
\text { Science }\end{array}$ & $\begin{array}{c}2 \\
\text { Hard } \\
\text { Science }\end{array}$ & $\begin{array}{c}3 \\
\text { Hard } \\
\text { Science } \\
\end{array}$ & $\begin{array}{c}4 \\
\text { Hard } \\
\text { Science } \\
\end{array}$ & $\begin{array}{c}7 \\
\text { Hard } \\
\text { Science }\end{array}$ & $\begin{array}{c}8 \\
\text { Hard } \\
\text { Science } \\
\end{array}$ & $\begin{array}{c}5 \\
\text { Social } \\
\text { Science } \\
\end{array}$ & $\begin{array}{c}6 \\
\text { Social } \\
\text { Science }\end{array}$ & $\begin{array}{c}9 \\
\text { Social } \\
\text { Science } \\
\end{array}$ & $\begin{array}{c}10 \\
\text { Social } \\
\text { Science }\end{array}$ \\
\hline \multicolumn{11}{|c|}{ Question 4: Strengths of the model } \\
\hline Logical/Coherent & Yes & & & Yes & & & Yes & Yes & & Yes \\
\hline $\begin{array}{l}\text { Forces Directors } \\
\text { to Think About It }\end{array}$ & Yes & & Yes & & Yes & Yes & & & & \\
\hline Long Term Dev. & & Yes & & Yes & & & & & Yes & \\
\hline Work with Others & & & Yes & & & & & & & Yes \\
\hline $\begin{array}{l}\text { Relate to Strategic } \\
\text { Plan }\end{array}$ & & Yes & Yes & & & & & & & \\
\hline $\begin{array}{l}\text { Includes other } \\
\text { employees }\end{array}$ & & & & & & & & & Yes & \\
\hline $\begin{array}{l}\text { Focus on } \\
\text { Evaluation }\end{array}$ & & & & & & & & & Yes & \\
\hline \multicolumn{11}{|c|}{ Question 5: Suggestions for model changes } \\
\hline $\begin{array}{l}\text { Focus on } \\
\text { Constraint of } \\
\text { Resources }\end{array}$ & & Yes & Yes & Yes & & & & & & \\
\hline $\begin{array}{l}\text { Incorporate } \\
\text { Strategic Review }\end{array}$ & & Yes & & & & & & & & Yes \\
\hline $\begin{array}{l}\text { Emphasize } \\
\text { Context More }\end{array}$ & Yes & & & & & & Yes & & & \\
\hline Shorten it & & & & & & & & Yes & Yes & \\
\hline $\begin{array}{l}\text { Focus on Critical } \\
\text { Positions }\end{array}$ & & & Yes & & & & & & & \\
\hline $\begin{array}{l}\text { Incorporate HR } \\
\text { policies more }\end{array}$ & & & & & Yes & & & & & \\
\hline $\begin{array}{l}\text { Incorporate } \\
\text { sponsors more }\end{array}$ & & & & & & Yes & & & & \\
\hline \multicolumn{11}{|c|}{ Question 6: How would you know succession planning was success? } \\
\hline Long Term & Yes & Yes & Yes & Yes & Yes & Yes & Yes & Yes & Yes & Yes \\
\hline Short Term & & & & & Yes & & & Yes & & Yes \\
\hline \multicolumn{11}{|c|}{ Question 7: Other Comments } \\
\hline Current \& Alive & Yes & & Yes & & & Yes & & & & \\
\hline Too Thorough & & Yes & & & & & & Yes & Yes & \\
\hline Org. v. Employee & & & & & & Yes & & & & Yes \\
\hline Satisfaction & & & Yes & & & & & & Yes & \\
\hline $\begin{array}{l}\text { Internal v. } \\
\text { External Hires }\end{array}$ & & & & & & Yes & Yes & & & \\
\hline HR Issues & & & & & & & Yes & & & \\
\hline $\begin{array}{l}\text { Don't want to be } \\
\text { Administrators }\end{array}$ & & & & & & & & & & Yes \\
\hline $\begin{array}{l}\text { Founder's } \\
\text { Syndrome }\end{array}$ & Yes & & & & & & & & & \\
\hline $\begin{array}{l}\text { Others don't think } \\
\text { it's important }\end{array}$ & & & & & & & & Yes & & \\
\hline $\begin{array}{l}\text { Classification of } \\
\text { Faculty }\end{array}$ & & & & & & & & Yes & & \\
\hline $\begin{array}{l}\text { Development } \\
\text { doesn't work }\end{array}$ & & & & & & & Yes & & & \\
\hline
\end{tabular}




\begin{tabular}{|c|c|c|}
\hline & \# of Directors & $\begin{array}{l}\text { Themes Discussed in Interviews } \\
\text { (\# and Type of Directors) }\end{array}$ \\
\hline 1 - Not at all Important & 1 & Not a priority now (1 SS) \\
\hline \multicolumn{3}{|l|}{2 - Slightly Important } \\
\hline 3 - Fairly Important & 5 & $\begin{array}{l}\text { Funding drives the organization (3 HS) } \\
\text { Helps with retirements and employee turnover }(2 \mathrm{HS} \text {, } \\
\quad 1 \mathrm{SS}) \\
\text { SP should be informal (2 HS, 1 SS) } \\
\text { Focus on organization or individual? (2 HS, 1 SS) } \\
\text { Relevant with challenges (1 HS) } \\
\text { No authority to hire directors (2 SS) } \\
\text { People drive the organization (1 HS) } \\
\text { Technology drives the organization (1 HS) } \\
\text { Strategic Plan drives the organization (1 HS) } \\
\text { Not sure of benefits of succession planning (1 HS) } \\
\text { Less openness to engage in succession planning (1 SS) }\end{array}$ \\
\hline 4 - Quite Important & 2 & $\begin{array}{l}\text { Funding drives the organization (1 HS) } \\
\text { Helps with retirements and employee turnover }(2 \mathrm{HS}) \\
\text { Relevant with challenges (2 HS) }\end{array}$ \\
\hline 5 - Very Important & 2 & $\begin{array}{l}\text { Funding drives the organization (1 SS) } \\
\text { SP should be informal (1 HS) } \\
\text { People drive the organization (1 SS) } \\
\text { Technology drives the organization (1 SS) }\end{array}$ \\
\hline \multicolumn{3}{|c|}{$\begin{array}{l}\mathrm{N}=10 \\
\mathrm{HS}=\text { Hard Science Director } \\
\mathrm{SS}=\text { Social Science Director }\end{array}$} \\
\hline
\end{tabular}




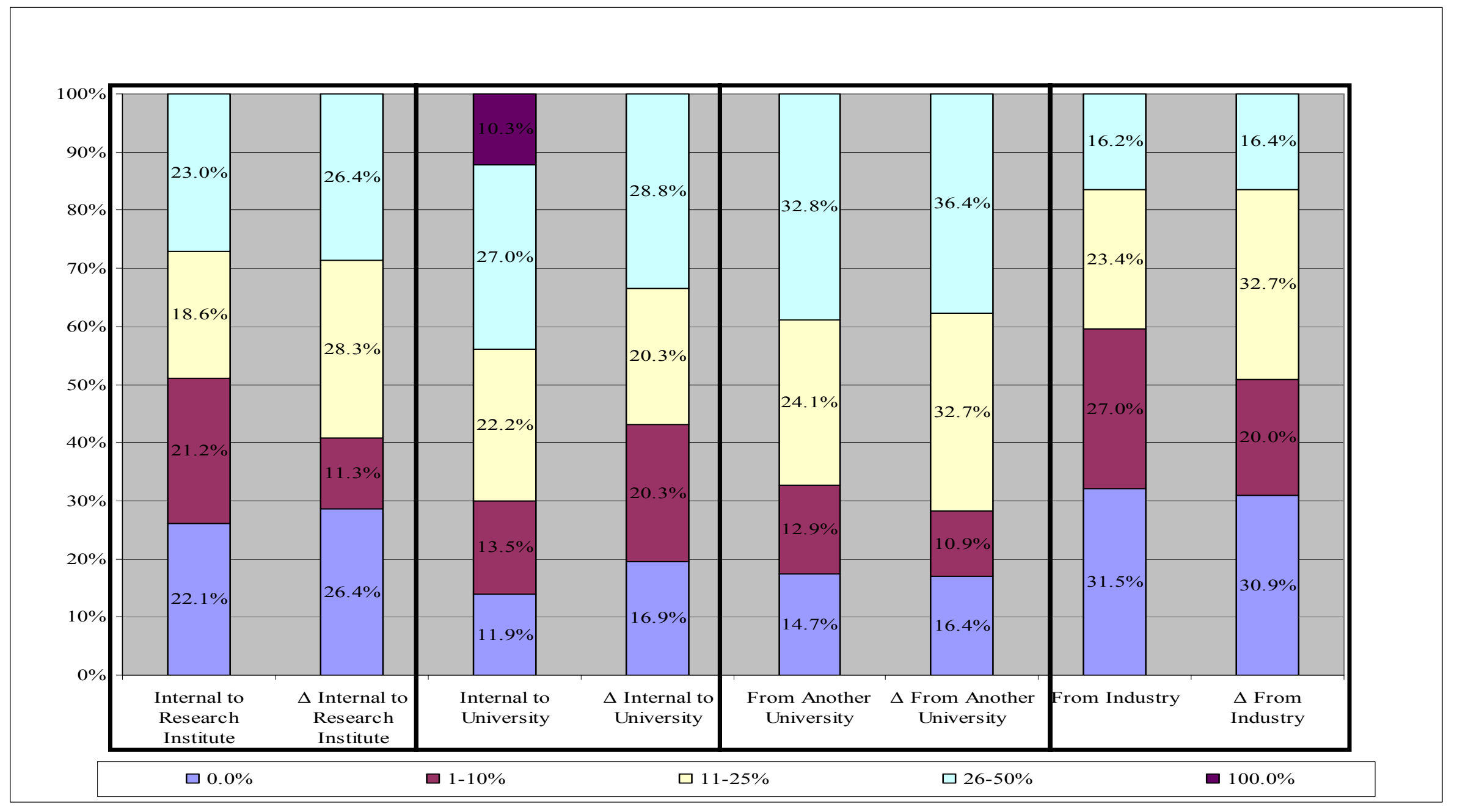

Figure 5. Where Employees Come From Reported by Executive Directors 


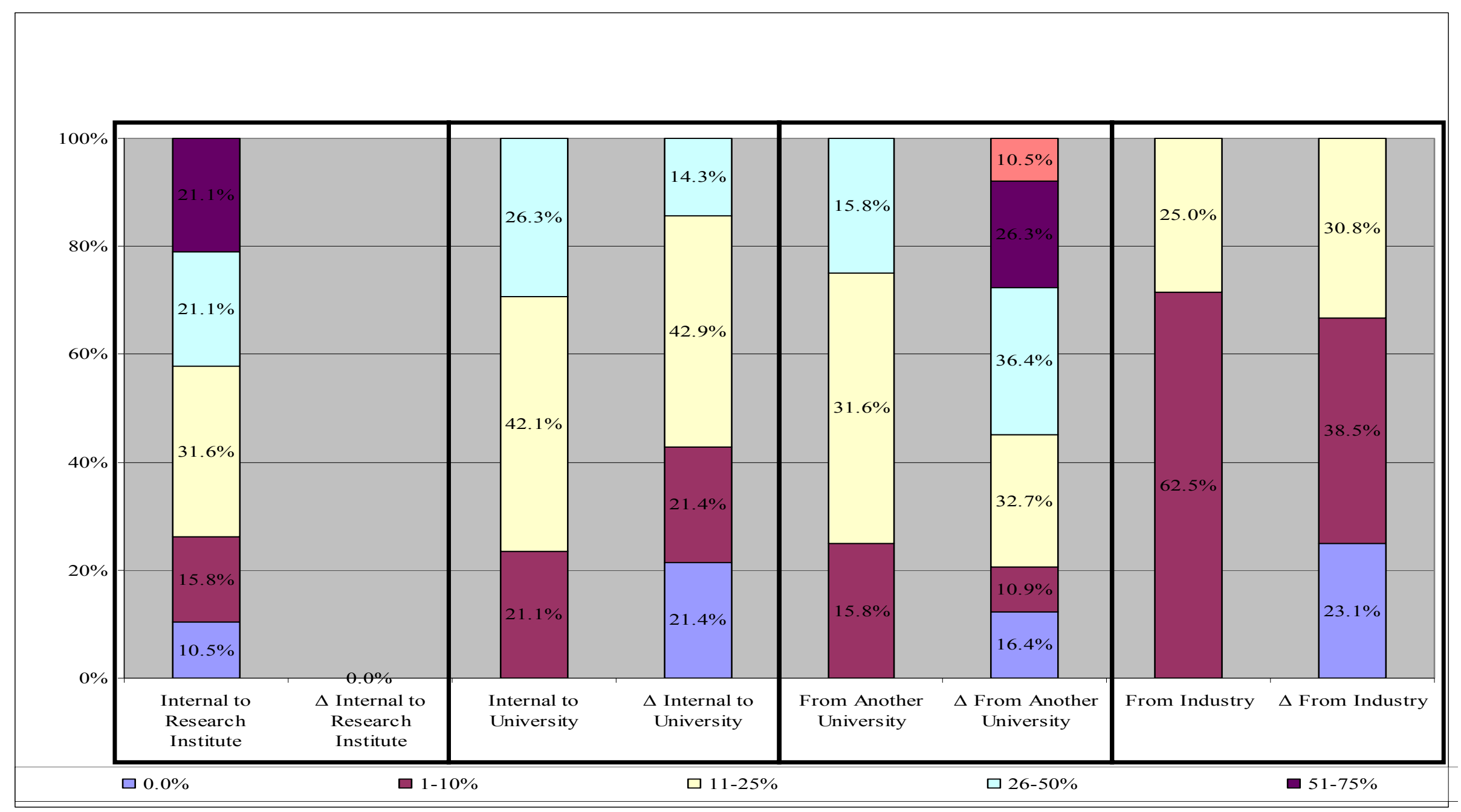

Figure 6. Where Employees Come From Reported by University Administrators 


\section{Appendix A: Policy Making Matrix ${ }^{10}$}

\begin{tabular}{|c|c|c|c|c|}
\hline POLICY LEVEL & $\begin{array}{c}\text { FUNDING } \\
\text { (appropriations) }\end{array}$ & $\begin{array}{c}\text { REGULATING } \\
\text { (statutory \& } \\
\text { administrative law) }\end{array}$ & $\begin{array}{l}\text { PLANNING } \\
\text { (commissions \& } \\
\text { organizations) }\end{array}$ & $\begin{array}{c}\text { COORDINATING } \\
\text { (governing departments } \\
\& \text { agencies) }\end{array}$ \\
\hline FEDERAL & $\begin{array}{ll}- & \text { Taxes (income) } \\
\text { - } & \text { Treasury bonds } \\
\text { Partnerships with Private } \\
\text { Foundations (Race to the } \\
\text { Top) }\end{array}$ & $\begin{array}{ll}\text { - } & \text { U.S. Constitution } \\
\text { - } & \text { Federal Laws }\end{array}$ & $\begin{array}{l}\text { National Collaborative for } \\
\text { Higher Ed Policy } \\
\text { - Commission on the } \\
\text { Future of Higher Ed } \\
\text { - GAO }\end{array}$ & $\begin{array}{ll}- & \text { U.S. Dept of Education } \\
\text { - } & \text { Funding Agencies (NSF, } \\
\text { NIH) }\end{array}$ \\
\hline STATE & $\begin{array}{ll}\text { - } & \text { Taxes (income, sales) } \\
\text { - } & \text { Municipal bonds } \\
\text { - } & \text { Federal }\end{array}$ & $\begin{array}{l}\text { - State Constitution } \\
\text { - } \quad \text { State Laws }\end{array}$ & $\begin{array}{l}\text { - Commission on the } \\
\text { University of the } 21^{\text {st }} \\
\text { Century } \\
\text { - Commission on the } \\
\text { Future of Higher Ed in } \\
\text { VA } \\
\text { JLARC }\end{array}$ & $\begin{array}{ll}\text { - } & \text { State Governing Entity } \\
\text { (SCHEV) } \\
\text { - } & \text { State Dept of Education }\end{array}$ \\
\hline $\begin{array}{l}\text { INSTITUTION: } \\
\text { University with Very } \\
\text { High Research Activity }\end{array}$ & $\begin{array}{ll}\text { - } & \text { Federal } \\
\text { - } & \text { State } \\
\text { - } & \text { Students (Tuition/Fees) } \\
\text { - } & \text { Foundation/Development }\end{array}$ & & - University Associations & $\begin{array}{l}\text { - } \quad \text { Board of Trustees } \\
\text { - }\end{array}$ \\
\hline $\begin{array}{l}\text { INSTITUTION } \\
\text { SUBUNIT: } \\
\text { University-wide } \\
\text { Research Institute }\end{array}$ & $\begin{array}{ll}\text { - } & \text { Federal (e.g., NSF, NIH) } \\
\text { - } & \text { State } \\
\text { - } & \text { Univivatsity } \\
\text { - } & \text { Private Forporation } \\
& \end{array}$ & & $\begin{array}{ll}\text { - } & \text { Discipline Associations } \\
\text { - } & \text { Private Corporations } \\
\text { - } & \text { Private Foundations }\end{array}$ & $\begin{array}{ll}\text { - } & \text { University } \\
\text { - } & \text { University or Committees } \\
\text { any) } \\
\text { - Office of Research } \\
\text { Compliance }\end{array}$ \\
\hline
\end{tabular}

\footnotetext{
${ }^{10}$ Based on Janosik, S. (2006). Policy making: A matrix perspective [Lecture handout]. Blacksburg, Virginia: Virginia Tech, School of Education, Educational Leadership \& Policy Studies. [Used with permission of Janosik]
} 
Appendix B: Overall Research Design Operationalized

\begin{tabular}{|c|c|c|c|c|}
\hline & \multicolumn{2}{|c|}{ Phase One } & Phase Two & Phase Three \\
\hline \multirow[t]{2}{*}{$\begin{array}{l}\text { Research } \\
\text { Questions }\end{array}$} & \multicolumn{4}{|c|}{$\begin{array}{l}\text { What processes of succession planning are relevant in a model of succession planning for university-wide research institutes } \\
\text { in four-year, doctoral university with very high research activity? }\end{array}$} \\
\hline & $\begin{array}{l}\text { According to the scholarly literatures related } \\
\text { to public, private and nonprofit organizations, } \\
\text { what processes of succession planning are } \\
\text { important, or appropriate, for university-wide } \\
\text { research institutes in four-year, doctoral } \\
\text { universities with very high research activity? }\end{array}$ & $\begin{array}{l}\text { What processes of succession planning do leaders in } \\
\text { complex public organizations generally, and } \\
\text { university-wide research institutes specifically, engage } \\
\text { in? }\end{array}$ & $\begin{array}{l}\text { Do leaders in university-wide } \\
\text { research institutes find this model } \\
\text { relevant to the strategic planning of } \\
\text { research institutes within their } \\
\text { organization? Why or why not? }\end{array}$ & $\begin{array}{l}\text { How might this model best be } \\
\text { implemented in university- } \\
\text { wide research institutes? }\end{array}$ \\
\hline $\begin{array}{l}\text { Relevant } \\
\text { Sub- } \\
\text { Questions }\end{array}$ & $\begin{array}{l}\text { Based on the process characteristics and the uni } \\
\text { possible to develop a process model for success } \\
\text { four-year, doctoral universities with very high } r\end{array}$ & $\begin{array}{l}\text { ersity research institute's context and culture, is it } \\
\text { on planning for university-wide research institutes in } \\
\text { search activity? }\end{array}$ & $\begin{array}{l}\text { What are the responses to the } \\
\text { proposed succession management } \\
\text { plan and its process of } \\
\text { implementation by key stakeholders } \\
\text { of research institutes at universities } \\
\text { with very high research activity? } \\
\text { How might such a succession plan } \\
\text { by implemented? }\end{array}$ & $\begin{array}{l}\text { Is the experimental process } \\
\text { model developed in phase one } \\
\text { a credible model? What are its } \\
\text { strengths and weaknesses? } \\
\text { Can one best practice model } \\
\text { for succession planning in } \\
\text { research institutes in U.S. } \\
\text { higher education be developed } \\
\text { from this study? } \\
\text { How portable is this best } \\
\text { practice model to other } \\
\text { research institutes in } \\
\text { institutions of higher } \\
\text { education? Can the process } \\
\text { model be applicable to other } \\
\text { research institutions as well as } \\
\text { other parts of the research } \\
\text { university? }\end{array}$ \\
\hline
\end{tabular}




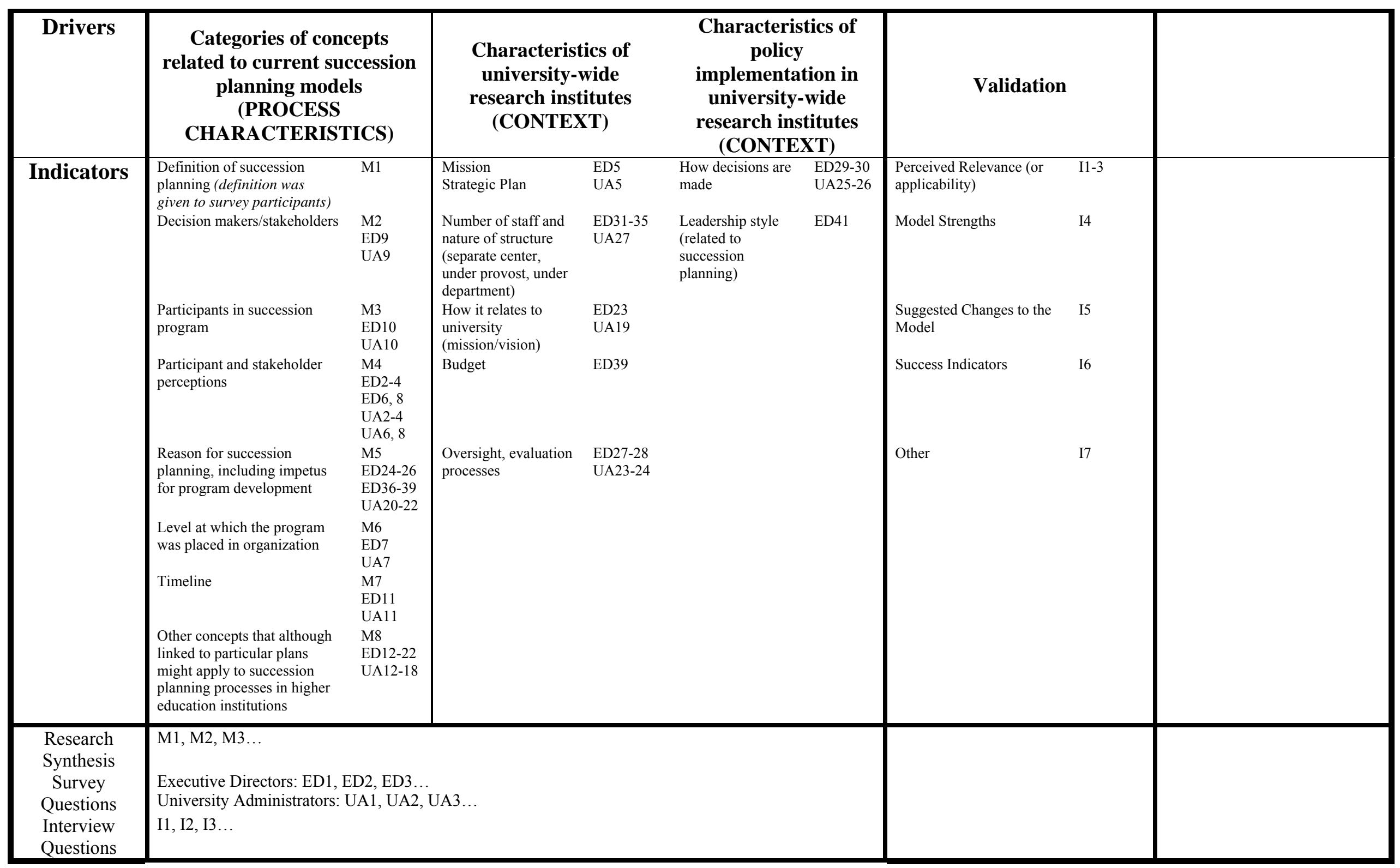




\section{Appendix C: Example of Survey Correspondence}

Week 1: Email prenotice letter and Minnis' support letter as attachment (with personal address)

From: Kimberly Carlson [KimCarlson2009@vt.edu]

Sent: August 10, 2010

To: $\quad$ NAME AND EMAIL OF CONTACT PERSON

Subject: $\quad$ Survey Related to Succession Planning in Universities with Very High Research

August 10, 2010

Dear Dr. [INSERT RECIPIENT'S NAME],

My name is Kimberly Carlson and I am a Ph.D. candidate in public administration and policy at Virginia Tech. Our university has undergone a major review of university research institutes and centers. Findings from this review have indicated that succession planning is an important topic for additional research. As such, I am focusing my dissertation research on human capital and succession planning needs of research institutes in universities with very high research activity. I am writing you today to ask for your help with this important and timely study.

Attached please find a letter from Minnis E. Ridenour, Senior Fellow for Resource Development at Virginia Tech, introducing you to this research. In the next few days, you will receive an email request to participate in this study by answering questions about your university and its university-wide research institutes.

I hope that you will take your time to help me with this survey. This research can only be successful with the generous help of people like you. Upon completion, my dissertation and the draft succession planning model will be made available to the public for your review.

Best,

Kimberly A. Carlson

Ph.D. Candidate

Center for Public Administration and Policy

Virginia Tech 


\title{
Week 2: Invitation email including URL and access code, web survey instructions, and informed
} consent letter

\author{
From: Kimberly A. Carlson [KimCarlson2009@vt.edu) \\ Sent: August 17, 2010 \\ To: $\quad$ NAME AND EMAIL OF CONTACT PERSON \\ Subject: $\quad$ VT Survey of Executive Directors of University-wide Research Institutes [VT Survey of \\ Vice Presidents of Research at Universities with Very High Research Activity]
}

August 17, 2010

Dear Dr. XXXXXX,

I am emailing today to ask for your participation in a survey that I am conducting for my dissertation research at the Center for Public Administration and Policy at Virginia Tech. You may have received a previous email from Minnis Ridenour requesting your participation in this research. We are asking Executive Directors of university-wide research institutes [university level administrators at research universities], like you, to reflect on human capital and succession planning needs at your institute [at research institutes in your university].

You and your research institute were selected from over 800 institutes in 79 U.S. universities [ONLY FOR ED EMAIL]. Your responses to this survey are very important and will help in understanding how succession planning processes may apply to research institutes generally. The survey results will help in the development of a succession planning model that then will be reviewed for relevancy to universitywide research institutes. Executive directors may volunteer to review the model through follow-up interviews.

This survey should take you approximately 20 minutes to complete. Please click on the link below to go to the survey website (or copy and paste the survey link into your Internet browser) and then enter the personal access code to begin the survey.

Survey link: http://surveymonkey.com/XXXXXXX

Personal Access code: XXXXX

Your participation in this survey is entirely voluntary, and all of your responses will be kept strictly confidential. The access code is used to remove any personally identifying information associated with your survey responses. Further information regarding the survey and research can be found on the attached informed consent sheet. Should you have any additional questions or comments, please feel free to contact me at KimCarlson2009@vt.edu or 540-250-7160.

I appreciate your time and consideration in completing the survey. Thank you ahead of time for your participation! It is through help from faculty and administrators like you that higher education institutions can continue to improve their organizations for the future.

Many thanks,

Kimberly A. Carlson

PhD Candidate

Center for Public Administration and Policy

Virginia Tech 
August 31, 2010

Two weeks ago I emailed you requesting your participation in an online survey because your research institute was selected from over 800 research institutes in 79 universities. This survey will help me better understand human capital and succession planning needs in institutes across the United States.

If you have already completed the online survey, please accept my sincere thanks. If not, please direct your browser to the survey link below to participate.

Survey link: http://www.surveymonkey.com/xxxxxxxxxxxxx

Personal Access code: $x x x x x$

I am especially grateful for your help with this important study, a major part of my doctoral dissertation.

Sincerely,

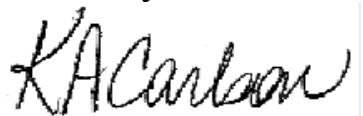

Kimberly A. Carlson, PhD Candidate, CPAP, Virginia Tech

BACK:

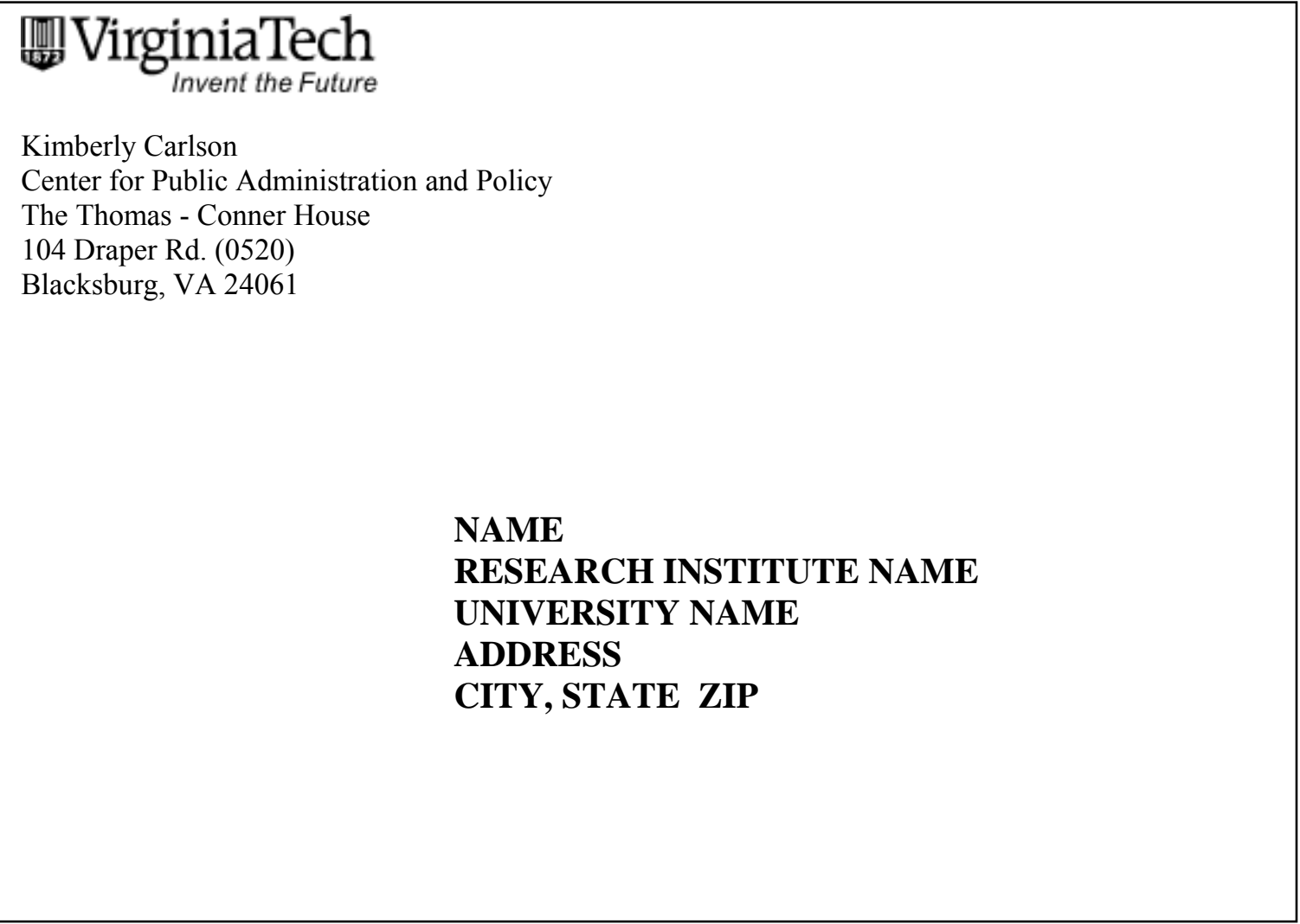


Week 4: Follow-up email with URL, access code and web survey (with closing date 3 weeks after the initial invitation email)

From: Kimberly A. Carlson [KimCarlson2009@vt.edu)

Sent: September 7, 2010

To: $\quad$ NAME AND EMAIL OF CONTACT PERSON

Subject: $\quad$ VT Survey for Succession Planning and Research Institutes

September 7, 2010

Dear XXXXXX,

I recently sent you an email asking you to respond to a survey regarding succession planning and human capital needs at your research institute [at university-wide research institutes in your university]. Your responses to this survey are important and will help me in developing a succession planning model that may be relevant to university-wide research institutes in universities such as yours.

While the survey is in-depth, it should only take you approximately 20 minutes to complete. If you have not already responded to the survey, I ask that you take a few minutes to complete it now.

Please click on the link below to go to the survey website (or copy and paste the survey link into your Internet browser) and then enter the personal access code to begin the survey.

Survey link: http://surveymonkey.com/XXXXXXX

Personal Access code: XXXXX

The survey will close on September 14, 2010. Your responses are important! Please complete the survey before the closing date. Getting feedback from faculty and administrators directly affiliated with university-wide research institutes is vital to this study

Thank you for your participation.

Sincerely,

Kimberly A. Carlson

PhD Candidate

Center for Public Administration and Policy

Virginia Tech 


\section{Appendix D: Example of Survey - Executive Director}

\section{Succession Planning in University Research Institutes Survey}

Welcome to my survey regarding succession planning for university-wide research institutes, an effort to better understand the importance of succession planning issues in university research institutes. Your institute was selected to participate in this study as one of more than 800 university-wide research institutes at 78 universities with very high research activity as classified by the Carnegie Foundation. The purpose of the survey is to better understand a variety of factors related to human resources and succession planning as they apply to your institute and university.

Please complete the survey by entering in the box below the Personal Access Code found in the email that I sent you. The survey should take you approximately 20 minutes to complete. All responses will remain confidential; only my research committee and I will have access to the survey results.

This survey is written for directors of research institutes. Several questions refer to senior or executive leaders within research institutes. "Senior or executive leaders" refer to you as director of the research institute or to co-directors; "managers" refer to other middle managers or coordinators.

This study has been reviewed and approved by the Virginia Tech Institutional Review Board for human subject participation. If you have any questions about the study, please contact me, Kimberly Carlson, at KimCarlson2009@vt.edu. If you have questions about your rights as a participant, please contact Dr. David Moore, VT IRB Chair, at moored@vt.edu or 540-231-4991.

\section{Please enter your Access Code listed in the email I sent you:}

[Used with Permission] Special thanks to William J. Rothwell for the use of several survey questions from his 2001 book Effective succession planning: Ensuring leadership continuity and building talent from within.* 


\section{The following questions are about succession planning in general.}

For this survey, succession planning is defined as:

"a deliberate and systematic effort by an organization to ensure leadership continuity in key positions, retain and develop intellectual and knowledge capital for the future, and encourage individual advancement" for all employees in the organization (Rothwell, 2001, p. 6).

2. How knowledgeable would you say you are about succession planning?

$\begin{array}{ccccc}\text { Not at All } & \text { Slightly } & \text { Moderately } & \text { Very } & \text { Extremely } \\ \text { Knowledgeable } & \text { Knowledgeable } & \text { Knowledgeable } & \text { Knowledgeable } & \text { Knowledgeable } \\ \boldsymbol{\nabla} & \boldsymbol{\nabla} & \boldsymbol{\nabla} & 4 & 5\end{array}$

3. To what extent do you think each of the following is an important characteristic of succession planning? (Please click on the circle of the appropriate response.)

\begin{tabular}{|c|c|c|c|c|c|}
\hline Succession planning... & $\begin{array}{l}\text { Strongly } \\
\text { Disagree }\end{array}$ & Disagree & $\begin{array}{l}\text { Neither } \\
\text { Agree nor } \\
\text { Disagree } \\
\nabla\end{array}$ & $\underset{\nabla}{\text { Agree }}$ & $\begin{array}{l}\text { Strongly } \\
\text { Agree }\end{array}$ \\
\hline $\begin{array}{l}\text { Offers development or } \\
\text { educational activities for } \\
\text { current employees............. }\end{array}$ & 1 & 2 & 3 & 4 & 5 \\
\hline $\begin{array}{l}\text { Promotes continuity in } \\
\quad \text { leadership......................... }\end{array}$ & 1 & 2 & 3 & 4 & 5 \\
\hline $\begin{array}{l}\text { Strategically plans for } \\
\quad \text { employment needs for the } \\
\quad \text { future........................ }\end{array}$ & 1 & 2 & 3 & 4 & 5 \\
\hline $\begin{array}{l}\text { Names successors of key/critical } \\
\text { positions....................... }\end{array}$ & 1 & 2 & 3 & 4 & 5 \\
\hline Takes too much time............... & 1 & 2 & 3 & 4 & 5 \\
\hline
\end{tabular}




\begin{tabular}{|c|c|c|c|c|c|}
\hline Succession planning... & $\begin{array}{l}\text { Strongly } \\
\text { Disagree }\end{array}$ & Disagree & $\begin{array}{l}\text { Neither } \\
\text { Agree nor } \\
\text { Disagree } \\
\nabla\end{array}$ & $\stackrel{\text { Agree }}{\nabla}$ & $\begin{array}{l}\text { Strongly } \\
\text { Agree }\end{array}$ \\
\hline $\begin{array}{l}\text { Focuses too much on the } \\
\text { individual's development } \\
\text { and not on organizational } \\
\text { planning as a whole.............. }\end{array}$ & 1 & 2 & 3 & 4 & 5 \\
\hline $\begin{array}{c}\text { Encourages a lack of diversity } \\
\text { because leaders are created } \\
\text { in the same image as current } \\
\text { leaders........................................ }\end{array}$ & 1 & 2 & 3 & 4 & 5 \\
\hline Other (please specify & 1 & 2 & 3 & 4 & 5 \\
\hline
\end{tabular}




\section{The following questions are about succession planning as it relates to}

your research institute.

4. To what extent have you considered succession planning for your research institute?

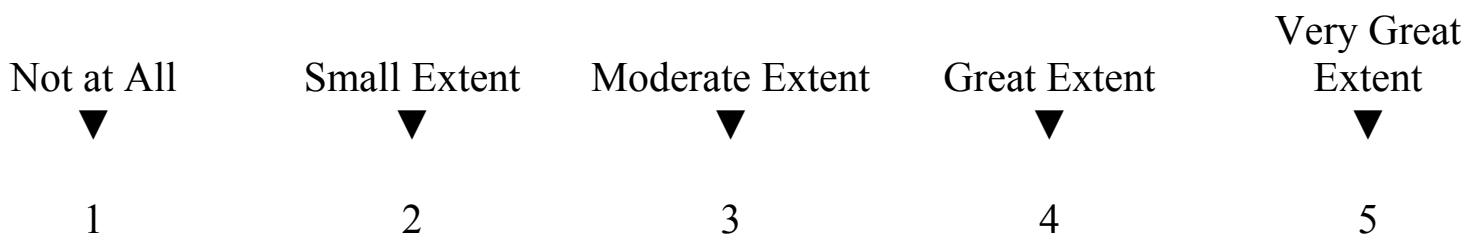

5. Does your research institute have a strategic plan for the next five to ten years?

0 No

1 Yes

6. There are many reasons why decision-makers in universities may wish to establish a succession program. To what extent is each of the following reasons important to your research institute?*

\section{A succession program would:}

$\begin{array}{ccccc}\text { Not at all } & \text { Slightly } & \text { Fairly } & \text { Quite } & \text { Very } \\ \text { important } & \text { important } & \text { important } & \text { Important } & \text { Important } \\ \nabla & \boldsymbol{\nabla} & \boldsymbol{\nabla} & \boldsymbol{\nabla} & \boldsymbol{\nabla}\end{array}$

Contribute to implementing the organization's strategic plan

2

3

4

5

Help downsize / reduce staffing

1

2

3

4

Help individuals realize their career plans within the organization

Encourage the advancement of

diverse groups - such as minorities or women - in future jobs within the organization 


\section{A succession program would:}

Preserve institutional

knowledge as our workforce evolves...

Provide increased opportunities for "high potential" workers

Prepare for immediate loss of key employees in critical positions

Improve employee retention.....

Other (please specify
Not at all Slightly Fairly Quite Very important important important Important Important

$\begin{array}{ll}\nabla & \nabla \\ 1 & 2\end{array}$
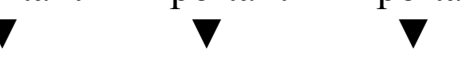

4

2

3

4

5

$\begin{array}{lllll}1 & 2 & 3 & 4 & 5\end{array}$


Research institute priorities........?

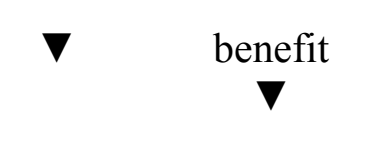

Support by current university senior leadership...............?

1

2

3

4

Support by current senior leaders in research institute...........?
1

2

3

4

Support by current faculty in research institute. $?$ 1

2 3

4 5

Support by current staff in research institute...........................?

Financial resources................?
Ability to consult with succession planning experts................?

Other (please specify

9. To what extent would people in the following positions at your university be involved in the decision to put in place a succession program for your research institute?

\begin{tabular}{|c|c|c|c|c|c|}
\hline & Not at All & $\begin{array}{c}\text { Small } \\
\text { Extent } \\
\nabla\end{array}$ & $\begin{array}{c}\text { Moderate } \\
\text { Extent } \\
\nabla\end{array}$ & $\begin{array}{c}\text { Great } \\
\text { Extent } \\
\boldsymbol{\nabla}\end{array}$ & $\begin{array}{c}\text { Very } \\
\text { Great } \\
\text { Extent } \\
\nabla\end{array}$ \\
\hline President of the university............ & 1 & 2 & 3 & 4 & 5 \\
\hline $\begin{array}{l}\text { Vice-president of research at the } \\
\text { university................................... }\end{array}$ & 1 & 2 & 3 & 4 & 5 \\
\hline $\begin{array}{l}\text { Advisory board of the research } \\
\text { institute..................................... }\end{array}$ & 1 & 2 & 3 & 4 & 5 \\
\hline
\end{tabular}




\begin{tabular}{|c|c|c|c|}
\hline & Small & Moderate & Great \\
\hline Not at All & $\begin{array}{c}\text { Extent } \\
\boldsymbol{\nabla}\end{array}$ & $\begin{array}{c}\text { Extent } \\
\boldsymbol{\nabla}\end{array}$ & $\begin{array}{c}\text { Extent } \\
\boldsymbol{\nabla}\end{array}$ \\
\hline
\end{tabular}

Executive director of the research

institute.............................

1

23

4

5

Research faculty in the research institute.

12

3

4

5

Research staff in the research

institute........................

12

3

4

5

Post-docs in the research

institute...

12

3

4

5

Graduate students in the research institute.

Human resource manager in the university...............................

Human resource manager in the research institute.

Other (please specify:

10. To what extent would each of these research institute employees participate in a succession program once it is put in place?

$\begin{array}{ccccc} & & & & \text { Very } \\ \text { Not at All } & \text { Extent } & \text { Moderate } & \text { Great } & \text { Great } \\ \boldsymbol{\nabla} & \boldsymbol{\nabla} & \text { Extent } & \text { Extent } & \text { Extent } \\ & & \boldsymbol{\nabla} & \boldsymbol{\nabla} & \boldsymbol{\nabla}\end{array}$

Senior Leaders (ex: Executive

Director)

1

2

3

4

5

Managers

1

2

3

4

5

Staff

1

2

3

4

5 


\begin{tabular}{|c|c|c|c|c|c|}
\hline & Not at All & $\begin{array}{c}\text { Small } \\
\text { Extent } \\
\nabla\end{array}$ & $\begin{array}{c}\text { Moderate } \\
\text { Extent } \\
\nabla\end{array}$ & $\begin{array}{c}\text { Great } \\
\text { Extent } \\
\nabla\end{array}$ & $\begin{array}{c}\text { Very } \\
\text { Great } \\
\text { Extent } \\
\nabla\end{array}$ \\
\hline Residential Faculty.................. & 1 & 2 & 3 & 4 & 5 \\
\hline Adjunct / Affiliated Faculty.......... & 1 & 2 & 3 & 4 & 5 \\
\hline Graduate Students.................... & 1 & 2 & 3 & 4 & 5 \\
\hline Other (please specify & & & & & \\
\hline ) & 1 & 2 & 3 & 4 & 5 \\
\hline
\end{tabular}

11. In your opinion, what type of development program would be planned for each of the following participants in succession programs?

$\begin{array}{cccc} & & \text { Multiple } \\ & & \text { Multiple } & \text { Experiences } \\ \text { None } & \text { Experience } & \text { over 1 Year } & \text { over Multiple } \\ \nabla & \boldsymbol{\nabla} & \boldsymbol{\nabla} & \text { Years }\end{array}$

Senior Leaders (ex: Executive

Director).....................

Managers........................

Staff.............................

Residential Faculty.

Adjunct / Affiliated Faculty.......

Post-Docs.......................

Graduate Students.

1

2

3

4

Other (please specify 
12. Please rank the importance of the following methods in developing (or training) research institute employees. (Please fill in your rank order in the spaces provided using 1 as the least important and 6 as the most important.)

Job rotation (e.g., opportunities to learn different areas of an organization)

Stretch assignments (e.g., a project that pushes one's skill limits)

Job enrichment (e.g., opportunities to use all of one's skills)

Mentoring (e.g., opportunities to discuss works situations with more

experienced co-workers)

Training related to succession development

Other (please specify

13. In your opinion, which of the following characteristics of succession planning would be important to your research institute?*

\section{The succession plan would:}

Not at all

important

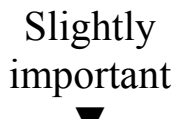

Fairly important

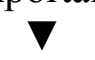

2

3

4

5

Devise a means to keep records for individuals who are designated as successors

Establish a means to clarify present position responsibilities...........

Establish a means to clarify future position responsibilities...

2

3

4

Establish a way to forecast future talent needs. 1

2

3

4 5

Establish individual employee development plans

Other (please specify 
14. Does your research institute currently take part in activities related to succession planning?

$0 \quad$ No $\rightarrow$ (Please skip to 16)

1 Yes

15. (If Yes) In which types of succession planning activities does your research institute currently take part?

$\underline{\text { No }} \quad \underline{\text { Yes }}$

Job rotation (e.g., opportunities to learn different areas of an organization) ............?

Stretch assignments (e.g., a project that pushes one's skill limits)............................?

Job enrichment (e.g., opportunities to use all of one's skills $). . . \ldots \ldots \ldots \ldots \ldots \ldots \ldots \ldots \ldots$.

Mentoring (e.g., opportunities to discuss work situations with more experienced coworkers $) \ldots \ldots \ldots \ldots \ldots \ldots \ldots \ldots \ldots \ldots \ldots \ldots$ ?

Training related to succession development....? $\quad 0 \quad 1$

Other (please specify

0

1

16. In your opinion, which of the following characteristic(s) for evaluating succession programs would be important to your research institute?*

A succession program would establish:

measurable objectives for program operation...

a means to appraise individual performance.

$$
\begin{array}{lc}
\text { Not at all Slightly } \\
\text { important important }
\end{array}
$$

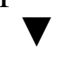

Fairly mportant
Quite

Very Important Important 


\section{A succession program would establish:}

a means to compare individual skills

to the requirements of a future

position.

a way to review organizational talent at least annually

a means to track development activities to prepare successors for eventual advancement........
Not at all Slightly Fairly Quite Very important important important Important Important

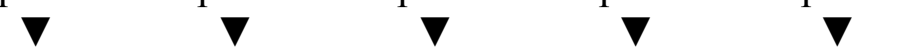

17. In your opinion, which of the following characteristics of a written succession plan would be important to your research institute?*

\section{A written succession plan would:}

$\begin{array}{ccccc}\text { Not at all } & \text { Slightly } & \text { Fairly } & \text { Quite } & \text { Very } \\ \text { Important } & \text { Important } & \text { Important } & \text { Important } & \text { Important } \\ \boldsymbol{\nabla} & \boldsymbol{\nabla} & \boldsymbol{\nabla} & \boldsymbol{\nabla} & \nabla\end{array}$

Be tied to the research center's strategic plans.................... 1

4

Be tied to the university's strategic

$$
\text { plans }
$$

Be tied to employee training

$$
\text { programs. }
$$

Have a prepared written purpose statement.

Have prepared written program

$$
\text { goals. }
$$

Have an established schedule of program events

Develop a means to budget for a succession program. 
18. What is your current position?

1 Senior Leader (ex: Executive Director)

2 Manager

3 Staff

4 Residential Faculty

5 Adjunct / Affiliated Faculty

6 Other (please specify

19. How long have you been in your current position?

1 Less than 1 year

2 1-2 years

3 3-5 years

4 More than 5 years

20. Was a succession plan in place when you took over your current position?

0 No $\rightarrow$ (Please skip to 22)

1 Yes

21. If yes, was the succession plan that was in place useful in your development process?

0 No

1 Yes

22. Please list any recommendations or general comments you have regarding succession planning in university-wide research institutes.

Open ended - leave space 


\section{The following questions are about your research institute in}

general.

23. To what extent does your research institute's mission relate to the university's mission?

$\begin{array}{ccccc}\text { Not at All } & \text { A Small Extent } & \text { Moderate Extent } & \text { Great Extent } & \begin{array}{c}\text { Very Great } \\ \text { Extent } \\ \boldsymbol{\nabla}\end{array} \\ 1 & 2 & \boldsymbol{\nabla} & 4 & 5\end{array}$

24. Based on your experience, approximately what percentage of key hires are internal hires from within the research institute compared to external hires from outside the research institute? $\%$ Internal to research institute $\%$ Internal to university $\%$ External to university but from another university $\%$ External to university but from industry

25. In your opinion, what changes in the percentages of internal and external key hires would you make in your answer to question 24 ?

$\%$ Internal to research institute $\%$ Internal to university

$\%$ External to university but from another university $\%$ External to university but from industry No changes

26. Generally, where have the current leaders in your research institute come from?

1 From within the institute

2 From outside the institute but inside the university

3 From another university

4 From industry

5 Other (please specify 


\section{How often is your research institute evaluated?}

1 Never

2 Yearly Review

3 Regular Cycle (e.g., every 5 years)

4 Other (please specify

28. Who is included in the evaluation of your research institute? (Click on all that apply)

1 External reviewers from non-university organizations

2 External reviewers from another university

3 Internal reviewers from the university

4 Internal reviewers from the institute

5 Other (please specify

29. How does your research institute typically create new policies?

1 Top-down within the research institute

2 Bottom-up within the research institute

3 Collaboration between all research institute employees

4 Collaboration among leaders of institute

5 Other (please specify

30. How are policies typically implemented (put in place) in your research institute?

1 Top-down within the research institute

2 Bottom-up within the research institute

3 Collaboration between all research institute employees

4 Collaboration among leaders of institute

5 Other (please specify

31. Which of the following characteristics describe your research institute?

$\underline{\text { No }} \quad \underline{\text { Yes }}$

Is university-wide.............................?

$0 \quad 1$

Is independent in regards to HR.................?

Is independent in regards to budgeting.........? $\quad 0 \quad 1$

Relies on sponsored research...............? $\quad 0 \quad 1$ 
Is independent in regards to administration.....? $\quad 0$

Is interdisciplinary in nature................? $\quad 0 \quad 1$

32. What year was your research institute created/founded?

$1 \quad$ Before 1950

2 1950-1959

3 1960-1969

$4 \quad 1970-1979$

$5 \quad 1980-1989$

$6 \quad 1990-1999$

$7 \quad 2000-2010$

33. Which of the following categories best describes the research focus of your research institute?

1 Physical Sciences

2 Mathematics

3 Computing

4 Engineering

5 Biological Sciences

6 Social Sciences

7 Humanities

8 Healthcare

9 Education

10 Law

11 Finance/Management

12 Other (please specify

34. To whom does your research institute report?

1 President / Chancellor of University

2 Provost / Academic VP

$3 \mathrm{VP} / \mathrm{VC}$ of Research

4 College/School

5 Department

6 Other (please specify

35. Approximately how many people does your research institute employ in each of the following categories? 


\begin{tabular}{|c|c|c|c|c|c|c|}
\hline & 0 & $1-5$ & $6-10$ & $11-15$ & $16-20$ & $\begin{array}{l}\text { More } \\
\text { than } 20\end{array}$ \\
\hline Staff........................... & 0 & 1 & 2 & 3 & 4 & 5 \\
\hline Faculty............. & 0 & 1 & 2 & 3 & 4 & 5 \\
\hline Post-Docs........... & 0 & 1 & 2 & 3 & 4 & 5 \\
\hline Graduate Students. & 0 & 1 & 2 & 3 & 4 & 5 \\
\hline Other................. & 0 & 1 & 2 & 3 & 4 & 5 \\
\hline
\end{tabular}

36. How many employees at your research institute may retire in the coming five years?
$0 \quad 0$
1 1-5
2 6-10
3 11-15
4 16-20
5 Other (please specify

37. How many employees at your research institute may retire in the coming ten years?
$0 \quad 0$
1 1-5
2 6-10
3 11-15
4 16-20
5 Other (please specify

38. Do you envision your research institute needing more employees in the future?

0 No $\rightarrow$ (Please skip to 39)

1 Yes 
39. Please indicate anticipated percentage growth in the next 5 years in the following categories.

$\begin{array}{ccccccc} & 10 \% & & & & & \\ 0 \% & \text { or } & 11- & 26- & 51- & 76- & \\ & \text { Less } & 25 \% & 50 \% & 75 \% & 99 \% & 100 \%\end{array}$

\begin{tabular}{|c|c|c|c|c|c|c|c|}
\hline Administration........ & 0 & 1 & 2 & 3 & 4 & 5 & 6 \\
\hline Faculty............... & 0 & 1 & 2 & 3 & 4 & 5 & 6 \\
\hline Staff................. & 0 & 1 & 2 & 3 & 4 & 5 & 6 \\
\hline Post-Docs............ & 0 & 1 & 2 & 3 & 4 & 5 & 6 \\
\hline Graduate Students... & 0 & 1 & 2 & 3 & 4 & 5 & 6 \\
\hline \multicolumn{8}{|l|}{ Other (please specify } \\
\hline & 0 & 1 & 2 & 3 & 4 & 5 & 6 \\
\hline
\end{tabular}

40. What is the overall annual budget for your research institute?

$1 \quad$ Under $\$ 1$ million
$2 \geq \$ 1$ million, $<\$ 5$ million
$3 \geq \$ 5$ million, $<\$ 10$ million
$4 \geq \$ 10$ million

41. To what extent would these leadership styles be successful at your research institute?

$\begin{array}{ccccc} & & & & \text { Very } \\ \text { Not at All } & \text { Extent } & \text { Moderate } & \text { Great } & \text { Great } \\ \boldsymbol{\nabla} & \boldsymbol{\nabla} & \boldsymbol{\nabla} & \boldsymbol{\nabla} & \text { Extent }\end{array}$

Leader tells the group exactly what should be done...

1

2

3

4

5

Leader provides guidance to others but allows for group input in decisions........................

1

2

3

4 
Leader offers little guidance but allows for group input in decisions........................

Leader offers little guidance, allowing group members to make decisions................

Leader focuses on organizing and developing individuals in the group.......................

Leader focuses on organizing and developing the group as a whole...

Group members follow leader only because they are paid to follow.

Leader inspires group members to achieve a shared vision..........

42. Would you be willing to participate in a one (1) hour follow-up interview with the researcher in this study?

0 No

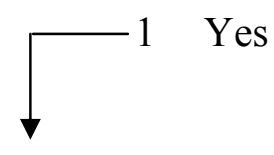

(If yes), please send your name, email address, and phone number to Kimberly Carlson at KimCarlson2009@,vt.edu. 


\section{The answers to your survey have been received.}

\section{Thank you for your time and help in my research!}

For more information regarding this study, please contact me:

Kimberly Carlson | KimCarlson2009@vt.edu | 1-540-231-5133 | C Kimberly Carlson 2010

Center for Public Administration and Policy, 104 Draper Rd. (0520), Blacksburg, VA 24061 


\section{Appendix D, continued: Example of Survey - University Administrator}

\section{Succession Planning in University Research Institutes Survey}

Welcome to my survey regarding succession planning for university-wide research institutes, an effort to better understand the importance of succession planning issues in university research institutes. Your university was selected to participate in this study as one of 78 universities that the Carnegie Foundation classifies as a doctoral university with very high research activity. The purpose of the survey is to better understand a variety of factors related to human resources and succession planning as they apply to university-wide research institutes at your university.

Please complete the survey by clicking on the next button at the bottom of the page. The survey should take you approximately 20 minutes to complete. All responses will remain confidential; only my research committee and I will have access to the survey results.

This study has been reviewed and approved by the Virginia Tech Institutional Review Board for human subject participation. If you have any questions about the study, please contact me, Kimberly Carlson, at KimCarlson2009@vt.edu. If you have questions about your rights as a participant, please contact Dr. David Moore, VT IRB Chair, at moored@vt.edu or 540-231-4991.

Please enter your Access Code listed in the email I sent you:

[Used with Permission] Special thanks to William J. Rothwell for the use of several survey questions from his 2001 book Effective succession planning: Ensuring leadership continuity and building talent from within.* 


\section{The following questions are about succession planning in general.}

For this survey, succession planning is defined as:

"a deliberate and systematic effort by an organization to ensure leadership continuity in key positions, retain and develop intellectual and knowledge capital for the future, and encourage individual advancement" for all employees in the organization (Rothwell, 2001, p. 6).

2. How knowledgeable would you say you are about succession planning?

\begin{tabular}{|c|c|c|c|c|}
\hline $\begin{array}{c}\text { Not at All } \\
\text { Knowledgeable } \\
\nabla\end{array}$ & $\begin{array}{c}\text { Slightly } \\
\text { Knowledgeable } \\
\nabla\end{array}$ & $\begin{array}{c}\text { Moderately } \\
\text { Knowledgeable }\end{array}$ & $\begin{array}{c}\text { Very } \\
\text { Knowledgeable }\end{array}$ & $\begin{array}{c}\text { Extremely } \\
\text { Knowledgeable }\end{array}$ \\
\hline 1 & 2 & 3 & 4 & 5 \\
\hline
\end{tabular}

3. To what extent do you think each of the following is an important characteristic of succession planning? (Please click on the circle of the appropriate response.)

\begin{tabular}{|c|c|c|c|c|c|}
\hline Succession planning... & $\begin{array}{l}\text { Strongly } \\
\text { Disagree } \\
\boldsymbol{\nabla}\end{array}$ & Disagree & $\begin{array}{c}\text { Neither } \\
\text { Agree nor } \\
\text { Disagree } \\
\nabla\end{array}$ & $\underset{\nabla}{\text { Agree }}$ & $\begin{array}{l}\text { Strongly } \\
\text { Agree } \\
\boldsymbol{\nabla}\end{array}$ \\
\hline $\begin{array}{l}\text { Offers development or } \\
\text { educational activities for } \\
\text { current employees................ }\end{array}$ & 1 & 2 & 3 & 4 & 5 \\
\hline 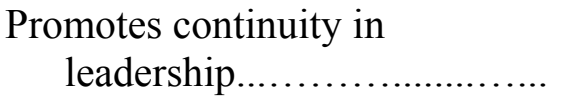 & 1 & 2 & 3 & 4 & 5 \\
\hline 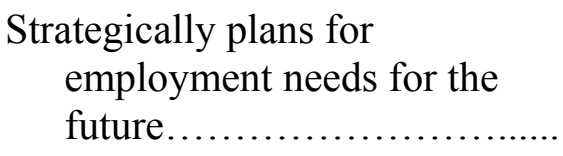 & 1 & 2 & 3 & 4 & 5 \\
\hline $\begin{array}{l}\text { Names successors of key/critical } \\
\text { positions............................. }\end{array}$ & 1 & 2 & 3 & 4 & 5 \\
\hline Takes too much time................. & 1 & 2 & 3 & 4 & 5 \\
\hline
\end{tabular}


individual's development and not on organizational

planning as a whole............

2

3

4

Encourages a lack of diversity

because leaders are created in the same image as current

leaders....................................

2

3

4

Other (please specify 
The following questions are about succession planning as it relates to university-wide research institutes at your university.

4. To what extent have you considered succession planning for research institutes at your university?

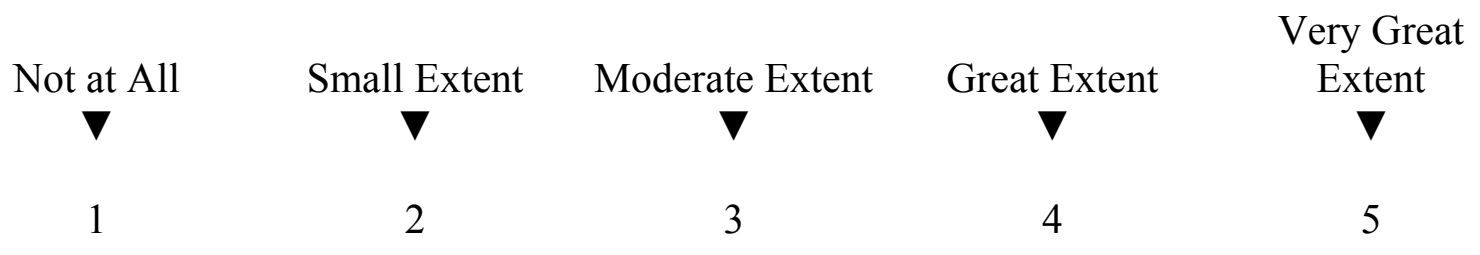

5. Do university-wide research institutes in your university have strategic plans for the next five to ten years?

2 No

3 Yes

4 Not aware

6. There are many reasons why decision-makers in universities may wish to establish a succession program. To what extent is each of the following reasons important to research institutes at your university?*

\section{A succession program would:}

Not at all Slightly Fairly Quite Very important important important Important Important

Contribute to implementing the organization's strategic plan..........................

Help downsize / reduce staffing

Help individuals realize their career plans within the organization.................. 


\section{A succession program would:}

$\begin{array}{lcccc}\text { Not at all } & \text { Slightly } & \text { Fairly } & \text { Quite } & \text { Very } \\ \text { important } & \text { important } & \text { important } & \text { Important } & \text { Important } \\ \nabla & \nabla & \nabla & \nabla & \nabla\end{array}$

Encourage the advancement of

diverse groups - such as

minorities or women - in

future jobs within the

organization..................

1

2

3

4

5

Preserve institutional

knowledge as our workforce

evolves.

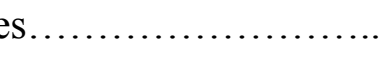

1

2

3

4

5

Provide increased opportunities

for "high potential" workers

1

2

3

4

5

Prepare for immediate loss of key employees in critical positions.....................

Improve employee retention.....

1

2

3

5

Other (please specify

7. In your opinion, at what level would a succession program for university-wide research institutes be located (or housed) in your university?

6 Senior executive level in University

7 Human resource level in University

8 Senior executive level in Research Institute

9 Human resource level in Research Institute

10 Other (please specify 
8. To what degree does each of these factors inhibit or benefit a succession program in research institutes at your university?

\begin{tabular}{|c|c|c|c|c|c|}
\hline & $\underset{\nabla}{\text { Inhibit }}$ & $\begin{array}{c}\text { Slightly } \\
\text { inhibit } \\
\nabla\end{array}$ & $\begin{array}{c}\text { Neither } \\
\text { inhibit nor } \\
\text { benefit } \\
\nabla\end{array}$ & $\begin{array}{c}\text { Somewhat } \\
\text { benefit } \\
\nabla\end{array}$ & Benefit \\
\hline University policy/procedures......? & 1 & 2 & 3 & 4 & 5 \\
\hline $\begin{array}{l}\text { Research institute } \\
\quad \text { policy/procedures.............? }\end{array}$ & 1 & 2 & 3 & 4 & 5 \\
\hline University priorities...............? & 1 & 2 & 3 & 4 & 5 \\
\hline Research institute priorities.........? & 1 & 2 & 3 & 4 & 5 \\
\hline $\begin{array}{l}\text { Support by current university } \\
\quad \text { senior leadership..............? }\end{array}$ & 1 & 2 & 3 & 4 & 5 \\
\hline $\begin{array}{l}\text { Support by current senior leaders } \\
\text { in research institute.............? }\end{array}$ & 1 & 2 & 3 & 4 & 5 \\
\hline $\begin{array}{l}\text { Support by current faculty in } \\
\quad \text { research institute...............? }\end{array}$ & 1 & 2 & 3 & 4 & 5 \\
\hline $\begin{array}{l}\text { Support by current staff in research } \\
\text { institute.......................? }\end{array}$ & 1 & 2 & 3 & 4 & 5 \\
\hline Financial resources.................? & 1 & 2 & 3 & 4 & 5 \\
\hline $\begin{array}{l}\text { Ability to consult with succession } \\
\text { planning experts...............? }\end{array}$ & 1 & 2 & 3 & 4 & 5 \\
\hline Other (please specify & 1 & 2 & 3 & 4 & 5 \\
\hline
\end{tabular}


9. To what extent would people in the following positions at your university be involved in the decision to put in place a succession program for university-wide research institutes at your university?

President of the university.

\section{Not at All

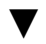

1

Vice-president of research at the university

Advisory board of the research institute.

Executive director of the research institute...

Research faculty in the research institute.

Research staff in the research institute.

Post-docs in the research institute...

Graduate students in the research institute.

Human resource manager in the university......................

Human resource manager in the research institute.

Other (please specify:

$\begin{array}{ccc}\text { Small } & \text { Moderate } & \text { Great } \\ \text { Extent } & \text { Extent } & \text { Extent } \\ \boldsymbol{\nabla} & \boldsymbol{\nabla} & \boldsymbol{\nabla}\end{array}$

Very

Great

Extent

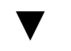

5

3

4

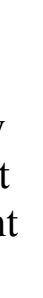


10. To what extent would each of these research institute employees participate in a succession program once it is put in place?

$\begin{array}{ccccc} & & & & \text { Very } \\ \text { Not at All } & \text { Small } & \text { Moderate } & \text { Great } & \text { Great } \\ \boldsymbol{\nabla} & \boldsymbol{\nabla} & \text { Extent } & \text { Extent } & \text { Extent }\end{array}$

Senior Leaders (ex: Executive

Director)

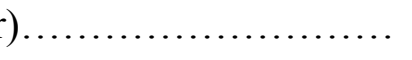

0

1

2

3

4

Managers

0

1

2

3

4

Staff

0

1

2

3

4

Residential Faculty.

0

1

2

3

Adjunct / Affiliated Faculty.

0

1

2

3

Graduate Students.

0

1

2

3

4

Other (please specify

0

1

2

3

4

11. In your opinion, what type of development program would be appropriate for each of the following participants in succession programs in university-wide research institutes?

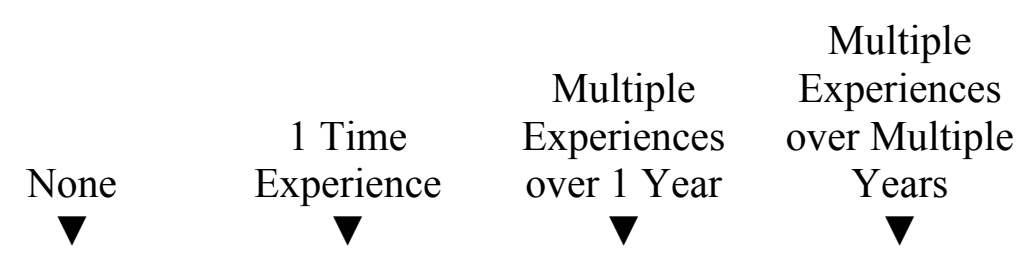

Senior Leaders (ex: Executive

Director).

0

1

2

3

Managers

0

0

1

2

3

Staff.

Residential Faculty

0

0

1

2 


\begin{tabular}{|c|c|c|c|c|}
\hline & None & $\begin{array}{c}1 \text { Time } \\
\text { Experience } \\
\nabla\end{array}$ & $\begin{array}{c}\text { Multiple } \\
\text { Experiences } \\
\text { over } 1 \text { Year } \\
\nabla\end{array}$ & $\begin{array}{c}\text { Multiple } \\
\text { Experiences } \\
\text { over Multiple } \\
\text { Years } \\
\nabla\end{array}$ \\
\hline Post-Docs........................ & 0 & 1 & 2 & 3 \\
\hline Graduate Students............. & 0 & 1 & 2 & 3 \\
\hline Other (please specify & & & & \\
\hline ) & 0 & 1 & 2 & 3 \\
\hline
\end{tabular}

12. Please rank the importance of the following methods in developing (or training) research institute employees. (Please fill in your rank order in the spaces provided using 1 as the least important and 5 as the most important.)

Job rotation (e.g., opportunities to learn different areas of an organization)

Stretch assignments (e.g., a project that pushes one's skill limits)

Job enrichment (e.g., opportunities to use all of one's skills)

Mentoring (e.g., opportunities to discuss work situations with more experienced co-workers)

Training related to succession development

13. In your opinion, which of the following characteristics in succession planning would be important to university-wide research institutes in your university?*

\section{The succession plan would:}

Not at all important

Slightly
important

$\begin{array}{cc}\text { Quite } & \text { Very } \\ \text { Important } & \text { Important } \\ \nabla & \nabla\end{array}$

Identify the groups that the program would serve, in priority order....

Devise a means to keep records for individuals who are designated as successors
1

1
2

3

4

5 


\section{The succession plan would:}

$\begin{array}{lcccc}\text { Not at all } & \text { Slightly } & \text { Fairly } & \text { Quite } & \text { Very } \\ \text { important } & \text { important } & \text { important } & \text { Important } & \text { Important } \\ \boldsymbol{\nabla} & \boldsymbol{\nabla} & \boldsymbol{\nabla} & \boldsymbol{\nabla} & \end{array}$

Establish a means to clarify present position responsibilities...........

Establish a means to clarify future position responsibilities...........

Establish a way to forecast future talent needs....

12

3

4

Establish individual employee development plans.... 1

2

3

4 5

Other (please specify

14. Do research institutes in your university currently take part in activities related to succession planning?

2 No $\rightarrow$ (Please skip to 16)

3 Yes

4 Not aware $\rightarrow$ (Please skip to 16 )

15. (If Yes) In which types of succession planning activities do your research institutes currently take part?

$\underline{\text { No }} \quad \underline{\text { Yes }} \quad \underline{\text { Not Aware }}$

Job rotation (e.g., opportunities to learn different areas of an organization).

1

Stretch assignments (e.g., a project that pushes one's skill limits)

0

1 2

Job enrichment (e.g., opportunities to use all of one's skills)...............................? 


\section{$\underline{\text { No }} \quad \underline{\text { Yes }} \quad \underline{\text { Not Aware }}$}

Mentoring (e.g., opportunities to discuss work situations with more experienced co-

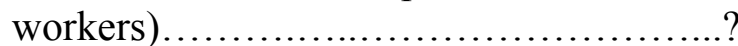

0

1

Training related to succession development....?

0

1 2

Other (please specify

0

16. In your opinion, which of the following characteristic(s) for evaluating succession programs would be important to research institutes in your university?*

\section{A succession program would establish:}

Measurable objectives for program

operation.

A means to appraise individual

performance.

A means to compare individual skills

to the requirements of a future

position

A way to review organizational

talent at least annually

A means to track development activities to prepare successors

for eventual advancement........

Not at all
important
$\nabla$

Slightly

Fairly

Quite

Very

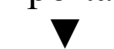

imp

Importan
Important
1
2
3
4
5

1

2

3

4

5

2

3

4

5

2

3

4

5

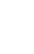

1

2

3

4

5 
17. In your opinion, which of the following characteristics of a written succession plan would be important to research institutes at your university?*

$\begin{array}{lcccc}\text { Aot at all } & \text { Slightly } & \text { Fairly } & \text { Quite } & \text { Very } \\ \text { important } & \text { important } & \text { important } & \text { Important } & \text { Important } \\ \text { A written succession plan would: } & \boldsymbol{\nabla} & \boldsymbol{\nabla} & \boldsymbol{\nabla} & \end{array}$

Be tied to the research center's strategic plans................. $\quad 1$

12

3

4

5

Be tied to the university's strategic plans.

1

2

3

4

5

Be tied to employee training

programs......................

1

2

3

4

5

Have a prepared written purpose statement.

1

2

3

4

5

Have prepared written program goals.

1 2 3

4 5

Have an established schedule of program events

1 2 3 4 5

Develop a means to budget for a succession program.

1 2 3

4

18. Please list any recommendation(s) or general comments you have regarding succession planning in university-wide research institutes at your university.

Open ended - leave space 


\section{The following are general questions about university-wide research institutes in your university.}

19. To what extent do research institutes' missions relate to the university's mission?

$\begin{array}{ccccc}\text { Not at All } & \text { Small Extent } & \text { Moderate Extent } & \text { Great Extent } & \begin{array}{c}\text { Very Great } \\ \text { Extent } \\ \boldsymbol{\nabla}\end{array} \\ 1 & 2 & 3 & 4 & 5\end{array}$

20. Based on your experience, approximately what percentage of key hires are internal hires from within the research institute compared to external hires from outside the research institute?

$\%$ Internal to research institute

$\%$ Internal to university

$\%$ External to university but from another university

$\%$ External to university but from industry

21. In your opinion, what changes in the percentages of internal and external key hires would you make in your answer to question 20 ?

$\%$ Internal to research institute

$\%$ Internal to university

$\%$ External to university but from another university

$\%$ External to university but from industry

No change

22. Generally, where did the current leadership in the research institutes in your university come from?

6 From within the institute

7 From outside the institute but inside the university

8 From another university

9 From industry

10 Other (please specify 


\section{How often are your research institutes evaluated?}

5 Never

6 Yearly Review

7 Regular Cycle (e.g., every 5 years)

8 Other (please specify

24. Who is included in the evaluation of your research institutes? (Click on all that apply)

6 External reviewers from non-university organizations

7 External reviewers from another university

8 Internal reviewers from the university

9 Internal reviewers from the institute

10 Other (please specify

25. How do research institutes in your university typically create new policies?

6 Top-down within the research institute

7 Bottom-up within the research institute

8 Collaboration between all research institute employees

9 Collaboration among leaders of the research institute

10 Other (please specify

26. How are policies typically implemented (put in place) in research institutes in your university?

6 Top-down within the research institute

7 Bottom-up within the research institute

8 Collaboration between all research institute employees

9 Collaboration among leaders of the research institute

10 Other (please specify

27. Which of the following characteristics describe university-wide research institutes in your university?

$\underline{\text { No }} \quad \underline{\text { Yes }}$

Reports to a university-level official, such as

the Vice President of Research.............? 0 ?

Is independent in regards to HR..............? $\quad 0 \quad 1$ 


$$
\underline{\text { No }} \quad \underline{\text { Yes }}
$$

Is independent in regards to budgeting..........

Relies on sponsored research..................?

$0 \quad 1$

Is independent in regards to administration....?

$0 \quad 1$

Is interdisciplinary in nature..................? $\quad 0 \quad 1$ 


\section{The answers to your survey have been received.}

\section{Thank you for your time and help in my research!}

For more information regarding this study, please contact me:

Kimberly Carlson | KimCarlson2009@vt.edu | 1-540-231-5133 | C Kimberly Carlson 2010

Center for Public Administration and Policy, 104 Draper Rd. (0520), Blacksburg, VA 24061 


\section{Appendix E: Universities and Research Institutes}

These are the universities for the initial surveys. Each university has multiple research institutes - these were narrowed down based on VT's definition of university-wide research institute. The number in parenthesis behind the school name is the confirmed number of university-wide research institutes. If a school does not have a number that school did not confirmed their number of research centers that are similar to Virginia Tech's university-wide research institutes.

1. Virginia Polytechnic Institute and State University (6)

- Fralin Life Science Institute

- Institute for Critical Technology and Applied Science (ICTAS)

- Institute for Society, Culture, and Environment

- Virginia Bioinformatics Institute

- Virginia Tech Transportation Institute

- Virginia Tech Carilion School of Medicine and Research Institute

SCHEV APPROVED / TOP 30 RESEARCH / AAU MEMBER / PUBLIC LAND GRANT

2. Cornell University-Endowed Colleges (17)

3. Ohio State University-Main Campus

4. Pennsylvania State University-Main Campus (6)

5. Texas A \& $M$ University

6. University of California-Berkeley

7. University of California-Davis (23)

8. University of Florida (10)

9. University of Illinois at Urbana-Champaign (4)

10. University of Minnesota-Twin Cities (3)

11. University of Wisconsin-Madison (17)

SCHEV APPROVED / TOP 30 RESEARCH / AAU MEMBER / PUBLIC

12. University of Colorado at Boulder (11)

13. University of Michigan, Ann Arbor (5)

14. University of Pittsburgh

15. University of Southern California (Private) (3)

16. The University of Washington-Seattle (2)

SCHEV APPROVED / AAU MEMBER / PUBLIC LAND GRANT

17. Iowa State University (16)

18. Michigan State University

19. Purdue University (11)

20. Rutgers, The State University of New Jersey

21. University of Maryland, College Park

22. University of Missouri-Columbia (19)

SCHEV APPROVED / AAU MEMBER / PUBLIC

23. State University of New York at Buffalo 
24. Stony Brook University (0)

25. The University of Texas at Austin

SCHEV APPROVED / PUBLIC LAND GRANT

26. North Carolina State University (7)

TOP 30 RESEARCH / AAU MEMBER / PUBLIC LAND GRANT

27. University of Arizona

28. Massachusetts Institute of Technology (Private)

TOP 30 RESEARCH / AAU MEMBER / PUBLIC

29. University of California - Los Angeles (2)

30. University of California - San Diego (1)

31. University of North Carolina at Chapel Hill

TOP 30 RESEARCH / AAU MEMBER

32. Columbia University in the City of New York

33. Duke University

34. Harvard University

35. Johns Hopkins University

36. Stanford University (16)

37. University of Pennsylvania

38. Washington University in St. Louis

TOP 30 RESEARCH / PUBLIC

39. Georgia Institute of Technology

40. University of Colorado at Denver (1)

AAU MEMBER / PUBLIC LAND GRANT

41. University of Nebraska at Lincoln

AAU MEMBER / PUBLIC

42. Indiana University - Bloomington

43. University of California - Irvine (29)

44. University of California - Santa Barbara

45. University of Iowa

46. University of Kansas (9)

47. University of Virginia

\section{AAU MEMBER}

48. California Institute of Technology

49. Brandeis University

50. Brown University (5)

51. Carnegie Mellon University

52. Case Western Reserve University

53. Emory University (0) 
54. New York University (0)

55. Northwestern University (29)

56. Princeton University

57. Rice University (0)

58. Tulane University of Louisiana

59. University of Chicago (1)

60. University of Rochester

61. Vanderbilt University

62. Yale University (0)

PUBLIC LAND GRANT

63. Colorado State University

64. Kansas State University

65. Montana State University - Bozeman (4)

66. Louisiana State University (12)

67. Oregon State University

68. University of California - Riverside (2)

69. University of Connecticut

70. University of Delaware

71. University of Georgia (1)

72. University of Hawaii at Manoa (2)

73. University of Kentucky (9)

74. University of Massachusetts - Amherst

75. University of Tennessee (11)

76. Washington State University (4)

\section{PUBLIC}

77. Arizona State University at Tempe

78. Florida State University (3)

79. SUNY at Albany

80. University of Alabama at Birmingham (0)

81. University of California - Santa Cruz (1)

82. University of Cincinnati

83. University of Illinois at Chicago (6)

84. University of New Mexico (4)

85. University of South Carolina - Columbia

86. University of South Florida (0)

87. University of Utah

88. Wayne State University (13) 


\section{Appendix F: Median Number of Research Institutes per School per Category}

Median

Median by category

Virginia Tech

SCHEV Approved / Top 30 Research / AAU Members / Public Land Grant

SCHEV Approved / Top 30 Research / AAU Members / Public

SCHEV Approved / AAU Members / Public Land Grant

SCHEV Approved / AAU Members / Public

SCHEV Approved / Public Land Grant

Top 30 Research / AAU Members / Public Land Grant

Top 30 Research / AAU Members / Public

Top 30 Research / AAU Members

Top 30 Research / Public

AAU Members / Public Land Grant

AAU Members / Public

AAU Members

Public Land Grant

Public

$\begin{array}{cccccc}\text { All Schools } & \begin{array}{c}\text { Reporting } \\ \text { Schools }\end{array} & \begin{array}{c}\text { Science } \\ \text { Based }\end{array} & \begin{array}{c}\text { Social } \\ \text { Science } \\ \text { Based }\end{array} & \begin{array}{c}\text { Science }- \\ \text { All Schools }\end{array} & \begin{array}{c}\text { Social } \\ \text { Science - } \\ \text { All Schools }\end{array} \\ 11.0 & 4.0 & & & 8.0 & 2.0\end{array}$

\begin{tabular}{|c|c|c|c|}
\hline $\begin{array}{l}\mathbf{6 . 0} \\
(n=1)\end{array}$ & $\begin{array}{l}\mathbf{6 . 0} \\
(n=1)\end{array}$ & 5.0 & 1.0 \\
\hline $13.5(n=10)$ & $\begin{array}{l}\mathbf{1 0 . 0} \\
(\mathrm{n}=7)\end{array}$ & 10.0 & 2.0 \\
\hline $\begin{array}{l}\mathbf{5 . 0} \\
(\mathrm{n}=5)\end{array}$ & $\begin{array}{l}\mathbf{4 . 0} \\
(n=4)\end{array}$ & 3.0 & 2.0 \\
\hline $\begin{array}{l}17.5 \\
(n=6)\end{array}$ & $\begin{array}{l}16.0 \\
(n=3)\end{array}$ & 15.0 & 4.0 \\
\hline $\begin{array}{l}111.0 \\
(n=3)\end{array}$ & $\begin{array}{l}\mathbf{0 . 0} \\
(\mathrm{n}=1)\end{array}$ & 71.0 & 39.0 \\
\hline $\begin{array}{l}7.0 \\
(n=1)\end{array}$ & $\begin{array}{l}7.0 \\
(n=1)\end{array}$ & 6.0 & 1.0 \\
\hline $\begin{array}{l}63.0 \\
(n=2)\end{array}$ & $\begin{array}{l}\text { NA } \\
(\mathrm{n}=0)\end{array}$ & 47.0 & 16.0 \\
\hline $\begin{array}{l}2.0 \\
(n=3)\end{array}$ & $\begin{array}{l}1.5 \\
(n=2)\end{array}$ & 2.0 & 0.0 \\
\hline $\begin{array}{l}\mathbf{1 6 . 0} \\
(\mathrm{n}=7)\end{array}$ & $\begin{array}{l}\mathbf{1 6 . 0} \\
(\mathrm{n}=1)\end{array}$ & 8.0 & 8.0 \\
\hline $\begin{array}{l}13.0 \\
(n=2)\end{array}$ & $\begin{array}{l}\mathbf{1 . 0} \\
(\mathrm{n}=1)\end{array}$ & 10.5 & 2.5 \\
\hline $\begin{array}{l}\mathbf{1 7 . 0} \\
(\mathrm{n}=1)\end{array}$ & $\begin{array}{l}\text { NA } \\
(\mathrm{n}=0)\end{array}$ & 15.0 & 2.0 \\
\hline $\begin{array}{l}19.5 \\
(n=6)\end{array}$ & $\begin{array}{l}\mathbf{1 9 . 0} \\
(\mathrm{n}=2)\end{array}$ & 11.0 & 5.5 \\
\hline $\begin{array}{l}29.0 \\
(n=15)\end{array}$ & $\begin{array}{l}\mathbf{0 . 5} \\
(n=7)\end{array}$ & 6.0 & 7.0 \\
\hline $\begin{array}{l}\mathbf{1 0 . 0} \\
(n=14)\end{array}$ & $\begin{array}{l}\mathbf{4 . 0} \\
(n=8)\end{array}$ & 7.5 & 1.5 \\
\hline $\begin{array}{l}5.5 \\
(n=12)\end{array}$ & $\begin{array}{l}3.5 \\
(n=7)\end{array}$ & 3.0 & 2.0 \\
\hline
\end{tabular}




\section{Appendix G: Example of Interview Correspondence}

\section{Phone Call/Email:}

This is Kimberly Carlson. You participated in my survey in fall 2010 about succession planning for university-wide research institutes. In this survey you indicated a willingness to participate in a follow-up interview. That is why I am calling/emailing you today.

This follow-up includes your reviewing a proposed model for succession planning and an interview. The interview questions are related to whether the model would be relevant and useful to you or your institute. The review should take approximately 30 minutes and the interview should take between 30 and 45 minutes.

Are you still available to participate in my research follow-up? If so, when would be the best time to schedule an interview?

I would like to mail the model and interview questions to you. What is the best mailing address to send it to you?

Thank you for your time.

Best, Kimberly Carlson

Ph.D. Candidate

Virginia Tech 


\section{Letter:}

March 1, 2011

Name

Address

City, State Zip

Dear Dr. [INSERT RECIPIENT'S NAME],

Thank you for agreeing to participate in a follow-up interview related to succession planning in university-wide research institutes. Please find enclosed a proposed model for a succession planning process and interview questions that we discussed in our phone call/email correspondence.

The model is written as a guide for a group of decision makers to develop a succession planning program. If completing the process fully, it would take between four and six months to complete. I am not asking that you answer the questions in the model at this time; instead, I would like you to review it for its relevance to your institute. Do you think the model would be helpful to you while developing a program for succession planning for your research institute?

The interview questions are meant as a starting point in our conversation. There may be other questions that develop as we continue through the interview.

I look forward to discussing the model with you.

Best,

Kimberly A. Carlson

Ph.D. Candidate

Center for Public Administration and Policy

Virginia Tech 


\section{Appendix H: Interview Questions}

1. In the survey, you said that succession planning was/was not relevant to the strategic planning of your institute. Why or why not?

2. What was your initial reaction to the proposed model?

a. Do you have any questions? Can I clarify anything about the model?

3. After reviewing the proposed succession planning model, how relevant do you think it is to your institute?

4. After reviewing the model, what would you say are its strengths?

5. Looking at the model's steps or characteristics, what changes might you suggest?

6. If a succession planning model were implemented in your research institute, how would you know that it was successful?

7. Is there anything else you might tell me about the proposed succession planning model? Or succession planning generally? 


\section{Appendix I: Demographics of Universities that Participated in Research}

\begin{tabular}{|c|c|c|c|c|c|c|c|c|c|}
\hline & $\begin{array}{c}\text { Total \# } \\
\text { Institutes }\end{array}$ & $\begin{array}{c}\# \\
\text { Participating } \\
\text { Institutes }\end{array}$ & $\begin{array}{c}\text { UA* } \\
\text { Participated }\end{array}$ & $\begin{array}{c}\# \\
\text { Students } * *\end{array}$ & $\begin{array}{c}\text { Univ. } \\
\text { Budget } * * *\end{array}$ & $\begin{array}{l}\text { Public or } \\
\text { Private }\end{array}$ & $\begin{array}{c}\text { AAU } \\
\text { Member }\end{array}$ & $\begin{array}{l}\text { Land- } \\
\text { Grant } \\
\text { Mission }\end{array}$ & $\begin{array}{c}\text { Top } 30 \\
\text { Research }\end{array}$ \\
\hline \multicolumn{10}{|l|}{ ARIZONA } \\
\hline $\begin{array}{l}\text { Arizona State University } \\
\text { Tempe, AZ }\end{array}$ & 5 & $1(20 \%)$ & No & 70,440 & $\$ 1.895 \mathrm{~B}$ & Public & No & No & No \\
\hline $\begin{array}{l}\text { University of Arizona } \\
\text { Tucson, AZ }\end{array}$ & 6 & $2(33 \%)$ & No & 39,086 & $\$ 1.008 \mathrm{~B}$ & Public & Yes & Yes & No \\
\hline \multicolumn{10}{|l|}{ CALIFORNIA } \\
\hline $\begin{array}{l}\text { Cal. Institute of Tech. } \\
\text { Pasadena, CA }\end{array}$ & 4 & $2(50 \%)$ & No & 2,175 & $\$ 2.299 \mathrm{~B}$ & Private & Yes & No & No \\
\hline $\begin{array}{l}\text { Stanford University } \\
\text { Stanford, CA }\end{array}$ & 17 & $6(35.3 \%)$ & No & 15,666 & $\$ 3.650 \mathrm{~B}$ & Private & Yes & No & Yes \\
\hline $\begin{array}{l}\text { Univ. of Cal., Berkeley } \\
\text { Berkeley, CA }\end{array}$ & 31 & $7(22.6 \%)$ & No & 35,838 & $\$ 1.904 \mathrm{~B}$ & Public & Yes & Yes & Yes \\
\hline $\begin{array}{l}\text { Univ. of Cal., Davis } \\
\text { Davis, CA }\end{array}$ & 21 & $4(19 \%)$ & No & 31,392 & $\$ 3.1 \mathrm{~B}$ & Public & Yes & Yes & Yes \\
\hline $\begin{array}{l}\text { Univ. of Cal., Irvine } \\
\text { Irvine, CA }\end{array}$ & 29 & $4(13.8 \%)$ & Yes & 26,994 & $\$ 20.1 \mathrm{~B}$ & Public & Yes & No & No \\
\hline $\begin{array}{l}\text { Univ. of Cal., Riverside } \\
\text { Riverside, CA }\end{array}$ & 2 & $1(50 \%)$ & No & 20,746 & $\$ 470 \mathrm{M}$ & Public & No & Yes & No \\
\hline $\begin{array}{l}\text { Univ. of Cal., San Diego } \\
\text { San Diego, CA }\end{array}$ & 1 & $0(0 \%)$ & Yes & 29,176 & $\$ 2.71 \mathrm{~B}$ & Public & Yes & No & Yes \\
\hline $\begin{array}{l}\text { Univ. of Cal., Santa } \\
\text { Barbara } \\
\text { Santa Barbara, CA }\end{array}$ & 24 & $3(12.5 \%)$ & No & 22,218 & $\$ 469 \mathrm{M}$ & Public & Yes & No & No \\
\hline $\begin{array}{l}\text { Univ. of So. California } \\
\text { Los Angeles, CA }\end{array}$ & 3 & $1(33.3 \%)$ & Yes & 39,593 & $16.665 \mathrm{~B}$ & Public & Yes & No & Yes \\
\hline
\end{tabular}




\begin{tabular}{|c|c|c|c|c|c|c|c|c|c|}
\hline & $\begin{array}{c}\text { Total \# } \\
\text { Institutes }\end{array}$ & $\begin{array}{c}\# \\
\text { Participating } \\
\text { Institutes }\end{array}$ & $\begin{array}{c}\text { UA* } \\
\text { Participated }\end{array}$ & $\begin{array}{c}\# \\
\text { Students } * *\end{array}$ & $\begin{array}{c}\text { Univ. } \\
\text { Budget*** }\end{array}$ & $\begin{array}{l}\text { Public } \\
\text { or } \\
\text { Private }\end{array}$ & $\begin{array}{c}\text { AAU } \\
\text { Member }\end{array}$ & $\begin{array}{l}\text { Land- } \\
\text { Grant } \\
\text { Mission }\end{array}$ & $\begin{array}{c}\text { Top } 30 \\
\text { Research }\end{array}$ \\
\hline \multicolumn{10}{|l|}{ COLORADO } \\
\hline $\begin{array}{l}\text { Univ. of Colorado at Boulder } \\
\text { Boulder, CO }\end{array}$ & 11 & $3(27.3 \%)$ & Yes & 29,952 & $\$ 1.085 \mathrm{~B}$ & Public & Yes & No & Yes \\
\hline \multicolumn{10}{|l|}{ CONNECTICUT } \\
\hline $\begin{array}{l}\text { Univ. of Connecticut } \\
\text { Storrs, CT }\end{array}$ & 7 & $2(28.6 \%)$ & Yes & 28,679 & $\$ 981.3 \mathrm{M}$ & Public & No & Yes & No \\
\hline \multicolumn{10}{|l|}{ DELAWARE } \\
\hline $\begin{array}{l}\text { Univ. of Delaware } \\
\text { Newark, DE }\end{array}$ & 13 & $3(23.1 \%)$ & No & 21,177 & $\$ 800 \mathrm{M}$ & Public & No & Yes & No \\
\hline \multicolumn{10}{|l|}{ FLORIDA } \\
\hline $\begin{array}{l}\text { Florida State University } \\
\text { Tallahassee, FL }\end{array}$ & 3 & $2(66.7 \%)$ & No & 40,838 & $\$ 1.130 \mathrm{~B}$ & Public & No & No & No \\
\hline $\begin{array}{l}\text { Univ. of Florida } \\
\text { Gainesville, FL }\end{array}$ & 10 & $2(20 \%)$ & No & 49,827 & $\$ 4.3 \mathrm{~B}$ & Public & Yes & Yes & Yes \\
\hline \multicolumn{10}{|l|}{ GEORGIA } \\
\hline $\begin{array}{l}\text { Georgia Institute of Technology } \\
\text { Atlanta, GA }\end{array}$ & 28 & $7(25 \%)$ & Yes & 20,720 & $\$ 1.199 \mathrm{~B}$ & Public & No & No & Yes \\
\hline $\begin{array}{l}\text { University of Georgia } \\
\text { Athens, GA }\end{array}$ & 1 & $0(0 \%)$ & Yes & 34,677 & $\$ 1.36 \mathrm{~B}$ & Public & No & Yes & No \\
\hline \multicolumn{10}{|l|}{ HAWAII } \\
\hline $\begin{array}{l}\text { University of Hawaii Manoa } \\
\text { Honolulu, HI }\end{array}$ & 2 & $0(0 \%)$ & Yes & 20,337 & $\$ 4.6 \mathrm{M}$ & Public & No & Yes & No \\
\hline \multicolumn{10}{|l|}{ INDIANA } \\
\hline $\begin{array}{l}\text { Indiana Univ. - Bloomington } \\
\text { Bloomington, IN }\end{array}$ & 20 & $8(40 \%)$ & No & 42,464 & $\begin{array}{l}\$ 1.036 \mathrm{~B} \\
(2007-08)\end{array}$ & Public & Yes & No & No \\
\hline $\begin{array}{l}\text { Purdue University } \\
\text { West Lafayette, IN }\end{array}$ & 11 & $3(27.3 \%)$ & No & 39,726 & $\$ 907 \mathrm{M}$ & Public & Yes & Yes & No \\
\hline
\end{tabular}




\begin{tabular}{|c|c|c|c|c|c|c|c|c|c|}
\hline & $\begin{array}{l}\text { Total \# } \\
\text { Institutes }\end{array}$ & $\begin{array}{c}\# \\
\text { Participating } \\
\text { Institutes }\end{array}$ & $\begin{array}{c}\text { UA* } \\
\text { Participated }\end{array}$ & $\begin{array}{c}\# \\
\text { Students** }\end{array}$ & $\begin{array}{c}\text { Univ. } \\
\text { Budget }\end{array}$ & $\begin{array}{l}\text { Public } \\
\text { or } \\
\text { Private }\end{array}$ & $\begin{array}{c}\text { AAU } \\
\text { Member }\end{array}$ & $\begin{array}{l}\text { Land- } \\
\text { Grant } \\
\text { Mission }\end{array}$ & $\begin{array}{c}\text { Top } 30 \\
\text { Research }\end{array}$ \\
\hline \multicolumn{10}{|l|}{ ILLINOIS } \\
\hline $\begin{array}{l}\text { Northwestern University } \\
\text { Evanston, IL }\end{array}$ & 28 & $3(10.7 \%)$ & No & 14,988 & $\$ 1.603 \mathrm{~B}$ & Private & Yes & No & No \\
\hline $\begin{array}{l}\text { Univ. of Illinois at Chicago } \\
\text { Chicago, IL }\end{array}$ & 6 & $2(33.3 \%)$ & Yes & 27,850 & $\$ 1.648 \mathrm{~B}$ & Public & No & No & No \\
\hline $\begin{array}{l}\text { Univ. of IL, Urbana- } \\
\text { Champaign } \\
\text { Champaign, IL }\end{array}$ & 4 & $2(50 \%)$ & No & 43,862 & $\$ 1.559 \mathrm{~B}$ & Public & Yes & Yes & Yes \\
\hline \multicolumn{10}{|l|}{ IOWA } \\
\hline $\begin{array}{l}\text { Iowa State University } \\
\text { Ames, IA }\end{array}$ & 15 & $4(26.7 \%)$ & No & 28,682 & $\$ 504 \mathrm{M}$ & Public & Yes & Yes & No \\
\hline $\begin{array}{l}\text { Univ. of Iowa } \\
\text { Iowa City, IA }\end{array}$ & 8 & $4(50 \%)$ & No & 30825 & $\$ 2.815 \mathrm{~B}$ & Public & Yes & No & No \\
\hline \multicolumn{10}{|l|}{ KANSAS } \\
\hline $\begin{array}{l}\text { Kansas State University } \\
\text { Manhattan, KS }\end{array}$ & 14 & $5(35.7 \%)$ & No & 23,588 & $\$ 2.815 \mathrm{M}$ & Public & No & Yes & No \\
\hline $\begin{array}{l}\text { Univ. of Kansas } \\
\text { Lawrence, KS }\end{array}$ & 9 & $4(44.4 \%)$ & Yes & 28,697 & $\$ 530 \mathrm{M}$ & Public & Yes & No & No \\
\hline \multicolumn{10}{|l|}{ KENTUCKY } \\
\hline $\begin{array}{l}\text { Univ. of Kentucky } \\
\text { Lexington, KY }\end{array}$ & 9 & $5(55.6 \%)$ & Yes & 28,037 & $\$ 2.47 \mathrm{~B}$ & Public & No & Yes & No \\
\hline \multicolumn{10}{|l|}{ LOUISIANA } \\
\hline $\begin{array}{l}\text { Louisiana State University } \\
\text { Baton Rouge, LA }\end{array}$ & 9 & $2(22.2 \%)$ & No & 29,451 & $\$ 3.583 B$ & Public & No & Yes & No \\
\hline $\begin{array}{l}\text { Tulane University } \\
\text { New Orleans, LA }\end{array}$ & 13 & $3(23.1 \%)$ & No & 12,622 & $\$ 727 \mathrm{M}$ & Private & Yes & No & No \\
\hline
\end{tabular}




\begin{tabular}{|c|c|c|c|c|c|c|c|c|c|}
\hline & $\begin{array}{l}\text { Total \# } \\
\text { Institutes }\end{array}$ & $\begin{array}{c}\# \\
\text { Participating } \\
\text { Institutes }\end{array}$ & $\begin{array}{c}\text { UA* } \\
\text { Participated }\end{array}$ & $\begin{array}{c}\# \\
\text { Students** }\end{array}$ & $\begin{array}{c}\text { Univ. } \\
\text { Budget }{ }^{* * *}\end{array}$ & $\begin{array}{l}\text { Public } \\
\text { or } \\
\text { Private }\end{array}$ & $\begin{array}{c}\text { AAU } \\
\text { Member }\end{array}$ & $\begin{array}{l}\text { Land- } \\
\text { Grant } \\
\text { Mission }\end{array}$ & $\begin{array}{c}\text { Top } 30 \\
\text { Research }\end{array}$ \\
\hline \multicolumn{10}{|l|}{ MARYLAND } \\
\hline $\begin{array}{l}\text { Johns Hopkins University } \\
\text { Baltimore, MD }\end{array}$ & 17 & $3(17.6 \%)$ & Yes & 6,838 & $\$ 4.019 \mathrm{~B}$ & Private & Yes & No & Yes \\
\hline $\begin{array}{l}\text { Univ. of Maryland, College } \\
\text { Park } \\
\text { College Park. MD }\end{array}$ & 5 & $1(20 \%)$ & No & 37,641 & $\$ 1.626 \mathrm{~B}$ & Public & Yes & Yes & No \\
\hline \multicolumn{10}{|l|}{ MASSACHUSETTS } \\
\hline $\begin{array}{l}\text { Brandeis University } \\
\text { Waltham, MA }\end{array}$ & 14 & $4(28.6 \%)$ & Yes & $\begin{array}{l}5,598 \\
\text { (Fall 2009) } \\
\end{array}$ & $\$ 280.3 \mathrm{M}$ & Private & Yes & No & No \\
\hline $\begin{array}{l}\text { Mass. Institute of Technology } \\
\text { Cambridge, MA }\end{array}$ & 18 & $2(11.1 \%)$ & No & 10,566 & $\$ 2.382 \mathrm{~B}$ & Public & Yes & Yes & No \\
\hline $\begin{array}{l}\text { Univ. of Mass., Amherst } \\
\text { Amherst, MA }\end{array}$ & 10 & $3(30 \%)$ & Yes & 27,269 & $\$ 941.8 \mathrm{M}$ & Public & No & Yes & No \\
\hline \multicolumn{10}{|l|}{ MICHIGAN } \\
\hline $\begin{array}{l}\text { Michigan State University } \\
\text { East Lansing, MI }\end{array}$ & 13 & $3(23.1 \%)$ & No & 47,131 & $\$ 1.018 \mathrm{~B}$ & Public & Yes & Yes & No \\
\hline $\begin{array}{l}\text { Univ. of Michigan, Ann Arbor } \\
\text { Ann Arbor, MI }\end{array}$ & 4 & $2(50 \%)$ & No & 41,924 & $\$ 1.553 \mathrm{~B}$ & Public & Yes & No & Yes \\
\hline $\begin{array}{l}\text { Wayne State University } \\
\text { Detroit, MI }\end{array}$ & 13 & $4(30.8 \%)$ & No & 32,564 & $\$ 572 \mathrm{M}$ & Public & No & No & No \\
\hline \multicolumn{10}{|l|}{ MINNESOTA } \\
\hline $\begin{array}{l}\text { Univ. of Minnesota, Twin } \\
\text { Cities } \\
\text { Minneapolis, MN }\end{array}$ & 3 & $1(33.3 \%)$ & No & 51,721 & $\$ 3.345 \mathrm{~B}$ & Public & Yes & Yes & Yes \\
\hline \multicolumn{10}{|l|}{ MISSOURI } \\
\hline $\begin{array}{l}\text { Univ. of Missouri, Columbia } \\
\text { Columbia, MO }\end{array}$ & 10 & $2(20 \%)$ & No & 32,415 & $\$ 1.020 \mathrm{~B}$ & Public & Yes & Yes & No \\
\hline
\end{tabular}




\begin{tabular}{|c|c|c|c|c|c|c|c|c|c|}
\hline & $\begin{array}{l}\text { Total \# } \\
\text { Institutes }\end{array}$ & $\begin{array}{c}\# \\
\text { Participating } \\
\text { Institutes }\end{array}$ & $\begin{array}{c}\text { UA* } \\
\text { Participated }\end{array}$ & $\begin{array}{c}\# \\
\text { Students** }\end{array}$ & $\begin{array}{c}\text { Univ. } \\
\text { Budget*** }\end{array}$ & $\begin{array}{l}\text { Public } \\
\text { or } \\
\text { Private }\end{array}$ & $\begin{array}{c}\text { AAU } \\
\text { Member }\end{array}$ & $\begin{array}{l}\text { Land- } \\
\text { Grant } \\
\text { Mission }\end{array}$ & $\begin{array}{c}\text { Top } 30 \\
\text { Research }\end{array}$ \\
\hline \multicolumn{10}{|l|}{ NEBRASKA } \\
\hline $\begin{array}{l}\text { Univ. of Nebraska, Lincoln } \\
\text { Lincoln, NE }\end{array}$ & 7 & $2(28.6 \%)$ & No & 24,610 & $\$ 767.2 \mathrm{M}$ & Public & Yes & Yes & No \\
\hline \multicolumn{10}{|l|}{ NEW JERSEY } \\
\hline $\begin{array}{l}\text { Princeton University } \\
\text { Princeton, NJ }\end{array}$ & 9 & $2(22.2 \%)$ & No & 7,802 & $\$ 1.410 \mathrm{~B}$ & Private & Yes & No & No \\
\hline $\begin{array}{l}\text { Rutgers University } \\
\text { New Brunswick, NJ }\end{array}$ & 44 & $12(27.3 \%)$ & No & 38,912 & $\$ 1.740 \mathrm{~B}$ & Public & Yes & Yes & No \\
\hline \multicolumn{10}{|l|}{ NEW MEXICO } \\
\hline $\begin{array}{l}\text { Univ. of New Mexico } \\
\text { Albuquerque, NM }\end{array}$ & 4 & $1(25 \%)$ & No & 28,757 & $\$ 1.432 \mathrm{~B}$ & Public & No & No & No \\
\hline \multicolumn{10}{|l|}{ NEW YORK } \\
\hline $\begin{array}{l}\text { Columbia University } \\
\text { New York, NY }\end{array}$ & 34 & $5(14.7 \%)$ & Yes & 27,606 & $\$ 3.064 \mathrm{~B}$ & Private & Yes & No & Yes \\
\hline $\begin{array}{l}\text { Cornell University } \\
\text { Ithaca, NY }\end{array}$ & 12 & $5(41.7 \%)$ & No & 22,024 & $\$ 3.124 \mathrm{~B}$ & Public & Yes & Yes & Yes \\
\hline $\begin{array}{l}\text { Univ. at Albany } \\
\text { Albany, NY }\end{array}$ & 10 & $3(30 \%)$ & No & 7,661 & $\$ 156.18 \mathrm{M}$ & Public & No & No & No \\
\hline $\begin{array}{l}\text { Univ. at Buffalo } \\
\text { Buffalo, NY }\end{array}$ & 27 & $3(11.1 \%)$ & No & 29,048 & $\$ 346.96 \mathrm{M}$ & Public & Yes & No & No \\
\hline $\begin{array}{l}\text { University of Rochester } \\
\text { Rochester, NY }\end{array}$ & 1 & $0(0 \%)$ & Yes & 10,111 & $\begin{array}{l}\$ 2.52 \mathrm{~B} \\
(2009-10)\end{array}$ & Private & Yes & No & No \\
\hline \multicolumn{10}{|l|}{ NORTH CAROLINA } \\
\hline $\begin{array}{l}\text { Duke University } \\
\text { Durham, NC }\end{array}$ & 10 & $1(10 \%)$ & Yes & 14,248 & $\begin{array}{l}\$ 2.13 \mathrm{~B} \\
(2009-10)\end{array}$ & Private & Yes & No & Yes \\
\hline $\begin{array}{l}\text { NC State University } \\
\text { Raleigh, NC }\end{array}$ & 7 & $4(57.1 \%)$ & No & 34,376 & \$1.13B & Public & No & Yes & No \\
\hline $\begin{array}{l}\text { UNC, Chapel Hill } \\
\text { Chapel Hill, NC }\end{array}$ & 15 & $8(53.3 \%)$ & No & 29,390 & $\begin{array}{l}\$ 2.28 \mathrm{~B} \\
(2009-10)\end{array}$ & Public & Yes & No & Yes \\
\hline
\end{tabular}




\begin{tabular}{|c|c|c|c|c|c|c|c|c|c|}
\hline & $\begin{array}{c}\text { Total \# } \\
\text { Institutes }\end{array}$ & $\begin{array}{c}\# \\
\text { Participating } \\
\text { Institutes } \\
\end{array}$ & $\begin{array}{c}\text { UA* } \\
\text { Participated }\end{array}$ & $\begin{array}{c}\# \\
\text { Students }\end{array}$ & $\begin{array}{c}\text { Univ. } \\
\text { Budget*** }\end{array}$ & $\begin{array}{l}\text { Public or } \\
\text { Private }\end{array}$ & $\begin{array}{c}\text { AAU } \\
\text { Member }\end{array}$ & $\begin{array}{l}\text { Land- } \\
\text { Grant } \\
\text { Mission }\end{array}$ & $\begin{array}{c}\text { Top } 30 \\
\text { Research }\end{array}$ \\
\hline \multicolumn{10}{|l|}{ OHIO } \\
\hline $\begin{array}{l}\text { Ohio State University } \\
\text { Columbus, OH }\end{array}$ & 5 & $1(20 \%)$ & No & 64,077 & $\$ 1.255 \mathrm{~B}$ & Public & Yes & Yes & Yes \\
\hline $\begin{array}{l}\text { University of Cincinnati } \\
\text { Cincinnati, OH }\end{array}$ & 6 & $3(50 \%)$ & No & 32,283 & $\$ 1.016 \mathrm{~B}$ & Public & No & No & No \\
\hline \multicolumn{10}{|l|}{ OREGON } \\
\hline $\begin{array}{l}\text { Oregon State University } \\
\text { Corvallis, OR }\end{array}$ & 13 & $3(23.1 \%)$ & Yes & 23,761 & $\$ 316 \mathrm{M}$ & Public & No & Yes & No \\
\hline \multicolumn{10}{|l|}{ PENNSYLVANIA } \\
\hline $\begin{array}{l}\text { Carnegie Mellon University } \\
\text { Pittsburgh, PA }\end{array}$ & 9 & $1(11.1 \%)$ & No & 11,618 & $\$ 874 \mathrm{M}$ & Private & Yes & No & No \\
\hline $\begin{array}{l}\text { Pennsylvania State University } \\
\text { University Park, PA }\end{array}$ & 6 & $3(50 \%)$ & Yes & 45,233 & $\$ 4.016 \mathrm{~B}$ & Public & Yes & Yes & Yes \\
\hline $\begin{array}{l}\text { Univ. of Pennsylvania } \\
\text { Philadelphia, PA }\end{array}$ & 15 & $2(13.3 \%)$ & No & 19,842 & $\$ 5.26 \mathrm{M}$ & Private & Yes & No & Yes \\
\hline $\begin{array}{l}\text { Univ. of Pittsburgh } \\
\text { Pittsburgh, PA }\end{array}$ & 20 & $4(20 \%)$ & Yes & 28,823 & $\$ 1.756 \mathrm{~B}$ & Public & Yes & No & Yes \\
\hline \multicolumn{10}{|l|}{ SOUTH CAROLINA } \\
\hline $\begin{array}{l}\text { University of South Carolina } \\
\text { Columbia, SC }\end{array}$ & 3 & $0(0 \%)$ & Yes & 29,597 & $\$ 838.5 \mathrm{M}$ & Public & No & No & No \\
\hline \multicolumn{10}{|l|}{ TENNESSEE } \\
\hline $\begin{array}{l}\text { Univ. of Tennessee } \\
\text { Knoxville, TN }\end{array}$ & 11 & $2(18.2 \%)$ & No & 30,312 & $\$ 527.7 \mathrm{M}$ & Public & No & Yes & No \\
\hline $\begin{array}{l}\text { Vanderbilt University } \\
\text { Nashville, TN }\end{array}$ & 14 & $5(35.7 \%)$ & No & 12,714 & $\$ 3.263 \mathrm{M}$ & Private & Yes & No & No \\
\hline
\end{tabular}




\begin{tabular}{|c|c|c|c|c|c|c|c|c|c|}
\hline & $\begin{array}{l}\text { Total \# } \\
\text { Institutes }\end{array}$ & $\begin{array}{c}\# \\
\text { Participating } \\
\text { Institutes }\end{array}$ & $\begin{array}{c}\text { UA* } \\
\text { Participated }\end{array}$ & $\begin{array}{c}\# \\
\text { Students** }\end{array}$ & $\begin{array}{c}\text { Univ. } \\
\text { Budget*** }\end{array}$ & $\begin{array}{l}\text { Public or } \\
\text { Private }\end{array}$ & $\begin{array}{c}\text { AAU } \\
\text { Member }\end{array}$ & $\begin{array}{l}\text { Land- } \\
\text { Grant } \\
\text { Mission }\end{array}$ & $\begin{array}{c}\text { Top } 30 \\
\text { Research }\end{array}$ \\
\hline \multicolumn{10}{|l|}{ TEXAS } \\
\hline $\begin{array}{l}\text { Texas A \& M University } \\
\text { College Station, TX }\end{array}$ & 19 & $7(36.8 \%)$ & No & 49,129 & $\$ 1.227 \mathrm{~B}$ & Public & Yes & Yes & Yes \\
\hline $\begin{array}{l}\text { Univ. of Texas, Austin } \\
\text { Austin. TX }\end{array}$ & 10 & $4(40 \%)$ & No & 51,195 & $\$ 2.14 \mathrm{~B}$ & Public & Yes & No & No \\
\hline \multicolumn{10}{|l|}{ UTAH } \\
\hline $\begin{array}{l}\text { Univ. of Utah } \\
\text { Salt Lake City, UT }\end{array}$ & 13 & $4(30.8 \%)$ & Yes & 30,819 & $\$ 418.3 \mathrm{M}$ & Public & No & No & No \\
\hline \multicolumn{10}{|l|}{ VIRGNIA } \\
\hline $\begin{array}{l}\text { Univ. of Virginia } \\
\text { Charlottesville, VA }\end{array}$ & 5 & $1(20 \%)$ & No & 21,049 & $\$ 2.5 \mathrm{~B}$ & Public & Yes & No & No \\
\hline \multicolumn{10}{|l|}{ WASHINGTON } \\
\hline $\begin{array}{l}\text { Washington State University } \\
\text { Pullman, WA }\end{array}$ & 4 & $2(50 \%)$ & No & 26,308 & $\$ 829.8 \mathrm{M}$ & Public & No & Yes & No \\
\hline $\begin{array}{l}\text { Univ. of Washington, Seattle } \\
\text { Seattle, WA }\end{array}$ & 2 & $1(50 \%)$ & No & 45,943 & $\$ 3.493 \mathrm{~B}$ & Public & Yes & No & Yes \\
\hline \multicolumn{10}{|l|}{ WISCONSIN } \\
\hline $\begin{array}{l}\text { Univ. of Wisconsin-Madison } \\
\text { Madison, WI }\end{array}$ & 16 & $3(18.8 \%)$ & No & 42,595 & $\$ 2.701 \mathrm{~B}$ & Public & Yes & Yes & Yes \\
\hline
\end{tabular}


Appendix J: Proposed Model for Succession Planning for University-Wide Research Institutes 


\section{Executive Summary}

\section{Description}

University and research institute administrators are becoming more aware of the benefits of succession planning for their university-wide research institutes; yet, many administrators do not fully understand or may even fear succession planning. As such, this model was developed to guide administrators through the process of developing a succession plan that is appropriate for their institutes. It focuses on processes and on directing decision makers through the development of a plan, not on specific elements of the plan itself. Although some recommendations appear toward the end of this document, an actual succession plan would be based on the decisions of those involved and the context of the institute and its university.

This model is based on an extensive analysis of scholarly literature related to succession planning and on the results of surveys of executive directors of university-wide research institutes as well as university-level administrators at universities with very high research activity. The research synthesis of the literature included succession planning programs found in the for-profit, government, and non-profit sectors and in higher education. Elements found in articles covering all three sectors and that survey respondents reported to be important were used in the model.

After careful consideration of the literature and needs of research institutes, I chose to focus on a more holistic view of succession planning. This model relies on William Rothwell's (2001) ${ }^{11}$ definition of succession planning and management:

a deliberate and systematic effort by an organization to ensure leadership continuity in key positions, retain and develop intellectual and knowledge capital for the future, and encourage individual advancement [for all employees in the organization]. (p. 6)

Rothwell's definition not only emphasizes organizational needs and aligning human capital with the organization's strategic plan, it also emphasizes the development of individuals.

\footnotetext{
${ }^{11}$ Rothwell, W. J. (2001). Effective succession planning: Ensuring leadership continuity and building talent from within (2nd ed.). AMACOM: New York.
} 


\section{Elements in the model include:}

$\checkmark$ definition of succession planning,

- decision makers,

- participants,

- stakeholder perceptions,

- context and impetus for developing a succession plan,

- organizational placement of the program, and

- a timeline.

Each of these elements is described in further detail throughout the model. Although these elements will change depending on the nature of individual institutes, this model is designed to help decision makers define the elements for their own needs, using the literature and survey results as benchmarks. 
Context variables include the institute's:

- mission,

- size,

- budget,

- decision processes,

- typical methods of policy implementation, and

- the relationship the institute has with its home university.

Figure 1 is a conceptual model of the elements included in the process. The succession planning model proposed here is an organic one that has the institute's strategic plan at its core and is surrounded by the context in which it is developed. The model is circular because the process of succession is not a single event but a program that continues and evolves over time through repetition of steps. 


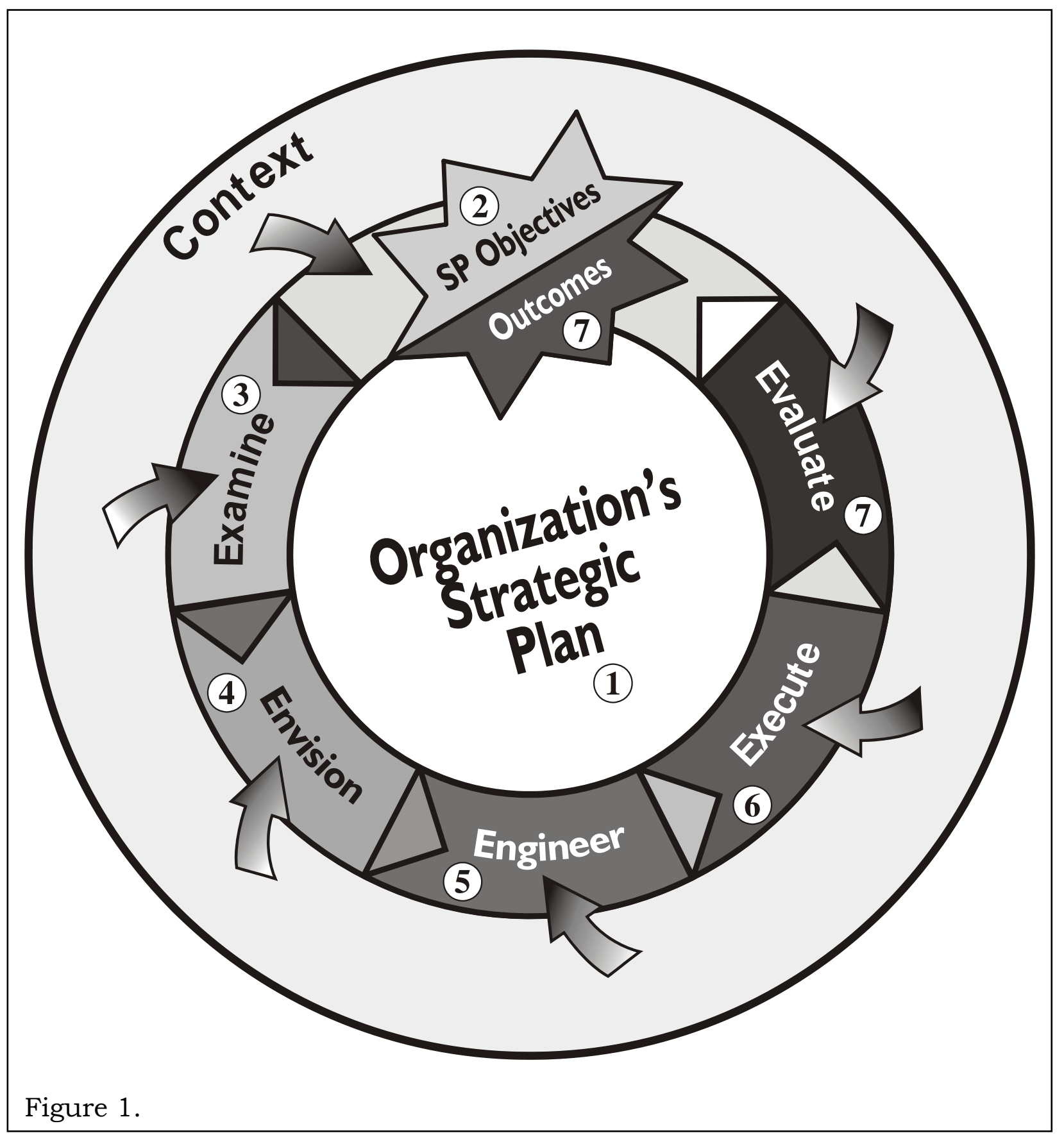




\section{Navigating the model:}

\begin{tabular}{|c|c|c|}
\hline \multirow{5}{*}{ 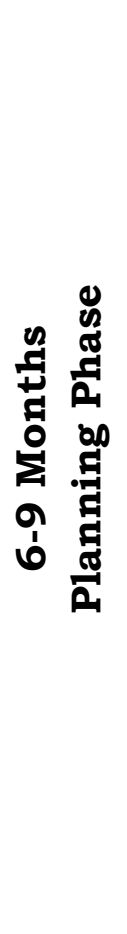 } & Step 1: & Decision makers begin with their institute's strategic plan. \\
\hline & Step 2: & Decision makers write objectives for the succession program. \\
\hline & Step 3: & $\begin{array}{l}\text { Examine - decision makers ask how far their institute is from } \\
\text { its stated objectives. }\end{array}$ \\
\hline & Step 4: & $\begin{array}{l}\text { Envision - decision makers ask about current strengths that } \\
\text { enhance their objectives and strengths that need further } \\
\text { development. }\end{array}$ \\
\hline & Step 5: & $\begin{array}{l}\text { Engineering - a time for decision makers to decide how best } \\
\text { to bridge the gap between current strengths and future needs. }\end{array}$ \\
\hline พ & Step 6: & $\begin{array}{l}\text { Execute - decision makers implement the program that they } \\
\text { have developed. }\end{array}$ \\
\hline 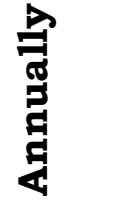 & Step 7: & $\begin{array}{l}\text { Evaluate - an analysis of the program to see if outcomes } \\
\text { match stated objectives. }\end{array}$ \\
\hline
\end{tabular}

The arrows coming into the model are inputs related to each phase - available resources, skills and talents of current employees, goals and vision for the future of the organization, future organizational and employee needs. 


\section{Step 1: The Core}

\section{Decision Makers}

Before the succession planning process can begin and decisions can be made, a decision making team should be assembled.

The literature agrees that the following people should definitely be involved in decision making: the organization's executive director, senior management, and human resources personnel. Survey results are similar: decision makers should include the university-level administrator to whom the institute reports (e.g. the vice president of research), the research institute's executive director, and institute faculty. Some scholars also believe that employees should be involved in the process to help enhance communication and transparency of the decisions that are being made, especially in an organization with dispersed governance like most universities. Both the literature and the survey results show that people think support from top administrators is key to the success of the program.

Several survey respondents also reported that they are not familiar with succession planning. As such, consultations with HR executives or other outside consultants who specialize in succession planning may be helpful. Smaller institutes may need to rely on university personnel more than internal representatives.

If the institute has an advisory board that is involved in governance issues, it may be important to consult with them as well.

Who are your institute's decision makers? These decision makers will become your succession planning development team.

- University-level Administrator

- Institute Executive Director

- Institute Faculty Representative

- Institute Staff Representative

- HR / Consultant (if desired)

- Advisory Board (if desired) 


\section{Organization's Strategic Plan}

The vast majority of the articles reviewed agree that succession plans should be based on an organization's strategic plan. After the decision makers are assembled, they begin the process by reviewing the institute's strategic plan. If the institute does not have a formal strategic plan, decisions can be made based on the mission and vision of the institute.

1. Looking at the strategic plan, what are your major goals for the next 3-5 years? If no strategic plan, what are ways the institute can better accomplish its mission?

2. What human capital, or employee, needs are related to these goals?

3. Based on the strategic plan goals and the human capital needs, what three areas would you like the succession planning program to address? These are broad areas to guide the succession planning decisions, such as diversity, recruitment, retention, and leadership development. 


\section{Step 2: Objectives}

The succession planning literature agrees that a holistic view of succession planning is appropriate. It will be recalled that survey respondents were given Rothwell's definition; based on this definition, they were asked which characteristics of succession planning would be important for their institutes.

Survey respondents agreed that important characteristics of succession planning are that it:

- Offers development or education activities for current employees;

- Promotes continuity in leadership; and

- Strategically plans for employment needs for the future.

Executive directors who responded to the survey also think naming successors for key or critical positions is important.

Beyond the strategic plan and its areas of focus, a major input in the objectives is the reason why the organization wants to develop a succession plan. The literature found four reasons for succession planning: retirements of the baby boom generation, key leadership transitions, a changing work environment, and a changing workforce.

The survey respondents reported similar reasons for developing a succession plan. Succession plans:

- Help moderate challenges associated with the up to $25 \%$ growth in their institute's administration, faculty and staff in the future;

- Help ease transitions related to retirements since one to five of their employees will retire in five years and up to 10 employees will retire in ten years;

- Contribute to implementing the organization's strategic plan

- Help individuals realize their career plans within the institute;

- Encourage the advancement of diverse groups in future jobs within the institute;

- Preserve institutional knowledge as the workforce evolves;

- Provide increased opportunities for "high potential" employees; 
- Prepare for immediate loss of key employees in critical positions; and

- Improve employee retention.

When looking at a holistic model of succession planning, objectives range from an emergency plan to fill key positions in the institute to developing the leadership skills for all employees to enhance the performance of the entire organization. This model refers to the emergency plan as the short term plan, while enhancing leadership skills throughout the entire organization as the long term plan.

What are your objectives for the succession planning program?

4. Ensure leadership continuity:

5. Retain and develop intellectual and knowledge capital:

6. Encourage individual advancement for all employees

7. Other: 


\section{Step 3: Examine}

The examine phase is a time to reflect on your institute and its current state. You are asking how far from the objectives are we? Scholars agree that an honest assessment of one's organization should be conducted to better understand how succession planning can fit the organization.

\section{Short-Term}

1. Looking at your strategic plan and its goals and vision, what current positions in your institute are important to the success of the institute?

2. Do you have job descriptions for these key positions? If no job descriptions exist, your team should work with the current employees in these positions to develop job descriptions, including required education, responsibilities, and competencies.

3. Reviewing the job descriptions of these key positions, what competencies rise to the top?

4. What competencies seem to be general skills that may be important for all employees? 
5. Reviewing the key jobs and employees within those jobs, what knowledge or information do these employees have that may be necessary to complete these jobs? Or to keep the institute operating smoothly?

6. Is this knowledge and information captured in a way that can be shared with others? If so, how is it captured? If not, what method of recording would work best for your institute, for example, mentoring, written knowledge or information, networking?

\section{Long-Term}

1. Looking at your strategic plan and its vision and goals, what positions will your institute need to accomplish its strategic goals in the next three to five years? If the committee cannot decide on particular positions, you can focus on skills or expertise that will be important to accomplishing your strategic plan goals.

2. What competencies rise to the top for these future jobs or expertise? 
3. What competencies seem to be general skills that may be important for all employees?

4. When comparing these competencies with the knowledge and skills of current employees, are there any skills or competencies that do not currently exist in your institute? 


\section{Step 4: Envision}

This phase focuses on closing any gaps between the succession planning objectives, specified in step 2, and existing conditions, determined in step 3.

1. Continuing the gap analysis from step 3, what strengths do the current employees have that can enhance achieving the objectives?

2. What strengths need to be developed to help accomplish the objectives? These strengths can be related, but not limited, to skills, for example, in research, grant writing, organizational development, people management skills, leadership development, ethics, networking, or entrepreneurship.

\section{Benefits/Challenges}

Every program has benefits and challenges. Most survey respondents agreed that institute priorities and support by university and institute leaders, faculty and staff were beneficial to succession program. Most institutes have some characteristics or strengths that may enhance a succession plan.

Although scholars found that stakeholders believed that succession planning was important, they also agree there are challenges to consider. I found similar results in the survey responses with questions like:

- Are there enough resources in time, money, and human capital to implement a succession plan?

- How do we get our employees to buy into the importance of succession planning?

- Will university policies and procedures, especially those related to hiring, limit the success of a succession planning program? 
Several scholars argue that these challenges can be mitigated by remaining open and flexible to new ideas, while also assessing any actions taken to make sure they are having a positive impact. Other solutions include being inclusive in the decision making process, being open and communicative with faculty and staff, and seeking out development activities that have the greatest impact for the fewest resources. Developing a pool of talent that is ready and available to apply for open leadership positions, without determining ahead of time who will be promoted to which position, also may help alleviate restrictions related to public agencies' open hiring regulations.

Note the benefits and challenges to the following items. If a challenge, what are some ways that you can reduce its impact on the success of a succession program?

1. University policy/procedures:

2. Research institute policy/procedures:

3. University priorities:

4. Research institute priorities: 
5. Support by current university senior leadership:

6. Support by current senior leaders in institute:

7. Support by current faculty in institute:

8. Support by current staff in institute:

9. Financial resources:

10. Other benefits/strengths or challenges: 
Another challenge that the literature highlights is being transparent and communicative about each phase in the succession planning process.

What are some communication activities you can undertake to promote better transparency of the process? Suggested items could include: periodic updates, written plan that is distributed to all employees, general and jobspecific competencies that are written down and available for review, and accessibility to written evaluation reviews.

Another item to consider in this step - do you have the expertise to engineer, or design, a succession plan? Or do you need an outside consultant? 


\section{Step 5: Engineer}

\section{Short term plan}

Every institute should develop a plan to help it continue to operate in case of an emergency. If something should happen to a key leader in the institute, how would the organization handle that person's responsibilities in the short-term?

Most organizations examined in the literature focus their emergency plans on readiness factors - who could take over key positions now, in one year, and in three years? People who could do the job now may be those in a similar position in the university who could move laterally. Others who are not currently ready could be in one year with minimal developmental experiences or in three years with several opportunities for development.

The focus on a short-term plan may seem like replacement planning but it could involve a temporary placement while the institute conducts a search for a permanent employee. The institute should consider internal candidates as well as external ones, including the temporary leader if he or she is interested.

1. If something should happen to key leaders in the organization, which employees, within the institute or in the general university, would be ready to take over the leaders' responsibilities, at least temporarily? If your team does not want to name particular people, similar positions in the institute or university could be named instead.

Institute Executive Director - Ready Now

Ready In 1 Year

Ready in 3 Years

Key Leader - $\quad$ Ready Now

Ready In 1 Year

Ready in 3 Years 
Key Leader - $\quad$ Ready Now

Ready In 1 Year

Ready in 3 Years

Other - Ready Now

Ready In 1 Year

Ready in 3 Years

2. What are the competencies that need to be developed in the employees in the ready in one year category? Again, if your team does not want to identify particular employees by name, you could focus on the competencies of similar positions and how transferrable those competencies are to the institute position.

NAME

NAME

NAME

NAME

3. What are the competencies that need to be developed in the employees, or similar positions, in the ready in three years category?

NAME

NAME

NAME

NAME 


\section{Long term plan}

A long term plan should focus more on developing a pool of employees who could become the institute's leaders or take on new areas of research without identifying which employee would take over which position. It is also an opportunity to identify new or expanded areas that the institute might delve into and the competencies current employees may need to develop to work in those areas or the types of employees the institute may need to hire.

As identified earlier, what general competencies could every staff person learn to help better the organization overall?

If the institute is small, institute leader(s) may not have employees to develop a pool-based approach. They still may be able to focus on competencies that current employee(s) should develop over the next three to five years to better the institute in general and the employee(s) specifically.

\section{Participants}

The literature suggests that every employee should have access to developmental opportunities, especially employees that seem like "high potential leaders." All employees would have opportunities to develop leadership skills and learn organizational knowledge that would help the institute overall; the skills and knowledge would not be related to specific job responsibilities.

The survey responses emphasize the higher level employees as those who should participate in the succession program - senior leaders (e.g., the executive director) and managers. The respondents vary in their responses but a majority also thinks staff and residential faculty should be involved to a small or moderate extent. Survey respondents who are familiar with or have considered succession planning tend to think that all employees, including graduate students, should be involved in succession planning activities. 
1. Which of your employees do you think should participate in the succession planning program once it is in place? If you prefer not to name individual names, you can focus on types of positions.

2. Which of these employees, or positions, do you consider to have "high potential"? High potential employees are people in your institute who have shown some promise related to leadership skills or abilities beyond their scope of responsibilities. These employees may be ones that are promoted to higher positions and given more responsibilities as their careers progress.

3. If a group of "high potential" employees were to have the opportunity to be promoted to key leadership positions, what competencies should they learn to be successful in those positions? These competencies could include management abilities, skills related to budgeting and fiscal issues, or knowledge about how to deal with human resources challenges.

\section{Organizational Placement}

Organizational placement refers to the person or office in the institute that will be responsible for the implementation of the succession program or will coordinate it. The program may include participants at multiple levels of the institute, but the coordinator is the person who makes sure it is implemented, evaluates it on a regular basis, and makes any changes to the program as necessary. 
Both the literature and the survey responses show that most organizations coordinate, or would like to coordinate, their succession programs at the executive director or human resources levels. If the institute does not have a human resources department, it could rely on the executive director to coordinate or to partner with the university's human resources department to help coordinate the program.

Several survey respondents suggest the succession program should be coordinated at multiple levels of the university, such as the senior executive levels at both the university and the institute or involve collaboration between the institute's senior executive level and human resources.

1. Who (or what unit) will be responsible for the coordination of your succession program?

2. Will other employees or offices partner with the coordinator to help implement the succession plan? If so, who?

\section{Timeline}

The literature agrees that succession programs will take months to prepare and plan and one to three years to implement, depending on the organization's size, complexity, and needs. One author who researched national research institutes affiliated with universities suggests a 10 year planning horizon. ${ }^{12}$ Another author states that it is important to set timeframes and deadlines with some urgency or the organization may not actually implement the succession program as developed. ${ }^{13}$

Knowing your institute, its needs, and the people in it, what is the best timeline for planning and implementation of the succession program?

Planning (e.g., January-March 2011)

Implementation (e.g., April 2011 - May 2013)

\footnotetext{
${ }^{12}$ Roddy, N. (2004). Leadership capacity building model: Developing tomorrow's leadership in science and technology: An example in succession planning and management. Public Personnel Management, 33(4), 487-496.

${ }^{13}$ Clunies, J. P. (2004). Benchmarking succession planning \& executive development in higher education: Is the academy ready now to employ these corporate paradigms? Academic Leadership, 2(4). Retrieved from http://academicleadership.org/article/Benchmarking_Succession_Planning_Executive_Development_in_Higher_Educa tion/benchmarking
} 


\section{Specific Program Recommendations}

Although the focus of this model is on process, the literature and survey did address specific recommendations for the succession plan. These recommendations included types of development experiences, the contents of the written succession plan, and the characteristics of succession planning that are important to research institutes.

Types of Development Experiences. During the survey pre-testing, I found that university administrators think of development timelines in terms of number of development opportunities over a certain amount of time, rather than months and years for design and implementation of the program. The options in the final study were none, a one time experience, multiple experiences over one year, or multiple experiences over multiple years. Survey respondents agree that senior executives and managers should have multiple experiences over multiple years. Residential faculty and staff should have one time experiences. All other employees should have no development experiences.

Thinking about these responses related to the frequency of development experiences, which employees in your institute should have development experiences and how often should those be?

Institute Executive Director

Manager

Residential Faculty

Staff

Key Leader

Other 
Reviewing the competencies identified in earlier steps, what type of development experience(s) would best suit the learning of those competencies? Types of experiences could include one-time workshops, opportunities to network with others in similar positions over one year, or mentoring over multiple years.

Institute Executive Director:

Competency

Type of experience

Manager:

Competency

Type of experience

Residential Faculty:

Competency

Type of experience

Staff:

Competency

Type of experience

Key Leader:

Competency

Type of experience

Other:

Competency

Type of experience 
Written Plan. According to the literature, the actual plan that is developed should include individual employee plans and job descriptions for current and future job needs, if possible. Survey respondents had similar responses. The most important written characteristic is that the succession plan should be tied to the institute's strategic plan. Next, it should be tied to the university's strategic plan. Succession plans also should have a prepared written purpose statement and program goals. When decision makers are developing their objectives for the succession plan, each of these goals and purpose statements should be based on the strategic plan, as evidenced by the "core" of the model.

Other important characteristics include tying the succession plan to employee training programs and developing a means to budget for the program.

Employee Development Opportunities. The literature found that opportunities for employees should include learning leadership skills, mentoring and coaching, networking to help exchange institute or university knowledge, cross-training to learn different areas of the institute, and off-site learning such as becoming members of professional associations and giving presentations to the university's board of trustees.

Survey respondents think mentoring is the most important method of development for institute employees, followed by job enrichment, stretch assignments, and finally job rotation.

Mentoring: matching less experienced employees with more experienced ones to have conversations about the institute, necessary skills and competencies, and how to navigate various challenges within their jobs.

- Job enrichment: giving employees opportunities to use all their skills and strengths even if it is not part of their job responsibilities.

- Stretch assignments: opportunities that push an employee's skills to the limits, allowing the employee to begin to feel comfortable with skills they rarely use.

Job rotations: opportunities to learn different areas of an institute that an employee may not have already experienced. Smaller institutes may use the broader university to facilitate job rotation opportunities. 
Important Succession Planning Characteristics. Five characteristics of succession planning were reported as fairly, quite or very important to institutes. The succession plan should:

- identify which groups the program will serve;

- establish a means to clarify both present and future position responsibilities;

- establish a way to forecast future talent needs; and

- have a mechanism to develop individual employee plans.

The first three characteristics were addressed in earlier steps.

Although several of the steps in this process have been more general in nature, it is important to develop individual career goals for each employee in your institute. Each employee's supervisor or mentor should sit down with each employee to map out a career trajectory. The next page provides an example of an individual employee plan.

Resources. Much of the literature emphasizes the need for resources to successfully implement a succession plan. Resources can include both funds to pay for development activities and human resources to buy out time to coordinate or participate in the succession planning.

1. What type of monetary funding is available to implement a succession plan?

2. What human resources are available to enhance the success of the succession program?

3. As the program develops over time, are their additional resources that could be secured in the future? If so, what are these resources? How can you secure them? When would they become available? 


\section{Personal Employee Development Plan}

Employee Name

Position

Supervisor

Career Aspiration(s)

Current Strengths

Competencies needed to meet career goals

How best can employee develop needed competencies?

How often should employee have development experiences?

Timeline for competency development.

What resources can be applied to employee's development?

How will the employee's development be evaluated? 


\section{Step 6: Execute}

The "execute" phase is the time when the institute implements the program that it has designed in the planning phase. The timing of this phase may take between one and three years to fully implement.

1. When implementing your succession plan, certain contextual elements may enable or limit the success of your program. Thinking back to step four, what strengths or challenges will affect the implementation of your program?

2. What are some ways to overcome those challenges to better ensure success of the program?

3. Many institutes may find available resources to be a challenge to the success of the program. Are there opportunities to partner with other institutes or groups within, or external to, the university to help leverage resources, such as joint development activities? 
4. Which groups within the university may become partners for the succession program?

5. What groups external to the university may become partners for the succession program?

6. Based on your timeline identified in step five, when is the best time to implement this program?

7. What are some ways to communicate the plan, its opportunities, and its importance to your employees? 


\section{Step 7: Evaluate}

In the evaluation phase, decision makers or program coordinators ask if the executed plan is meeting the original objectives. If the outcomes of the program do not match the objectives, what changes to the plan need to be made to better meet those original objectives? Do the original objectives need to shift to better reflect the institute's strategic plan and its future needs?

The evaluation phase can work concurrently with the execute phase. The program coordinators should evaluate the program as it goes along, at least annually, to make sure that the program is successful before too many resources are wasted on an ineffective program.

In order to best evaluate the program, the literature recommends that succession plans have clear expectations and measures of success for both the program and the participants and that decision makers and coordinators remain flexible in changing the succession plan as well as job descriptions when needed. Survey respondents report that evaluations of succession plans should have the following characteristics: measurable objectives, an appraisal system for individual performance, a way to compare current skills to future job requirements, and a method of annually reviewing the institute's talent and skills.

1. Does your institute currently evaluate employees? If yes, how might this current evaluation system incorporate the new succession planning activities? 


\section{Model Overview}

\begin{tabular}{|c|c|c|}
\hline \multirow{9}{*}{ 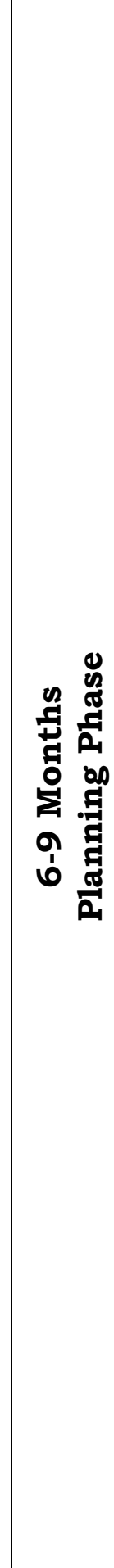 } & \multirow{2}{*}{ Step 1: } & $\begin{array}{l}\text { Decision Makers: Who are your institute's decision makers } \\
\text { for succession planning (SP)? }\end{array}$ \\
\hline & & $\begin{array}{l}\text { Strategic Plan: What are your major goals for the next } 3-5 \\
\text { years? What employee needs relate to these goals? What } \\
\text { three areas would you like the SP to address? }\end{array}$ \\
\hline & Step 2: & Objectives: What are your objectives for SP program? \\
\hline & Step 3: & $\begin{array}{l}\text { Short Term: What current positions are important to the } \\
\text { success of the institute? What are the job descriptions of } \\
\text { these positions? What competencies rise to the top? What } \\
\text { competencies are general skills for all employees? What } \\
\text { knowledge in these positions needs to be passed on? How is } \\
\text { or how can this knowledge be captured? }\end{array}$ \\
\hline & & $\begin{array}{l}\text { Long Term: What positions will your institute need in the } \\
\text { next } 3-5 \text { years? What competencies of these future positions } \\
\text { rise to the top? What competencies are general skills for all } \\
\text { employees? What skills or competencies of these future } \\
\text { positions do not currently exist in your institute? }\end{array}$ \\
\hline & & $\begin{array}{l}\text { Gap Analysis: What strengths do current employees have } \\
\text { that can enhance institute objectives? What strengths need } \\
\text { to be developed? }\end{array}$ \\
\hline & Step 4: & $\begin{array}{l}\text { Benefits/Challenges: What characteristics or strengths of } \\
\text { the institute or university are beneficial to succession } \\
\text { planning? What are some ways to reduce the impact of SP } \\
\text { challenges? }\end{array}$ \\
\hline & & $\begin{array}{l}\text { Other: What are some communication activities you can } \\
\text { undertake to promote better transparency of the SP process? } \\
\text { Do you have the expertise to design an SP or do you need a } \\
\text { consultant? }\end{array}$ \\
\hline & Step 5: & $\begin{array}{l}\text { Short Term: Who would be ready to take over key positions } \\
\text { now, in } 1 \text { year, in } 3 \text { years? What competencies do each of } \\
\text { your employees need to develop to be prepared to take over } \\
\text { these key positions? }\end{array}$ \\
\hline
\end{tabular}




\begin{tabular}{|c|c|c|}
\hline \multirow{7}{*}{ 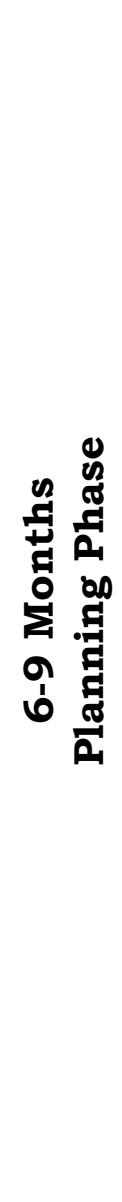 } & \multirow{7}{*}{ Step 5: } & $\begin{array}{l}\text { Long Term: What general competencies could every staff } \\
\text { person learn to better the organization overall? }\end{array}$ \\
\hline & & $\begin{array}{l}\text { Participants: Which employees should participate in SP? } \\
\text { Who do you consider to have "high potential"? What } \\
\text { competencies do these "high potential" employees need to be } \\
\text { promoted? }\end{array}$ \\
\hline & & $\begin{array}{l}\text { Organizational Placement: Who will be responsible for the } \\
\text { coordination of the SP? Will other offices partner with the } \\
\text { coordinator? }\end{array}$ \\
\hline & & $\begin{array}{l}\text { Timeline: What is your timeline for planning (6-9 months) } \\
\text { and implementation (1-2 years)? }\end{array}$ \\
\hline & & $\begin{array}{l}\text { Types of Development Experiences: Which employees } \\
\text { should have development experiences, how often, and what } \\
\text { kind? }\end{array}$ \\
\hline & & $\begin{array}{l}\text { Resources: What funding is available for the SP? What } \\
\text { human resources are available to enhance the SP? What } \\
\text { future resources can be secured, how and when? }\end{array}$ \\
\hline & & $\begin{array}{l}\text { Personal Employee Development Plan: Complete an } \\
\text { individual plan for each employee involved in the SP. }\end{array}$ \\
\hline 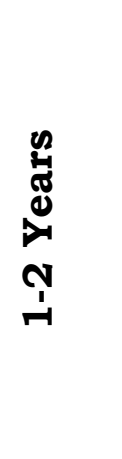 & Step 6: & $\begin{array}{l}\text { Execute: What strengths or challenges will affect the } \\
\text { implementation of your program? What are some ways to } \\
\text { overcome these challenges to better ensure success of the } \\
\text { program? Are there opportunities to partner with other } \\
\text { institutes or groups to leverage SP resources? Which groups } \\
\text { would make good SP partners, internally and externally? } \\
\text { When is the best time to implement this program? What are } \\
\text { ways to communicate the SP and its opportunities to } \\
\text { employees? }\end{array}$ \\
\hline 㣽 & Step 7: & $\begin{array}{l}\text { Evaluate: Does your institute currently evaluate employees? } \\
\text { How might this current evaluation system incorporate the } \\
\text { new SP activities? }\end{array}$ \\
\hline
\end{tabular}

